Verônica Mantovani Bueno

Delimitação de espécies em Rhinebothroides Mayes, Brooks \& Thorson, 1981 (Cestoda: Tetraphyllidea) com ênfase no complexo Rhinebothroides freitasi (Rego, 1979)

São Paulo 
Verônica Mantovani Bueno

\title{
Delimitação de espécies em Rhinebothroides Mayes, Brooks \& Thorson, 1981 (Cestoda: Tetraphyllidea) com ênfase no complexo Rhinebothroides freitasi (Rego, 1979)
}

\author{
Species delimitation in Rhinebothroides Mayes, Brooks \& \\ Thorson, 1981 (Cestoda: Tetraphyllidea) with emphasis on the \\ Rhinebothroides freitasi (Rego, 1979) complex
}

Dissertação apresentada ao Instituto de Biociências da Universidade de São Paulo para a obtenção do título de Mestre em Ciências Biológicas, na área de Zoologia.

Orientador: Prof. Dr. Fernando Portella de Luna Marques

São Paulo

2010 
Bueno, Verônica Mantovani

Delimitação de espécies em Rhinebothroides Mayes, Brooks \&

Thorson, 1981 (Cestoda: Tetraphyllidea) com ênfase no complexo Rhinebothroides freitasi (Rego, 1979). $i x+121 \mathrm{p}$.

Dissertação (Mestrado) - Instituto de Biociências da Universidade de São Paulo. Departamento de Zoologia.

1. Parasitologia; 2. Sistemática Molecular; 3. Taxonomia; 4. Helmintologia; 5. Neotropical

Universidade de São Paulo. Instituto de Biociências. Departamento de Zoologia

\section{Comissão Julgadora}

$\operatorname{Prof(a).~Dr(a).~}$

$\operatorname{Prof}(a) . \operatorname{Dr}(a)$.

Prof. Dr. Fernando P. de Luna Marques 
Dedico esse trabalho aos meus pais, por todo o apoio e carinho, sempre. 


\section{Agradecimentos}

Gostaria de agradecer em primeiro lugar aos meus pais, Luciana Paola Mantovani e Fernando Maciel Bueno por todo apoio, amor, carinho e paciência infindáveis por toda a duração desse trabalho. Sem eles, tenho certeza que eu não teria conseguido realizar tanta coisa. Agradeço também a minha irmã querida, Bárbara Mantovani Bueno, por proporcionar momentos de descontração mesmo estando longe durante a etapa final desse trabalho.

Agradeço especialmente ao meu orientador, Dr. Fernando Portella de Luna Marques, por ter me ensinado tanto e por sempre acreditar na minha capacidade como pesquisadora, mesmo em momentos onde eu mesma não acreditava.

Não posso deixar de agradecer aos meus colegas de laboratório que tornaram esse trabalho possível de ser realizado. Ao Denis Jacob Machado, por ter tido a competência de extrair DNA de animais tão pequenos e por me ajudar (muito) na compilação dos dados moleculares. À colega e amiga Natália da Matta Luchetti, por ter me ensinado tudo o que sei sobre técnicas laboratoriais de morfologia - minhas lâminas também agradecem. À colega Laura Canal, por ter organizado o material para tombo no MZUSP. Ao Prof. Dr. Marcus Vinicius Domingues, por ter sido meu "co-orientador", amigo pra todas as horas e por me ensinar muito sobre taxonomia de parasitas. Ao colega e amigo Mauro Cardoso Júnior, por me aguentar horas e horas falando sobre Rhinebothroides e por compartilhar comigo idéias importantes sobre parasitas de elasmobrânquios. Ao colega e amigo Dr. Felipe Martins, que me ajudou com a compreensão de dados moleculares.

Agradeço de coração o trabalho dos técnicos do departamento de Zoologia Ênio Mattos e Eduardo Tadeu Mattos (in memorian) por terem me acompanhado em inúmeras sessões de microscopia eletrônica e me ensinado muito sobre técnicas de morfologia. Agradeço especialmente ao bom papo e ao ótimo humor em todos os momentos. Agradeço a Prof. Dra Elisabeth Höfling, por ter me dado a oportunidade de aprender a manusear o microscópio eletrônico, sem isso esse trabalho não teria sido possível. Agradeço o Prof. Dr. Alberto de Freitas Ribeiro, coordenador do Laboratório de Biologia Celular e Microscopia Eletrônica e Confocal por ter me dado a oportunidade de manusear o microscópio eletrônico do Instituto de Biociências - USP. Agradeço aos funcionários desse laboratório, o técnico Márcio Valentim Cruz, por ter me ensinado a controlar todos aqueles botões do microscópio eletrônico e ter tido a paciência de me auxiliar sempre que foi necessário e também ao técnico e pesquisador Waldir Caldeira, por ter me auxiliado ao microscópio eletrônico.

Agradeço ao Prof. Dr. Marcelo Carvalho por ter me atendido sempre que necessário e me ensinado tanto sobre taxonomia. Agradeço também a todos os membros do laboratório do Prof. Dr. Marcelo Carvalho, em especial aos pesquisadores João Paulo Capretz Batista da Silva, Tiago Loboda e Mateus da Costa Soares por disponibilizarem literatura pertinente a família Potamotrygonidae e pelas informações taxonômicas supridas, necessárias para a conclusão desse trabalho.

Agradeço a toda a equipe do Laboratório de Sistemática Molecular por toda a ajuda concedida e ao alto astral 
sempre presente no laboratório. Em especial, agradeço a pesquisadora Sabrina Barone por ter me passado parte de seu conhecimento sobre edição de sequências nucleotídicas e extração de DNA. Agradeço também a pesquisadora Maíra Concistré por ter ajudado na obtenção de sequências de Rhinebothroides. Agradeço também a técnica responsável pelo SSDNA - IQ-USP Luci Deise Navarro pelo sequenciamento das amostras de DNA obtidas.

Agradeço ao pesquisador e amigo Dr. Tiago Sobreira por toda a consultoria computacional concedida durante a fase de análise de dados. Tenho certeza que esse trabalho teria sido muito mais difícil sem sua ajuda.

Agradeço ao curador do Manter Laboratory of Parasitology - Prof. Dr. Scott Lyell Gardner, por ter gentilmente cedido parte do material tipo examinado nesse trabalho. Agradeço também ao curador do U.S. Parasite Collection - Dr. Eric P. Hoberg, por ter emprestado parte do material tipo analisado nesse estudo. Agradecimentos especiais ao curador e curador associado da coleção de parasitologia do Museo Argentino de Ciencias Naturales "Bernardino Rivadavia” Lic. Fabián Tricárico e Alejandro Tablado pelo empréstimo de parte do material tipo analisado nesse trabalho. E finalmente ao curador Dr. Marcelo Knoff da Coleção Helmintológica do Instituto Oswaldo Cruz pelos espécimes emprestados prontamente.

Agradeço à Prof. Dra. Verônica Ivanov, da Universidad de Buenos Aires, por toda a informação concedida sobre espécimes de Rhinebothroides coletados na Argentina. Agradeço o Prof. Dr. Florian Reyda pela amizade, por toda ajuda disponibilizada e por algumas das sequências de DNA utilizadas na análise filogenética. Agradeço também a Dr. Claire Healy por algumas das sequências nucleotídicas utilizadas nesse trabalho.

Gostaria de agradecer às secretárias do departamento de Zoologia, em especial às secretárias Luzineia Ongaro Juquer, Maria Lúcia Vieira e Marly Salviano de Almeida por todo apoio durante todas as etapas desse projeto. Agradeço também aos funcionários da secretária de pós-graduação do Instituto de Biociências - USP.

Meus agradecimentos especiais vão aos meus amigos do IB-USP: Max Maronna, Mauro Cardoso Júnior, Marcus Vinicius Domingues, Patrícia Lopes, Mateus da Costa Soares, Talita Zupo, João Paulo (Gordo), Thiago Fernandes, Riviane Garcez, Sabrina Barone, Sabrina Timão, Felipe Martins e Lina Almeida por terem me proporcionado tantas risadas e tantas discussões interessantes sobre biologia. Vocês todos moram no meu coração! Agradeço também às minhas amigas Janice Muriel Cunha e Ilana Fichberg do MZUSP pelo apoio.

Aos meus amigos para toda a vida, que me entendem melhor do que ninguém e me ajudaram bastante a manter uma vida social fora da biologia: André Garcia, Ariel Wollinger, Bianca Temple de Moraes, Bruna Daniel, Carla Machado, Carol Pessini, Dayan Sansone, Karina Vanes, Luciano Andrade, Mariana Zdravca, Natalia Pisani e Tico Volpato.

Em especial, gostaria de agradecer meu namorado, Lula, por todo amor, apoio, paciência, dedicação e amizade durante todo o projeto. Sem isso eu não teria realizado esse trabalho.A realização desse trabalho foi possível graças ao financiamento direto do CNPQ na forma de bolsa de mestrado (Proc. No. 131624/2007-5), e o auxílio individual à pesquisa financiado pela FAPES P(Proc. No. 2008/09436-8) em nome de F.P.L. Marques. 


\section{ÍNDICE}

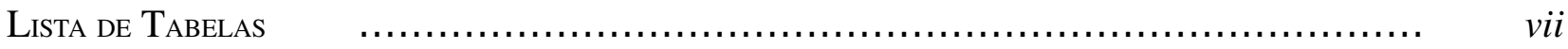

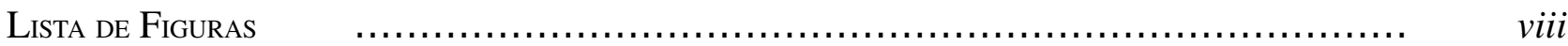

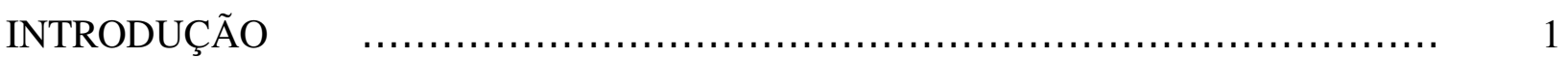

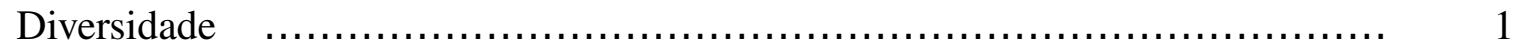

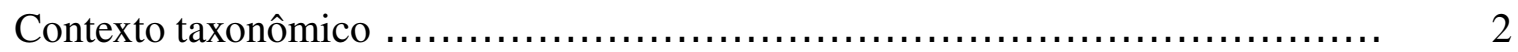

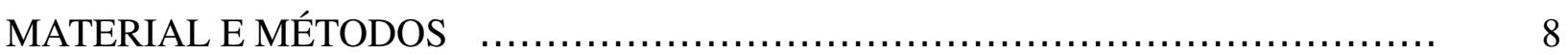

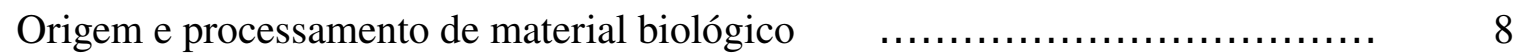

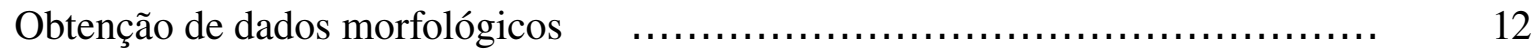

Material tipo e vouchers examinados ......................................... 14

Obtenção de dados moleculares $\quad$........................................ 14

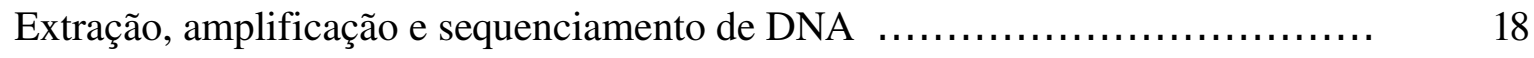

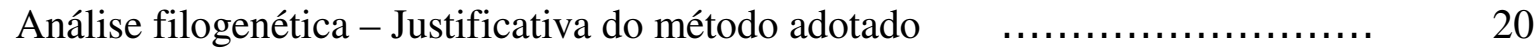

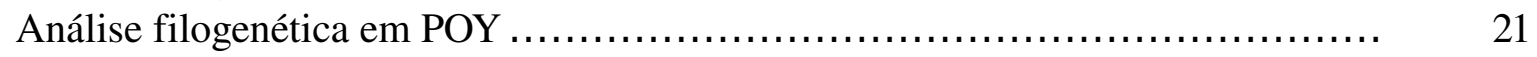

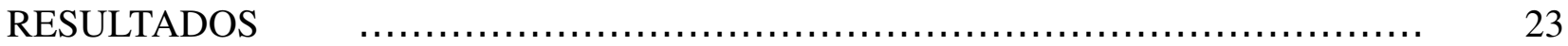

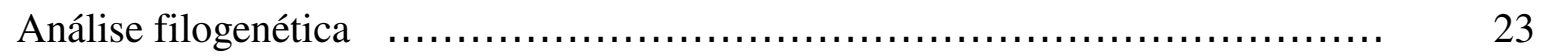

Análise morfológica - Complexo Rhinebothroides freitasi .................... 32

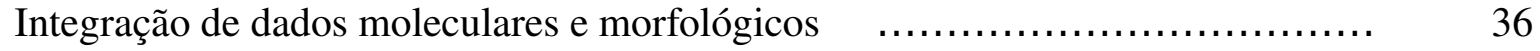

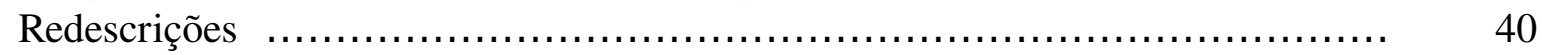

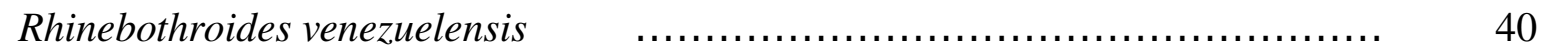

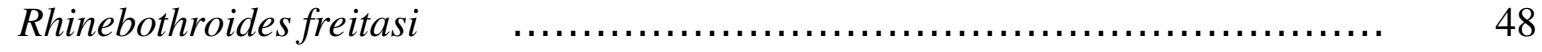

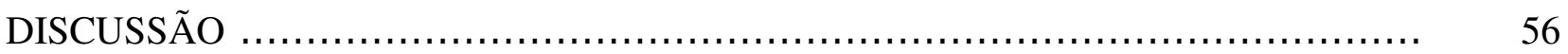

Delimitação de espécies em Rhinebothroides $\quad$............................ 56

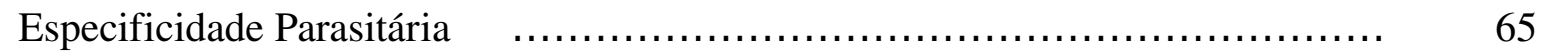

Relações filogenéticas de Rhinebothroides e grupos relacionados $\ldots \ldots \ldots \ldots \ldots \ldots . . \ldots 1$

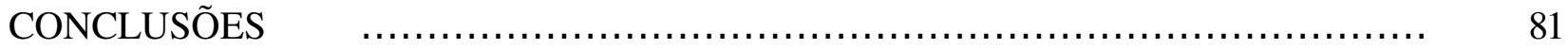

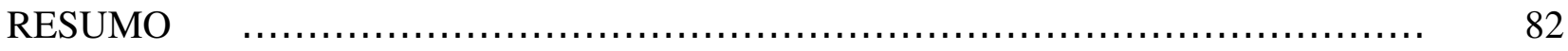

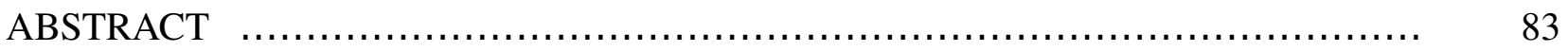

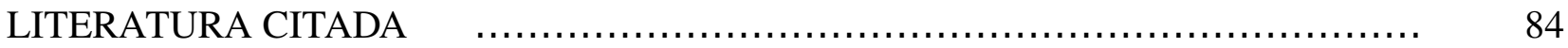

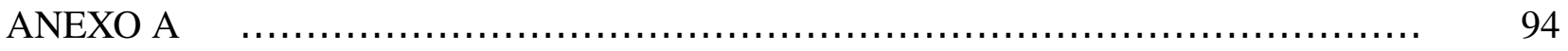

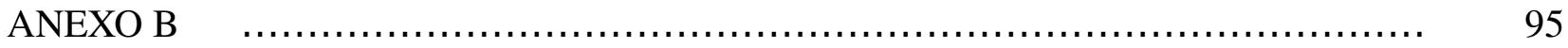




\section{Lista de Tabelas}

Tabela 1. Representatividade biogeográfica de hospedeiros amostrada.

10

Tabela 2. Parâmetros morfológicos utilizados.

Tabela 3. Material examinado de coleções de referência.

16

Tabela 4. Iniciadores empregados na obtenção de dados moleculares.

Tabela 5. Protocolos de amplificação.

Tabela 6. Representatividade genômica, taxonômica, biogeográfica e de hospedeiros. 24

Tabela 7. Resultado da análise de congruência.

Tabela 8. Hospedeiros infectados por membros do complexo $R$. freitasi.

Tabela 9. Dados morfológicos obtidos para indivíduos de R. venezuelensis. 43

Tabela 10. Dados morfológicos obtidos para indivíduos de R. freitasi. 


\section{Lista de Figuras}

Figura 1. Morfologia geral de Rhinebothroides spp. ............................... 6

Figura 2. Representatividade biogeográfica das amostras. $\quad \ldots \ldots \ldots \ldots \ldots \ldots \ldots \ldots \ldots \ldots \ldots \ldots . \quad 9$

Figura 3. Regiões de captura de micrografias eletrônicas de varredura. $\quad \ldots \ldots \ldots \ldots \ldots \ldots \ldots . . . \ldots$

Figura 4. Hipótese filogenética para haplótipos de Rhinebothroides. $\quad$................. 31

Figura 5. Plot de sensibilidade para os clados de Rhinebothroides. ...................... 33

Figura 6. Plot de sensibilidade para grupos de clados de Rhinebothroides................. 34

Figura 7. Caracterização e variação morfológica de Rhinebothroides glandularis. ........... 37

Figura 8. Caracterização morfológica de Rhinebothroides scorzai. ....................... 38

Figura 9. Caracterização morfológica de Rhinebothroides moralarai. $\quad$................... 39 3

Figura 10. Morfologia de Rhinebothroides venezuelensis. $\quad \ldots \ldots \ldots \ldots \ldots \ldots \ldots \ldots \ldots \ldots \ldots \ldots, 41$

Figura 11. Micrografias eletrônicas de varredura para Rhinebothroides venezuelensis. $\quad$... 42

Figura 12. Morfologia de Rhinebothroides freitasi. ............................... 50

Figura 13. Micrografias eletrônicas de varredura para Rhinebothroides freitasi. $\quad$.......... 51

Figura 14. Mapas de distribuição para as espécies de Rhinebothroides. $\quad$.................. 59

Figura 15. Hipóteses filogenéticas disponíveis para Rhinebothroides. $\quad \ldots \ldots \ldots \ldots \ldots \ldots \ldots . . \ldots 3$

Figura 16. Otimização dos caracteres propostos por Zamparo et al. (1999). $\quad$ …......... 74 


\section{Introdução}

\section{Diversidade}

O parasitismo, associação entre organismos onde o associado obtém recursos advindos do organismo hospedeiro, é uma das formas de vida mais bem sucedidas entre os eucariotos. Essa afirmativa baseia-se na observação de que, praticamente, todos os metazoários de vida livre convivem com pelo menos um organismo associado - i.e., um parasita. Historicamente, acredita-se que o parasitismo em Metazoa evoluiu pelo menos sessenta vezes independentemente durante sua diversificação em nosso planeta (Poulin \& Morand, 2000). Consequentemente, esses organismos apresentam alto grau de diversidade tanto específica quanto de ciclos de vida, estratégias de reprodução e dispersão.

Os padrões de diversidade encontrados para parasitas podem estar associados ás características tanto do parasita quanto do hospedeiro. A distribuição da diversidade parasitária entre os táxons hospedeiros não reflete simplesmente a diversidade de espécies do hospedeiro; associações históricas e aspectos ecológicos parecem ser bastante importantes (Poulin \& Morand, 2000). Uma possível explicação para o nível de diversificação observado em linhagens parasitárias é o fato de que a especiação simpátrica é muito mais comum em parasitas do que em organismos de vida livre (de Meêus et al., 1998).

Delimitar espécies de parasitas é frequentemente muito difícil devido ao limitado número de caracteres morfológicos exibidos por esses organismos (Criscione et al., 2005). Mesmo quando todas as espécies de parasitas são amostradas em todas as espécies de hospedeiros presentes em uma dada localidade, o reconhecimento acurado das espécies de parasitas encontradas ainda pode ser problemático (Poulin \& Morand, 2000). Uma espécie de parasita pode explorar mais de uma espécie de hospedeiro, tendo, por consequência, algumas diferenças morfológicas intraespecíficas de acordo com o hospedeiro parasitado (Poulin \& Morand, 2000). Neste caso, ignorar a variabilidade intraespecífica resultaria em uma noção sobrestimada da diversidade de parasitas para esse sistema 
(Poulin \& Morand, 2000). Por outro lado, linhagens distintas podem ser consideradas como uma única espécie, devido a semelhanças morfológicas, real ou desconhecida, independente do número de hospedeiros nas quais são encontradas. Dentro deste cenário, teríamos o que chamamos de espécies crípticas, as quais não representam a diversidade de linhagens encontradas no sistema.

De forma geral, o uso atual de dados moleculares em sistemática tem resultado na descoberta de muitas espécies crípticas em diversos grupos de Metazoa (Belyaeva \& Taylor, 2009; Bickford et al., 2007; Calvo et al., 2009; Daniels et al., 2009; Detwiller et al., 2010; Goodman et al., 2009a; Goodman et al., 2009b; Jousson et al., 2000; Leung et al., 2009; Pfenninger \& Schwenk, 2007; Rosas-Valdez et al., 2004). Para grupos representados por linhagens de parasitas, isto não tem sido diferente. Por exemplo, algumas espécies de Cestoda e Nematoda consideradas por muito tempo capazes de parasitar várias espécies de hospedeiros, têm se mostrado, na realidade, constituir complexos de espécies relacionadas, porém distintas, cada uma altamente específica a uma espécie de hospedeiro (Poulin \& Morand, 2000; Poulin, 2007). Espécies crípticas, embora muito semelhantes morfologicamente e frequentemente vivendo em simpatria, são entidades historicamente isoladas e deveriam ser consideradas espécies distintas se um dos objetivos da Sistemática é documentar a diversidade de linhagens em nosso planeta. Adicionalmente, nossa compreensão dos mecanismos responsáveis pelos processos de diversificação biológica é dependente do reconhecimento de entidades historicamente isoladas.

\section{Contexto taxonômico}

Um grupo particular de Cestoda, primariamente parasitas de elasmobrânquios, os Tetraphyllidea, é particularmente interessante do ponto de vista de sua especificidade e padrões de co-evolução (Caira \& Jensen, 2001). Morfologicamente, os tetrafilídeos constituem um dos grupos mais diversificados de cestóideos, especialmente em relação aos seus escoleces e os intrigantes padrões de associação com seus hospedeiros (Caira \& Jensen, 2001).

Os parasitas da ordem Tetraphyllidea são atualmente divididos em oito famílias sendo que 
duas são as mais diversas: os Onchobothriidae e o Phyllobothriidae (Euzet, 1994). Os Onchobothriidae são aqueles tetrafilídeos que apresentam ganchos em seus escoleces, como forma de ancoramento no hospedeiro. Os Phyllobothriidae não apresentam ganchos, seus escoleces lembram a forma de uma folha e, por isso, são assim chamados. Entretanto, evidências contra o monofiletismo de Tetraphyllidea como atualmente definido têm se acumulado (Caira \& Jensen, 2001; Euzet, 1994).

Recentemente, Healy et al. (2009) propuseram uma nova ordem dentro de Cestoda denominada Rhinebothriidea, em um estudo focado na sub-família Rhinebothriinae Euzet, 1956. O estudo foi baseado em dados morfológicos e moleculares para 58 terminais que demonstram claramente o parafiletismo da ordem Tetraphyllidea e o monofiletismo da subfamília Rhinebothriinae Euzet, 1956. Esses resultados levaram os autores a elevar essa subfamília ao nível de ordem, propondo a ordem Rhinebothriidea. De acordo com Healy et al. (2009), os gêneros que compõe a ordem Rhinebothriidea são: Anthocefalum, Echeneibothrium, Rhabdotobothrium, Rhinebothrium, Rhinebothroides, Scalithrium, Spongiobothrium, Rhodobothium, além de 4 gêneros e um rhinebothriídeo não descritos.

Dentre os gêneros inseridos atualmente em Rhinebothriidea, Rhinebothroides é o foco do presente estudo. Parasitas do gênero Rhinebothroides são encontrados apenas em arraias de água doce da família Potamotrygonidae. Os potamotrigonídeos são endêmicos da região Neotropical e formam um grupo hoje representado por aproximadamente 20 espécies, divididas em três gêneros: Paratrygon Duméril, 1865, Potamotrygon Garman, 1913 e Plesiotrygon Rosa, Castello \& Thorson, 1987 (Marques, 2000; de Carvalho et al. 2003). A origem e diversificação destes organismos tem sido explicada por diversas hipóteses (Marlier, 1967, Brooks et al., 1981b, Brooks, 1992, Lovejoy et al., 1998, Marques, 2000; de Carvalho et al., 2004) que, exceto pelo cenário dispersionista de Marlier (1967), evocam eventos de ingressões marinhas no continente seguidos de especiação após a ocorrência de eventos paleogeográficos distintos em diferentes escalas temporais. Brooks et al. 
(1981b) foram pioneiros, não somente por propor a primeira hipótese envolvendo eventos de vicariância, mas também por utilizar dados parasitológicos, em propor que o grupo teria se originado durante o Cretáceo ( 100 m.a.). Posteriormente, hipóteses (e.g. Lovejoy et al., 1998 e Marques 2000) baseadas no relógio molecular de um fragmento de um gene mitocondrial (mtDNA) Citocromo b, contestaram a hipótese de Brooks et al. (1981b) e propuseram que ingressões marinhas a partir da região do Caribe no Mioceno ( 20 m.a.) resultaram no isolamento do ancestral desses elasmobrânquios devido a alterações no escoamento do paleo-Orinoco-Amazonas ( 11m.a.). De Carvalho et al. (2004), considerando dados morfológicos para linhagens recentes e extintas de Miliobatiformes, atribui a origem de Potamotrygonidae a eventos mais antigos (i.e. Eoceno, $\sim 50$ m.a.). Independente da ausência de consenso sobre os eventos que deram origem ao grupo, é certo que os potamotrigonídeos descendem de um ancestral marinho assim como a maior parte de sua fauna de parasitas.

O gênero Rhinebothroides foi proposto por Mayes et al. (1981) para receber Rhinebothroides moralarai, parasita de Potamotrygon magdalenae do Rio Magdalena, espécie tipo do gênero; $R$. circularisi, parasita de Potamotrygon constellata ( $P$. circularis na descrição original) do rio Itacuaí, Atalaia do Norte/AM; e Rhinebothroides scorzai, parasita de Potamotrygon orbignyi ${ }^{1}$ (originalmente identificado como Paratrygon histrix) do delta do Orinoco, Venezuela (Lopéz-Neyra \& Diaz -Ungriá, 1958). Em comum, essas espécies possuíam botrídios quadrados ao invés de alongados, vesículas seminais internas, abertura do poro genital no mesmo nível do ístmo do ovário e lobos ovarianos assimétricos - resultado da consequente redução do lobo poral (Mayes et al., 1981). Posteriormente, Brooks et al. (1981a) fizeram uma revisão taxonômica dos parasitas de potamotrigonídeos e descreveram Rhinebothroides glandularis e Rhinebothroides venezuelensis parasitas de Potamotrygon orbignyi ${ }^{1}$ (originalmente identificado como Potamotrygon histrix) do delta do Orinoco e reconheceram Rhinebothrium freitasi (Rego, 1979), parasita de Potamotrygon

1 A identificação destes hospedeiros foi retificada por Brooks \& Amato (1992). 
orbignyi (originalmente identificado como Potamotrygon histrix) ${ }^{2}$ como membro do gênero Rhinebothroides. Mais de uma década depois, Brooks \& Amato (1992) descreveram Rhinebothroides mclennanae parasita de Potamotrygon motoro, próximo a Corumbá, MS, Brasil. Até este momento, Rhinebothroides dispunha de sete espécies nominais.

Na mais recente revisão taxonômica de Rhinebothroides publicada por Marques \& Brooks (2003), das sete espécies reconhecidas para o gênero, três foram consideradas sinonímias júnior: Rhinebothroides freitasi $=R$. circularisi e $R$. venezuelensis, e Rhinebothroides glandularis $=R$. mclennanae. Dentre as espécies do complexo Rhinebothroides freitasi (sensu Marques \& Brooks, 2003) a sobreposição no número de loculi, dimensões das proglótides grávidas e maduras, saco do cirro, ovário e número de testículos, únicos caracteres propostos para diagnose destas espécies, levaram Marques \& Brooks (2003) a justificar a sinonímia proposta. Posteriormente, Ivanov (2004) descreveu Rhinebothroides campbelli, parasita de Potamotrygon motoro, do rio Colastiné, Santa Fé, Argentina e revalidou a espécie $R$. mclennanae. De acordo com a autora, das 8 espécies nominais disponíveis para Rhinebothroides, seis deveriam ser consideradas como válidas.

A ampla distribuição biogeográfica e de hospedeiros exibida por membros do complexo $R$. freitasi sugere a presença de equívocos na concepção das espécies nominais disponíveis para o complexo. Adicionalmente, R. campbelli, além de apresentar morfologia muito similar a $R$. venezuelensis, não possui nenhum caráter discreto que permita diferenciar esta espécie daquelas hoje atribuídas ao complexo R. freitasi (sensu Marques \& Brooks, 2003). Conclui-se que esta nova espécie faça parte do mesmo complexo e que um estudo mais detalhado seja necessário para refinar a taxonomia de Rhinebothroides.

A taxonomia de Rhinebothroides tem sido exclusivamente baseada na morfologia de indivíduos adultos (Figura 1A-C), uma vez que as larvas são desconhecidas. Membros de Rhinebothroides possuem um escólex anterior (órgão de ancoramento no hospedeiro) e um estróbilo, composto por inúmeras proglótides. O escólex é composto por quatro botrídios 2 Uma vez que Potamotrygon histrix é endêmica da bacia do Paraná, deve tratar-se também de P. orbignyi. 


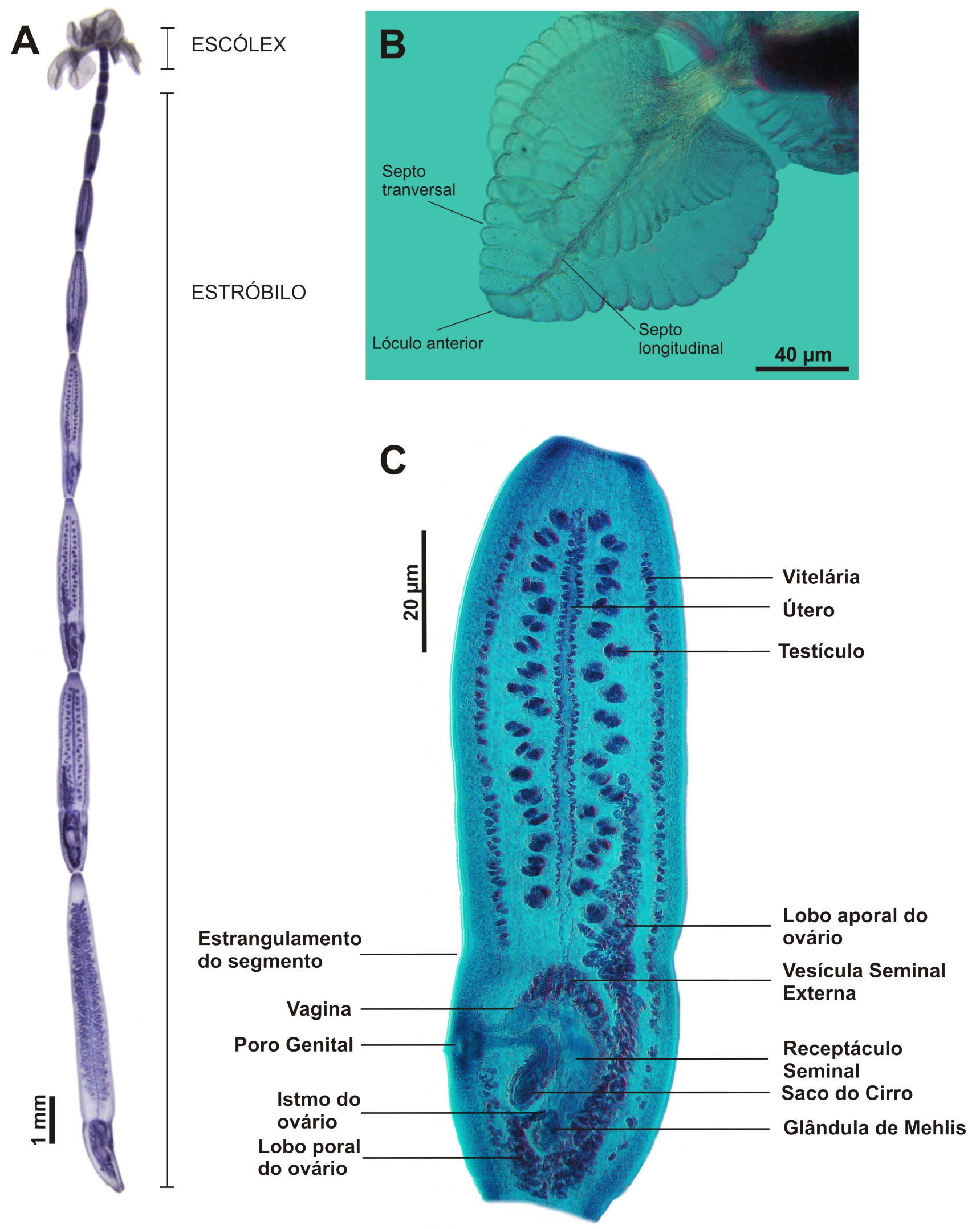

Figura 1. Morfologia geral de Rhinebothroides spp. A - espécime adulto completo. B - Detalhe do botrídeo sob microscopia óptica. C - morfologia da proglótide madura. 
pedunculados com septos marginais e transversais formando lóculos (Fig. 1B) como nos outros membros de Rhinebothriidea (Healy et al., 2009). Cada proglótide possui um aparelho sexual feminino e um masculino (Fig.1C). O aparelho sexual masculino é formado pelos testículos ( 20-100), todos conectados ao vaso deferente que se conecta ao órgão copulatório chamado cirro coberto por estruturas tegumentares chamadas microtríquias - localizado dentro do saco do cirro. A vesícula seminal interna, uma das características diagnósticas de Rhinebothroides (Brooks et al., 1981a), está localizada dentro do saco do cirro (Fig. 1C). O aparelho sexual feminino é composto por uma vagina com esfíncter muscular e posteriormente expandida, formando um receptáculo seminal; um ovário assimétrico (diagnóstico de Rhinebothroides) formado por dois lobos, um poral e outro aporal, sendo o lobo poral reduzido; um útero tubular e duto uterino; uma glândula de Mehlis; e, inúmeros folículos vitelínicos distribuídos lateralmente em cada proglótide. Tanto a vagina como o cirro entram no átrio genital, o qual se abre ao meio exterior através do poro genital. Os poros genitais estão no primeiro quarto posterior de cada proglótide e se alternam irregularmente.

Ao contrário de outras espécies do gênero, as quais são definidas por possuir diferentes características discretas (presença de células glandulares em $R$. glandularis e $R$. mclennanae; organização dos testículos e vitelária não interrompida ao nível do poro genital em $R$. scorzai e presença de espinitríquias ao invés de filitríquias no cirro de $R$. moralarai) que fogem do plano comum descrito acima, representantes do complexo $R$. freitasi são definidos apenas por pequenas diferenças observadas em dados merísticos e morfométricos extraídos de atributos que estão presentes em todas as espécies nominais do gênero. Em parte, esta é a razão pela qual a história taxonômica das espécies que compõe este complexo tem sido convoluta. Soma-se a isso o fato da maioria das espécies do gênero terem sido descritas com base em um número restrito de espécimes, em geral coletados de uma ou poucas localidades próximas e de uma espécie de hospedeiro.

Diante do cenário atual, fica evidente que a sistemática de Rhinebothroides, em geral, e do 
complexo R. freitasi, em particular, ainda permanece com inúmeras questões em aberto. Estas se referem ao reconhecimento ou não das espécies nominais incluídas neste complexo, à compreensão dos padrões de variação morfológica dentro do gênero bem como os padrões de especificidade apresentadas pelas espécies atribuídas à Rhinebothroides. Neste estudo, partiu-se da premissa de que a inclusão de dados moleculares na sistemática do gênero pode ser útil da delimitação de espécies cuja circunscrição atual é ambígua que, conjugada à reavaliação dos caracteres morfológicos até o presente utilizados na taxonomia do grupo e em posse de uma representatividade biogeográfica sem precedentes, poderá promover os avanços desejados na taxonomia do grupo. Dentro deste contexto, este estudo parte da análise filogenética de diversos haplótipos atribuídos à Rhinebothroides com o objetivo de refinar a sistemática deste componente de nossa fauna e compreender melhor suas relações de parentesco e os níveis de variação morfológica exibida por esses organismos, bem como os padrões de especificidade destes parasitas.

\section{Material e Métodos}

\section{Coletas, processamento de material biológico, identificação de parasitas}

Durante o período de 1995 a 2007, 946 espécimes pertencentes à família Potamotrygonidae foram coletados, representando cerca de 30 espécies potencialmente distintas sendo que aproximadamente 14 espécies ainda devem ser descritas formalmente. Estes hospedeiros foram obtidos utilizando diferentes métodos de captura tais como espinhéis, arpões e redes de arrasto. Os potamotrigonídeos ocorrem nas principais bacias hidrográficas da América do Sul, em rios que drenam para o Oceano Atlântico, com exceção da Bacia do Rio São Francisco, em rios que drenam ao Oceano Atlântico da Mata Atlântica no nordeste e sudeste do Brasil, em parte da Bacia do Rio Paraná e ao sul do Rio La Plata na Argentina (de Carvalho et al., 2003). A representatividade biogeográfica e de hospedeiros das amostras utilizadas nesse estudo está listada na Tabela 1 e representada na Figura 2. Os nomes atribuídos nesse estudo a hospedeiros não descritos segue aqueles utilizados por Marques \& 


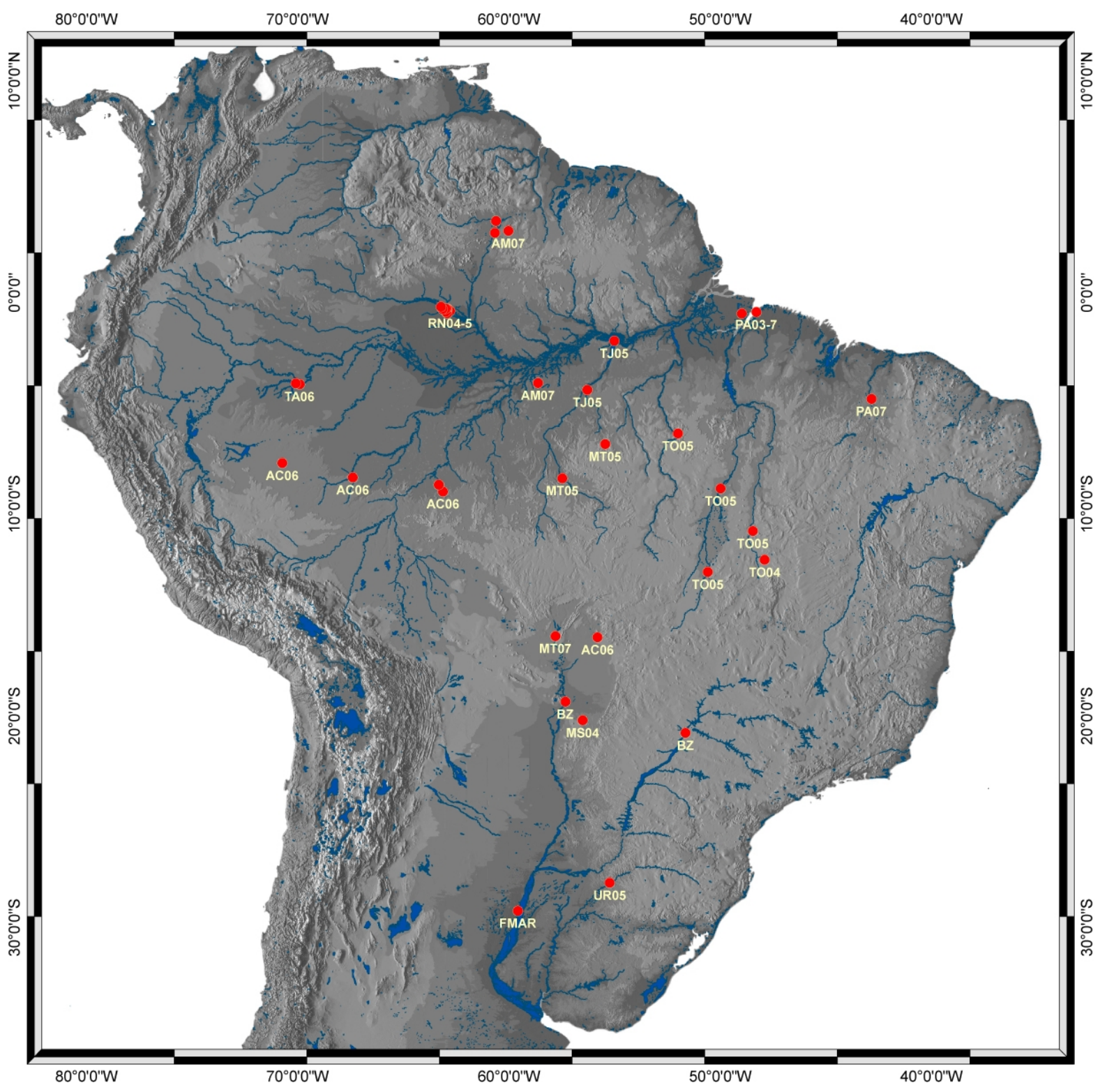

Figura 2. Representatividade biogeográfica das amostras disponíveis para esse estudo. Códigos de coleta seguem aqueles de Marques \& Domingues (2006). 


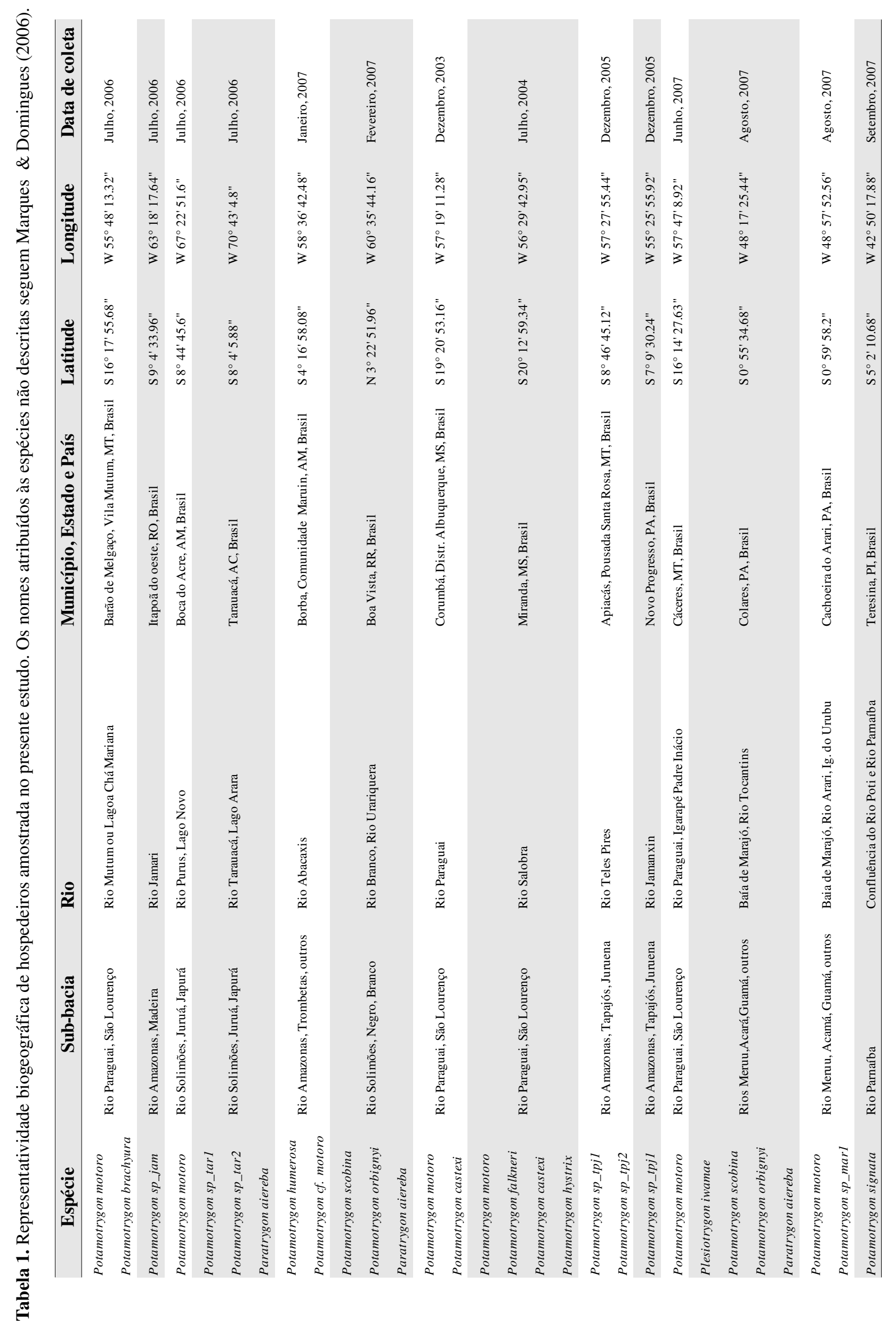




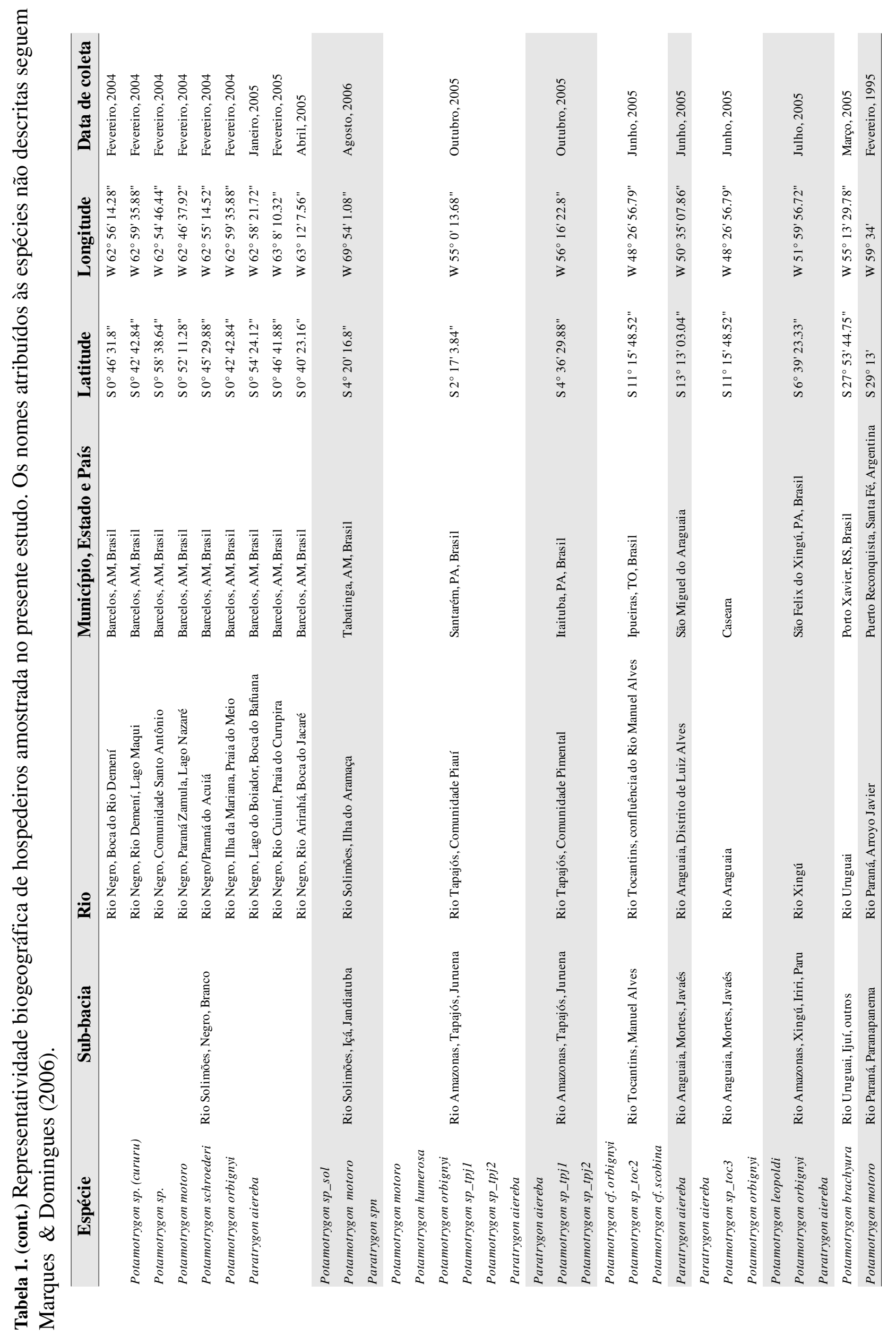


Domingues (2006).

Imediatamente após as coletas, os hospedeiros foram anestesiados e suas válvulas espirais foram removidas, abertas por uma incisão longitudinal e fixadas em formalina $4 \%$ a $60{ }^{\circ} \mathrm{C}$ ou ETOH 92-100\%, para estudos morfológicos e moleculares; respectivamente. Válvulas espirais fixadas em formalina foram posteriormente transferidas para ETOH 70\% e triadas em laboratório para a remoção e seleção de parasitas. Aquelas fixadas em ETOH 92-100\% foram triadas da mesma forma, porém seus parasitas foram estocados em ETOH $100 \%$ e mantidos a $-20^{\circ} \mathrm{C}$.

\section{Obtenção de dados morfológicos}

\section{Preparações totais para microscopia óptica}

Exemplares de Rhinebothroides foram hidratados em séries alcoólicas regressivas, corados com Hematoxilina de Delafield ou de Mayer, desidratados em séries alcoólicas progressivas, diafanizados em Salicilato de Metila e montados em lâmina e lamínula com Bálsamo do Canadá. Após a montagem, os exemplares foram identificados sob o microscópio óptico e aqueles reconhecidos como membros do complexo $R$. freitasi foram separados para a obtenção de dados morfométricos e merísticos.

Os dados morfológicos foram obtidos com uma ocular micrométrica acoplada a um microscópio óptico Olympus BX-51. Todas as medidas foram obtidas de segmentos terminais maduros (i.e. poro genital aberto) e/ou grávidos de forma a permitir a comparação entre indivíduos. As medidas estão todas expressas em micrômetros, exceto se indicado de outra forma. A descrição dos parâmetros morfológicos utilizados estão na Tabela 2.

\section{Microscopia eletrônica de Varredura.}

Os espécimes selecionados para microscopia eletrônica de varredura tiveram seus escóleces removidos e o estróbilo montado em lâminas permanentes, como descrito acima, para identificação sob microscopia óptica e atribuição de material testemunho. Os escóleces foram hidratados em séries alcoólicas regressivas, imersos em solução de Tetróxido de Ósmio 1\% por aproximadamente 


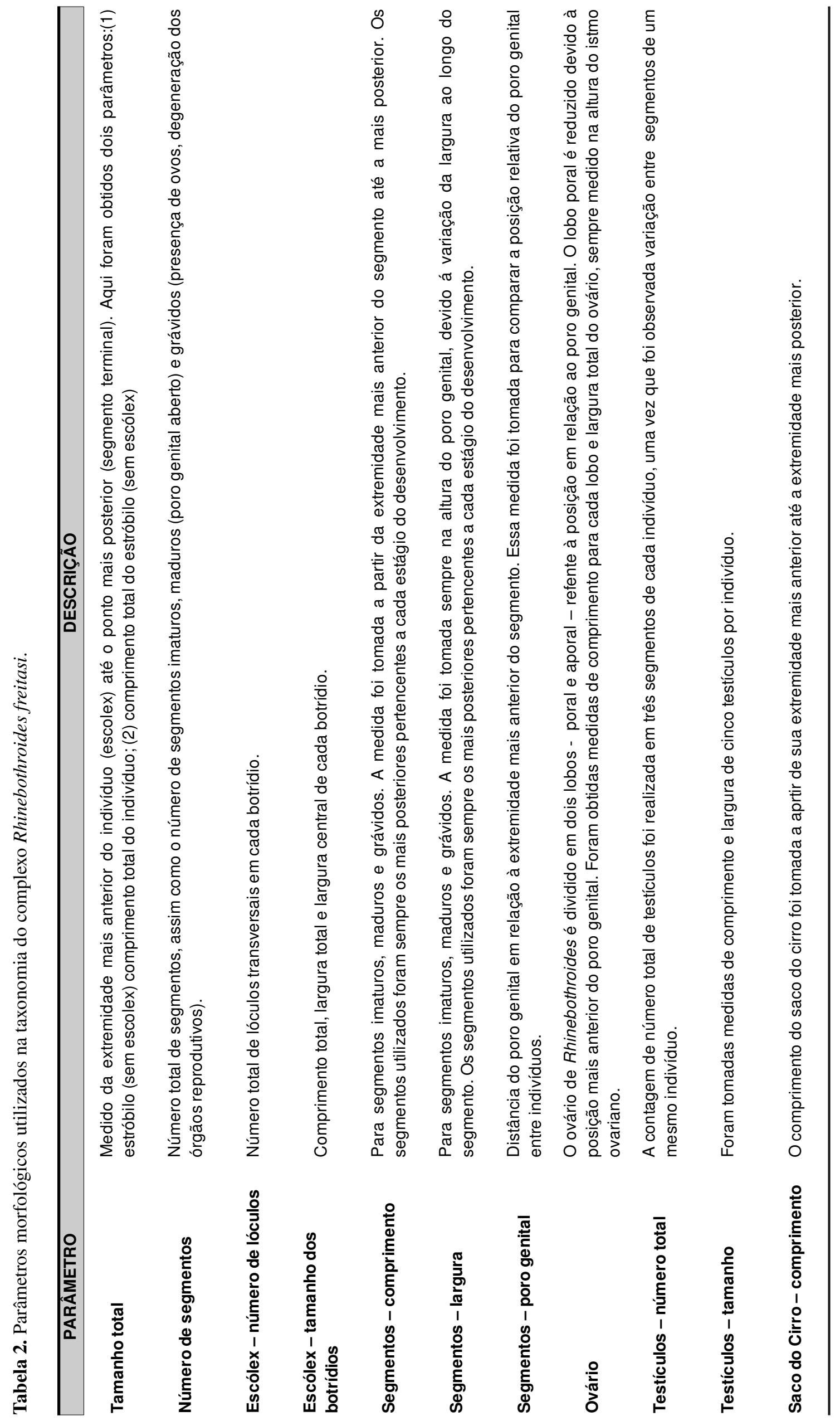


uma hora, desidratados em séries alcoólicas progressivas, submetidos ao ponto crítico no equipamento Balzers CPD 030, montados em suportes de alumínio (stubs) e cobertos por ouro no metalizador Balzers SCD 050. Concluída a preparação, esses espécimes foram examinados sob o microscópio eletrônico de varredura no Instituto de Biociências (IB-USP), Zeiss DSM-940. As regiões de captura de imagens seguem aquelas consideradas por Ivanov (2004) com algumas modificações, como ilustrado na Figura 3.

As micrografias foram analisadas com o programa UTHSCSA Image Tool ver. 3.00 (Wilcox et al., 2002). As imagens foram subdividas em quadrantes de $1 \mu \mathrm{m}$ x $1 \mu \mathrm{m}$ para análise da densidade de estruturas tegumentares, i.e., microtríquias. Para cada imagem foram selecionados 10 quadrantes aleatoriamente nos quais foi efetuada a contagem de microtríquias. Adicionalmente, foram medidas cinco microtríquias de cada tipo em cada imagem. A terminologia empregada na descrição das microtríquias segue aquela proposta por Chervy (2009).

\section{Material tipo e vouchers examinados}

Material tipo e vouchers foram generosamente emprestados pelas seguintes instituições:

HWML, Manter Laboratory of Parasitology, University of Nebraska - Lincoln, Estados Unidos; USNPC, United States National Parasite Collection, Beltsville, Maryland, Estados Unidos; CHIOC, Coleção Helmintológica do Instituto Oswaldo Cruz, Rio de Janeiro, Brasil; MACN-Pa, Museo Argentino de Ciencias Naturales, Buenos Aires, Argentina. O material tipo e vouchers examinados no presente estudo estão na Tabela 3.

\section{Obtenção de dados moleculares}

A seleção dos espécimes buscou representar a diversidade biogeográfica e de hospedeiros das amostras disponíveis. Procurou-se obter sequências de COI e 28S para pelo menos 2 indivíduos para cada morfotipo presente em cada espécie de hospedeiro de uma determinada localidade. Sequências de ITS-1 foram obtidas prioritariamente para espécimes pertencentes ao complexo $R$. freitasi para os quais haviam sido obtidas sequências de COI e $28 \mathrm{~S}$, embora o mesmo tenha sido 


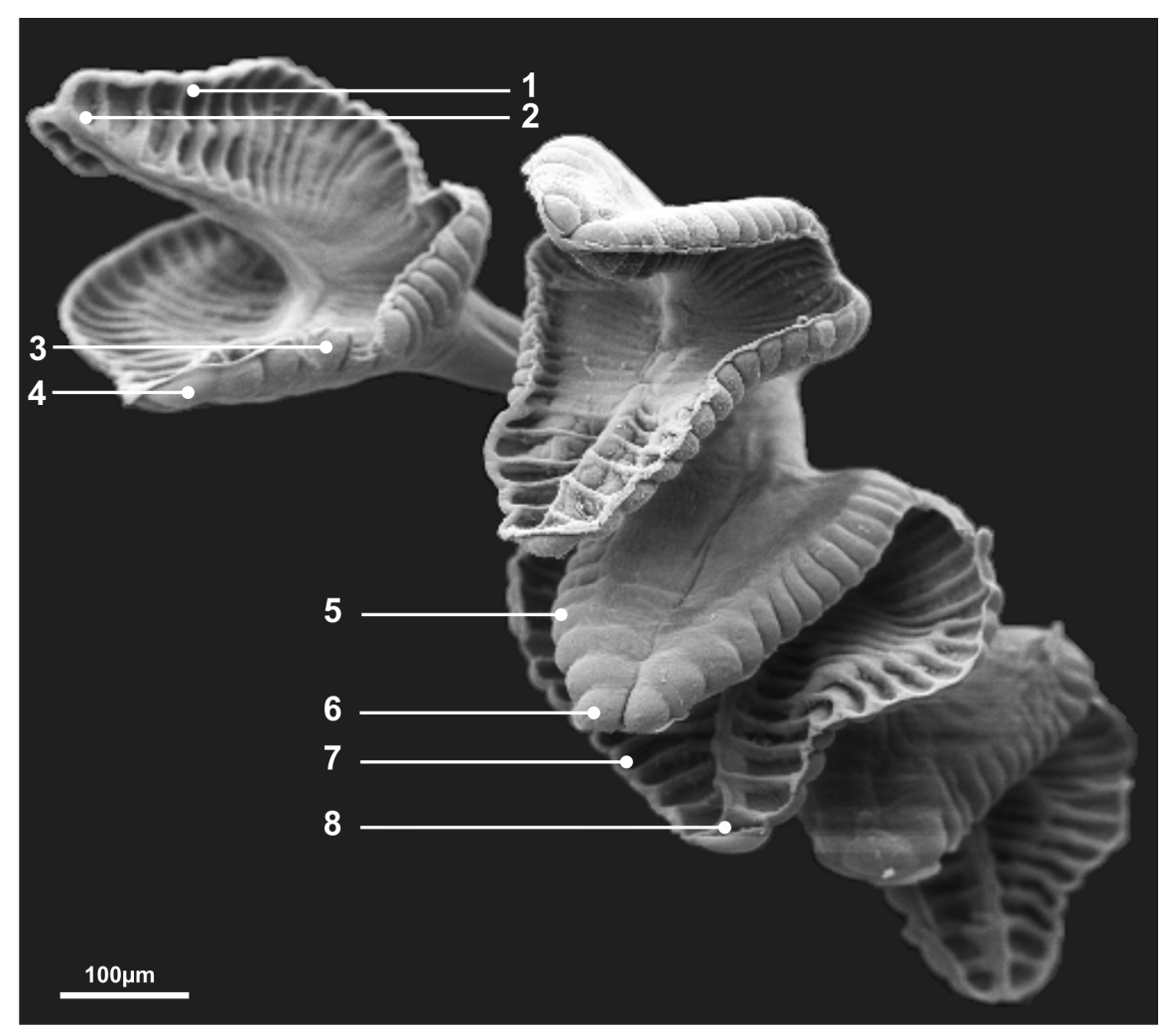

Figura 3. Regiões de captura de micrografias eletrônicas de varredura (modificadas de Ivanov, 2004) utilizadas para os exemplares de Rhinebothroides. Legenda: 1 - região central da superfície distal do botrídeo, $4^{\circ}$ septo a partir da extremidade posterior, 2 - extremidade posterior da superfície distal do botrídeo, 3 - região central da superfície proximal do botrídeo, $4^{\circ}$ septo a partir da extremidade anterior, 4 - extremidade anterior da superfície proximal do botrídeo, 5 - região central da superfície proximal do botrídeo, $4^{\circ}$ septo a partir da extremidade posterior, 6 extremidade posterior da superfície proximal do botrídeo, 7 - região central da superfície distal do botrídeo, $4^{\circ}$ septo a partir da extremidade anterior, 8 - extremidade anterior da superfície distal do botrídeo. 
Tabela 3. Material examinado procedentes de coleções de referência e utilizado em descrições originais.

\begin{tabular}{|c|c|c|c|c|c|}
\hline № de tombo & Espécie & Localidade & Hospedeiro & Categoria & Material \\
\hline HWML21007 & R. glandularis & Delta do Rio Orinoco, perto de Curiapo, Venezuela & P. histrix $†$ & parátipo & espécime completo \\
\hline HWML21007 & R. glandularis & Delta do Rio Orinoco, perto de Curiapo, Venezuela & P. histrix $\dagger$ & parátipo & espécimes incompletos \\
\hline HWML21007 & R. glandularis & Delta do Rio Orinoco, perto de Curiapo, Venezuela & P. histrix $\dagger$ & parátipo & espécime incompleto \\
\hline HWML21007 & R. glandularis & Delta do Rio Orinoco, perto de Curiapo, Venezuela & P. histrix $\dagger$ & parátipo & espécime incompleto \\
\hline HWML21007 & R. glandularis & Delta do Rio Orinoco, perto de Curiapo, Venezuela & P. histrix $\dagger$ & parátipo & espécime incompleto \\
\hline HWML21007 & R. glandularis & Delta do Rio Orinoco, perto de Curiapo, Venezuela & P. histrix $†$ & parátipo & espécime completo \\
\hline HWML21007 ${ }^{1}$ & R. glandularis & Delta do Rio Orinoco, perto de Curiapo, Venezuela & P. histrix $\dagger$ & parátipo & espécime incompleto \\
\hline HWML21007 ${ }^{1}$ & R. glandularis & Delta do Rio Orinoco, perto de Curiapo, Venezuela & P. histrix $\dagger$ & parátipo & espécime completo \\
\hline HWML21007' & R. glandularis & Delta do Rio Orinoco, perto de Curiapo, Venezuela & P. histrix $\dagger$ & parátipo & espécime completo \\
\hline HWML21015² & R. scorzai & Delta do Rio Orinoco, Venezuela & P. histrix $†$ & voucher & espécime incompleto \\
\hline HWML21015² & R. scorzai & Delta do Rio Orinoco, Venezuela & P. histrix $\dagger$ & voucher & espécime completo \\
\hline HWML21015² & R. scorzai & Delta do Rio Orinoco, Venezuela & P. histrix $\dagger$ & voucher & espécime completo \\
\hline HWML21015² & R. scorzai & Delta do Rio Orinoco, Venezuela & P. histrix $†$ & voucher & vários espécimes imaturos \\
\hline HWML21015² & R. scorzai & Delta do Rio Orinoco, Venezuela & P. histrix $†$ & voucher & espécime incompleto \\
\hline HWML21015² & R. scorzai & Delta do Rio Orinoco, Venezuela & P. histrix $†$ & voucher & espécime incompleto \\
\hline HWML21015² & R. scorzai & Delta do Rio Orinoco, Venezuela & P. histrix $\dagger$ & voucher & proglótides soltas \\
\hline HWML21015² & R. scorzai & Delta do Rio Orinoco, Venezuela & P. histrix $\dagger$ & voucher & espécime incompleto \\
\hline HWML21015² & R. scorzai & Delta do Rio Orinoco, Venezuela & P. histrix $†$ & voucher & espécime imaturo \\
\hline HWML21015² & R. scorzai & Delta do Rio Orinoco, Venezuela & P. histrix $†$ & voucher & 3 espécimes imaturos \\
\hline HWML21014² & R. scorzai & Delta do Rio Orinoco, Venezuela & P. histrix $\dagger$ & voucher & espécime incompleto \\
\hline HWML21014² & R. scorzai & Delta do Rio Orinoco, Venezuela & P. histrix $\dagger$ & voucher & segmento grávido \\
\hline HWML210203 & R. circularisi & Rio Itacuai, Atalaia do Norte, Brasil & P. circularis * & parátipo & espécime completo \\
\hline HWML21020 3 & R. circularisi & Rio Itacuai, Atalaia do Norte, Brasil & P. circularis * & parátipo & espécime completo \\
\hline HWML21020 3 & R. circularisi & Rio Itacuai, Atalaia do Norte, Brasil & P. circularis * & parátipo & espécime completo \\
\hline HWML21020 3 & R. circularisi & Rio Itacuai, Atalaia do Norte, Brasil & P. circularis * & parátipo & escólex \\
\hline HWML21020 3 & R. circularisi & Rio Itacuai, Atalaia do Norte, Brasil & P. circularis * & parátipo & espécime incompleto \\
\hline HWML210203 & R. circularisi & Rio Itacuai, Atalaia do Norte, Brasil & P. circularis * & parátipo & espécime completo \\
\hline HWML210203 & R. circularisi & Rio Itacuai, Atalaia do Norte, Brasil & P. circularis * & parátipo & espécime imaturo \\
\hline HWML21020 3 & R. circularisi & Rio Itacuai, Atalaia do Norte, Brasil & P. circularis * & parátipo & espécime completo \\
\hline HWML21020³ & R. circularisi & Rio Itacuai, Atalaia do Norte, Brasil & P. circularis * & parátipo & espécime completo \\
\hline HWML210203 & R. circularisi & Rio Itacuai, Atalaia do Norte, Brasil & P. circularis * & parátipo & espécime imaturo \\
\hline HWML21025 & R. venezuelensis & Delta do Rio Orinoco, perto de Curiapo, Venezuela & P. histrix $\dagger$ & voucher & espécime completo \\
\hline HWML21025 & R. venezuelensis & Delta do Rio Orinoco, perto de Curiapo, Venezuela & P. histrix $†$ & voucher & espécime completo \\
\hline HWML34092 ${ }^{1}$ & R. venezuelensis & Corumbá, MS, Brasil & P. motoro & voucher & espécime completo \\
\hline HWML34092 ${ }^{1}$ & R. venezuelensis & Corumbá, MS, Brasil & P. motoro & voucher & espécime completo \\
\hline HWML34092 & R. venezuelensis & Corumbá, MS, Brasil & P. motoro & voucher & espécime completo \\
\hline HWML21005 & R. venezuelensis & Delta do Rio Orinoco, perto de Curiapo, Venezuela & P. histrix $\dagger$ & parátipo & proglótides soltas \\
\hline HWML21005ㅇ & R. venezuelensis & Delta do Rio Orinoco, perto de Curiapo, Venezuela & P. histrix $\dagger$ & parátipo & espécime incompleto \\
\hline
\end{tabular}

$\S=$ estróbilo de Rhinebothroides, escólex de Acanthobothrium; $\dagger=$ hospedeiro originalmente identificado como $P$. histrix, mas retificado em Brooks \& Amato (1992) como P. orbygnyi; \# = espécime pertence a $R$. glandularis; * = P. circularis é sinônimo júnior de $P$. constellata ou $P$. motoro (de Carvalho et al., 2003). Números referem-se às publicações de: 1, Brooks, Mayes \& Thorson (1981); 2, Brooks, Mayes \& Thorson (1981) para R. scorzai; 3, Mayes, Brooks \& Thorson, (1981a - sinonímia junior de R. freitasi por Marques \& Brooks, 2003); 4, Brooks, Mayes \& Thorson, 1981 para R. moralarai; 5, Rego (1979); 6, Ivanov (2004); e 7, Brooks \& Amato (1992). 
Tabela 3. (cont.) Material examinado procedentes de coleções de referência e utilizado em descrições originais.

\begin{tabular}{|c|c|c|c|c|c|}
\hline № de tombo & Espécie & Localidade & Hospedeiro & Categoria & Material \\
\hline HWML21005 & R. venezuelensis & Delta do Rio Orinoco, perto de Curiapo, Venezuela & P. histrix $\dagger$ & parátipo & proglótides grávidas \\
\hline HWML21005 & R. venezuelensis & Delta do Rio Orinoco, perto de Curiapo, Venezuela & P. histrix $\dagger$ & parátipo & espécime completo \\
\hline HWML21005 & R. venezuelensis & Delta do Rio Orinoco, perto de Curiapo, Venezuela & P. histrix $\dagger$ & parátipo & espécime completo \\
\hline HWML21005 & R. venezuelensis & Delta do Rio Orinoco, perto de Curiapo, Venezuela & P. histrix $\dagger$ & parátipo & espécime completo \\
\hline HWML21006 & R. venezuelensis & Delta do Rio Orinoco, perto de Curiapo, Venezuela & P. histrix $\dagger$ & parátipo & espécime completo \\
\hline HWML21006 & R. venezuelensis & Delta do Rio Orinoco, perto de Curiapo, Venezuela & P. histrix $\dagger$ & parátipo & espécime completo \\
\hline HWML21006 & R. venezuelensis & Delta do Rio Orinoco, perto de Curiapo, Venezuela & P. histrix $\dagger$ & parátipo & espécime completo \\
\hline HWML21006 & R. venezuelensis & Delta do Rio Orinoco, perto de Curiapo, Venezuela & P. histrix $†$ & parátipo & espécime completo \\
\hline HWML21006 & R. venezuelensis & Delta do Rio Orinoco, perto de Curiapo, Venezuela & P. histrix $\dagger$ & parátipo & espécime completo \\
\hline HWML21006 & R. venezuelensis & Delta do Rio Orinoco, perto de Curiapo, Venezuela & P. histrix $\dagger$ & parátipo & espécime completo \\
\hline HWML21006 ${ }^{1}$ & R. venezuelensis & Delta do Rio Orinoco, perto de Curiapo, Venezuela & P. histrix $†$ & parátipo & espécime completo \\
\hline HWML202554 & R. moralarai & Rio Magdalena, San Cristóbal, Colômbia & P. magdalenae & parátipo & espécime completo \\
\hline HWML202554 & R. moralarai & Rio Magdalena, San Cristóbal, Colômbia & P. magdalenae & parátipo & 2 proglótides grávidas \\
\hline HWML202554 & R. moralarai & Rio Magdalena, San Cristóbal, Colômbia & P. magdalenae & parátipo & espécime imaturo \\
\hline $\mathrm{CHIOC} 31.486 b^{5}$ & R. freitasi & Rio Amazonas, Maicuru, Pará, Brasil & P. histrix $†$ & parátipo & proglótides soltas \\
\hline $\mathrm{CHIOC} 31.486 \mathrm{c}^{5}$ & R. freitasi & Rio Amazonas, Maicuru, Pará, Brasil & P. histrix $†$ & parátipo & proglótides soltas imaturas \\
\hline CHIOC31.486 $\mathrm{d}^{5}$ & R. freitasi & Rio Amazonas, Maicuru, Pará, Brasil & P. histrix $\dagger$ & parátipo & escólex \\
\hline $\mathrm{CHIOC} 31.486 \mathrm{e}^{5}$ & R. freitasi & Rio Amazonas, Maicuru, Pará, Brasil & P. histrix $\dagger$ & parátipo & 2 escoleces \\
\hline $\mathrm{CHIOC} 32.818 \mathrm{a}^{1} \#$ & R. venezuelensis & Corumbá, MS, Brasil & P. motoro & voucher & espécime completo \\
\hline CHIOC32.818b ${ }^{1}$ & R. venezuelensis & Corumbá, MS, Brasil & P. motoro & voucher & espécime completo \\
\hline CHIOC $32.818 \mathrm{c}^{1}$ & R. venezuelensis & Corumbá, MS, Brasil & P. motoro & voucher & espécime imaturo \\
\hline CHIOC32.818d ${ }^{1}$ & R. venezuelensis & Corumbá, MS, Brasil & P. motoro & voucher & espécime completo \\
\hline $\mathrm{CHIOC} 32.818 \mathrm{e}^{1}$ & R. venezuelensis & Corumbá, MS, Brasil & P. motoro & voucher & espécime completo \\
\hline $\mathrm{CHIOC} 32.818 f^{1}$ & R. venezuelensis & Corumbá, MS, Brasil & P. motoro & voucher & espécime completo \\
\hline USNPC735454 & R. moralarai & Rio Magdalena, San Cristóbal, Colômbia & P. magdalenae & parátipo & espécime completo \\
\hline USNPC76362 3 & R. circularisi & Rio Itacuai, Atalaia do Norte, Brasil & P. circularis * & parátipo & espécime completo \\
\hline USNPC75704² & R. scorzai & Delta do Rio Orinoco, Venezuela & P. histrix $\dagger$ & voucher & espécime completo \\
\hline USNPC75708 & R. glandularis & Delta do Rio Orinoco, perto de Curiapo, Venezuela & P. histrix $\dagger$ & parátipo & espécime completo \\
\hline USNPC75708 1 & R. glandularis & Delta do Rio Orinoco, perto de Curiapo, Venezuela & P. histrix $\dagger$ & parátipo & espécime completo \\
\hline USNPC75706 & R. venezuelensis & Delta do Rio Orinoco, perto de Curiapo, Venezuela & P. histrix $\dagger$ & parátipo & espécime completo \\
\hline USNPC75706 & R. venezuelensis & Delta do Rio Orinoco, perto de Curiapo, Venezuela & P. histrix $†$ & parátipo & espécime completo \\
\hline USNPC94696 & R. campbelli & Rio Colastiné, Santa Fé, Argentina & P. motoro & parátipo & espécime completo \\
\hline MACN-Pa-412/16 & R. campbelli & Rio Colastiné, Santa Fé, Argentina & P. motoro & holótipo & espécime completo \\
\hline MACN-Pa- $412 / 2^{6}$ & R. campbelli & Rio Colastiné, Santa Fé, Argentina & P. motoro & parátipo & espécime completo \\
\hline MACN-Pa- $412 / 3^{6}$ & R. campbelli & Rio Colastiné, Santa Fé, Argentina & P. motoro & parátipo & espécime completo \\
\hline $\mathrm{CHIOC} 32.814 \mathrm{~b}^{7}$ & R. mclennanae & Corumbá, MS, Brasil & P. motoro & parátipo & espécime completo \\
\hline $\mathrm{CHIOC} 32.814 \mathrm{c}^{7}$ & R. mclennanae & Corumbá, MS, Brasil & P. motoro & parátipo & espécime completo \\
\hline CHIOC $32.814 d^{7}$ & R. mclennanae & Corumbá, MS, Brasil & P. motoro & parátipo & espécime completo \\
\hline CHIOC $32.814 \mathrm{e}^{7}$ & R. mclennanae & Corumbá, MS, Brasil & P. motoro & parátipo & espécime completo \\
\hline $\mathrm{CHIOC} 32.814 \mathrm{f}^{7}$ & R. mclennanae & Corumbá, MS, Brasil & P. motoro & parátipo & espécime completo \\
\hline
\end{tabular}

$\S=$ estróbilo de Rhinebothroides, escólex de Acanthobothrium; $\dagger=$ hospedeiro originalmente identificado como $P$. histrix, mas retificado em Brooks \& Amato (1992) como P. orbygnyi; \# = espécime pertence a $R$. glandularis; * $=P$. circularis é sinônimo júnior de $P$. constellata ou $P$. motoro (de Carvalho et al., 2003). Números referem-se às publicações de: 1, Brooks, Mayes \& Thorson (1981); 2, Brooks, Mayes \& Thorson (1981) para R. scorzai; 3, Mayes, Brooks \& Thorson, (1981a - sinonímia junior de R. freitasi por Marques \& Brooks, 2003); 4, Brooks, Mayes \& Thorson, 1981 para R. moralarai; 5, Rego (1979); 6, Ivanov (2004); e 7, Brooks \& Amato (1992). 
feito para alguns exemplares das outras espécies do gênero. Anterior à extração de DNA genômico cada espécime foi fotografado e divido em três partes, das quais o escólex e os segmentos terminais do estróbilo foram destinados à preparação de lâminas, e o restante destinado ao protocolo de extração. A preparação de lâminas permanentes desse material testemunho seguiu o mesmo protocolo adotado na confecção de lâminas permanentes para estudos morfológicos descrito acima e foram depositados em coleções de referência (ver Resultados).

\section{Extração de DNA, polimerase chain reaction (PCR), sequenciamento e análise}

Os fragmentos dos espécimes destinados à extração de DNA genômico foram colocados em tubos de $200 \mu 1$, deixados para secar em temperatura ambiente por aproximadamente 30 ", lavados em TE duas vezes por 30" - para total remoção de ETOH - e posteriormente submetidos ao protocolo de extração. As extrações foram realizadas utilizando o kit InstaGene ${ }^{\mathrm{TM}}$ Matrix (Bio-Rad), seguindo o protocolo do fabricante, exceto pela redução do volume para $30 \mu \mathrm{l}$ ao invés de $100 \mu \mathrm{l}$.

As regiões amplificadas nesse estudo foram selecionadas de acordo com estudo de Reyda (2007), que considerou as regiões D1-D3 do gene nuclear 28S e um fragmento do gene mitocondrial Citocromo Oxidase sub-unidade I (COI). Segundo o autor, estes genes propiciaram taxas de substituições que permitiram a identificação de espécies para membros de Rhinebothrium encontrados em potamotrigonídeos e permite que os dados obtidos neste estudo possam ser analisados em conjunto com os dados de Reyda (2007). Adicionalmente, a região nuclear correspondente ao ITS-1 foi incluída neste estudo na expectativa de obter maior resolução filogenética para determinados clados. Os iniciadores utilizados e os protocolos de PCR são descritos nas Tabelas 4 e 5, respectivamente.

Após a verificação em gel de agarose $2 \%$, as amplificações foram purificadas utilizando o kit AMPure $^{\mathrm{TM}}$ (Agencourt) e quantificadas utilizando gel de agarose e low DNA mass ladder (Invitrogen, Inc.). Posteriormente, as amostras foram amplificadas com o fluóforo BigDye® Terminator v3.1 Cycle Sequencing Kit (Applied Biosystems), precipitadas segundo instruções do 
fabricante e submetidas à leitura em um sequenciador ABI 3100 Genetic Analyzer no Centro de Sequenciamento do Departamento de Química da USP - IQ/USP, São Paulo.

Tabela 4. Iniciadores empregados na obtenção de dados moleculares.

\begin{tabular}{|ccc|}
\hline Fragmento & Nome & Iniciador $($ primer) \\
\hline \hline \multirow{2}{*}{$28 \mathrm{~S}$} & $\mathrm{C} 1$ & 5'-ACCCGCTGAATTTAAGCAT-3' \\
& $\mathrm{D} 2$ & 5'-TGGTCCTTTCAAGAC-3' \\
& Rob2 & 5'-CACGYACTRTTTACTCTC-3' \\
& LSU-330F & 5'-CAAGTACCGTGAGGGAAAGTT-3' \\
& nLCO & 5'-TTTACTYTRGAYCATAAGCGT-3' \\
& Sean2 & 5'-AAGCAGAACCAAATTTACGAT-3' \\
& ITS-1A & 5'-GATACAAGGTTTCCGTAGGTG-3' \\
& ITS 1 & 5'-GAGCCGAGTGATCCACC-3' \\
\hline
\end{tabular}

Tabela 5. Protocolos de amplificação utilizados na obtenção de sequências nucleotídicas.

\begin{tabular}{|c|c|c|c|c|c|c|c|c|c|c|c|c|}
\hline Fragmento & & $28 S$ & & & $28 S$ & & & CO1 & & & ITS1 & \\
\hline \multirow[t]{2}{*}{ primers } & \multicolumn{3}{|c|}{$\mathrm{C} 1+\mathrm{Rob} 2$ ou LSU-330F+D2 } & \multicolumn{3}{|c|}{$\mathrm{C} 1+\mathrm{D} 2$} & \multicolumn{3}{|c|}{$\mathrm{nLCO}+\mathrm{Sean} 2$} & \multicolumn{3}{|c|}{ ITS-1A+ITS-R3A } \\
\hline & tempo & $\mathrm{T}\left({ }^{\circ} \mathrm{C}\right)$ & $\mathrm{n}^{\circ}$ ciclos & tempo & $\mathrm{T}\left({ }^{\circ} \mathrm{C}\right)$ & $\mathrm{n}^{\circ}$ ciclos & tempo & $\mathrm{T}\left({ }^{\circ} \mathrm{C}\right)$ & $\mathrm{n}^{\circ}$ ciclos & tempo & $\mathrm{T}\left({ }^{\circ} \mathrm{C}\right)$ & $\mathrm{n}^{\circ}$ ciclos \\
\hline denaturação inicial & $5^{\prime}$ & 94 & 1 & $4^{\prime}$ & 94 & 1 & $2^{\prime}$ & 94 & 1 & $5^{\prime}$ & 94 & 1 \\
\hline denaturação & $30 "$ & 94 & 35 & $30 "$ & 94 & 35 & $30 "$ & $94 / 94$ & $10 / 25$ & $30 "$ & 94 & 35 \\
\hline anelamento & $30 "$ & 60 & 35 & $30 "$ & 60 & 35 & $1^{\prime}$ & $48 / 50$ & $10 / 25$ & $30 "$ & 50 & 35 \\
\hline extensão & $40 "$ & 72 & 35 & 1'30" & 72 & 35 & $1 ' 20 "$ & $72 / 72$ & $10 / 25$ & 1'30" & 72 & 35 \\
\hline extensão final & $7^{\prime}$ & 72 & 1 & $7^{\prime}$ & 72 & 1 & $7^{\prime}$ & 72 & 1 & $7^{\prime}$ & 72 & 1 \\
\hline
\end{tabular}

Sequências contíguas foram montadas e editadas usando o programa Consed/PhredPhrap (Ewing \& Green, 1998; Ewing et al., 1998; Gordon et al., 1998; Gordon et al., 2001). As sequências de COI foram alinhadas com o auxílio do programa Clustal W (Thompson et al., 1994) implementado no programa BioEdit (Hall, 1999), e traduzidas para verificação da presença de stop códons. As sequências de 28S e ITS-1 foram analisadas utilizando o algoritmo de otimização direta (Wheeler, 1996) implementado no programa POY versão 4.1 .2 (Váron et al., 2009), descrito detalhadamente abaixo. Esse é um dos algoritmos utilizados na reconstrução de árvores sob homologia dinâmica (Wheeler, 1996; 2001), especialmente para os marcadores sujeitos a alinhamento (não codificadores). 


\section{Análise filogenética - Justificativa do método adotado}

O resultado de uma análise filogenética baseada em dados moleculares é dependente do alinhamento das sequências (Aagesen, 2005). Tradicionalmente, análises filogenéticas desse tipo de dados são feitas em duas etapas distintas. Inicialmente, um alinhamento múltiplo das sequências é efetuado com programas como Clustal W (Thompson et al., 1994) e que subsequentemente, é submetido à inferência filogenética independente do critério de otimização escolhido (e.g. máxima verossimilhança, análise bayesiana e/ou parcimônia). Morrison \& Ellis (1997) demonstraram empiricamente o quanto o resultado das reconstruções filogenéticas é mais sensível aos diferentes regimes de custos/algoritmos de alinhamento do que ao critério de otimização aplicado. Desta forma, o alinhamento deve ser considerado uma etapa fundamental em estudos filogenéticos.

Alguns autores argumentam que topologia e alinhamento são dependentes, uma vez que todos os programas disponíveis para alinhamento múltiplo dependem de árvore guia na escolha dos pares que são alinhados sequencialmente (Lake, 1991; Phillips et al., 2000; Wheeler, 1995, 1996, 2003; Aagesen, 2005). Na expectativa de acomodar buscas de topologias e alinhamento em um único processo computacional, Wheeler (1996) desenvolveu o algoritmo de otimização direta, que elimina um dos passos das análises tradicionais, utilizando sequências desalinhadas na reconstrução de hipóteses filogenéticas resultado do exame concomitante de topologias e alinhamento. Consequentemente, esse método elimina a dependência do alinhamento de uma única árvore guia (gerada frequentemente por algoritmos fenéticos tais como Neighbor Joining ou UPGMA) e o tratamento inconsistente de INDELs (inserções/deleções) (Wheeler, 1996; Aagesen, 2005).

Alinhamentos são também dependentes de funções de custo para transversões, transições e INDELs (e.g. inserções e/ou deleções). Esses regimes de custo são arbitrários, uma vez que seus valores e/ou razões só podem ser obtidos com base em uma topologia pré-existente (Wheeler, 1995; 1996). Desta forma, a análise sob diferentes regimes de custo se torna crucial em reconstruções filogenéticas para que se possa avaliar a dependência das topologias ou parte delas em relação a 
parâmetros de alinhamento. Com essa finalidade, é fundamental que diferentes matrizes de custo sejam implementadas para o mesmo conjunto de dados e as topologias resultantes sejam então comparadas para avaliar a estabilidade de clados diante de diferentes parâmetros de alinhamento (i.e. análise de sensibilidade; Wheeler, 1995; Giribet, 2001). A avaliação da congruência entre os bancos de dados é feita através do cálculo do ILD (Incongruence Length Difference, Mickevich \& Farris, 1981) para cada um dos parâmetros de alinhamento implementados na análise, de forma a detectar o regime de custo que minimiza eventos de homoplasia entre as partições (porém veja Aagesen et al., 2005; Dowton \& Austin, 2002; Ramirez, 2006).

\section{Análise filogenética em POY}

Partições de fragmentos sujeitos a alinhamento (i.e., 28S e ITS-1), bem como a análise simultânea de todos os dados (i.e., 28S, ITS-1 e COI, este último sob homologia estática), foram submetidos à análise cladística utilizando o algoritmo de otimização direta sob o critério de otimização de parcimônia implementado no programa POY versão 4.1.2 (Váron et al., 2009). As análises em POY foram realizadas no cluster do Departamento de Zoologia - IB/USP utilizando 16 processadores INTEL ${ }^{\circledR}$ Core $^{\mathrm{TM}} 2$ Quad - totalizando 64 CPUs com $3.2 \mathrm{GHz}$. A análise cladística parcial do COI foi efetuada em TNT (Goloboff et al., 2008), no qual a busca da topologia mais parcimoniosa foi obtida após 1000 adições aleatórias, mantendo o máximo de 10 topologias por réplica submetidas ao refinamento pelo algoritmo de TBR.

As análises em POY consideraram vários regimes de custo de alinhamento (i.e. custo para gaps, transversões e transições), de forma a detectar clados sensíveis a tais funções de custo (análise de sensibilidade sensu Wheeler, 1995 e Giribet, 2001). Tradicionalmente, análises de sensibilidade aplicam as mesmas funções de custo a todas as partições incluídas na análise (Wheeler \& Hayashi, 1998; Frost et al., 2001, Edgecombe \& Giribet, 2009; Giribet, 2001; Giribet \& Edgecombe, 2006; Giribet et al., 2001), assumindo implicitamente que a maior congruência de caracteres está neste espaço de parâmetros. Não há evidências empíricas que suportem essa premissa, ao contrário, 
sabemos que diferentes regiões do genoma exibem taxas de substituição distintas sugerindo que o mais apropriado, dentro do contexto de análise de sensibilidade, seria aplicar funções de custo distintas para cada marcador incluído na análise; refinando assim o espaço de parâmetros considerado.

Foram adotados 9 parâmetros de alinhamento nos quais os custos de substituição entre transições e transversões variaram na proporção de 1:1, 1:2 e 2:1 e a razão de custo entre INDELs e substituições variaram na proporção de 1:1, 2:1 e 4:1, respectivamente. Adicionalmente, foi implementado o custo de 4xINDELs para gaps de abertura (i.e. affine gaps) uma vez que a implementação de custos diferenciados para gap de abertura parece aumentar empiricamente a congruência de caracteres (Aagesen, 2005). Todas as combinações entre parâmetros e partições foram avaliadas, gerando um espaço de 243 parâmetros de alinhamento (nove parâmetros para 28S e ITS-1 e três parâmetros para COI, uma vez que este último não está sujeito a INDELs).

Para as análises parciais, foram realizadas 400 adições aleatórias (comando: build(400), cada uma mantendo uma única topologia sujeita à refinamento pelo algoritmo TBR (comando: swap()). As buscas foram efetuadas considerando a seguinte sequência de comandos: leitura das partições de 28S e ITS-1 $(\operatorname{read}())$, implementação das funções de custo individuais levando em consideração custos distintos para abertura e extensão de regiões de gaps (transform ((names:("*.fas"), tcm:"matriz_de custo"),gap_opening:N)), submissão de dados pré-alinhados de COI e implementação de custo (read(prealigned:("coi.fas",tcm:"matriz_de_custo"))), definição do ponto de enraizamento (set(root:"AF286930_Litobothrium_janovyi")), e busca de topologias pela construção de 120 árvores de Wagner (Wagner, 1961) refinadas pelo algoritmo de TBR (comandos: build(120), swap()), seleção da(s) topologia(s) mais curta(s) (select()) e arquivos de saídas (report()). Exemplo dos scripts utilizados tanto nas análises parciais como nas totais pode ser visto no Anexo A.

Após a busca e diagnose para cada parâmetro, a hipótese de trabalho foi escolhida com base 
na congruência de caracteres expresso pela métrica denominada ILD (Incongruence Length Difference, Mickevich \& Farris, 1981), dentro do contexto de análise de congruência (sensu Wheeler, 1995 e Giribet, 2001). O cálculo de ILD utilizado nesse estudo segue a fórmula determinada por Wheeler \& Hayashi (1998), na qual ILD=(custo da análise simultânea - somatória das análises parciais)/custo da análise simultânea). O ILD foi calculado para todos os 243 parâmetros testados e aquele com o menor ILD (combinação de parâmetros que maximiza a congruência entre os diferentes bancos de dados) foi selecionado.

A compilação dos resultados da análise de sensibilidade (sensu Wheeler, 1995 e Giribet, 2001) foi realizada com o programa Cladescan (Sanders, 2009) e a edição das árvores foi feita em Figtree v. 1.2.3 (Rembaut, 2007). A topologia contendo comprimento de ramos aproximados foi gerada com o programa PAUP* (Swofford, 2002) após a transformação dos alinhamentos implícitos produzidos em POY em um arquivo no formato NEXUS no qual foi implementada uma aproximação dos regimes de custo utilizados durante as buscas (Anexo B).

\section{Resultados}

\section{Análise filogenética}

Ao todo, 250 espécimes de Rhinebothroides foram submetidos aos protocolos de extração de DNA genômico, dos quais 62 foram selecionados para análise cladística de acordo com o sucesso na obtenção de sequências nucleotídicas para os marcadores contemplados neste estudo. Adicionalmente, 21 terminais foram incluídos na análise como grupo-externo, cujas sequencias foram obtidas dos estudos de Healy (2006) e Reyda (2007). A lista completa de todos os terminais utilizados na análise, bem como sua identificação, hospedeiro, local de coleta e marcadores obtidos está na Tabela 6.

As funções de custo implementadas nos parâmetros de alinhamento, o custo das topologias obtidas para a análise simultânea e as parciais, e os valores de ILD estão expressos na Tabela 7. 


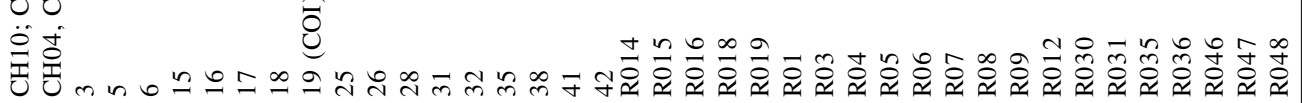

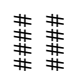

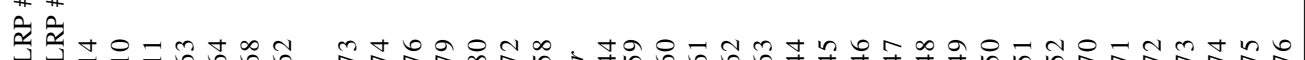

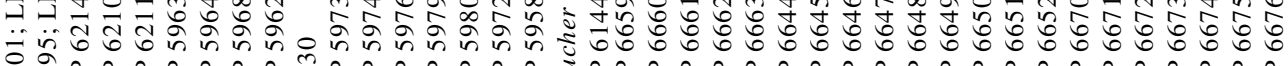

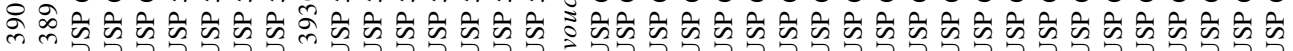

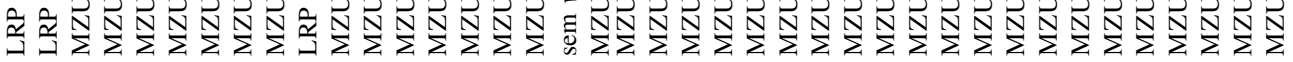

约

$\bullet \bullet \bullet \bullet \bullet \bullet \bullet \bullet \bullet \bullet \bullet \bullet \bullet \bullet \bullet \bullet$

$\bullet \bullet \bullet \bullet \bullet \bullet \bullet \bullet \bullet \bullet \bullet \bullet \bullet \bullet \bullet \bullet \bullet \bullet \bullet \bullet \bullet \bullet \bullet \bullet \bullet \bullet \bullet \bullet \bullet \bullet \bullet \bullet \bullet \bullet \bullet \bullet \bullet \bullet \bullet \bullet$

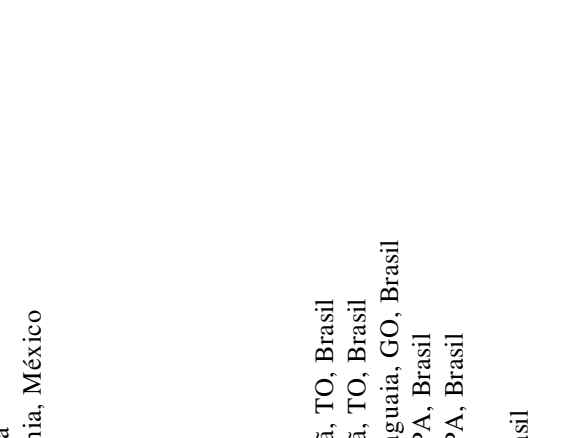

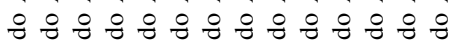

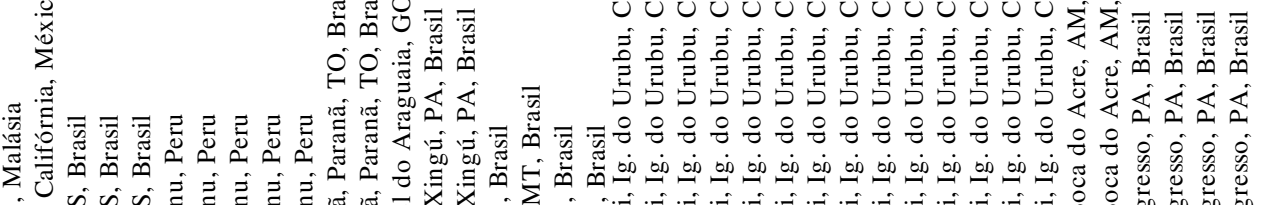

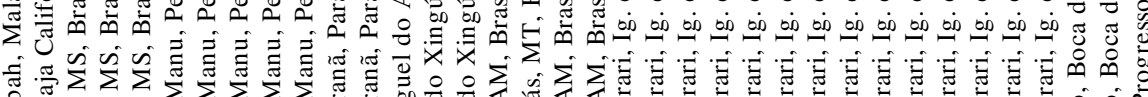

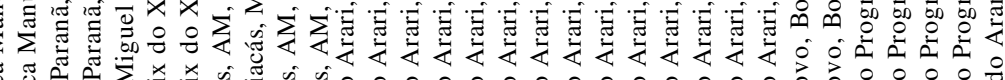

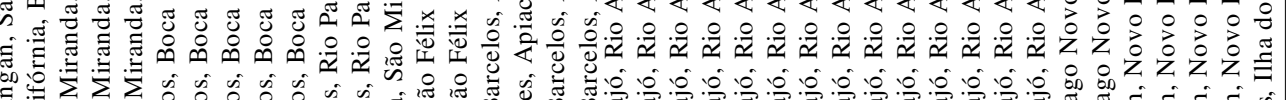

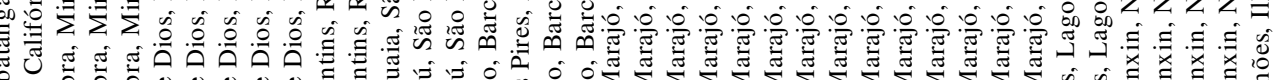

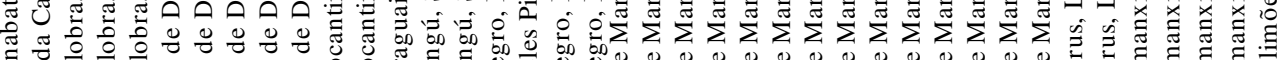

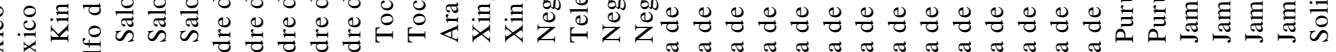

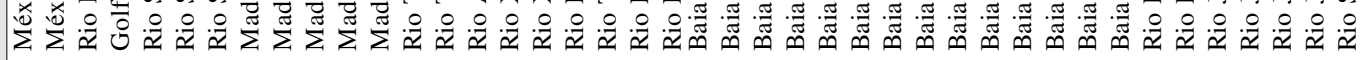

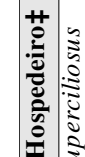

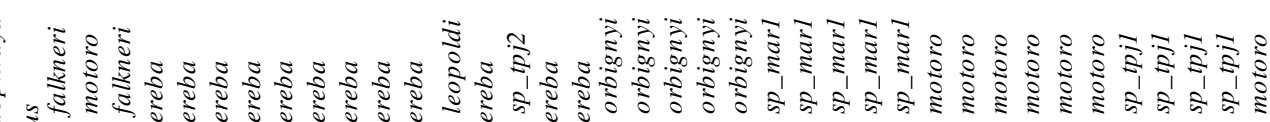

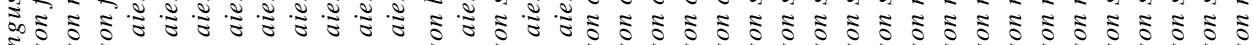

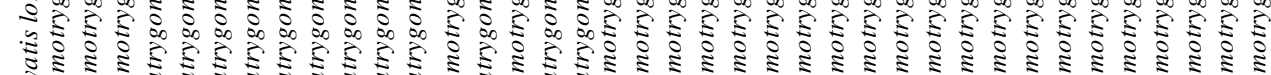

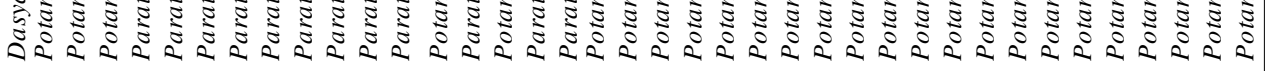
उ.

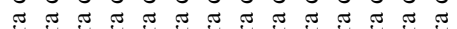

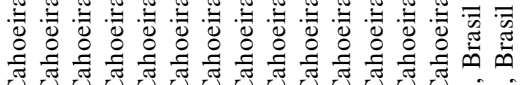

类

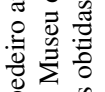

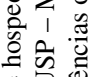

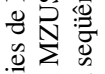

论

$+1)$

我跣

政

0

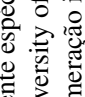

害言

氙

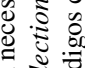

:

ษั

흔

跑

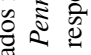

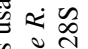

छั ญ

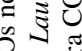

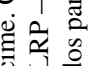

过

范家

要

要

年

静

ठै.

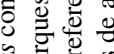

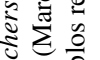

产

豆究。

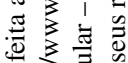

过

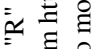

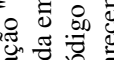

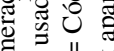

言, 品

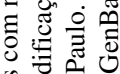

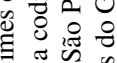

过 : च :

3.

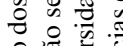

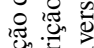

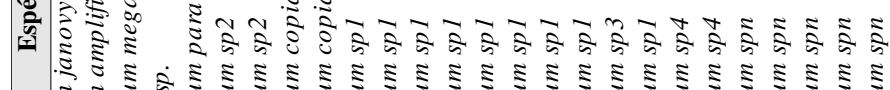

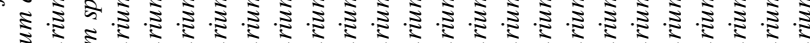




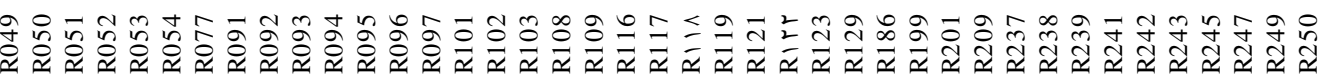

\section{赵}

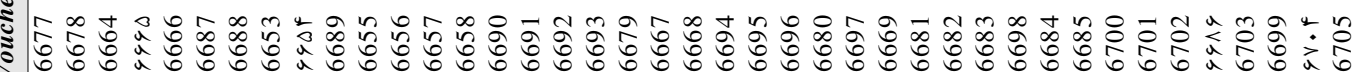

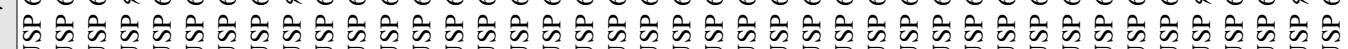
$\frac{N}{2} \frac{N}{2} \frac{N}{2} \frac{N}{2} \frac{N}{2} \frac{N}{2} \frac{N}{2} \frac{N}{2} \frac{N}{2} \frac{N}{2} \frac{N}{2} \frac{N}{2} \frac{N}{2} \frac{N}{2} \frac{N}{2} \frac{N}{2} \frac{N}{2} \frac{N}{2} \frac{N}{2} \frac{N}{2} \frac{N}{2} \frac{N}{2} \frac{N}{2} \frac{N}{2} \frac{N}{2} \frac{N}{2} \frac{N}{2} \frac{N}{2} \frac{N}{2} \frac{N}{2} \frac{N}{2} \frac{N}{2} \frac{N}{2}$

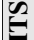

荠

$\bullet \bullet \bullet \bullet \bullet$

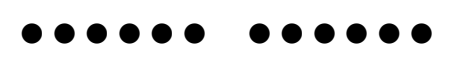

$\bullet \bullet \bullet \bullet \bullet \bullet \bullet \bullet \bullet$

$\bullet \bullet \bullet \bullet \bullet \bullet \bullet$

$\bullet \bullet \bullet \bullet \bullet \bullet \bullet \bullet \bullet \bullet \bullet \bullet \bullet \bullet \bullet \bullet \bullet \bullet \bullet \bullet \bullet \bullet \bullet \bullet \bullet \bullet \bullet \bullet \bullet \bullet \bullet \bullet \bullet \bullet \bullet \bullet \bullet \bullet \bullet \bullet \bullet$

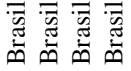

安离

妾公至

悹密

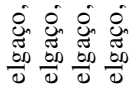

$\sum \sum_{0}$

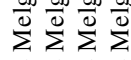

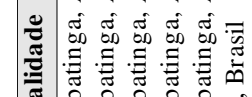

串

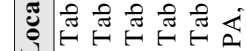

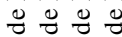

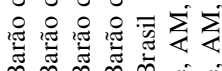

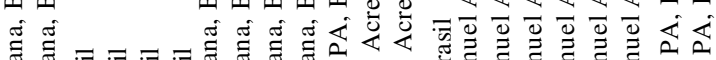

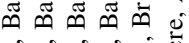

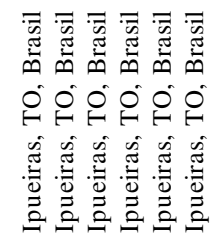

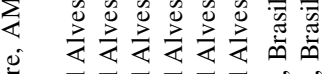

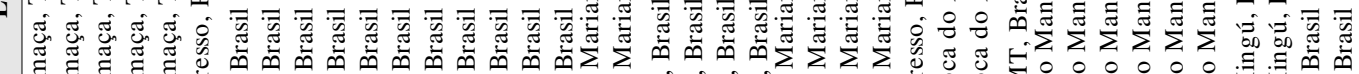

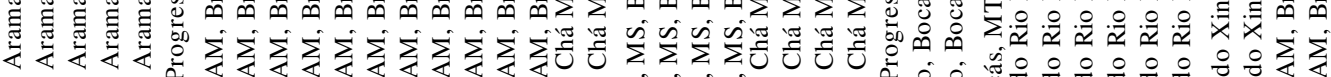

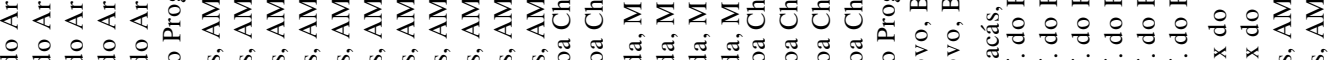

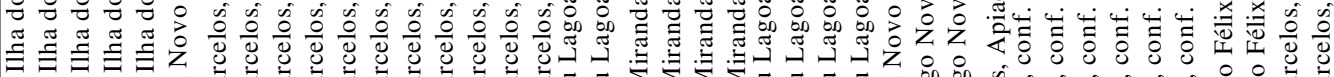
siी

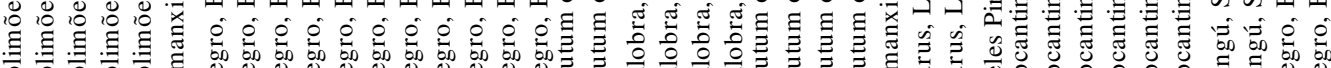

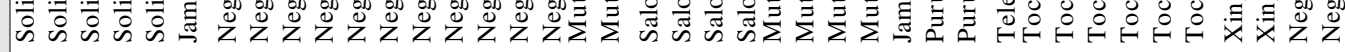

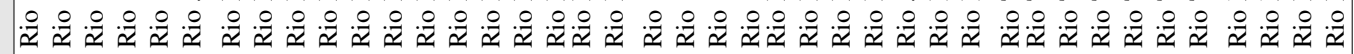

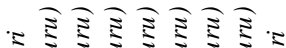
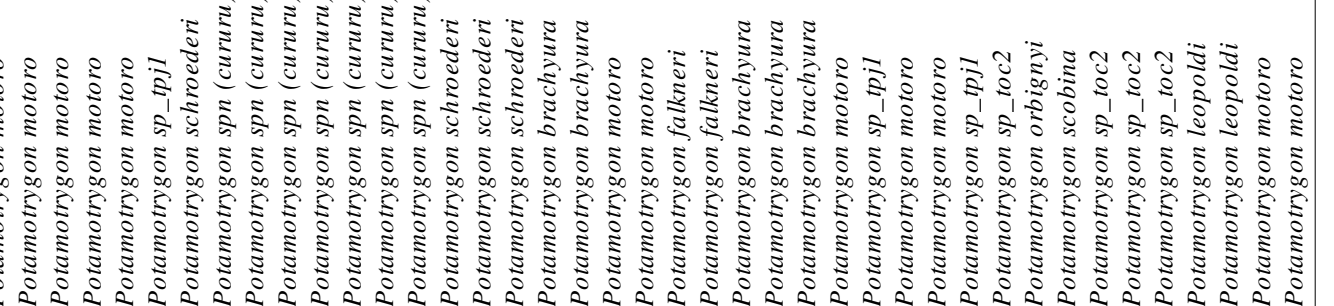
Tabela 7. Resultado da análise de congruência: parâmetros, custos relativos de alinhamento, comprimento de topologias parciais e totais e valores de ILD. Parâmetro em cinza exibe o menor ILD.

\begin{tabular}{|c|c|c|c|c|c|c|c|c|c|}
\hline Parâmetro & ITS-1 & parcial ITS-1 & $28 S$ & parcial 28S & $\mathrm{CO1}$ & parcial C01 & $\sum$ parciais & Total & ILD \\
\hline 1 & mIII & 381 & m111 & 644 & m111 & 878 & 1903 & 1947 & 0.02260 \\
\hline 2 & $\operatorname{m111}$ & 381 & mIII & 644 & m112 & 1375 & 2400 & 2452 & 0.02121 \\
\hline 3 & m111 & 381 & m111 & 644 & m121 & 1203 & 2228 & 2280 & 0.02281 \\
\hline 4 & $\operatorname{m111}$ & 381 & m112 & $111 \varepsilon$ & m111 & 878 & 2373 & 2503 & 0.05194 \\
\hline 5 & m111 & 381 & $\operatorname{m112}$ & 1114 & $\operatorname{m112}$ & 1375 & 2870 & 3010 & 0.04651 \\
\hline 6 & m111 & 381 & m112 & 1114 & m121 & 1203 & หาด^ & 2837 & 0.04900 \\
\hline 7 & $\operatorname{m111}$ & 381 & m121 & 986 & m111 & 878 & 2245 & 2370 & 0.05274 \\
\hline 8 & m111 & 381 & m121 & 986 & m112 & 1375 & 2742 & 2872 & 0.04526 \\
\hline 9 & m111 & 381 & m121 & 986 & m121 & 1203 & 2570 & 2705 & 0.04991 \\
\hline 10 & m111 & 381 & m211 & 836 & m111 & 878 & 2095 & 2220 & 0.05631 \\
\hline 11 & $\mathrm{~m} 111$ & 381 & mrI I & 836 & m112 & 1375 & 2592 & 2728 & 0.04985 \\
\hline 12 & $\operatorname{m111}$ & 381 & m211 & 836 & m121 & 1203 & 2420 & 2556 & 0.05321 \\
\hline 13 & $\operatorname{m111}$ & 381 & m212 & 1466 & m111 & $\wedge \vee \wedge$ & 2725 & 2995 & 0.09015 \\
\hline 14 & $\mathrm{~m} 111$ & 381 & m212 & 1466 & m112 & 1375 & 3222 & 3503 & 0.08022 \\
\hline 15 & $\operatorname{m111}$ & 381 & m212 & 1466 & m121 & 1203 & 3050 & 3333 & $\cdot . \wedge દ ૧ ।$ \\
\hline 16 & m111 & 381 & m221 & 1354 & m111 & 878 & 2613 & 2882 & 0.09334 \\
\hline 17 & $\operatorname{m111}$ & 381 & m221 & 1354 & m112 & 1375 & 3110 & 3391 & 0.08287 \\
\hline 18 & $\operatorname{m111}$ & нА। & m221 & 1354 & m121 & 1203 & 2938 & 3218 & 0.08701 \\
\hline 19 & m111 & 381 & m411 & 1165 & $\operatorname{m111}$ & 878 & 2424 & 2689 & 0.09855 \\
\hline 20 & $\operatorname{m111}$ & 381 & m411 & 1170 & m112 & 1375 & 2921 & 3198 & 0.08662 \\
\hline 21 & m111 & 381 & m411 & 1165 & m121 & 1203 & 2749 & 3026 & 0.09154 \\
\hline 22 & m111 & 381 & m412 & 2069 & m111 & 878 & גז" & 3861 & 0.13805 \\
\hline 23 & $\operatorname{m111}$ & 381 & m412 & 2069 & m112 & 1375 & 3825 & 4371 & 0.12491 \\
\hline 24 & $\operatorname{m111}$ & 381 & m412 & 2069 & m121 & 1203 & 3653 & 4199 & 0.13003 \\
\hline ro & m111 & 381 & m421 & 2001 & m111 & 878 & 3260 & 3799 & 0.14188 \\
\hline 26 & m111 & 381 & m421 & 2001 & m112 & 1375 & 3757 & 4311 & 0.12851 \\
\hline 27 & m111 & 381 & mEr I & 2001 & m121 & 1203 & 3585 & 4135 & 0.13301 \\
\hline 28 & m112 & 682 & m111 & 644 & m111 & 878 & 2204 & 2173 & -0.01427 \\
\hline 29 & m112 & 682 & m111 & 644 & miIr & 1375 & 2701 & 2679 & -0.00821 \\
\hline 30 & m112 & 682 & m111 & 644 & m121 & 1203 & 2529 & 2506 & -0.00918 \\
\hline 31 & m112 & 682 & m112 & 1114 & m111 & 878 & 2674 & rVRr & 0.02159 \\
\hline 32 & $\mathrm{~m} 112$ & 682 & $\operatorname{m112}$ & 1114 & m112 & 1375 & 3171 & 3241 & 0.02160 \\
\hline 33 & $\operatorname{m112}$ & 682 & m112 & 1114 & m121 & 1203 & 2999 & 3069 & 0.02281 \\
\hline 34 & ri & 682 & m121 & 986 & m111 & 878 & 2546 & 2601 & 0.02115 \\
\hline 35 & m112 & 682 & m121 & 986 & m112 & 1375 & 3043 & 3106 & 0.02028 \\
\hline 36 & m112 & 682 & m121 & $9 \wedge 7$ & m121 & 1203 & 2871 & 2937 & 0.02247 \\
\hline 37 & m112 & 682 & m211 & 836 & m111 & 878 & 2396 & 2449 & 0.02164 \\
\hline 38 & $\mathrm{~m} 112$ & 682 & m211 & 836 & m112 & 1375 & КА१ฯ & 2958 & 0.02197 \\
\hline 39 & $\operatorname{m112}$ & 682 & m211 & 836 & m121 & 1203 & 2721 & 2786 & 0.02333 \\
\hline 40 & $\mathrm{~m} 112$ & 682 & $\mathrm{~m} 212$ & 1466 & m111 & 878 & 3026 & 3227 & 0.06229 \\
\hline દ) & m112 & 682 & m212 & 1466 & m112 & 1375 & 3523 & 3737 & 0.05727 \\
\hline 42 & m112 & 682 & $\mathrm{~m} 212$ & 1466 & m121 & 1203 & 3351 & 3565 & 0.06003 \\
\hline 43 & $\mathrm{~m} 112$ & 682 & mrri & 1354 & m111 & 878 & 2914 & 3115 & 0.06453 \\
\hline 44 & $\operatorname{m112}$ & 682 & m221 & 1354 & m112 & 1375 & 3411 & 3628 & 0.05981 \\
\hline 45 & m112 & 682 & m221 & 1354 & m121 & $1 \pi \cdot \mu$ & 3239 & 3452 & 0.06170 \\
\hline 46 & m112 & 682 & m411 & 1165 & m111 & 878 & 2725 & 2924 & 0.06806 \\
\hline 47 & m112 & 682 & m411 & 1165 & m112 & 1375 & 3222 & 3434 & $. .7 / \vee \varepsilon$ \\
\hline 48 & $\mathrm{~m} 112$ & 682 & m411 & 1165 & m121 & 1203 & 3050 & 3261 & 0.06470 \\
\hline 49 & $\mathrm{~m} 112$ & 682 & m412 & 2069 & m111 & 878 & 3629 & 4097 & 0.11423 \\
\hline 50 & $\operatorname{m112}$ & $7 \wedge r$ & m412 & 2069 & m112 & 1375 & 4126 & 4609 & 0.10479 \\
\hline 51 & m112 & 682 & m412 & 2069 & m121 & 1203 & 3954 & 4435 & 0.10846 \\
\hline 52 & m112 & 682 & m421 & 2001 & mI। I & 878 & 3561 & 4034 & 0.11725 \\
\hline 53 & $\mathrm{~m} 112$ & 682 & m421 & 2001 & m112 & 1375 & 4058 & 4547 & 0.10754 \\
\hline 54 & m112 & 682 & m421 & 2001 & m121 & 1203 & 3886 & $\varepsilon \mu \vee$ & 0.11096 \\
\hline 55 & m121 & 653 & m111 & 644 & m111 & 878 & 2175 & 2136 & -0.01826 \\
\hline 56 & m121 & 653 & m111 & 644 & m112 & 1375 & 2672 & 2641 & -0.01174 \\
\hline 57 & miri & 653 & m111 & 644 & m121 & 1203 & 2500 & 2472 & -0.01133 \\
\hline 58 & m121 & 653 & m112 & 1114 & m111 & 878 & 2645 & 2701 & 0.02073 \\
\hline 59 & m121 & 653 & $\operatorname{m112}$ & $111 \varepsilon$ & m112 & 1375 & 3142 & 3207 & 0.02027 \\
\hline 60 & m121 & 653 & m112 & 1114 & m121 & 1203 & 2970 & 3037 & 0.02206 \\
\hline 61 & m121 & 653 & m121 & 986 & m111 & 878 & roiv & 2567 & 0.01948 \\
\hline
\end{tabular}


Tabela 7. (cont.) Resultado da análise de congruência: parâmetros, custos relativos de alinhamento, comprimento de topologias parciais e totais e valores de ILD. Parâmetro em cinza exibe o menor ILD.

\begin{tabular}{|c|c|c|c|c|c|c|c|c|c|}
\hline Parâmetro & ITS-1 & parcial ITS-1 & $28 S$ & parcial 28S & CO1 & parcial C01 & $\sum$ parciais & Total & ILD \\
\hline 62 & m121 & 653 & m121 & 986 & m112 & 1375 & 3014 & 3070 & 0.01824 \\
\hline 63 & m121 & 653 & m121 & 986 & m121 & 1203 & 2842 & 2904 & 0.02135 \\
\hline 64 & m121 & 653 & m211 & 836 & m111 & 878 & 2367 & 2421 & 0.02230 \\
\hline 65 & m121 & 653 & m211 & 836 & m112 & 1375 & 2864 & 2926 & 0.02119 \\
\hline 66 & m121 & 653 & m211 & 836 & m121 & 1203 & 2692 & 2758 & 0.02393 \\
\hline 67 & m121 & 653 & m212 & 1466 & m111 & 878 & 2997 & 3206 & 0.06519 \\
\hline 68 & m121 & 653 & m212 & 1466 & m112 & 1375 & 3494 & 3716 & 0.05974 \\
\hline 69 & m121 & 653 & m212 & 1466 & m121 & 1203 & 3322 & 3544 & 0.06264 \\
\hline 70 & m121 & 653 & m221 & 1354 & m111 & 878 & 2885 & 3095 & 0.06785 \\
\hline 71 & m121 & 653 & m221 & 1354 & $\operatorname{m112}$ & 1375 & 3382 & 3602 & 0.06108 \\
\hline 72 & m121 & 653 & m221 & 1354 & m121 & 1203 & 3210 & 3433 & 0.06496 \\
\hline 73 & m121 & 653 & m411 & 1165 & m111 & 878 & 2696 & 2900 & 0.07034 \\
\hline 74 & m121 & 653 & m411 & 1165 & m112 & 1375 & 3193 & 3409 & 0.06336 \\
\hline 75 & m121 & 653 & m411 & 1165 & m121 & 1203 & 3021 & 3238 & 0.06702 \\
\hline 76 & m121 & 653 & m412 & 2069 & m111 & 878 & 3600 & 4081 & 0.11786 \\
\hline 77 & m121 & 653 & m412 & 2069 & m112 & 1375 & 4097 & 4589 & 0.10721 \\
\hline 78 & m121 & 653 & m412 & 2069 & m121 & 1203 & 3925 & 4419 & 0.11179 \\
\hline 79 & m121 & 653 & m421 & 2001 & m111 & 878 & 3532 & 4012 & 0.11964 \\
\hline 80 & m121 & 653 & m421 & 2001 & m112 & 1375 & 4029 & 4519 & 0.10843 \\
\hline 81 & m121 & 653 & m421 & 2001 & m121 & 1203 & 3857 & 4352 & 0.11374 \\
\hline 82 & m211 & 576 & m111 & 644 & m111 & 878 & 2098 & 2066 & -0.01549 \\
\hline 83 & m211 & 576 & m111 & 644 & m112 & 1375 & 2595 & 2571 & -0.00933 \\
\hline 84 & m211 & 576 & m111 & 644 & m121 & 1203 & 2423 & 2398 & -0.01043 \\
\hline 85 & m211 & 576 & m112 & 1114 & m111 & 878 & 2568 & 2623 & 0.02097 \\
\hline 86 & m211 & 576 & m112 & 1114 & m112 & 1375 & 3065 & 3129 & 0.02045 \\
\hline 87 & m211 & 576 & m112 & 1114 & m121 & 1203 & 2893 & 2957 & 0.02164 \\
\hline 88 & m211 & 576 & m121 & 986 & m111 & 878 & 2440 & 2489 & 0.01969 \\
\hline 89 & m211 & 576 & m121 & 986 & m112 & 1375 & 2937 & 2991 & 0.01805 \\
\hline 90 & m211 & 576 & m121 & 986 & m121 & 1203 & 2765 & 2824 & 0.02089 \\
\hline 91 & m211 & 576 & m211 & 836 & m111 & 878 & 2290 & 2339 & 0.02095 \\
\hline 92 & $\mathrm{~m} 211$ & 576 & m211 & 836 & m112 & 1375 & 2787 & 2847 & 0.02107 \\
\hline 93 & m211 & 576 & m211 & 836 & m121 & 1203 & 2615 & 2675 & 0.02243 \\
\hline 94 & m211 & 576 & m212 & 1466 & m111 & 878 & 2920 & 3115 & 0.06260 \\
\hline 95 & m211 & 576 & m212 & 1466 & m112 & 1375 & 3417 & 3623 & 0.05686 \\
\hline 96 & m211 & 576 & m212 & 1466 & m121 & 1203 & 3245 & 3453 & 0.06024 \\
\hline 97 & $\mathrm{~m} 211$ & 576 & m221 & 1354 & m111 & 878 & 2808 & 3002 & 0.06462 \\
\hline 98 & m211 & 576 & m221 & 1354 & m112 & 1375 & 3305 & 3514 & 0.05948 \\
\hline 99 & m211 & 576 & m221 & 1354 & m121 & 1203 & 3133 & 3338 & 0.06141 \\
\hline 100 & m211 & 576 & m411 & 1165 & m111 & 878 & 2619 & 2809 & 0.06764 \\
\hline 101 & m211 & 576 & m411 & 1165 & m112 & 1375 & 3116 & 3318 & 0.06088 \\
\hline 102 & $\mathrm{~m} 211$ & 576 & m411 & 1165 & m121 & 1203 & 2944 & 3146 & 0.06421 \\
\hline 103 & m211 & 576 & m412 & 2069 & m111 & 878 & 3523 & 3981 & 0.11505 \\
\hline 104 & m211 & 576 & m412 & 2069 & m112 & 1375 & 4020 & 4491 & 0.10488 \\
\hline 105 & $\mathrm{~m} 211$ & 576 & m412 & 2069 & m121 & 1203 & 3848 & 4319 & 0.10905 \\
\hline 106 & m211 & 576 & m421 & 2001 & m111 & 878 & 3455 & 3920 & 0.11862 \\
\hline 107 & m211 & 576 & m421 & 2001 & m112 & 1375 & 3952 & 4431 & 0.10810 \\
\hline 108 & m211 & 576 & m421 & 2001 & m121 & 1203 & 3780 & 4255 & 0.11163 \\
\hline 109 & $\mathrm{~m} 212$ & 1055 & m111 & 644 & m111 & 878 & 2577 & 2408 & -0.07018 \\
\hline 110 & $\mathrm{~m} 212$ & 1055 & m111 & 644 & m112 & 1375 & 3074 & 2915 & -0.05455 \\
\hline 111 & m212 & 1055 & m111 & 644 & m121 & 1203 & 2902 & 2742 & -0.05835 \\
\hline 112 & m212 & 1055 & m112 & 1114 & m111 & 878 & 3047 & 2974 & -0.02455 \\
\hline 113 & $\mathrm{~m} 212$ & 1055 & m112 & 1114 & m112 & 1375 & 3544 & 3482 & -0.01781 \\
\hline 114 & m212 & 1055 & m112 & 1114 & m121 & 1203 & 3372 & 3311 & -0.01842 \\
\hline 115 & m212 & 1055 & m121 & 986 & m111 & 878 & 2919 & 2841 & -0.02746 \\
\hline 116 & $\mathrm{~m} 212$ & 1055 & m121 & 986 & m112 & 1375 & 3416 & 3345 & -0.02123 \\
\hline 117 & m212 & 1055 & m121 & 986 & m121 & 1203 & 3244 & 3179 & -0.02045 \\
\hline 118 & m212 & 1055 & m211 & 836 & m111 & 878 & 2769 & 2690 & -0.02937 \\
\hline 119 & $\mathrm{~m} 212$ & 1055 & m211 & 836 & m112 & 1375 & 3266 & 3199 & -0.02094 \\
\hline 120 & m212 & 1055 & m211 & 836 & m121 & 1203 & 3094 & 3027 & -0.02213 \\
\hline 121 & $\mathrm{~m} 212$ & 1055 & m212 & 1466 & m111 & 878 & 3399 & 3465 & 0.01905 \\
\hline 122 & m212 & 1055 & m212 & 1466 & m112 & 1375 & 3896 & 3975 & 0.01987 \\
\hline 123 & $\mathrm{~m} 212$ & 1055 & m212 & 1466 & m121 & 1203 & 3724 & 3803 & 0.02077 \\
\hline
\end{tabular}


Tabela 7. (cont.) Resultado da análise de congruência: parâmetros, custos relativos de alinhamento, comprimento de topologias parciais e totais e valores de ILD. Parâmetro em cinza exibe o menor ILD.

\begin{tabular}{|c|c|c|c|c|c|c|c|c|c|}
\hline Parâmetro & ITS-1 & parcial ITS-1 & $28 S$ & parcial 28S & $\mathrm{CO1}$ & parcial CO1 & $\sum$ parciais & Total & ILD \\
\hline 124 & m212 & 1055 & m221 & 1354 & m111 & 878 & 3287 & 3353 & 0.01968 \\
\hline 125 & m212 & 1055 & m221 & 1354 & $\operatorname{m112}$ & 1375 & 3784 & 3866 & 0.02121 \\
\hline 126 & m212 & 1055 & m221 & 1354 & m121 & 1203 & 3612 & 3690 & 0.02114 \\
\hline 127 & m212 & 1055 & m411 & 1165 & $\operatorname{m111}$ & 878 & 3098 & 3164 & 0.02086 \\
\hline 128 & m212 & 1055 & m411 & 1165 & $\operatorname{m112}$ & 1375 & 3595 & 3672 & 0.02097 \\
\hline 129 & m212 & 1055 & m411 & 1165 & m121 & 1203 & 3423 & 3501 & 0.02228 \\
\hline 130 & $\mathrm{~m} 212$ & 1055 & m412 & 2069 & $\operatorname{m111}$ & 878 & 4002 & 4337 & 0.07724 \\
\hline 131 & m212 & 1055 & m412 & 2069 & m112 & 1375 & 4499 & 4847 & 0.07180 \\
\hline 132 & m212 & 1055 & m412 & 2069 & $\operatorname{m121}$ & 1203 & 4327 & 4675 & 0.07444 \\
\hline 133 & m212 & 1055 & m421 & 2001 & $\operatorname{m111}$ & 878 & 3934 & 4272 & 0.07912 \\
\hline 134 & m212 & 1055 & m421 & 2001 & $\operatorname{m112}$ & 1375 & 4431 & 4785 & 0.07398 \\
\hline 135 & m212 & 1055 & m421 & 2001 & $\operatorname{m121}$ & 1203 & 4259 & 4609 & 0.07594 \\
\hline 136 & m221 & 1038 & m111 & 644 & $\operatorname{m111}$ & 878 & 2560 & 2376 & -0.07744 \\
\hline 137 & m221 & 1038 & m111 & 644 & $\operatorname{m112}$ & 1375 & 3057 & 2881 & -0.06109 \\
\hline 138 & m221 & 1038 & m111 & 644 & $\operatorname{m121}$ & 1203 & 2885 & 2712 & -0.06379 \\
\hline 139 & m221 & 1038 & m112 & 1114 & $\operatorname{m111}$ & 878 & 3030 & 2940 & -0.03061 \\
\hline 140 & m221 & 1038 & m112 & 1114 & $\operatorname{m112}$ & 1375 & 3527 & 3446 & -0.02351 \\
\hline 141 & m221 & 1038 & m112 & 1114 & m121 & 1203 & 3355 & 3276 & -0.02411 \\
\hline 142 & m221 & 1038 & m121 & 986 & m111 & 878 & 2902 & 2809 & -0.03311 \\
\hline 143 & m221 & 1038 & m121 & 986 & $\operatorname{m112}$ & 1375 & 3399 & 3312 & -0.02627 \\
\hline 144 & m221 & 1038 & m121 & 986 & m121 & 1203 & 3227 & 3146 & -0.02575 \\
\hline 145 & m221 & 1038 & m211 & 836 & $\operatorname{m111}$ & 878 & 2752 & 2660 & -0.03459 \\
\hline 146 & m221 & 1038 & m211 & 836 & $\operatorname{m112}$ & 1375 & 3249 & 3167 & -0.02589 \\
\hline 147 & m221 & 1038 & m211 & 836 & m121 & 1203 & 3077 & 2996 & -0.02704 \\
\hline 148 & m221 & 1038 & m212 & 1466 & $\operatorname{m111}$ & 878 & 3382 & 3444 & 0.01800 \\
\hline 149 & m221 & 1038 & m212 & 1466 & $\operatorname{m112}$ & 1375 & 3879 & 3954 & 0.01897 \\
\hline 150 & m221 & 1038 & m212 & 1466 & m121 & 1203 & 3707 & 3782 & 0.01983 \\
\hline 151 & m221 & 1038 & m221 & 1354 & $\operatorname{m111}$ & 878 & 3270 & 3333 & 0.01890 \\
\hline 152 & m221 & 1038 & m221 & 1354 & $\operatorname{m112}$ & 1375 & 3767 & 3840 & 0.01901 \\
\hline 153 & m221 & 1038 & m221 & 1354 & m121 & 1203 & 3595 & 3670 & 0.02044 \\
\hline 154 & m221 & 1038 & m411 & 1165 & $\operatorname{m111}$ & 878 & 3081 & 3138 & 0.01816 \\
\hline 155 & m221 & 1038 & m411 & 1165 & $\operatorname{m112}$ & 1375 & 3578 & 3647 & 0.01892 \\
\hline 156 & m221 & 1038 & m411 & 1165 & m121 & 1203 & 3406 & 3476 & 0.02014 \\
\hline 157 & m221 & 1038 & m412 & 2069 & $\operatorname{m111}$ & 878 & 3985 & 4322 & 0.07797 \\
\hline 158 & m221 & 1038 & m412 & 2069 & m112 & 1375 & 4482 & 4829 & 0.07186 \\
\hline 159 & m221 & 1038 & m412 & 2069 & m121 & 1203 & 4310 & 4659 & 0.07491 \\
\hline 160 & m221 & 1038 & m421 & 2001 & $\operatorname{m111}$ & 878 & 3917 & 4253 & 0.07900 \\
\hline 161 & m221 & 1038 & m421 & 2001 & $\operatorname{m112}$ & 1375 & 4414 & 4759 & 0.07249 \\
\hline 162 & m221 & 1038 & m421 & 2001 & m121 & 1203 & 4242 & 4592 & 0.07622 \\
\hline 163 & m411 & 947 & m111 & 644 & $\operatorname{m111}$ & 878 & 2469 & 2303 & -0.07208 \\
\hline 164 & m411 & 947 & m111 & 644 & $\operatorname{m112}$ & 1375 & 2966 & 2808 & -0.05627 \\
\hline 165 & m411 & 947 & m111 & 644 & m121 & 1203 & 2794 & 2635 & -0.06034 \\
\hline 166 & m411 & 947 & m112 & 1114 & $\operatorname{m111}$ & 878 & 2939 & 2861 & -0.02726 \\
\hline 167 & m411 & 947 & m112 & 1114 & $\operatorname{m112}$ & 1375 & 3436 & 3367 & -0.02049 \\
\hline 168 & m411 & 947 & m112 & 1114 & m121 & 1203 & 3264 & 3195 & -0.02160 \\
\hline 169 & m411 & 947 & m121 & 986 & m111 & 878 & 2811 & 2731 & -0.02929 \\
\hline 170 & m411 & 947 & m121 & 986 & $\operatorname{m112}$ & 1375 & 3308 & 3233 & -0.02320 \\
\hline 171 & m411 & 947 & m121 & 986 & $\operatorname{m121}$ & 1203 & 3136 & 3065 & -0.02316 \\
\hline 172 & m411 & 947 & m211 & 836 & $\operatorname{m111}$ & 878 & 2661 & 2577 & -0.03260 \\
\hline 173 & m411 & 947 & m211 & 836 & $\operatorname{m112}$ & 1375 & 3158 & 3087 & -0.02300 \\
\hline 174 & m411 & 947 & m211 & 836 & m121 & 1203 & 2986 & 2913 & -0.02506 \\
\hline 175 & m411 & 947 & m212 & 1466 & m111 & 878 & 3291 & 3352 & 0.01820 \\
\hline 176 & m411 & 947 & m212 & 1466 & $\operatorname{m112}$ & 1375 & 3788 & 3860 & 0.01865 \\
\hline 177 & m411 & 947 & m212 & 1466 & m121 & 1203 & 3616 & 3688 & 0.01952 \\
\hline 178 & m411 & 947 & m221 & 1354 & $\operatorname{m111}$ & 878 & 3179 & 3238 & 0.01822 \\
\hline 179 & m411 & 947 & m221 & 1354 & $\operatorname{m112}$ & 1375 & 3676 & 3751 & 0.01999 \\
\hline 180 & m411 & 947 & m221 & 1354 & m121 & 1203 & 3504 & 3574 & 0.01959 \\
\hline 181 & m411 & 947 & m411 & 1165 & $\operatorname{m111}$ & 878 & 2990 & 3048 & 0.01903 \\
\hline 182 & m411 & 947 & m411 & 1165 & $\operatorname{m112}$ & 1375 & 3487 & 3557 & 0.01968 \\
\hline 183 & m411 & 947 & m411 & 1165 & $\operatorname{m121}$ & 1203 & 3315 & 3384 & 0.02039 \\
\hline 184 & m411 & 947 & m412 & 2069 & $\operatorname{m111}$ & 878 & 3894 & 4221 & 0.07747 \\
\hline 185 & m411 & 947 & m412 & 2069 & $\operatorname{m112}$ & 1375 & 4391 & 4730 & 0.07167 \\
\hline
\end{tabular}


Tabela 7. (cont.) Resultado da análise de congruência: parâmetros, custos relativos de alinhamento, comprimento de topologias parciais e totais e valores de ILD. Parâmetro em cinza exibe o menor ILD.

\begin{tabular}{|c|c|c|c|c|c|c|c|c|c|}
\hline Parâmetro & ITS-1 & parcial ITS-1 & $28 S$ & parcial 28S & CO1 & parcial CO1 & $\sum$ parciais & Total & ILD \\
\hline 186 & m411 & 947 & m412 & 2069 & m121 & 1203 & 4219 & 4557 & 0.07417 \\
\hline 187 & m411 & 947 & m421 & 2001 & m111 & 878 & 3826 & 4155 & 0.07918 \\
\hline 188 & m411 & 947 & m421 & 2001 & m112 & 1375 & 4323 & 4667 & 0.07371 \\
\hline 189 & m411 & 947 & m421 & 2001 & m121 & 1203 & 4151 & 4491 & 0.07571 \\
\hline 190 & m412 & 1774 & m111 & 644 & m111 & 878 & 3296 & 2880 & -0.14444 \\
\hline 191 & m412 & 1774 & m111 & 644 & m112 & 1375 & 3793 & 3387 & -0.11987 \\
\hline 192 & m412 & 1774 & m111 & 644 & m121 & 1203 & 3621 & 3212 & -0.12733 \\
\hline 193 & m412 & 1774 & m112 & 1114 & m111 & 878 & 3766 & 3440 & -0.09477 \\
\hline 194 & m412 & 1774 & $\operatorname{m112}$ & 1114 & m112 & 1375 & 4263 & 3948 & -0.07979 \\
\hline 195 & m412 & 1774 & m112 & 1114 & m121 & 1203 & 4091 & 3776 & -0.08342 \\
\hline 196 & m412 & 1774 & m121 & 986 & $\operatorname{m111}$ & 878 & 3638 & 3311 & -0.09876 \\
\hline 197 & m412 & 1774 & m121 & 986 & m112 & 1375 & 4135 & 3817 & -0.08331 \\
\hline 198 & m412 & 1774 & m121 & 986 & m121 & 1203 & 3963 & 3647 & -0.08665 \\
\hline 199 & m412 & 1774 & m211 & 836 & $\operatorname{m111}$ & 878 & 3488 & 3156 & -0.10520 \\
\hline 200 & m412 & 1774 & m211 & 836 & m112 & 1375 & 3985 & 3665 & -0.08731 \\
\hline 201 & m412 & 1774 & m211 & 836 & m121 & 1203 & 3813 & 3494 & -0.09130 \\
\hline 202 & m412 & 1774 & m212 & 1466 & m111 & 878 & 4118 & 3930 & -0.04784 \\
\hline 203 & m412 & 1774 & m212 & 1466 & m112 & 1375 & 4615 & 4440 & -0.03941 \\
\hline 204 & m412 & 1774 & m212 & 1466 & m121 & 1203 & 4443 & 4268 & -0.04100 \\
\hline 205 & m412 & 1774 & m221 & 1354 & $\operatorname{m111}$ & 878 & 4006 & 3822 & -0.04814 \\
\hline 206 & m412 & 1774 & m221 & 1354 & m112 & 1375 & 4503 & 4335 & -0.03875 \\
\hline 207 & m412 & 1774 & m221 & 1354 & m121 & 1203 & 4331 & 4160 & -0.04111 \\
\hline 208 & m412 & 1774 & m411 & 1165 & m111 & 878 & 3817 & 3632 & -0.05094 \\
\hline 209 & m412 & 1774 & m411 & 1165 & $\mathrm{~m} 112$ & 1375 & 4314 & 4141 & -0.04178 \\
\hline 210 & m412 & 1774 & m411 & 1165 & m121 & 1203 & 4142 & 3969 & -0.04359 \\
\hline 211 & m412 & 1774 & m412 & 2069 & m111 & 878 & 4721 & 4802 & 0.01687 \\
\hline 212 & m412 & 1774 & m412 & 2069 & m112 & 1375 & 5218 & 5312 & 0.01770 \\
\hline 213 & m412 & 1774 & m412 & 2069 & m121 & 1203 & 5046 & 5140 & 0.01829 \\
\hline 214 & m412 & 1774 & m421 & 2001 & m111 & 878 & 4653 & 4741 & 0.01856 \\
\hline 215 & m412 & 1774 & m421 & 2001 & $\operatorname{m112}$ & 1375 & 5150 & 5253 & 0.01961 \\
\hline 216 & m412 & 1774 & m421 & 2001 & m121 & 1203 & 4978 & 5076 & 0.01931 \\
\hline 217 & m421 & 1761 & m111 & 644 & m111 & 878 & 3283 & 2848 & -0.15274 \\
\hline 218 & m421 & 1761 & m111 & 644 & m112 & 1375 & 3780 & 3354 & -0.12701 \\
\hline 219 & m421 & 1761 & m111 & 644 & m121 & 1203 & 3608 & 3182 & -0.13388 \\
\hline 220 & m421 & 1761 & m112 & 1114 & m111 & 878 & 3753 & 3414 & -0.09930 \\
\hline 221 & m421 & 1761 & $\operatorname{m112}$ & 1114 & m112 & 1375 & 4250 & 3920 & -0.08418 \\
\hline 222 & m421 & 1761 & m112 & 1114 & m121 & 1203 & 4078 & 3750 & -0.08747 \\
\hline 223 & m421 & 1761 & m121 & 986 & m111 & 878 & 3625 & 3280 & -0.10518 \\
\hline 224 & m421 & 1761 & m121 & 986 & m112 & 1375 & 4122 & 3783 & -0.08961 \\
\hline 225 & m421 & 1761 & m121 & 986 & m121 & 1203 & 3950 & 3617 & -0.09207 \\
\hline 226 & m421 & 1761 & m211 & 836 & $\operatorname{m111}$ & 878 & 3475 & 3134 & -0.10881 \\
\hline 227 & m421 & 1761 & m211 & 836 & m112 & 1375 & 3972 & 3639 & -0.09151 \\
\hline 228 & m421 & 1761 & m211 & 836 & m121 & 1203 & 3800 & 3470 & -0.09510 \\
\hline 229 & m421 & 1761 & m212 & 1466 & m111 & 878 & 4105 & 3917 & -0.04800 \\
\hline 230 & m421 & 1761 & $\mathrm{~m} 212$ & 1466 & m112 & 1375 & 4602 & 4426 & -0.03977 \\
\hline 231 & m421 & 1761 & m212 & 1466 & m121 & 1203 & 4430 & 4254 & -0.04137 \\
\hline 232 & m421 & 1761 & m221 & 1354 & m111 & 878 & 3993 & 3803 & -0.04996 \\
\hline 233 & m421 & 1761 & m221 & 1354 & $\mathrm{~m} 112$ & 1375 & 4490 & 4315 & -0.04056 \\
\hline 234 & m421 & 1761 & m221 & 1354 & $\operatorname{m121}$ & 1203 & 4318 & 4141 & -0.04274 \\
\hline 235 & m421 & 1761 & m411 & 1165 & m111 & 878 & 3804 & 3613 & -0.05286 \\
\hline 236 & m421 & 1761 & m411 & 1165 & m112 & 1375 & 4301 & 4120 & -0.04393 \\
\hline 237 & m421 & 1761 & m411 & 1165 & m121 & 1203 & 4129 & 3951 & -0.04505 \\
\hline 238 & m421 & 1761 & m412 & 2069 & m111 & 878 & 4708 & 4791 & 0.01732 \\
\hline 239 & m421 & 1761 & m412 & 2069 & m112 & 1375 & 5205 & 5301 & 0.01811 \\
\hline 240 & m421 & 1761 & m412 & 2069 & m121 & 1203 & 5033 & 5129 & 0.01872 \\
\hline 241 & m421 & 1761 & m421 & 2001 & m111 & 878 & 4640 & 4730 & 0.01903 \\
\hline 242 & m421 & 1761 & m421 & 2001 & $\operatorname{m112}$ & 1375 & 5137 & 5239 & 0.01947 \\
\hline 243 & m421 & 1761 & m421 & 2001 & m121 & 1203 & 4965 & 5066 & 0.01994 \\
\hline
\end{tabular}


Observa-se que o resultado dos cálculos de ILD apresenta valores negativos, o que a priori sugere que os custos de algumas análises parciais referem-se a topologias sub-ótimas, pois valores negativos de ILD resultam quando o custo na análise simultânea é menor que a soma das parciais. Diante deste resultado, as análises parciais foram executadas 3 vezes na expectativa de reduzir o custo dessas topologias, o que não ocorreu. Outra possibilidade seria que a quantidade de dados lacunares para alguns terminais é responsável pelo comportamento não usual desta métrica. Neste sentido, foi feita uma re-análise dos dados excluindo 28 terminais que apresentavam dados lacunares (dados não apresentados) na expectativa de eliminar valores negativos para ILD. Os resultados desta análise sugerem que a proporção de dados lacunares não afeta os valores do conjunto de parâmetros com ILD negativo, pois $100 \%$ daqueles parâmetros continuaram a exibir ILD negativo e em $49.2 \%$ dos parâmetros a redução do número de terminais resultou em valores de ILD menores que anteriormente. Observa-se que para o conjunto de parâmetros nos quais as mesmas funções de custo são aplicadas às três partições de dados não ocorrem valores negativos de ILD. A presença de valores negativos, desta forma, permanece inexplicada e pode decorrer de alguma propriedade desta métrica decorrente da combinação de parâmetros distintos para cada uma das partições ou algum erro no código de POY.

Neste estudo optou-se por obedecer à lógica da análise de congruência na qual a escolha do conjunto de parâmetros de alinhamento é baseada no menor valor de ILD, pois ele expressa a redução/aumento de eventos de homoplasias em decorrência da análise simultânea de partições de diferentes origens sob determinados conjuntos de parâmetros. De acordo com os resultados apresentados na Tabela 7, o parâmetro 217 exibe o menor valor de ILD. Neste parâmetro foram aplicados custos para abertura de gaps, extensões de gap, transversões e transições na proporção de 4:4:2:1, 4:1:1:1 e 1:1 para ITS-1, 28S e COI, respectivamente.

A análise filogenética sob este regime de custo resultou em 18 topologias igualmente parcimoniosas. O consenso estrito destas árvores mantém a estrutura cladística básica da Figura 4. 


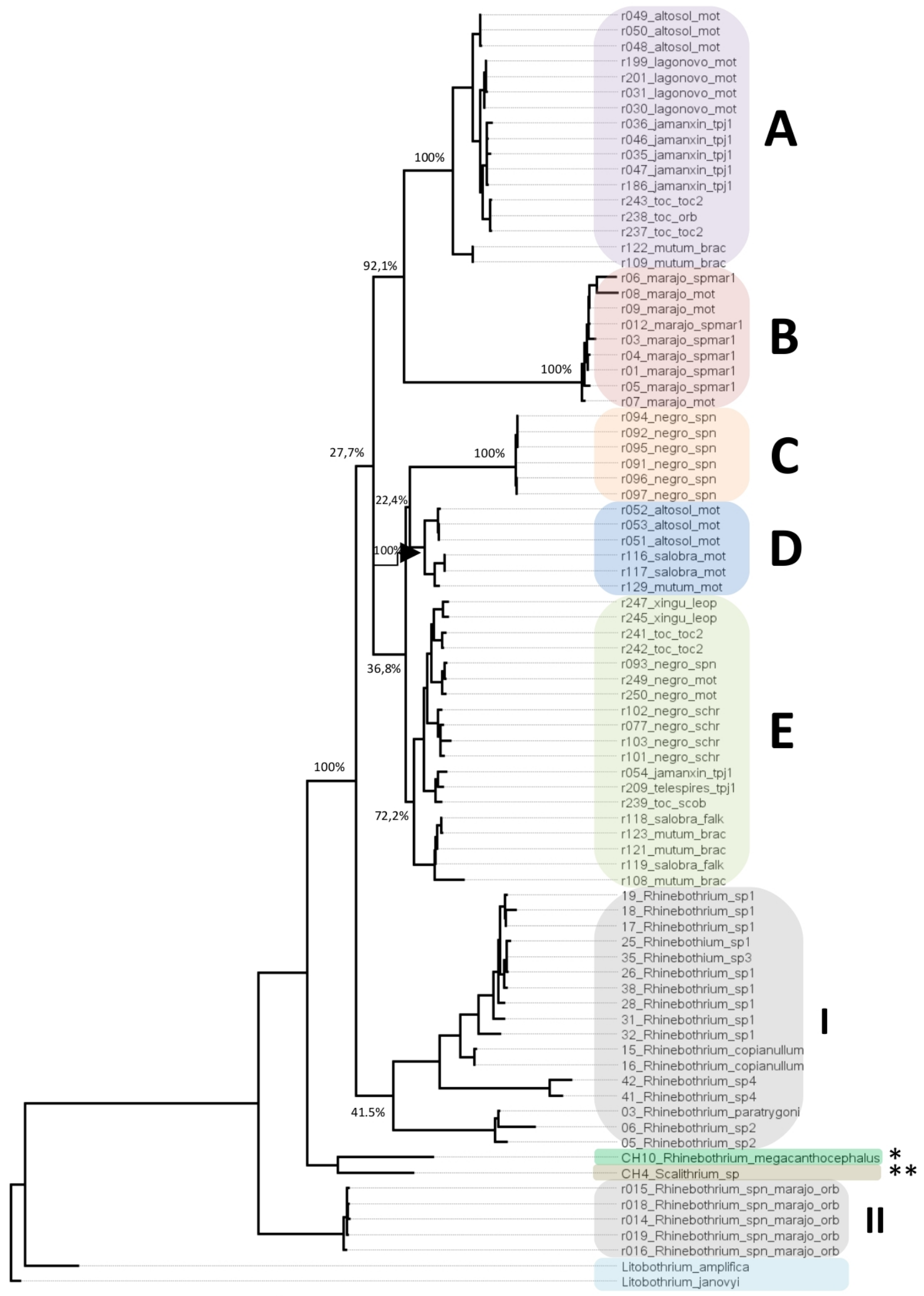

Figura 4. Hipótese filogenética para haplótipos de Rhinebothroides (clados A-E) baseada na otimização direta de 28S, ITS-1 e COI. Topologia representa uma dentre 18 topologias produzida pelo parâmetro 217. Comprimento dos ramos são aproximados (ver Material e Métodos). *Parasita de ambiente dulcícola da Malásia. ** Parasita de ambiente marinho da costa da Califórnia. Clados I e II são membros do gênero Rhinebothrium, parasitas de potamotrigonídeos. 
Esta topologia foi escolhida ao acaso dentre as 18 árvores e ilustra o comprimento aproximado dos ramos relativos ao número de transformações.

A análise de sensibilidade para os clados dentro de Rhinebothroides apresentou resultados bastante interessantes. Os clados A, B, C e D foram recuperados em 100\% no espaço de parâmetros, representada pelas porcentagens indicadas em seus respectivos ramos (Fig. 4) e os diagramas de Navajo (ou plotagens de sensibilidade) na Figura 5. Por outro lado, o clado E se apresentou mais sensível aos regimes de custo implementados, sendo recuperado em 72,2\% do espaço de parâmetros (Figs. 4 e 5). Clados mais inclusivos apresentaram maior sensibilidade ao conjunto de parâmetros imposto. O clado composto pelos grupos $(\mathrm{A}+\mathrm{B})$ foi recuperado em 92,1\% do espaço de parâmetros analisado, mostrando baixa sensibilidade a parâmetros de alinhamento (Figs. 4 e 6). Por outro lado, o grupo composto pelos clados $(\mathrm{C}+\mathrm{D})$ foi recuperado em $22,4 \%$ do espaço de parâmetros e o grupo contendo os clados (C+D+E) está presente em 36,8\% dos parâmetros analisados (Figs. 4 e 6), mostrando alta sensibilidade ás funções de custo de alinhamento. A monofilía do gênero Rhinebothroides também se mostrou sensível aos regimes de custo de alinhamento, sendo recuperada em 27,7\% das árvores obtidas na análise (Figs. 5 e 6). As topologias nas quais Rhinebothroides se mostrou parafilético frequentemente incluíam o clado composto por membros de Rhinebothrium neotropicais de água doce (clado I, Fig. 4). Por fím, a monofilía dos Rhinebothriidea em potamotrigonídeos não foi recuperada na análise, o que não corrobora os resultados obtidos por Reyda (2007).

\section{Análise morfológica - complexo $\underline{\text { Rhinebothroides freitasi }}$}

Dos 602 hospedeiros examinados nesse estudo, 219 válvulas espirais estavam infectadas por membros do gênero Rhinebothroides, das quais aproximadamente 50\% estavam infectadas por membros do complexo R. freitasi. A lista completa das espécies de hospedeiros infectados por membros desse complexo, assim como suas respectivas localidades e datas de coleta estão na Tabela 8. Vinte e cinco espécies potencialmente distintas de potamotrigonídeos foram examinadas, 


\section{Mapa de Parâmetros}

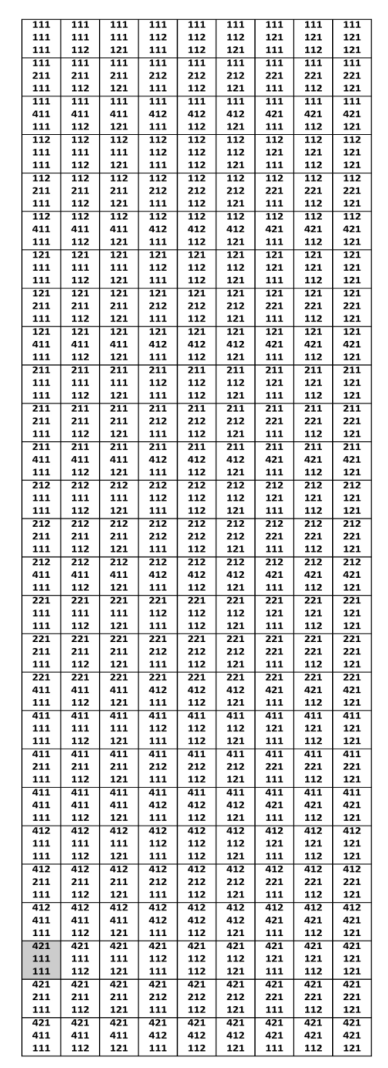

Clado C

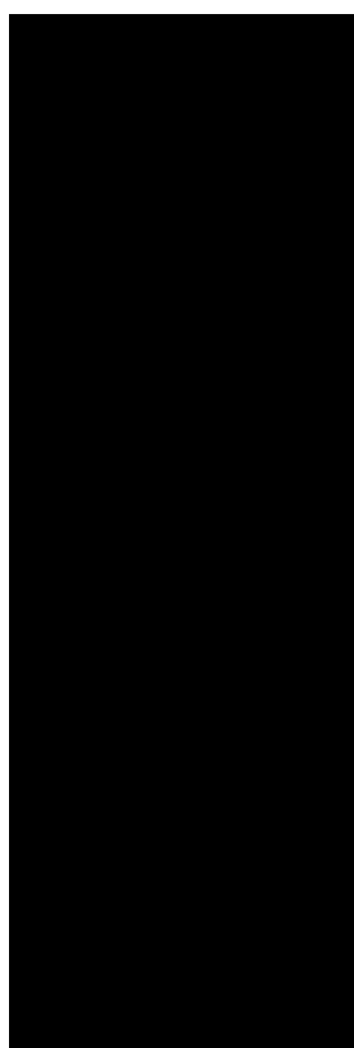

Clado A

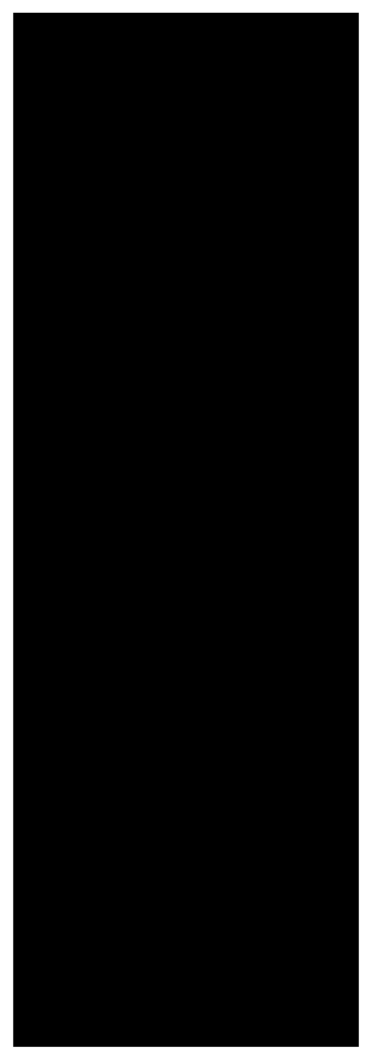

Clado D

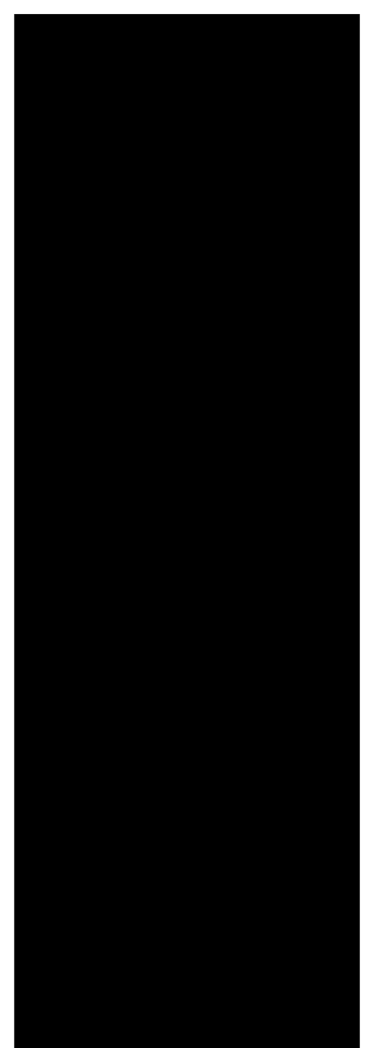

Clado B

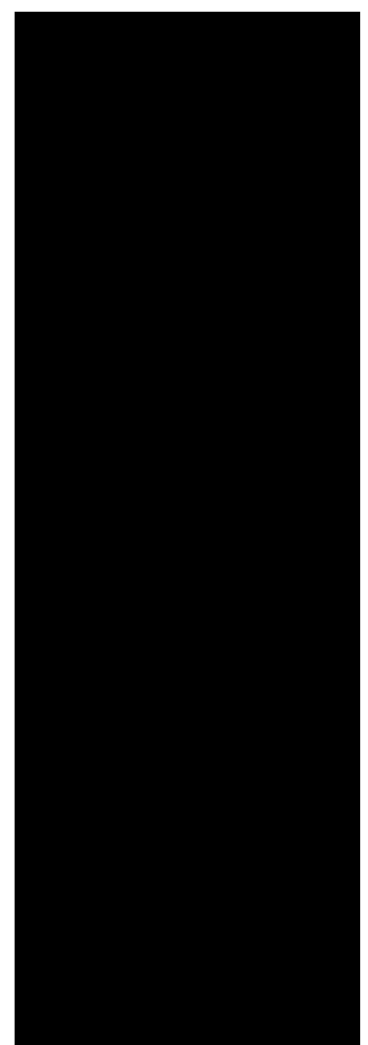

Clado E

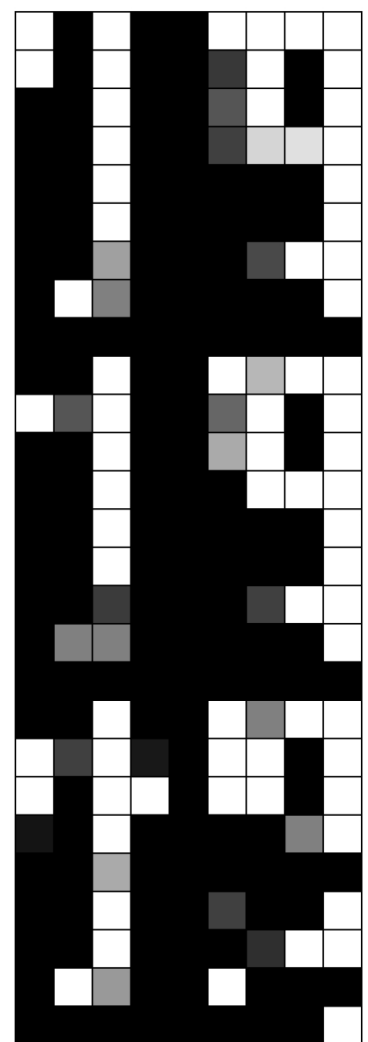

Figura 5. Plot de sensibilidade (ou diagrama de Navajo, sensu Wheeler, 1995 e Giribet, 2001) para os clados atribuídos às espécies de Rhinebothroides. Em "Mapa de parâmetros" estão representados os regimes de custo implementados na análise filogenética. Para cada parâmetro, temos o regime de custo para ITS-1, 28S e CO1, nesta ordem. O parâmetro selecionado pela análise de congruência aparece em cinza. Quadrados em preto representam a presença do clado em $100 \%$ das topologias, tons de cinza representam a presença dos mesmos em frequências menores que 100\%, quadrados brancos representam a ausência do clado para o respectivo conjunto de parâmetros. 


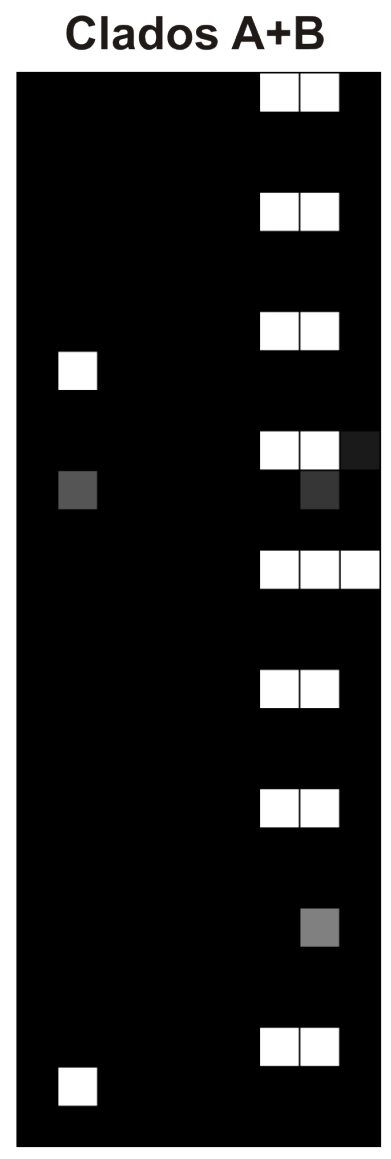

Clados $(C+D)+E$

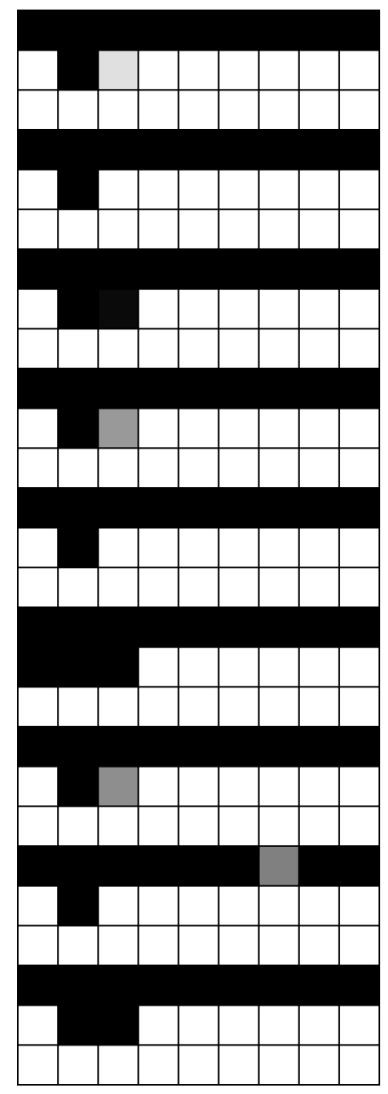

Clados C + D

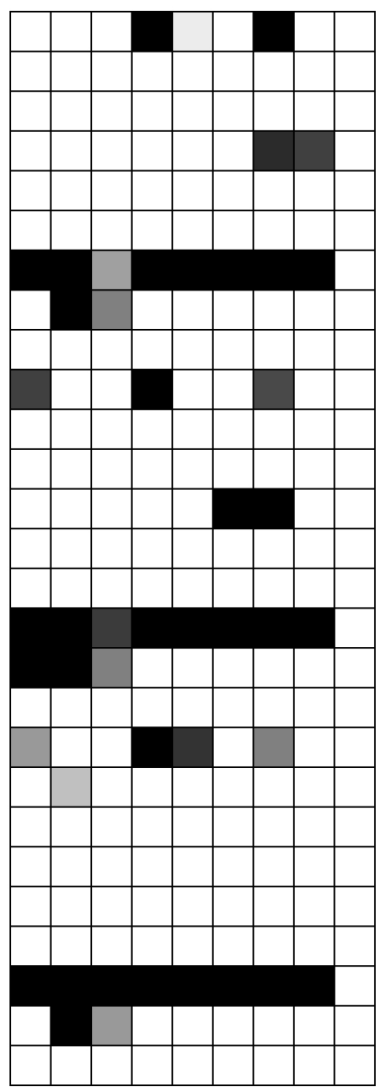

Rhinebothroides

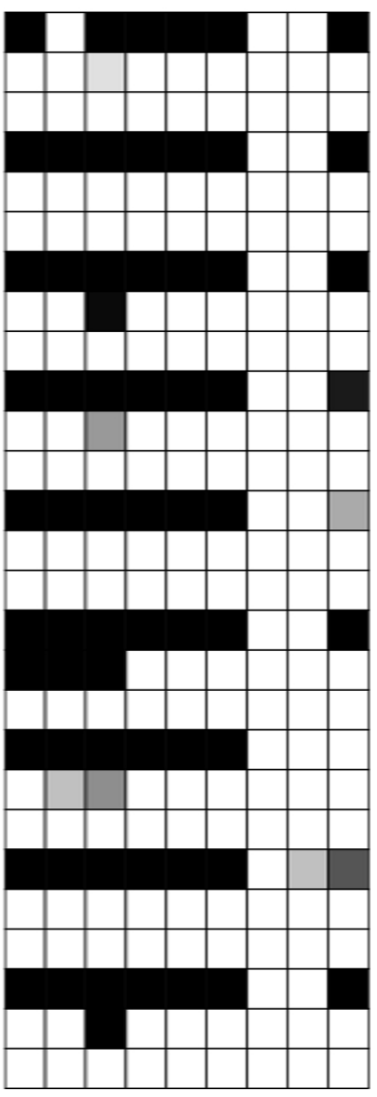

Figura 6. Plot de sensibilidade (ou diagrama de Navajo, sensu Wheeler, 1995 e Giribet, 2001) para combinações dos clados atribuídos às espécies de Rhinebothroides. Quadrados em preto representam a presença do clado em $100 \%$ das topologias, tons de cinza representam a presença dos mesmos em frequências menores que $100 \%$, quadrados brancos representam a ausência do clado para o respectivo conjunto de parâmetros. 


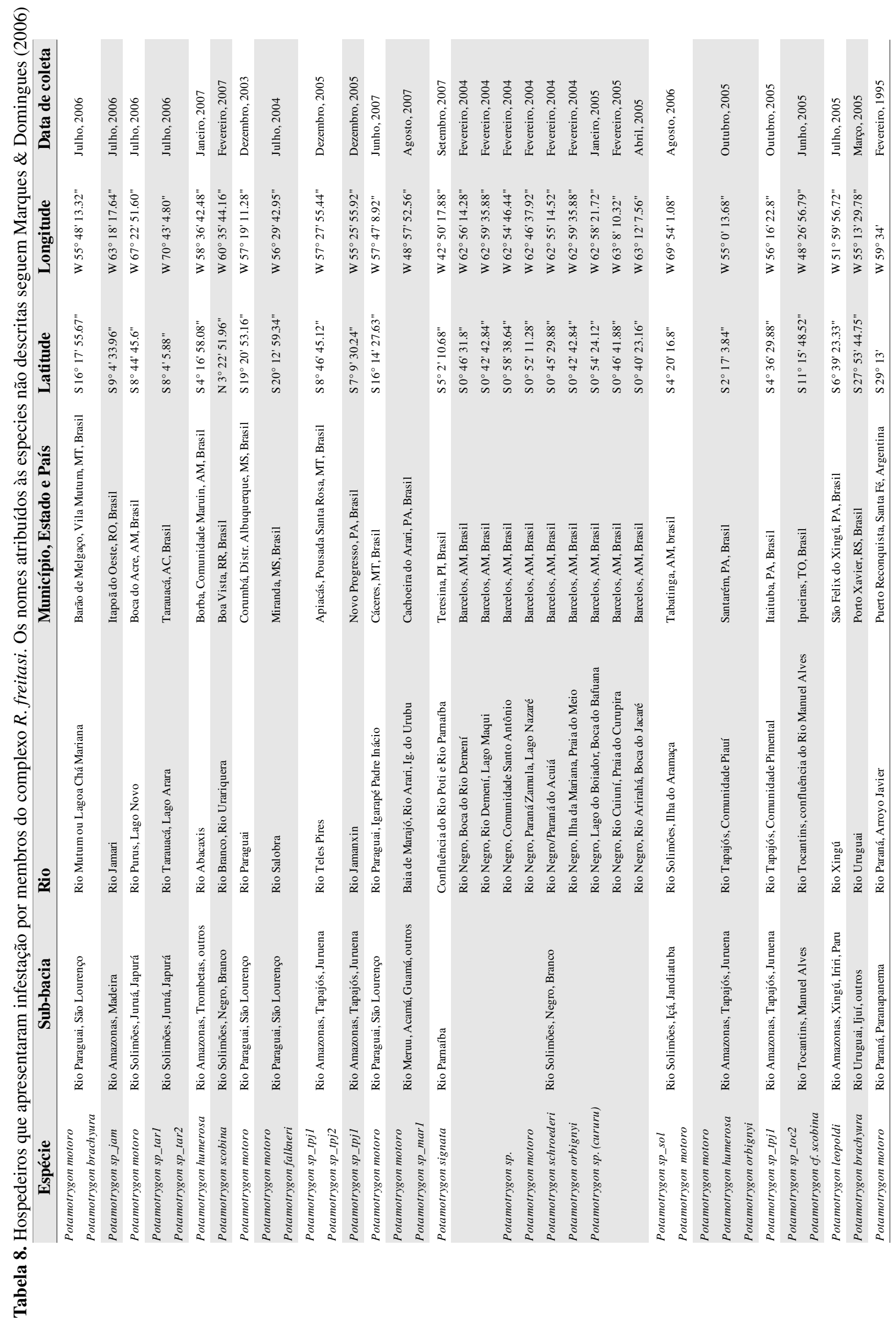


coletados em 14 sub-bacias foram analisadas, das quais 19 se apresentaram infestadas por membros do complexo de interesse em 13 sub-bacias (Tabela 8). Membros do complexo $R$. freitasi não foram encontrados na sub-bacia dos Rios Araguaia, Mortes e Javaés (Tabela 8).

A análise morfológica de representantes deste complexo permitiu o reconhecimento de dois morfotipos distintos. A comparação com o material tipo disponível para as espécies nominais pertencentes ao complexo $R$. freitasi mostrou que um dos morfotipos encontrados apresenta características coerentes com os conceitos de $R$. venezuelensis e $R$. campbelli e o outro apresenta características coerentes com os conceitos de $R$. freitasi e $R$. circularisi.

\section{Integração de dados moleculares e morfológicos}

Atualmente existem 8 espécies nominais para Rhinebothroides, das quais 6 são consideradas válidas. A comparação do material tipo disponível para essas espécies nominais com os vouchers moleculares e/ou representantes das populações de Rhinebothroides incluídas na análise cladística possibilitou identificar 5 clados que apresentam caracteres morfológicos consistentes (clados A, B, C, D e E; Fig. 4)

Membros do clado A são caracterizados por espécimes que possuem células glandulares próximas à região da vagina (Figura 7A-E). Existem duas espécies nominais para espécimes de Rhinebothroides com essa característica singular: $R$. glandularis e $R$. mclennanae, ambas consideradas válidas.

Membros do clado B são caracterizados por espécimes que apresentam proglótides robustas, testículos organizados em 3 fileiras ao invés das 1-2 observadas em outras espécies do gênero e folículos vitelínicos não interrompidos ao nível do poro genital (Figura 8A-C). Existe apenas uma espécie nominal que apresenta esse conjunto de características: $R$. scorzai.

Membros do clado C são caracterizados por espécimes que apresentam microtríquias que lembram espinhos no cirro (espinitríquias), facilmente visualizadas ao microscópio óptico (Figura 9A-D). Outros membros do gênero apresentam filitríquias cobrindo toda a extensão do órgão 

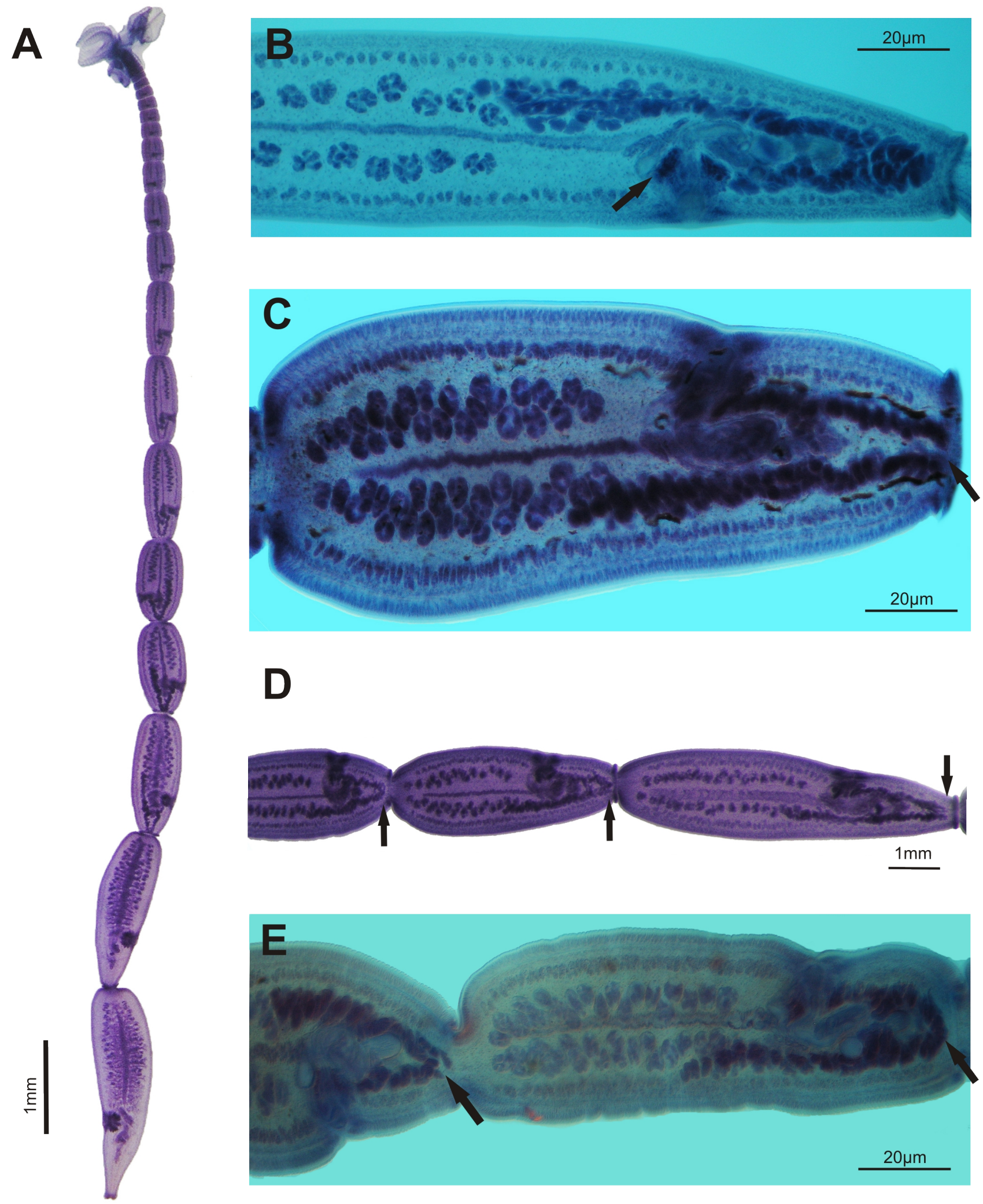

Figura 7. Caracterização morfológica e variação morfológica da região posterior do ovário de Rhinebothroides glandularis. A - Espécime adulto completo. B - Detalhe da proglótide de R. glandularis (a seta indica a posição das células glandulares próximas ao poro genital). C - Ovário em H, espécime do médio Rio Negro. D - Ovário em H, espécime do Rio Teles Pires. E - Ovário em A, espécime do Rio Solimões. 

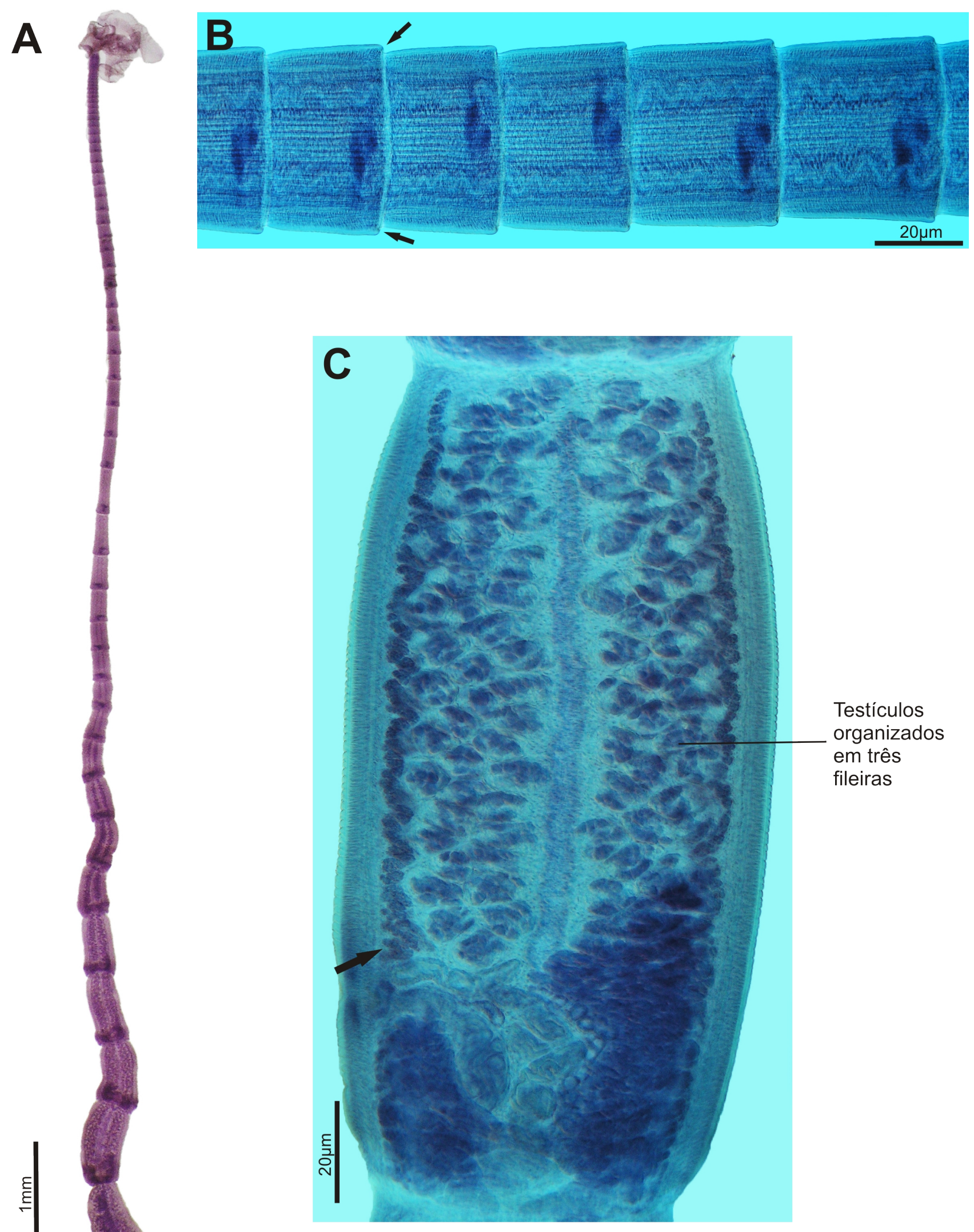

Figura 8. Caracterização morfológica de Rhinebothroides scorzai. A - Espécime adulto completo. B - Detalhe do estróbilo (seta indica a condição craspedota). C - Segmento maduro mostrando a organização dos testículos (seta indica a não interrupção da vitelária ao nível do poro genital). 


\section{A}
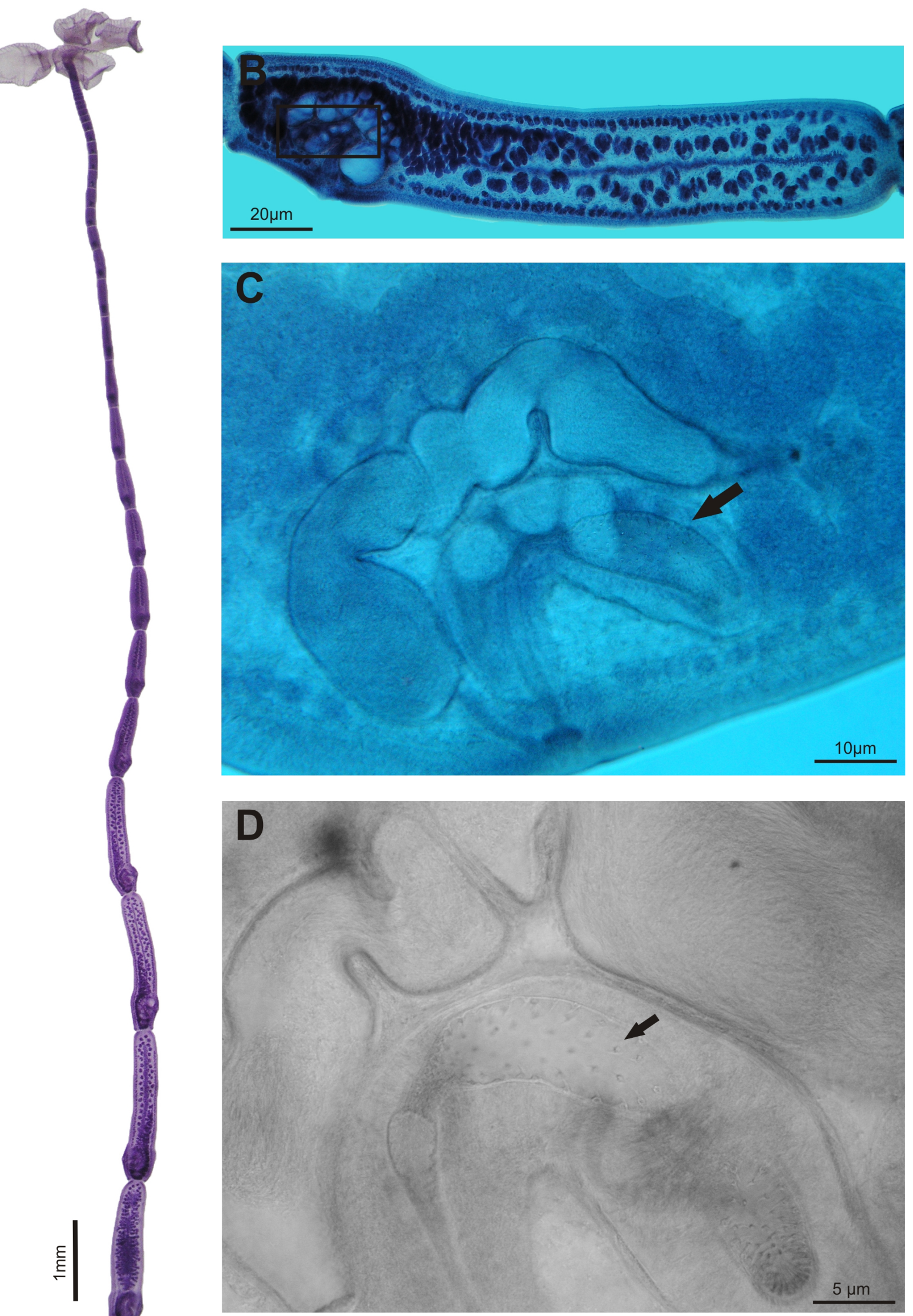

Figura 9. Caracterização morfológica de Rhinebothroides moralarai. A - Espécime adulto completo. B - Segmento maduro no qual retângulo indica a região do saco do cirro. $\mathrm{C}$ - Detalhe da região do saco do cirro (seta indica a presença de espinitríquias no cirro). D - Detalhe do cirro (seta indica espinitríquias no cirro). 
copulatório, também visíveis ao microscópio óptico. Existe uma espécie nominal com essa característica dentro do gênero: $R$. moralarai.

Baseado no conceito de $R$. freitasi de Marques \& Brooks (2003), este nome deveria ser atribuído aos espécimes incluídos nos clados D e E (Fig. 4), o que, de acordo com a topologia apresentada implica da parafilía desta espécie. Adicionalmente, o clado D poderia representar a mais recente espécie descrita para o gênero, $R$. campbelli. Essa constatação levou a busca de diagnose morfológica para esses clados e re-exame do material tipo de $R$. campbelli e das espécies nominais incluídas na sinonímia de $R$. freitasi. Considerou-se também o reconhecimento de dois morfotipos para membros desses dois clados, cada um deles associado a duas espécies nominais.

De acordo com as observações resultantes deste estudo, o clado D inclui representantes que possuem características coerentes com os conceitos de $R$. venezuelensis e $R$. campbelli e o clado E inclui representantes que apresentam características coerentes com os conceitos de $R$. freitasi e $R$. circularisi, refletindo os dois morfotipos encontrados na análise morfológica. Com base nesses dados, as decisões taxonômicas adotadas são:

\section{REDESCRIÇÕES}

\section{Rhinebothroides venezuelensis Brooks, Mayes \& Thorson, 1981}

Figuras 10A-E e 11A-E; Tabela 9

Sinonímias: Rhinebothroides freitasi (Rego, 1979) (em parte); Rhinebothroides campbelli Ivanov 2004, (nova sinonímia).

Redescrição: (Baseada em 107 preparações completas, 15 parátipos e 11 vouchers de $R$. venezuelensis (Tabela 3), holótipo e 3 parátipos de R. campbelli (Tabela 3) e 8 escóleces observadas sob MEV.) Estróbilo acraspedoto, apolítico, 2.8-30.8 mm de comprimento, com 5-29 segmentos. Proglótides divididas em região posterior e anterior por um estrangulamento no 1/3-1/4 posterior dos segmentos terminais e subterminais. Escoléx com quatro botrídios bilobados e pedunculados, com 425,7-1188,0 de comprimento total, lobo anterior com 198,0-910,8 de largura e lobo posterior 

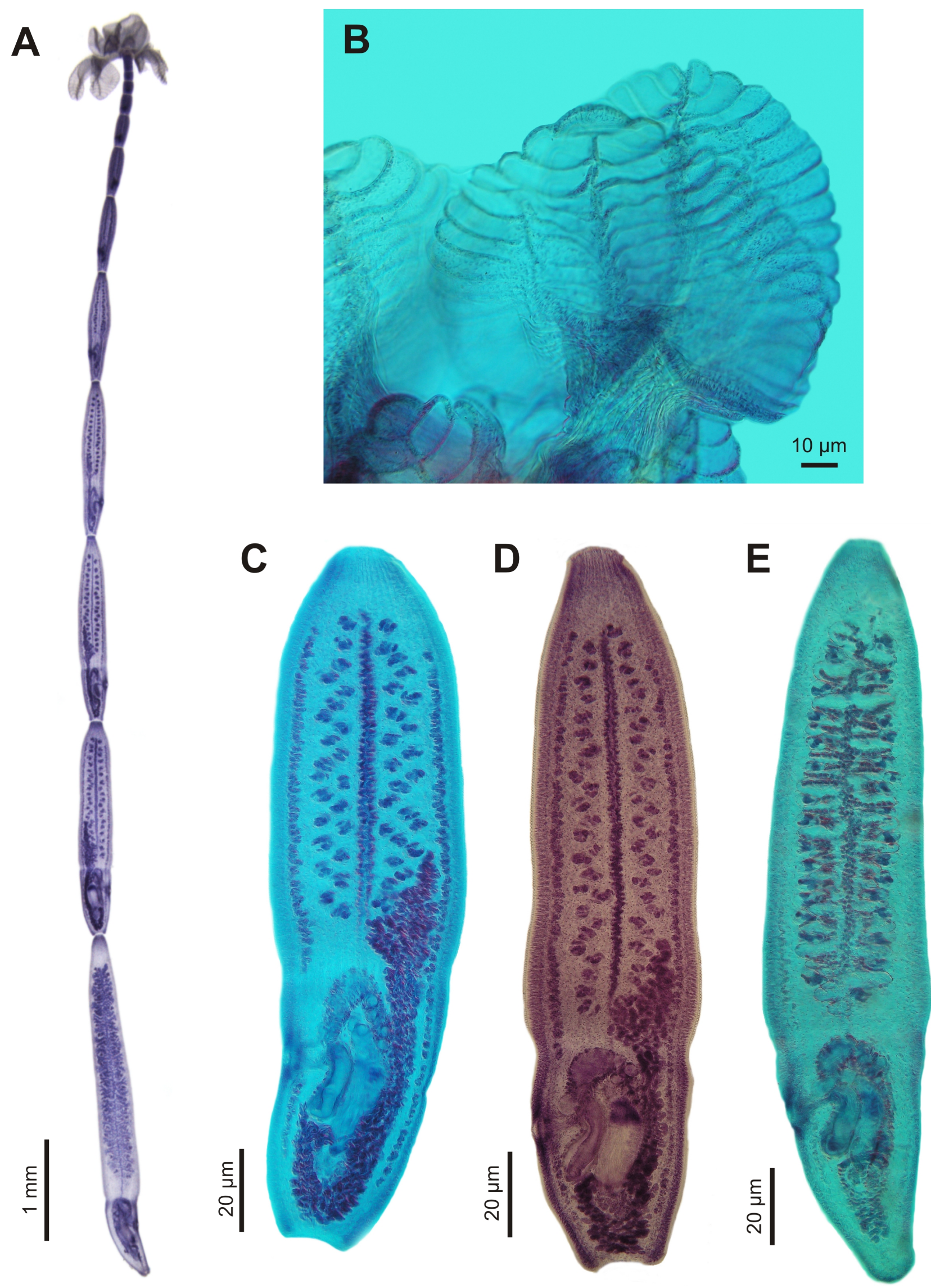

Figura 10. Morfologia de Rhinebothroides venezuelensis. A - Espécime adulto completo (MZUSP 6493). B - Detalhe do botrídeo no escólex (MZUSP 6488). C e D - Segmentos maduros, note variação na morfologia do lobo poral (MZUSP 6495 e 6493 respectivamente). E - Segmento grávido, após degeneração do ovário, vitelária e testículos (MZUSP 6489). 

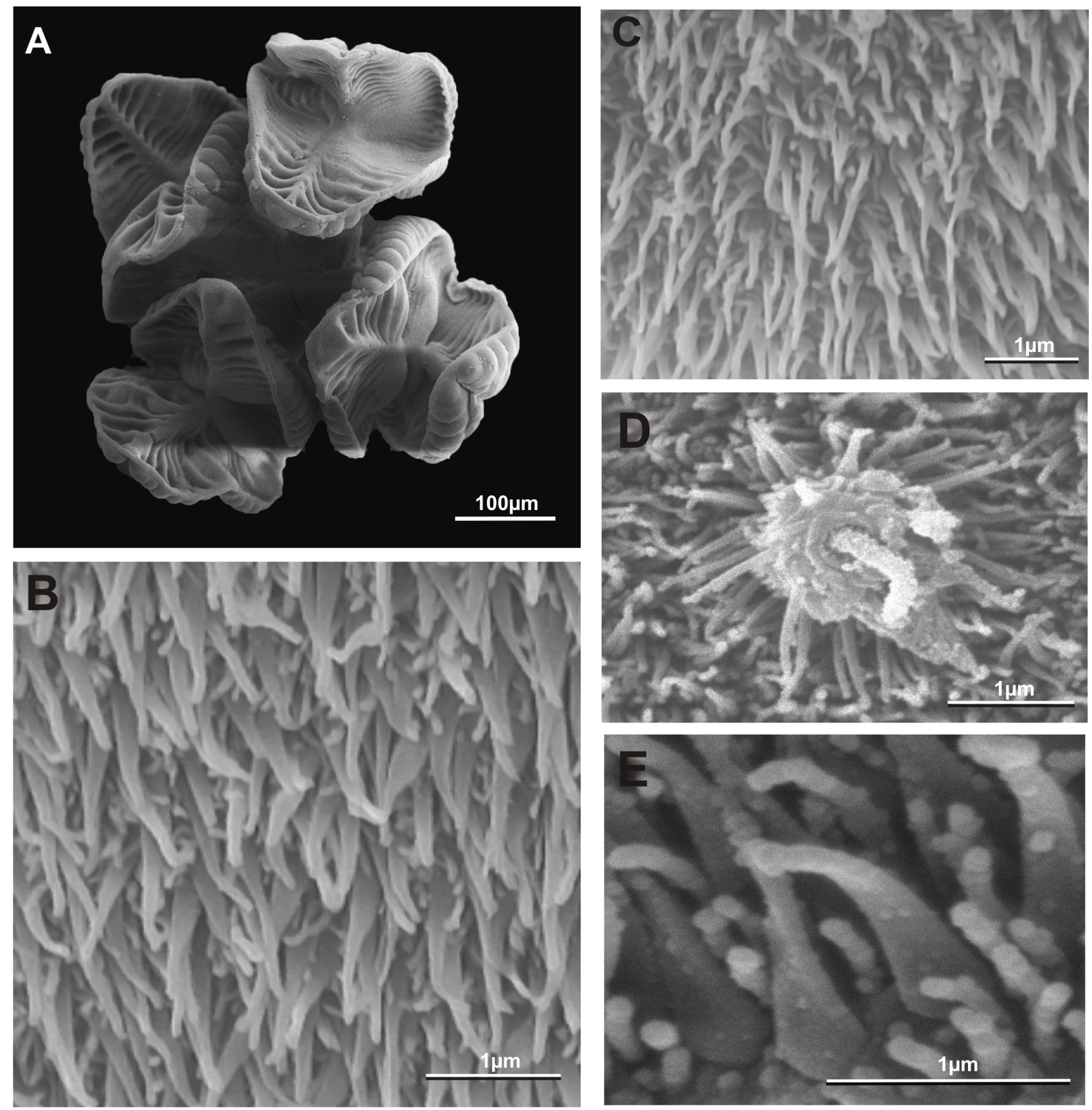

Figura 11. Micrografias eletrônicas de varredura para Rhinebothroides venezuelensis. A - escoléx (MZUSP 6635). B Microtríquias na região proximal (MZUSP 6616). C - Microtríquias na região distal (MZUSP 6616). D - Complexo ciliar presente na região distal (MZUSP 6616). E - Detalhe da estrutura dos dois tipos de microtríquias, espinitríquias gladiadas e filitríquias aciculares (MZUSP 6629). 


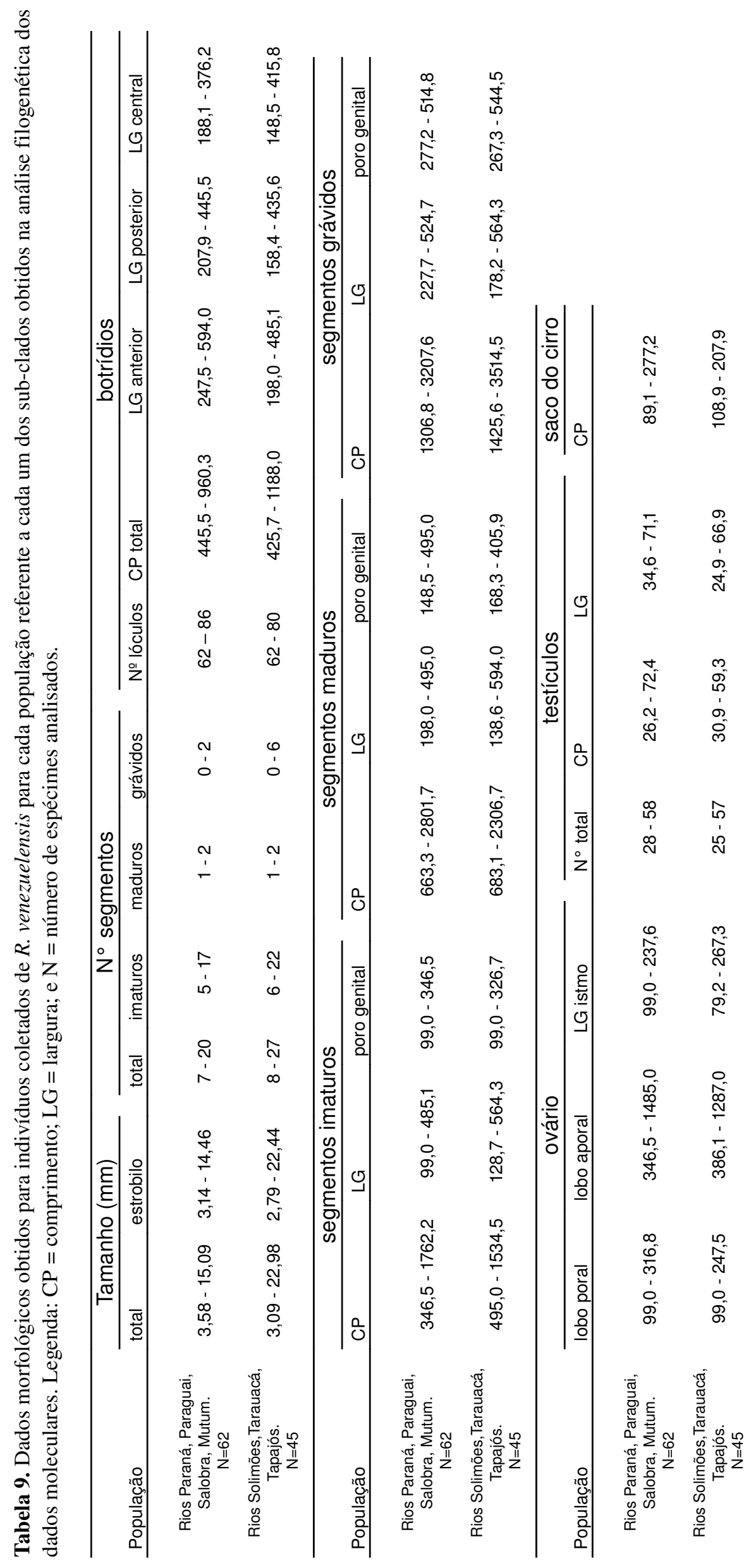


com 158,4-673,2 de largura, contendo lóculos marginais e transversais, 62-86 lóculos transversais por botrídio, lóculos marginais nem sempre visíveis. Superfície distal dos botrídios coberta por espinitríquias gladiadas, 0,58-1,14 de comprimento, com aproximadamente 5-13 microtríquias/ $\mathrm{m}^{2}$, interespaçadas por filitríquias aciculares pequenas de difícil visualização (Fig. 11). Superfície proximal dos botrídios coberta por espinitríquias gladiadas, 1,11-1,72 de comprimento, com aproximadamente 3-8 microtríquias $/ \mu^{2}$, interespaçadas por filitríquias aciculares com 0,33 de comprimento (Fig. 11). Proglótides imaturas mais largas do que longas; proglótides maduras com 663,3-2801,7 de comprimento e 138,6-752,4 de largura. Testículos redondos, distribuídos em dois campos separados pelo útero, cada campo com 1-2 colunas irregulares, restritos à região anterior do segmento, 25-62 testículos por segmento, 26,2-86,5 de comprimento, 24,9-93,9 de largura. O saco do cirro está posicionado a 1/5 da região posterior do segmento, com 89,1-277,2 de comprimento; contendo um cirro eversível coberto por microtríquias e vesícula seminal interna. Vesícula seminal externa funde-se ao saco do cirro próximo a terminação poral, se estende por todo o comprimento do saco do cirro fundindo-se ao vaso deferente próximo a extremidade posterior da proglótide e coberta por células fortemente coradas por toda sua extensão. Átrio genital raso, desprovido de microtríquias. Poros genitais alternados irregularmente. Vagina anterior ao saco do cirro, variando de pouco enrolada a semi-reta. Esfíncter vaginal e receptáculo seminal presentes. Ovário bilobado em visão frontal e em forma de $\mathrm{X}$ em cortes transversais, próximo à extremidade posterior da proglótide; lobos assimétricos; lobo aporal com 346,5 - 1485,0 de comprimento, se estendendo à região médio-anterior do segmento, sobrepondo alguns testículos; lobo poral com 99,0-356,4 de comprimento, se estendendo até nível do istmo ovariano. Ovário com 79,2-356,4 de largura na altura do istmo ovariano. Folículos vitelínicos laterais, vitelária se estendendo do nível da glândula de Mehlis até próximo da extremidade anterior da proglótide, interrompida próximo ao poro genital. Proglótides grávidas com 1306,8-4712,4 de comprimento e 178,2-742,5 de largura, desprovidas de gônadas. Útero em forma de saco, com divertículos laterais. 


\section{Sumário Taxonômico}

Hospedeiro-tipo: Potamotrygon orbignyi (Castelnau, 1855)

Local de infecção: válvula espiral.

Localidade-tipo: Delta do Orinoco, próximo a Curiapo, Venezuela.

Localidades adicionais: Rio Orinoco, próximo a Los Castillos; região do Lago Maracaibo, próximo a El Congo e Represa Tulé; Rio Cachirí, Zulia,Venezuela; Rio Salobra, Miranda, MS (S20¹2'59.34”, W56²9'42.95”); Rio Paraguai, Corumbá, Distr. de Albuquerque, MS (S19²0'53.1594”, W57²19'11.28”); Rio Mutum, Barão de Melgaço, MT (S16¹7'55.6794", W 5548'13.3194"); Rio Purus, Lago Novo, Boca do Acre, AM (S844'45.6", W67²2'51.6"); Rio Tarauacá, Lago Arara, Tarauacá, AC (S84'5.88", W7043'4.8"); Rio Paraguai, Igarapé Padre Inácio, Cáceres, MT (S16²14'27.63", W57²7'8.92"); Rio Solimões, Ilha do Aramaça, Tabatinga, AM (S4²0'16.8", W6954'1.08"); Rio Tapajós, Comunidade Pimental, Itaituba, PA (S4³6'29.8794", W56²6'22.8"); Rio Paraná, Arroyo Javier, Puerto Reconquista, Santa Fé, Argentina (S29 $\left.13^{\prime}, \mathrm{W} 59^{\circ} 34^{\prime}\right)$.

Hospedeiros adicionais: Potamotrygon yepezi, P. motoro, novos registros: $P$. sp_tarl, $P$. sp_tar2, P. sp_tpj1,Psp_sol.

Material examinado: $R$. venezuelensis: vouchers HWML 21025 (2 espécimes completos), HWML 34092 (3 espécimes completos), CHIOC 32.818a-f (5 espécimes completos, 1 espécime imaturo), parátipos HWML 21005 (3 espécimes completos, proglótides soltas, proglótides grávidas e 1 espécime incompleto), HWML 21006 (7 espécimes completos), USNPC 75706 (2 espécimes completos). R. campbelli: holótipo MACN-Pa 412/1, parátipos MACN-Pa 412/2-3, USNPC 94696. Detalhes do material tipo examinado estão na Tabela 3. Preparações totais adicionalmente examinadas, 107 espécimes no total, depositadas no Museu de Zoologia da Universidade de São Paulo sob os números MZUSP 6488 - 6515 e vouchers de MEV sob os números MZUSP 6597, 6598, 6616, 6617, 6628, 6629, 6633, 6635. 


\section{Comentários}

Brooks et al. (1981a), na descrição original da espécie, informaram que $R$. venezuelensis possuía estróbilo craspedoto, 20-30 segmentos e lobo ovariano aporal não se estendendo até a metade anterior da proglótide. Na ocasião, os autores não discutem as similaridades e/ou diferenças entre $R$. venezuelensis e $R$. freitasi, pois naquele momento $R$. freitasi era considerado membro de Rhinebothrium. Na descrição original de Rhinebothrium freitasi, Rego (1979) apresenta uma ilustração da proglótide na qual não há folículos vitelínicos pré-ovarianos. Quando Brooks et al. (1981a) transferiram R. freitasi para Rhinebothroides, estes autores utilizaram a ausência de folículos vitelínicos pré-ovarianos como característica diagnóstica desta espécie. Marques \& Brooks (2003) argumentaram que, embora os folículos vitelínicos pré-ovarianos não tivessem sido observados na proglótide ilustrada por Rego (1979), eles estavam presentes em outras proglótides livres no material tipo (parátipo CHIOC 31.486b). O exame de espécimes adicionais atribuídos a $R$. freitasi coletados no presente estudo revelou a presença de folículos vitelínicos pré-ovarianos. Marques \& Brooks (2003) também encontraram dificuldades em determinar a condição do estróbilo acraspedota e craspedota utilizada pra distinguir $R$. freitasi e $R$. venezuelensis, respectivamente. Segundo estes autores, a série tipo de $R$. freitasi consistia de proglótides livres e observaram uma variação intraespecífica para esse caráter na série tipo de $R$. venezuelensis que foi atribuída aos níveis de relaxamento destes vermes durante a fixação. Com relação à morfologia geral do ovário, Marques \& Brooks (2003) não consideraram a extensão dos lobos ovarianos como característica diagnóstica entre essas duas espécies e discutiram apenas a variação intraespecífica encontrada na extensão do lobo poral ovariano de $R$. freitasi (Marques \& Brooks, 2003:998, Fig. 3). Outros atributos merísticos e morfométricos apresentaram sobreposição entre as populações estudadas o que levou estes autores a proporem que $R$. freitasi fosse considerado sinonímia sênior de $R$. venezuelensis.

Ivanov (2004), subsequentemente, descreveu uma nova espécie de Rhinebothroides em 
Potamotrygon motoro coletado no Rio Paraná em Santa Fé, Argentina - R. campbelli - e comparou a extensão do lobo poral ovariano nesta espécie com R. freitasi (sensu Marques \& Brooks, 2003) no intuito de diferenciá-las. Segundo a autora, a lobo poral ovariano em $R$. campbelli se estende até a margem posterior do saco do cirro enquanto que em $R$. freitasi, este se estende até o nível mediano do saco do cirro. No entanto, a autora interpretou os desenhos de Marques \& Brooks (2003:998, Fig. 3) erroneamente, assumindo que se referiam à proglótides em estágios diferentes do desenvolvimento em um mesmo indivíduo. A ilustração apresentada por Marques \& Brooks (2003:998, Fig. 3) foi obtida de uma única lâmina contendo 15 proglótides livres (parátipo CHIOC 31.486b) das quais eles ilustraram um segmento imaturo (Marques \& Brooks, 2003:998, Fig. 3A) e dois segmentos maduros (Marques \& Brooks, 2003:998, Figs. 3B e C) mostrando as diferentes condições do lobo poral encontradas na série tipo. Conclui-se que a extensão do lobo poral em $R$. freitasi é um caráter variável e deve ser considerado com cautela na taxonomia desta espécie.

Outro caráter tradicionalmente utilizado na taxonomia de Rhinebothroides é a extensão relativa do lobo aporal ovariano. Ivanov (2004) comparou este caráter entre $R$. freitasi, $R$. venezuelensis e $R$. campbelli baseando-se nas descrições originais de $R$. freitasi e $R$. venezuelensis, e o exame de um parátipo desta última (USNPC 75706). A descrição original de $R$. venezuelensis sugere que o lobo aporal ovariano nesta espécie nunca se estende além do nível mediano do segmento, o que também nunca ocorre em $R$. freitasi (Brooks et al., 1981a; Rego, 1979). A partir destas observações, Ivanov (2004) considerou que a extensão do lobo aporal ovariano além do nível mediano da proglótide é um caráter diagnóstico para $R$. campbelli. No entanto, dos 15 parátipos e 11 vouchers de $R$. venezuelensis examinados neste estudo (Tabela 3), 6 apresentam lobo aporal se estendendo até a metade anterior do segmento (HWML 34092, 2 vouchers; HWML 21006, 2 vouchers e CHIOC 32818d,e). Adicionalmente, dos 3 parátipos e o holótipo de $R$. campbelli examinados (Tabela 3), 1 parátipo (MACN-Pa 412-2) apresenta lobo aporal que não se estende até a metade anterior do segmento. Estas observações revelam que as descrições originais omitiram a 
variação morfológica intraespecífica exibida por este caráter e questionam seu valor taxonômico na diagnose de $R$. campbelli proposta por Ivanov (2004).

Os membros do gênero Rhinebothroides possuem um estrangulamento no 1/3-1/4 posterior do segmento, o qual divide a proglótide em duas regiões. O exame de aproximadamente 400 espécimes de Rhinebothroides revelou uma forte relação entre a posição do estrangulamento e a extensão do lobo aporal ovariano. A posição dos testículos também é definida pela posição do estrangulamento uma vez que eles nunca são observados na região posterior ao estrangulamento da proglótide. Nos espécimes nos quais o lobo aporal ovariano se estende anteriormente ao estrangulamento da proglótide, este pode ou não sobrepor-se aos testículos posteriores. Consequentemente, naqueles espécimes nos quais o lobo aporal ovariano está confinado à região posterior ao estrangulamento, o lobo não se sobrepõe aos testículos. Esta constatação sugere uma nova interpretação para a posição relativa da extremidade anterior do lobo aporal ovariano em referência ao estrangulamento da proglótide ao invés da inconsistente sobreposição aos testículos e o alcance do meio do segmento.

Os espécimes de $R$. venezuelensis e $R$. campbelli apresentam o lobo ovariano aporal se estendendo além do estrangulamento da proglótide, enquanto que espécimes de $R$. freitasi apresentam lobo aporal ovariano confinado à região posterior ao estrangulamento. $\mathrm{O}$ exame de mais de 100 espécimes considerados como membros de $R$. venezuelensis provenientes de 9 localidades e 5 espécies de hospedeiros mostrou sempre a mesma condição do lobo aporal ovariano.

A morfologia do lobo poral ovariano em $R$. venezuelensis e $R$. campbelli também é similar. Em ambas, o lobo poral ovariano se estende anteriormente até o nível do istmo ovariano, mesmo que, em alguns exemplares atribuídos a $R$. freitasi ele pode ou não se estender anteriormente além do nível do istmo ovariano, como ressaltado e ilustrado por Marques \& Brooks (2003). Os valores merísticos e morfométricos obtidos para $R$. venezuelensis e $R$. campbelli mostraram sobreposição, tornando a distinção entre essas duas espécies impossível quando dependente destes caracteres. 
Desta forma considero que $R$. venezuelensis seja considerada uma espécie válida e sinonímia sênior de R. campbelli.

\section{Rhinebothroides freitasi (Rego, 1979) Brooks, Mayes \& Thorson, 1981}

Figuras 12A-E e 13A-E; Tabela 10.

Sinonímias: Rhinebothrium freitasi Rego, 1979; Rhinebothroides circularisi Mayes, Brooks \& Thorson, 1981.

Redescrição: (Baseado em 280 preparações totais, 11 parátipos de $R$. circularisi (Tabela 3), 4 parátipos de $R$. freitasi (Tabela 3) e 38 escóleces observadas sob MEV) Estróbilo acraspedoto, apolítico, 1,96-37,09 mm de comprimento, com 5-29 segmentos. Proglótides divididas em região posterior e anterior por um estrangulamento no 1/3-1/4 posterior dos segmentos terminais e subterminais. Escoléx com quatro botrídios bilobados e pedunculados, com 277,2-1296,9 de comprimento total, lobo anterior com 168,3-831,6 de largura e lobo posterior com 108,9-891,0 de largura, contendo lóculos marginais e transversais, 50-98 lóculos transversais por botrídio, lóculos marginais nem sempre visíveis. Superfície distal dos botrídios coberta por espinitríquias gladiadas, 0,72-1,37 de comprimento, com aproximadamente 4-19 microtríquias $/ \mu^{2}$, interespaçadas por filitríquias aciculares pequenas de difícil visualização (Fig. 13). Superfície proximal dos botrídios coberta por espinitríquias gladiadas, 0,88-1,77 de comprimento, com aproximadamente 2-11 microtríquias $/ \mu^{2}$, interespaçadas por filitríquias aciculares, 0,23-0,46 de comprimento (Fig. 13). Proglótides imaturas mais largas do que longas; proglótides maduras com 574,2-4276,8 de comprimento e 148,5-861,3 de largura. Testículos redondos, distribuídos em dois campos separados pelo útero, cada campo com 1-2 colunas irregulares, restritos à região anterior do segmento, 22-86 testículos por segmento, com 22,23-106,2 de comprimento e 24,7-111,2 de largura. O saco do cirro está posicionado a 1/5 da região posterior do segmento, com 79,2-337 de comprimento; contendo um cirro eversível coberto por microtríquias e vesícula seminal interna. A vesícula seminal externa se funde ao saco do cirro próximo a terminação poral, se estende por todo o comprimento do saco 
A
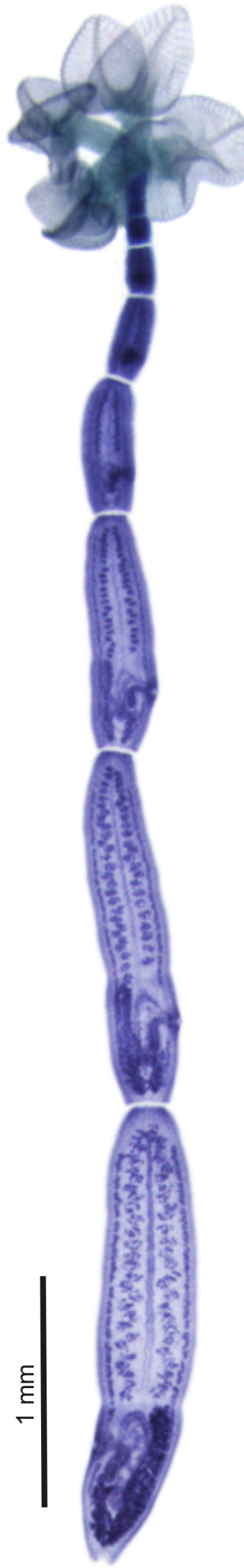

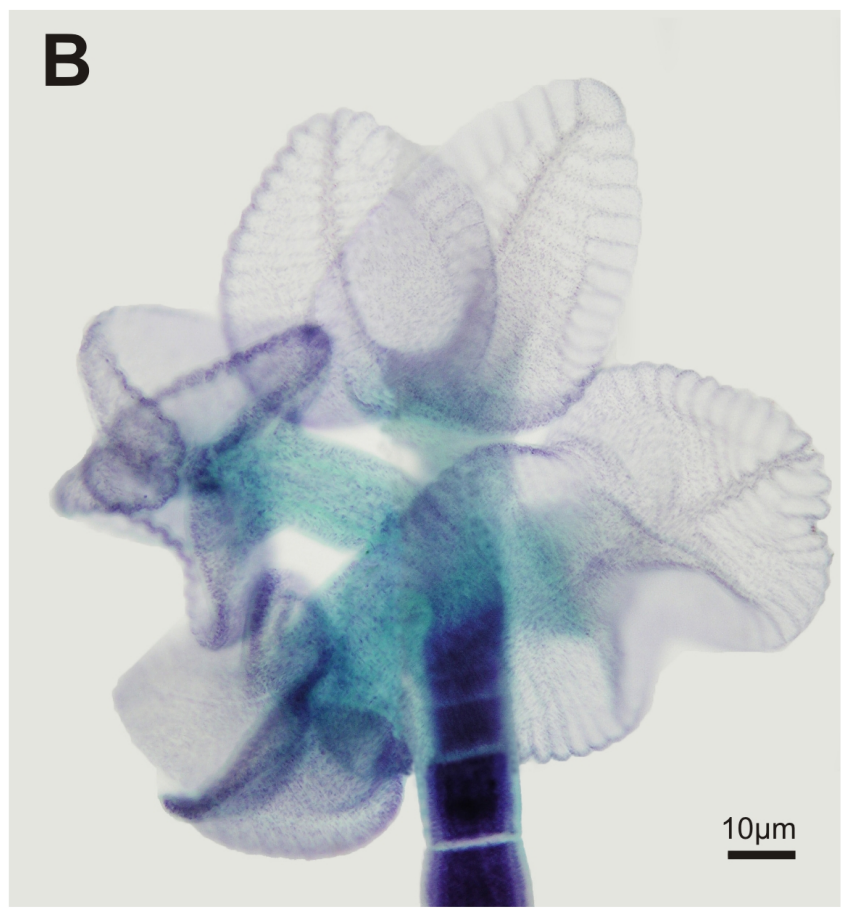

C

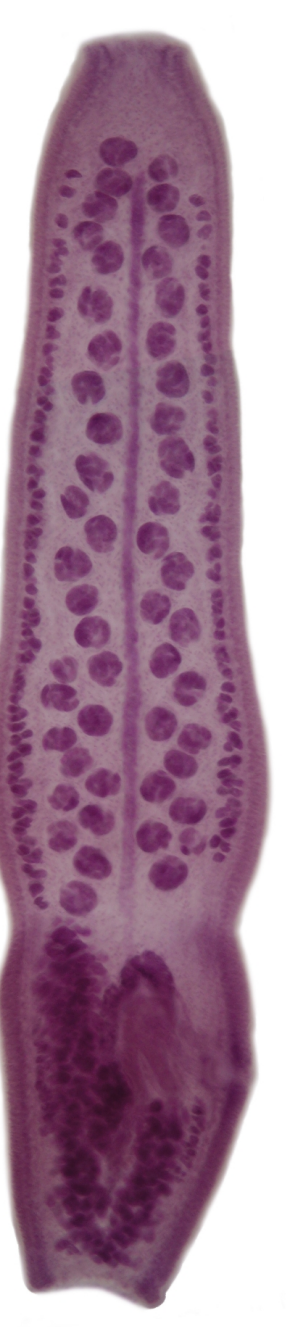

D

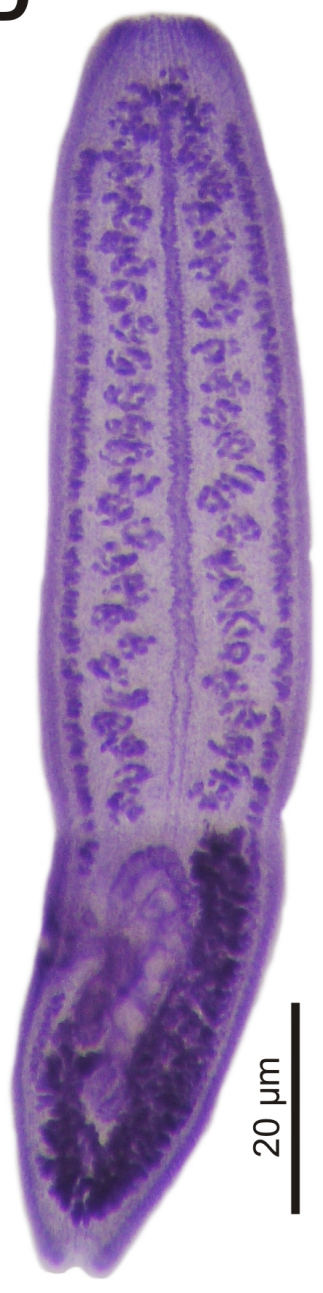

E

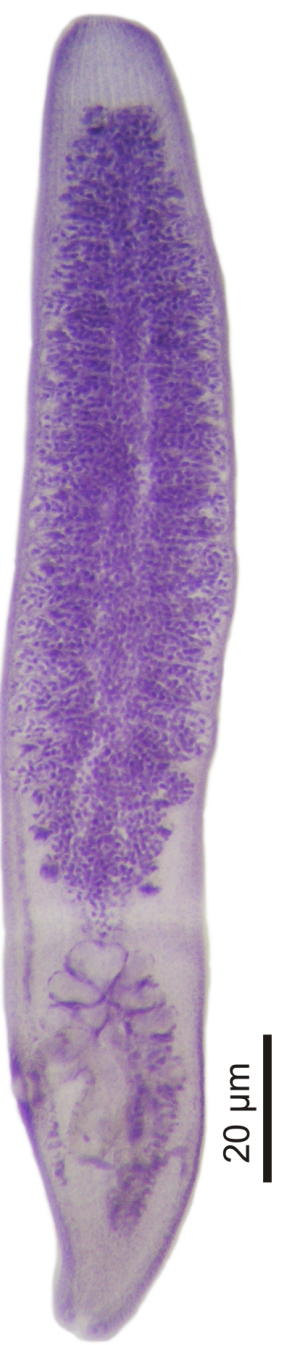

Figura 12. Morfologia de Rhinebothroides freitasi. A - Espécime adulto completo (MZUSP 6528). B - Detalhe do escólex (MZUSP 6528). C e D - Segmentos maduros, note variação na morfologia do lobo poral (MZUSP 6533 e 6528 , respectivamente). E - Segmento grávido após degeneração do ovário, vitelária e testículos (MZUSP 6529). 

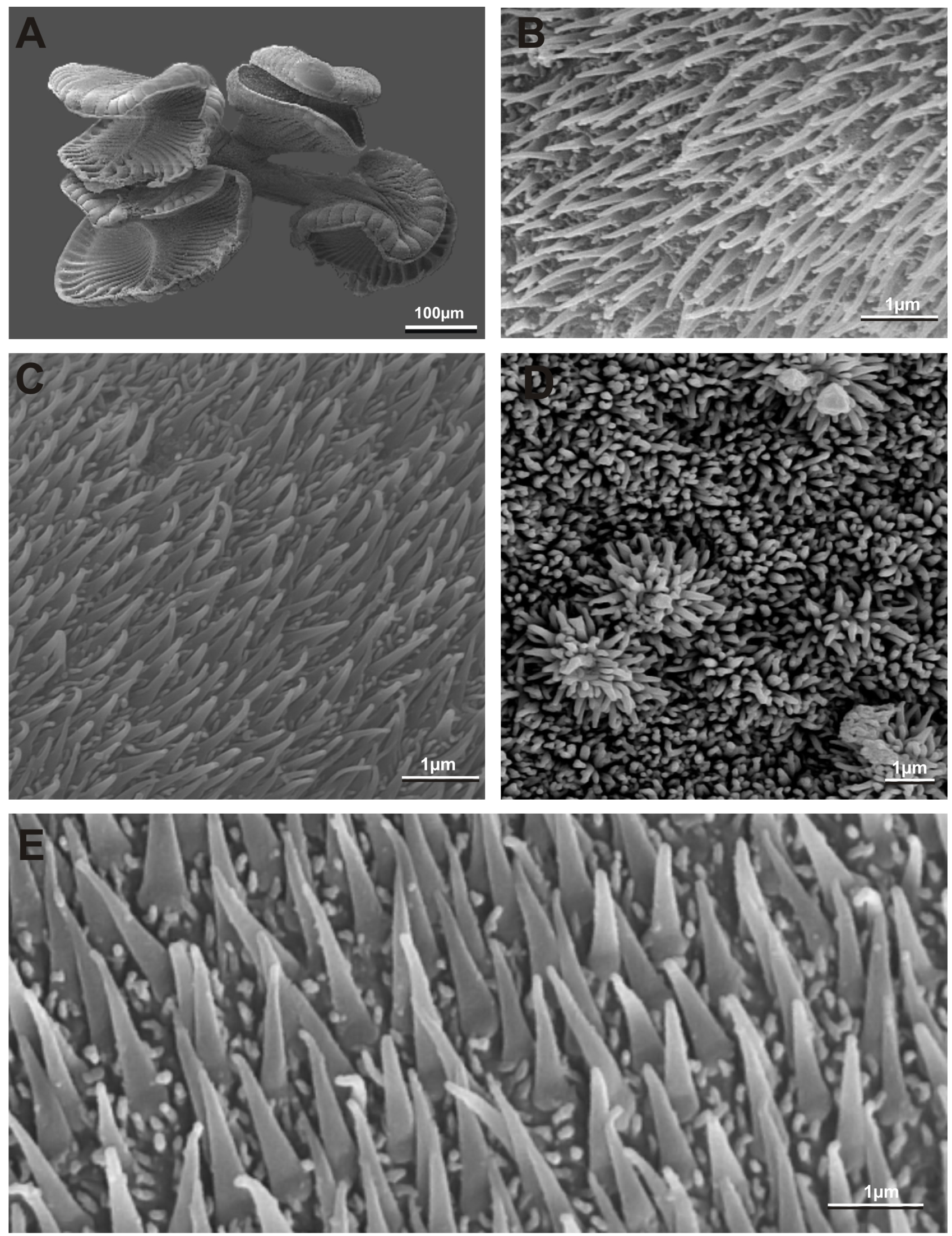

Figura 13. Micrografias eletrônicas de varredura para Rhinebothroides freitasi. A - escólex (MZUSP 6641). B microtríquias na região distal (MZUSP 6608). C - microtríquias na região proximal (MZUSP 6615). D - complexos ciliares na região distal (MZUSP 6641). E - estrutura dos dois tipos de microtríquias: espínitríquias gladiadas e filitríquias aciculares (MZUSP 6608). 


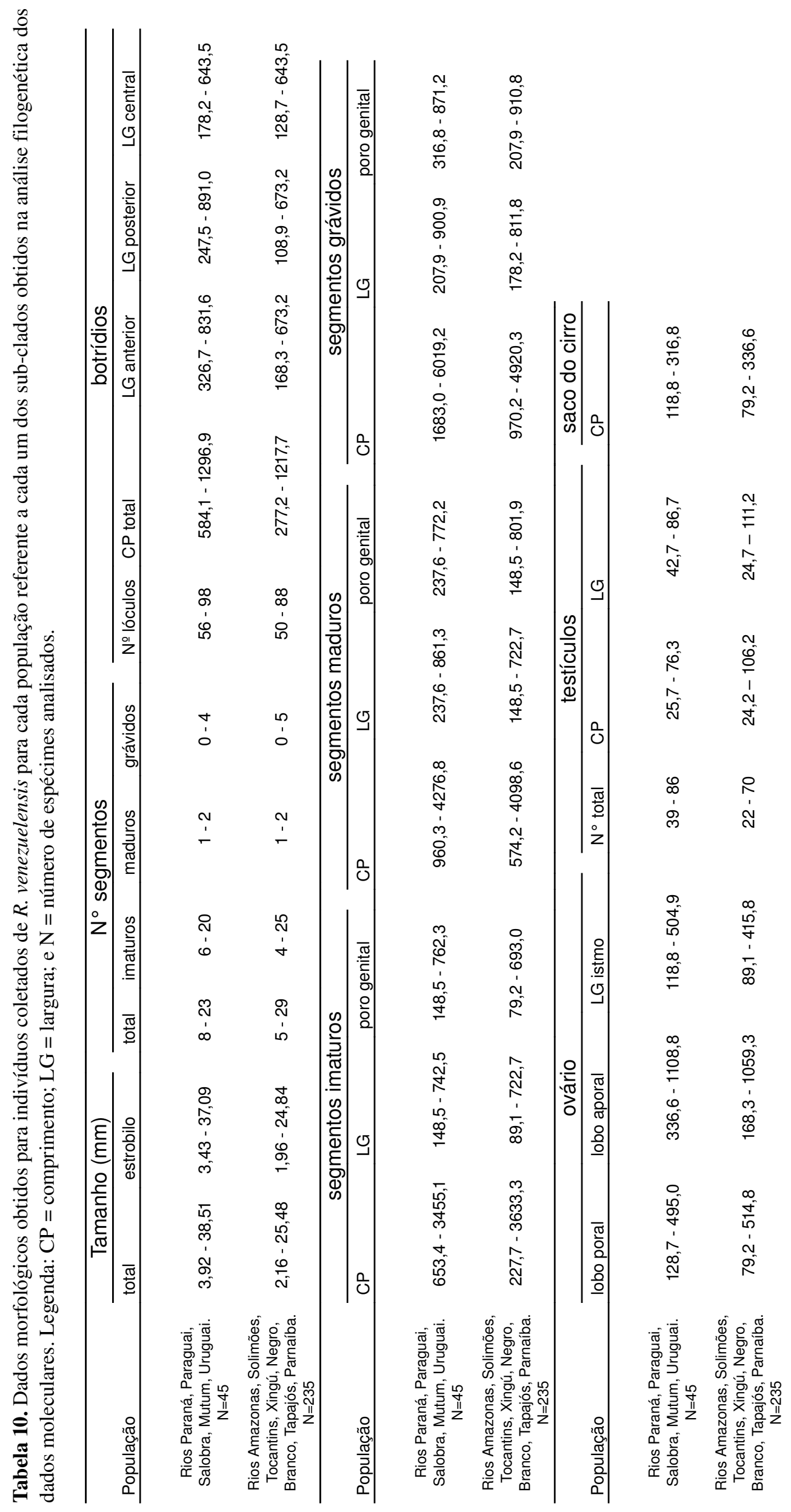


do cirro fundindo-se ao vaso deferente próximo a extremidade posterior da proglótide e é coberta por células fortemente coradas por toda sua extensão. O átrio genital é raso, desprovido de microtríquias. Os poros genitais alternados irregularmente. Vagina anterior ao saco do cirro, variando de pouco enrolada a semi-reta. Esfíncter vaginal e receptáculo seminal presentes. Ovário bilobado em visão frontal e em forma de $\mathrm{X}$ em cortes transversais, próximo à extremidade posterior da proglótide; lobos assimétricos; lobo aporal com 168,3-1108,8 de comprimento, se estendendo anteriormente até o nível do estrangulamento do segmento; lobo poral com 79,2-514,8 de comprimento e se estende anteriormente além do nível do istmo ovariano na maioria dos espécimes. Ovário com 89,1-544,5 de largura na altura do istmo. Folículos vitelínicos laterais, vitelária se estendendo do nível da glândula de Mehlis até próximo da extremidade anterior da proglótide, interrompida próximo ao poro genital. Proglótides grávidas com 970,2 -6019,2 de comprimento por 178,2-990,9 de largura, desprovidas de gônadas. Útero em forma de saco, com divertículos laterais.

\section{Sumário Taxonômico}

Hospedeiro-tipo: Potamotrygon orbignyi (Castelnau, 1855)

Local de infecção: válvula espiral.

Localidade-tipo: Rio Amazonas, Maicuru, Pará, Brasil.

Localidades adicionais: Lago Maracaibo, Venezuela; Rio Salobra, Miranda, MS (S20¹2'59.34”, W56²9'42.95”); Rio Mutum, Barão de Melgaço, MT (S16¹7'55.6794", W 5548'13.3194"); Rio Jamari, Itapoã do Oeste, RO (S94'33.96", W63¹8' 17.64"), Rio Purus, Lago Novo, Boca do Acre, AM (S844'45.6", W67²2'51.6"); Rio Abacaxis, Borba, Com. Maruin, AM (S4¹6'58.0794", $\quad$ W58³6'42.48"); Rio Urariquera, Boa Vista, RR (N3²2'51.9594", W60³5'44.1594"); Rio Teles Pires, Apiacás, Pousada Santa Rosa, MT (S846'45.1194", W57²7'55.44"); Rio Jamanxin, Novo Progresso, PA (S 79'30.24", W55²5'55.92"), Rio Paraguai, Igarapé Padre Inácio, Cáceres, MT (S16²1427.63", W57²7'8.92"); Baía de Marajó, Rio Arari, Ig. do Urubu, Cachoeira do Arari, PA (S059'58.2", W4857'52.5594"); Confluência dos Rios Poti e 
Parnaíba, Teresina, PI (S5²'10.6794", W4250'17.8794"); Rio Negro, Barcelos, AM (múltiplas localidades, ver Tabela 8); Rio Solimões, Ilha do Aramaça, Tabatinga, AM (S4²0'16.8", W6954'1.08"); Rio Tapajós, Com. Piauí, Santarém, PA (S2¹7'3.84", W550' 13.6794"); Rio Tocantins, confluência do Rio Manual Alves, Ipueiras, TO (S11¹5'48.52", W48²6'56.79"); Rio Uruguai, Porto Xavier, RS (S2753'44.75", W55¹3' 29.78").

Hospedeiros adicionais: Potamotrygon constellata, P. motoro, P. yepezi, P. falkneri, P. henlei, P. leopoldi, P. schroederi, P. scobina; novos registros: P. brachyura, P. signata, P. sp_jam, P. sp_tpj1, P. sp_tpj2, P. sp_marl, P. sp (cururu), P. sp (Rio Negro), P. sp_sol, P. humerosa, P. $s p \_t o c 2$.

Material examinado: $R$. circularisi: parátipos HWML 21020 (6 espécimes completos, 1 incompleto, 2 imaturos, 1 escoléx), USNPC 76362 (1 espécime completo). R. freitasi: CHIOC 31.486b-e (proglótides soltas, proglótides imaturas, 1 lâmina contendo uma escólex e 1 lâmina contendo 2 escóleces). Detalhes do material tipo examinado estão na Tabela 3. Preparações totais adicionalmente examinadas, 280 espécimes no total, estão depositadas no Museu de Zoologia da Universidade de São Paulo sob os números MZUSP 6516-6596 e vouchers de MEV sob os números MZUSP 6599-6615, 6618-6627, 6630-6634, 6636-6643.

\section{Comentários}

$\mathrm{Na}$ mais recente revisão do gênero Rhinebothroides, Marques \& Brooks (2003) consideraram R. circularisi, parasita de Potamotrygon circularis (=P. motoro ou P. constellata, de Carvalho et al., 2003) e R. venezuelensis, parasita de Potamotrygon orbignyi, ambas originalmente coletadas no Delta do Rio Orinoco, Venezuela, como sinonímias júnior de $R$. freitasi. Ao examinar o material tipo das três espécies nominais, Marques \& Brooks (2003) reportaram que os dados morfométricos e merísticos destas espécies exibiam variação intraespecífica com sobreposição, impedindo que os mesmos fossem utilizados na diagnose destas espécies nominais, especialmente no número de testículos e o formato do lobo poral ovariano. Estas foram as observações utilizadas 
por esses autores para propor as sinonímias de $R$. freitasi.

No entanto, esses autores ignoraram a posição relativa do lobo aporal ovariano em relação ao estrangulamento da proglótide e argumentaram que esse caráter apresenta variação morfológica intraespecífica como observado para o lobo poral ovariano. No presente estudo $R$. circularisi foi considerada sinônimo júnior de $R$. freitasi, baseado na reinterpretação de alguns caracteres, no exame da série tipo destas espécies e no exame de 280 espécimes coletados em 16 localidades provenientes de 16 espécies de hospedeiros.

Até o presente momento, $R$. freitasi é uma espécie nominal diagnosticada principalmente pela ausência de caracteres discretos. Outros membros do gênero apresentam características únicas, como por exemplo, a presença de células glandulares em torno do poro genital (e.g. R. glandularis e R. mclennanae), vitelária não interrompida ao nível do poro genital e segmentos relativamente robustos (e.g. R. scorzai) ou microtríquias que lembram espinhos no cirro (e.g. R. moralarai). Nenhuma característica discreta, como aquelas que garantem a diagnose destas espécies, foi até o presente identificada em membros de $R$. freitasi. No entanto, o exame da série tipo de $R$. freitasi e R. venezuelensis revelou uma característica importante relacionada à posição relativa da extremidade anterior do lobo aporal do ovário. Em R. freitasi, o lobo aporal do ovário nunca transcende o limite do estrangulamento da proglótide e está, portanto, restrito a região posterior do segmento. Rhinebothroides freitasi difere de $R$. venezuelensis justamente na extensão do lobo aporal do ovário, sendo que em $R$. venezuelensis este ultrapassa o nível do estrangulamento. Adicionalmente, o lobo poral de $R$. venezuelensis se estende até o nível do istmo ovariano, enquanto que em $R$. freitasi o lobo poral pode ou não ultrapassar o nível do istmo do ovário podendo alcançar o nível mediano do saco do cirro.

Os dados merísticos e morfométricos não aparentam conter informação taxonômica para estas espécies nominais (Tabelas 9 e 10). A obtenção destes dados para aproximadamente 400 espécimes revelou que estes atributos morfológicos exibem variabilidade intraespecífica que resulta 
em sobreposição de valores, principalmente em relação ao tamanho dos indivíduos e de seus órgãos reprodutivos. Diante disso, $R$. freitasi é considerada como uma espécie válida dentro do gênero Rhinebothroides.

\section{Discussão}

\section{Delimitação de espécies em $\underline{\text { Rhinebothroides: }}$ dados moleculares e morfológicos}

A compreensão dos mecanismos responsáveis pela diversificação biológica só é possível diante do reconhecimento de linhagens historicamente isoladas. No entanto, o reconhecimento destas linhagens históricas não é trivial, pois depende da disponibilidade de material biológico representativo e, muitas vezes, do uso de ferramentas que permitam acessar o conteúdo informativo de diferentes fontes de dados. A conjunção entre dados morfológicos e moleculares têm apresentado resultados valiosos para a sistemática de vários grupos de Metazoa (ver referências na Introdução). Este estudo deve ser considerado mais um exemplo desta abordagem, pois pela primeira vez na história taxonômica de Rhinebothroides as espécies são definidas pela circunscrição morfológica e molecular de grupos monofiléticos.

Atualmente existem 8 espécies nominais dentro do gênero Rhinebothroides, das quais 5-6 são consideradas válidas. No entanto, algumas práticas taxonômicas adotadas até o momento têm resultado na descrição de espécies baseadas em caracteres equívocos. Hoje, estes caracteres não permitem a diagnose de algumas espécies em posse de amostras de diferentes regiões e hospedeiros. Tradicionalmente, os estudos taxonômicos em Rhinebothroides têm se baseado em um número restrito de espécimes, em geral coletados de apenas uma espécie de hospedeiro de uma ou poucas localidades próximas (Brooks et al., 1981a; Brooks \& Amato, 1992; Mayes et al., 1981; Ivanov, 2004). A representatividade biogeográfica destes estudos aliada à quantidade de espécimes disponível a esses autores são, em parte, responsáveis pela formulação de conceito de espécies nominais circunscritas por caracteres que hoje se questiona seu valor taxonômico. Evidencia-se que 
a pouca disponibilidade de material biológico não permitiu a muitos autores avaliar de maneira adequada a variabilidade morfológica intra/interespecífica exibida por esses organismos. A compreensão desta variabilidade morfológica, que somente foi possível após o exame de aproximadamente 400 exemplares provenientes de 6 bacias hidrográficas e 28 hospedeiros, sugere que caracteres uma vez considerados discretos, são parte de um contínuo que inviabiliza totalmente seu uso em diagnoses - um problema que já havia sido identificado por Marques \& Brooks (2003) e usado para justificar algumas sinonímias no gênero.

A abrangência biogeográfica e de hospedeiros das amostras disponíveis para este estudo permitiu obter dados morfológicos e um padrão filogenético baseado em dados moleculares para diversas populações do gênero que propicia a um esquema taxonômico para Rhinebothroides robusto. A conjunção destes dados permitiu a melhor compreensão dos limites de variação morfológica das linhagens de Rhinebothroides, principalmente no que se refere àqueles caracteres tradicionalmente utilizados na taxonomia do grupo.

O contraste entre padrões topológicos e parâmetros morfométricos sugere que muitos dos caracteres utilizados tradicionalmente na taxonomia de Rhinebothroides (e.g., número de testículos e número lóculos em cada botrídio) exibem padrões de variação desconsiderados anteriormente. Um exemplo que sustenta essa asserção é ilustrado pelo padrão de variação morfológica exibida pelos membros do clado C (Fig. 4). Este clado, aqui considerado $R$. moralarai, é formado por haplótipos com distância igual ou pouco superior a zero, portanto exibindo baixa divergência molecular para ITS-2, 28S e COI, amostrados de uma única região biogeográfica, médio Rio Negro. Esta espécie foi originalmente descrita como Rhinebothrium moralarai, parasita de Potamotrygon magdalenae, do Rio Magdalena, Colômbia (Brooks \& Thorson, 1976). Brooks et al. (1981a) consideraram que esta espécie possui 45-47 lóculos em cada botrídio e 54-71 testículos por segmento e utilizou estes caracteres para diferenciar esta espécie das demais espécies do gênero. Marques \& Brooks (2003) registraram esta espécie para o médio Rio Negro como parasita de uma espécie ainda não descrita 
de Potamotrygon (Figura 14A). De acordo com esses autores, espécimes de $R$. moralarai encontrados no Rio Magdalena possuem 51-63 lóculos em cada botrídio e 55-63 testículos por segmento, ao passo que aqueles provenientes do Rio Negro possuem 49-55 e 43-69, respectivamente. Embora não tenha sido possível incluir haplótipos de $R$. moralarai do Rio Magdalena neste estudo, esse clado demonstra que a coesão molecular dos haplótipos do Rio Negro é seguida de considerável variação morfológica para parâmetros uma vez creditados como taxonomicamente relevantes. Vale ressaltar que estes e outros atributos morfométricos e merísticos encontrados para $R$. moralarai se sobrepõem àqueles reportados para $R$. glandularis e $R$. freitasi em Marques \& Brooks (2003:1003).

O mesmo padrão de congruência entre estrutura cladística e variação morfológica é exibida por membros do clado $\mathrm{B}$, aqui atribuídos à $R$. scorzai. Este clado inclui haplótipos obtidos da Ilha de Marajó, mas provenientes de duas espécies de hospedeiros, Potamotrygon motoro e Potamotrygon sp_marl (uma espécie não descrita do gênero). Esta espécie foi originalmente descrita como parasita de P. orbignyi do delta do Orinoco (Fig. 14A) por Lopéz-Neyra \& DiazUngriá (1958), que registraram a presença de 60-80 lóculos por botrídio e 86-98 testículos por segmento. Brooks et al. (1981a) registraram esta espécie para outros dois hospedeiros no delta do Orinoco, Paratrygon aiereba e Potamotrygon motoro. Posteriormente, Marques \& Brooks (2003) registraram esta espécie para P. motoro e P. orbignyi no baixo Amazonas - Ilha de Marajó. No entanto, é muito provável que o registro de Marques \& Brooks (2003) para P. orbignyi deva ser atribuído à espécie ainda não descrita de Potamotrygon, a mesma para as quais obtivemos nossas amostras moleculares. Se considerarmos os dados obtidos por Marques \& Brooks (2003) para $R$. scorzai provenientes do baixo Amazonas, os membros do clado B possuem 63-127 lóculos por botrídio e 65-98 testículos. A inclusão dos limites inferiores e posteriores obtidos pelo re-exame do material atribuído a $R$. scorzai por Brooks et al. (1981a) e pela descrição original de Lopéz-Neyra \& Diaz-Ungriá (1958) provenientes do Orinoco estenderia a amplitude de variação desses parâmetros 

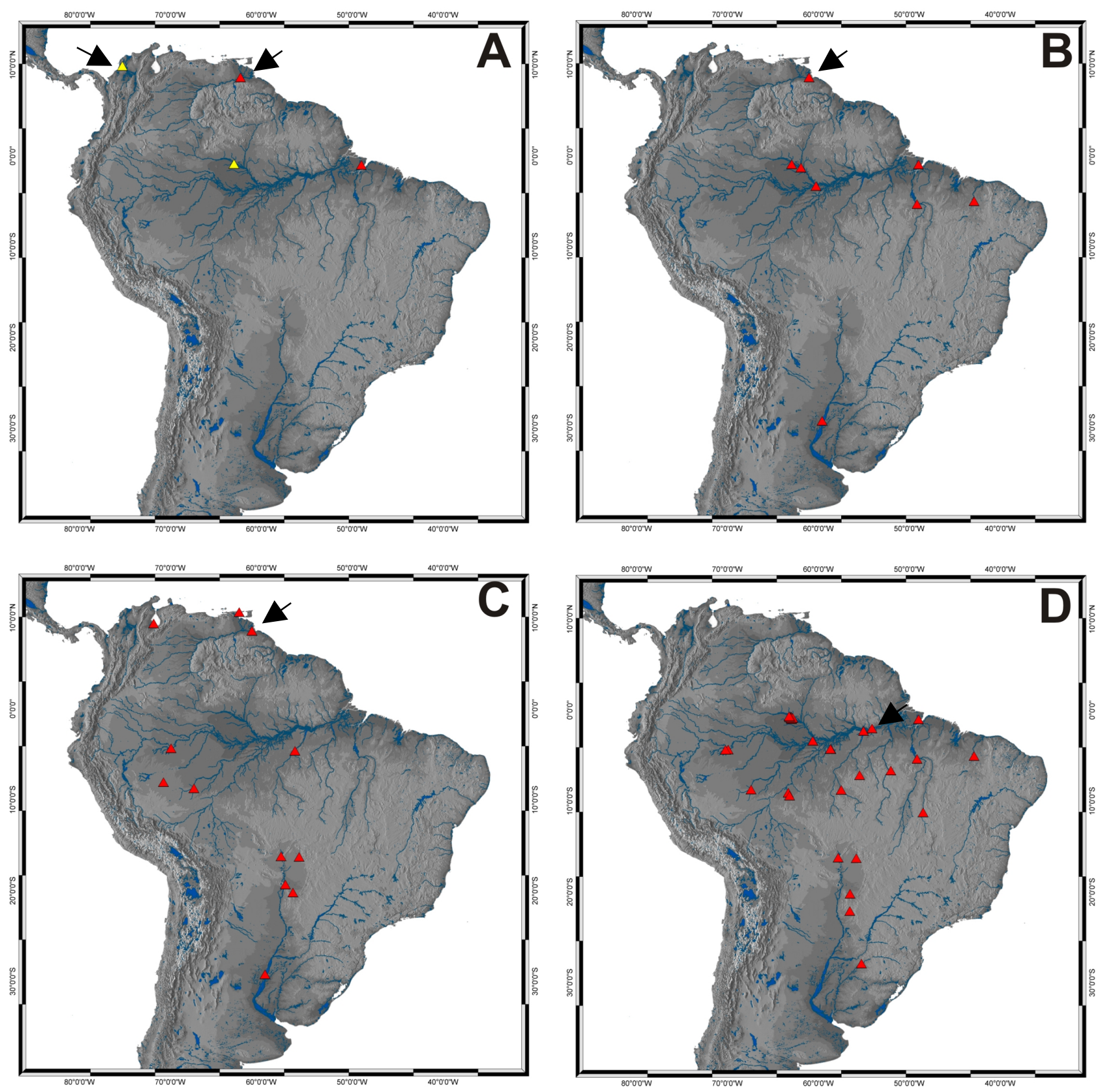

Figura 14. Mapas de distribuição para as espécies de Rhinebothroides reconhecidas neste estudo. A - Distribuição de $R$. scorzai (vermelho) e $R$. moralarai (amarelo). B - Distribuição de $R$. glandularis. C - Distribuição de $R$. venezuelensis. D - Distribuição de $R$. freitasi. Setas indicam a localidade tipo para cada espécie. 
merísticos para 60-127 lóculos por botrídio e 59-98 testículos (veja Marques \& Brooks, 2003:1017; Apêndice IV). Mesmo desconsiderando o impacto na amplitude destes parâmetros ao levar em consideração a população do Orinoco, uma vez que não foi possível incluir representantes desta população na análise cladística apresentada neste estudo, é evidente que a variação morfológica do clado B espelha aquela encontrada para o clado C. Esta observação sugere que estes atributos morfológicos têm pouco, ou nenhum, valor taxonômico para estas espécies.

Para os exemplos acima, embora tenhamos demonstrado a inutilidade de dados morfométricos e merísticos na diagnose destas espécies, ainda restam caracteres morfológicos que servem para identificar membros destes clados. Membros de Rhinebothroides moralarai (clado C) são caracterizados pela presença de espinitríquias no cirro, enquanto que outras espécies do gênero apresentam filitríquias no órgão copulatório (Figs. 4 e 9). Comparada com as demais espécies do gênero, membros de R. scorzai (Clado B) apresentam segmentos robustos, estróbilo craspedoto, testículos organizados em três fileiras e ausência de interrupção da vitelária ao nível do poro genital (Fig. 8). A presença de atributos morfológicos inequívocos para os membros destes clados explica em parte, porque, dentre as demais espécies atribuídas à Rhinebothroides, estas duas espécies possuem um histórico taxonômico mais simples em relação às demais. Adicionalmente, demonstra a congruência de dados moleculares com a morfologia destes haplótipos.

Um exemplo mais complexo, tanto taxonomicamente, quanto em relação a padrões de distribuição (Fig. 14B) e variação morfológica e molecular pode ser observado para os membros do clado A (Figs. 4 e 7). Todos os membros desse clado possuem células glandulares próximas à região do poro genital em conformidade com a morfologia de duas espécies nominais, $R$. glandularis e $R$. mclennanae. Destas, Marques \& Brooks (2003) consideram $R$. mclennanae sinonímia júnior de $R$. glandularis, ao passo que Ivanov (2004) considera ambas espécies válidas. Rhinebothroides glandularis foi descrita por Brooks et al. (1981a), parasita de Potamotrygon orbignyi (identificado como P. histrix na descrição original) do delta do Orinoco, Venezuela. Rhinebothroides mclennanae 
foi descrita por Brooks \& Amato (1992), parasita de P. motoro coletado próximo a Corumbá, Mato Grosso do Sul, Brasil. A sinonímia de Marques \& Brooks (2003) foi justificada pela observação de que os dados merísticos e morfométricos considerados para diagnosticar estas espécies exibiam sobreposição impedindo a circunscrição precisa entre estas espécies nominais com base nestes caracteres. Um ano mais tarde, Ivanov (2004) sugeriu que estas espécies poderiam ser diferenciadas pela morfologia do ovário, argumentando que em membros de $R$. mclennanae o ovário tem formato de "A" invertido enquanto que em $R$. glandularis essa estrutura tem forma de "H".

O exame da estrutura cladística para os haplótipos atribuídos a este complexo $R$. mclennanae/R. glandularis revela dois sub-clados, cada um restrito à regiões biogeográficas para as quais estas duas espécies nominais foram originalmente descritas (i.e. Bacias do Prata e Orinoco/Amazônica). De acordo com o conceito de R. mclennanae de Brooks \& Amato (1992) e Ivanov (2004), esta espécie está restrita à Bacia do Prata (i.e., Paraná e Paraguai) e parasitam uma única espécie de potamotrigonídeo, Potamotrygon motoro. Marques \& Brooks (2003), por sua vez, acreditam que $R$. glandularis está amplamente distribuída pela Bacia Amazônica e Orinoco, além de um registro para o Rio Paraguai proveniente do material utilizado na descrição de $R$. mclennanae, parasitando pelo menos seis espécies distintas de potamotrigonídeos. Desta forma, poder-se-ia argumentar que cada um desses sub-clados correspondem a uma dessas espécies nominais, cada qual restrita a uma bacia hidrográfica.

A dicotomia entre haplótipos morfologicamente semelhantes obtidos das bacias Amazônica e do Prata não é singular para este clado. Este padrão é também observado nos clados D e E (Fig. 4, discutidos detalhadamente abaixo). Marques \& Brooks (2003) já haviam demonstrado que os caracteres merísticos e morfométricos utilizados na diagnose destas espécies nominais apresentavam sobreposição, porém eles não consideraram a morfologia do ovário como potencial caráter diagnóstico. O exame dos parátipos de $R$. glandularis (Tabela 3) revelam que, de fato, as extremidades posteriores dos lobos ovarianos não estão em contato, diferindo do que se observa nos 
parátipos de R. mclennanae os quais aparentam estar em contato ou até mesmo fundidos (Tabela 3). Portanto, baseando-se apenas na limitada série tipo destas duas espécies nominais, teríamos um caráter morfológico que identificaria cada um dos sub-clados encontrados no clado A. No entanto, tal congruência está limitada a esses exemplares.

Caso a morfologia do ovário seja de fato diagnóstica para essas espécies nominais, esperaríamos encontrar um padrão congruente com a estrutura cladística do clado A. A previsão seria de que encontraríamos consistência morfológica nos ovários de indivíduos pertencentes às bacias Amazônica e do Prata, assumindo que, embora espécimes do Orinoco não tenham sido contempladas neste estudo, os haplótipos Amazônicos representam a espécie nominal $R$. glandularis. Estas expectativas se diluem ao constatar que, da mesma forma que muitos atributos morfométricos e merísticos, a forma do ovário é variável entre os exemplares confinados a cada uma dessas bacias hidrográficas.

Embora a resolução taxonômica do complexo $R$. glandularis/R. mclennanae esteja além do escopo deste estudo, uma análise preliminar revela que a morfologia do ovário não é consistente dentro do grupo, se apresentando em forma de "A" invertido na maior parte dos espécimes examinados. Representantes obtidos dos mesmos hospedeiros e localidades que os haplótipos Amazônicos apresentaram variação na morfologia do ovário como demonstrado na Figura 7A-E. Apesar de não ter sido possível a inclusão de representantes da fauna do médio Rio Negro para esse clado, espécimes em conformidade com a morfologia de $R$. glandularis/R. mclennanae obtidos dessa região foram examinados e constatou-se a presença de ambas variações morfológicas para o ovário (Fig. 7C). Embora este complexo mereça um estudo mais detalhado, o que se pode afirmar no momento é que não possuímos nenhum caráter morfológico que possa ser utilizado para diagnosticar membros de cada um destes sub-clados, sugerindo que o clado A deva ser considerado uma única espécie nominal, que por prioridade receberia o nome de $R$. glandularis.

Os haplótipos de Rhinebothroides venezuelensis (clado D, Fig. 4) e R. freitasi (clado E, Fig. 
4) exibem estrutura cladística similar àquela observada para $R$. glandularis, no sentido de apresentarem sub-clados restritos às bacias hidrográficas do Amazonas e do Prata. O conceito de $R$. venezuelensis adotado neste estudo inclui a espécie nominal $R$. campbelli, descrita por Ivanov (2004) como parasita de P. motoro do Rio Paraná. Desta forma, poderia ser argumentado que cada um destes sub-clados correspondem a uma espécie nominal. No entanto o conceito de espécie adotado neste estudo requer a obtenção de um grupo monofilético baseado em dados moleculares que apresente coerência morfológica. Neste sentido, como foi discutido acima (ver Comentários, página 27), membros do clado $\mathrm{D}$ apresentam lobo aporal ovariano que se estende além do estrangulamento médio-posterior da proglótide. Outros atributos morfológicos, como caracteres morfométricos e merísticos, não são passíveis de utilização na diagnose destas populações. Por exemplo, indivíduos do Paraná não diferem daqueles que ocorrem na bacia Amazônica quanto ao número de segmentos (7-20 vs. 8-27), número de testículos (28-58 vs. 25-57) e número de lóculos no botrídio (62-86 vs. 62-80), entre outros caracteres (veja Tabela 9). Com base nestas observações, este estudo reconhece apenas uma espécie para esse clado, $R$. venezuelensis (ver seção Resultados e na Tabela 9).

O mesmo raciocínio é adotado para justificar a validade de $R$. freitasi. A comparação entre o material tipo disponível para $R$. freitasi e $R$. circularisi e os haplótipos representantes dos terminais incluídos no clado E demonstrou que estes exemplares formam um grupo morfologicamente coeso, mesmo diante da existência de dois sub-clados com haplótipos restritos às bacias do Prata e Amazônica. A exemplo do que fora observado em outros casos similares acima, não há atributos merísticos e/ou morfométricos que permita distinguir estas populações (ver seção Resultados e Tabela 10). Desta forma, embora o conceito de $R$. freitasi proposto por Marques \& Brooks (2003) inclua erroneamente $R$. venezuelensis, este estudo corrobora a idéia inicialmente proposta por esses autores de que $R$. circularisi deva ser considerada sinonímia júnior de $R$. freitasi.

A estruturação cladística dos haplótipos das espécies distribuídas pelas bacias Amazônica e 
do Prata (i.e., R. glandulares, $R$. venezuelensis e $R$. freitasi, Fig. 14) sugere segregação e divergência molecular entre indivíduos destas populações. Isto pode explicar a variabilidade morfológica exibida pelos indivíduos representantes destas populações. Embora os dados morfométricos e merísticos não se apresentem como caracteres inequívocos na delimitação das espécies reconhecidas no presente estudo, alguns atributos morfológicos mostraram-se congruentes com a topologia e permitiu identificar algumas das espécies nominais. Deste exercício, observa-se que a conjunção de dados moleculares e morfológicos possibilitou resolver alguns problemas taxonômicos em Rhinebothroides. Os resultados deste estudo indicam que das 8 espécies nominais disponíveis atualmente para o grupo, a topologia revela 5 clados para os quais é possível observar características morfológicas diagnósticas congruentes com o material tipo de 5 espécies nominais. Diante desta congruência entre clados e coesão morfológica, este estudo considera 5 espécies como válidas.

Os resultados obtidos nesse estudo questionam os caracteres morfológicos tradicionalmente utilizados na taxonomia do gênero Rhinebothroides. Fica evidente que indivíduos coletados em bacias hidrográficas diferentes são em geral atribuídos a espécies diferentes, provavelmente devido a pequenas variações morfológicas intraespecíficas decorrentes da diminuição ou ausência temporária de fluxo gênico entre essas populações. Observa-se que a tomada exaustiva de dados merísticos e morfométricos de espécimes restritos a apenas um hospedeiro e uma localidade não permite a avaliação acurada da variabilidade morfológica encontrada nesses organismos e esta prática é responsável por grande parte dos equívocos taxonômicos em Rhinebothroides. Este estudo sugere que o exame de espécimes provenientes de diferentes populações é essencial para a avaliação desta variabilidade e que o uso de dados morfológicos em conjunção com dados moleculares pode levar a identificação de caracteres morfológicos mais consistentes para a taxonomia de Rhinebothroides. De maneira geral, estudos que contemplam grande representatividade biogeográfica e de hospedeiros e utilizam dados moleculares de diferentes origens aliados a dados morfológicos, podem revelar não só a existência de espécies crípticas como também nos permitir compreender melhor a variação 
intraespecífica de caracteres utilizados na taxonomia destes grupos. O corolário desta prática é a sinonímia de espécies nominais propostas na ausência da compreensão dos padrões de variação do grupo.

\section{Especificidade parasitária}

O espectro de espécies de hospedeiros utilizado por um parasita em cada um dos estágios de seu ciclo de vida é uma de suas características evolutivas mais fundamentais (Poulin, 2007). Diante da diversidade de linhagens de Metazoa com hábitos parasitários, espera-se que cada uma delas exiba graus de especificidade distintos. Parasitas podem ser específicos a uma espécie de hospedeiro (alto grau de especificidade), a um estágio do ciclo de vida do hospedeiro (e.g., nematodas do gênero Gyrinicola, parasitam apenas girinos, mas pode infectar até 5 famílias diferentes de anuros; Adamson, 1981; Adamson \& Caira, 1994), a uma região específica do trato digestivo (e.g., membros de Oxyurida, Adamson \& Caira, 1994) ou a um certo número de hospedeiros proximamente relacionados filogeneticamente (Poulin, 2007).

A especificidade parasitária pode ser vista como o resultado da combinação entre eventos históricos e condições ecológicas atuais (Adamson \& Caira, 1994; Jex et al., 2006; Randhawa et al., 2007; Poulin, 2007; Poulin \& Keeney, 2007). A ocorrência de uma espécie de parasita em mais de uma espécie de hospedeiro pode indicar a permanência de uma linhagem de parasita após eventos de especiação no hospedeiro que resultam da continuidade de fluxo gênico entre as populações de parasitas nos diferentes hospedeiros (Brant \& Orti, 2003). Este padrão de infecção (ou distribuição) também pode ser o resultado da colonização de novos hospedeiros (Poulin, 2007). Entretanto, a ocorrência de uma espécie de parasita em apenas uma espécie de hospedeiro sugere eventos de codivergência (Page \& Charleston, 1998), onde a diversificação da linhagem parasita acompanha o processo de especiação do hospedeiro. Além disso, a especiação do parasita também pode ser simpátrica, ou seja, dentro de uma mesma espécie de hospedeiro, resultando na diversificação da linhagem parasita independente da diversificação da linhagem hospedeira. Observa-se que a 
detecção desses eventos de associação histórica é possível somente diante da disponibilidade de hipóteses filogenéticas para ambas as linhagens (parasitas e hospedeiros) de forma a tornar possível a avaliação da congruência entre essas hipóteses. Para identificar os processos responsáveis pela associação entre parasitas e hospedeiros, é essencial que as entidades taxonômicas participantes sejam bem conhecidas para que estudos comparativos dentro de um contexto histórico (i.e. considerando filogenias) estejam livres de artefatos taxonômicos que possam obscurecer os padrões e processos responsáveis pela diversificação do sistema. Ao mesmo tempo, fatores ligados tanto à ecologia do hospedeiro quanto à do parasita podem ter um papel importante na manutenção da especificidade. Quando hospedeiros simpátricos são ecologicamente bastante similares, o número de hospedeiros utilizados por uma mesma linhagem parasita pode ser bastante alto (Adamson \& Caira, 1994), o que resulta em baixos níveis de especificidade.

Muitos estudos em tetrafilídeos parasitas de elasmobrânquios, especialmente marinhos, têm revelado que esses organismos exibem alto grau de especificidade parasitária (Caira \& Jensen, 2001; Healy, 2006; Fyler, 2009). Consequentemente, a maioria de suas espécies possui padrão de especificidade oioxênica (sensu Euzet \& Combes, 1980), ou seja, a espécie é encontrada em apenas uma espécie de elasmobrânquio. Healy (2006), por exemplo, que considerou os padrões de especificidade em várias espécies de filobothriídeos de diversas partes do mundo, acredita que a maioria das espécies de Phyllobothriidae marinhos exibe especificidade oioxênica. No entanto, a autora lista poucas exceções de espécies que parasitam duas espécies de elasmobrânquio (e.g., Scalithrium magniphallum, Rhinebothrium ditesticulum, $R$. urobatidium, $R$. chilensis e $R$. flexile). O estudo de Caira \& Jensen (2001), centrado na relação entre onchobothriídeos e seus hospedeiros, sugere que os altos níveis de especificidade observados para membros deste grupo não é resultado de eventos de co-divergência. A incongruência entre as hipóteses filogenéticas de hospedeiros e parasitas, embora tenhamos hipóteses preliminares sobre as relações de parentesco para membros de Elasmobranchii e Onchobothriidae (Caira \& Jensen, 2001), demonstra que outros eventos de 
associação histórica são responsáveis pela especificidade oioxênica observada para esses parasitas. Campbell \& Beveridge (2002) reporta que das 33 espécies do gênero Acanthobothrium que parasitam elasmobrânquios da costa australiana, 26 foram registradas para apenas uma espécie de hospedeiro, porém duas delas (i.e., A. robertsoni e A. adlardi) foram encontradas em oito espécies de elasmobrânquios. Essas observações sugerem que, de maneira geral, representantes marinhos de Tetraphyllidea exibem alto grau de especificidade, embora essa regra não se aplique a todas as espécies. Acanthobothrium, em especial, é o gênero mais diverso dentro de Onchobothriidae, ocorrendo em todas as ordens de elasmobrânquios amostrados para o grupo até o momento (Caira \& Jensen, 2001). Não é surpresa que as diferentes linhagens dentro de um gênero tão diversificado apresentem diferentes graus de especificidade.

Diferentemente dos padrões comuns encontrados em tetrafilídeos parasitas de elasmobrânquios marinhos, os tetrafilídeos que parasitam as arraias de água doce da América do Sul aparentam ser generalistas. Para os membros do gênero Potamotrygonocestus, por exemplo, são reconhecidas apenas 7 espécies parasitando 14 espécies de hospedeiros (Marques et al. 2003; Luchetti et al., 2008). Reyda \& Marques (em prep.) reconheceram quatro espécies de Rhinebothrium para 16 espécies de potamotrigonídeos. O mesmo padrão foi encontrado por Cardoso Jr. (em preparação) que reconhece 5 espécies de Acanthobothrium parasitando 25 espécies de arraias de água doce. Assumindo que estes autores documentaram de forma adequada a diversidade dos respectivos grupos em potamotrigonídeos, tudo indica que os padrões de especificidade em tetrafilídeos restritos aos sistemas fluviais Neotropicais diferem do que tem sido documentado para o ambiente marinho.

Por outro lado, essa discrepância poderia representar artefatos taxonômicos resultantes de erros amostrais. Atualmente, são reconhecidas 900 espécies de tetrafilídeos (Caira, 2010) para aproximadamente 300 espécies de elasmobrânquios, embora apenas 1/3 da diversidade deste grupo de hospedeiros tenha sido examinada até o momento (Nelson, 2006, Caira, com. pess.). A 
representatividade amostral de potamotrigonídeos utilizada nos estudos citados acima, no entanto, abrange pelo menos 2/3 da diversidade do grupo (Marques \& Domingues, 2006; de Carvalho et al., 2003, Deynat, 2006). Portanto, não se pode descartar a possibilidade de que os padrões observados para o sistema marinho não diferem daquele encontrado no sistema fluvial Neotropical, mas que são resultado do relativo baixo esforço amostral que caracteriza os estudos no sistema marinho.

Membros de Rhinebothroides exibem o mesmo padrão observado para outros tetrafilídeos encontrados em potamotrigonídeos. Os resultados obtidos neste estudo sugerem que membros deste gênero exibem especificidade estenoxênica (especificidade ao nível de gênero do hospedeiro, sensu Euzet \& Combes, 1980). Com exceção de $R$. scorzai, que parasita quatro espécies de hospedeiros, incluindo Paratrygon aiereba, todas as outras espécies do gênero parecem infestar apenas membros do gênero Potamotrygon. Rhinebothroides moralarai é registrado para dois hospedeiros, $R$. glandularis e $R$. venezuelensis já foram coletados em seis e sete hospedeiros, respectivamente, e $R$. freitasi possui o maior número de registros, 20 hospedeiros. O número elevado de espécies de hospedeiro para $R$. freitasi é uma das razões pelas quais se acreditava que essa espécie se tratava de um complexo. À medida que novas espécies de hospedeiros são amostradas, a expectativa seria que novas espécies de parasitas também seriam encontradas, o que não ocorreu para membros de Rhinebothroides até o momento. O padrão observado indica que os potamotrigonídeos provavelmente apresentam hábitos ecológicos bastante similares, permitindo às espécies de tetrafilídeos a colonização de novos hospedeiros com frequência. Adicionalmente, a diversificação de linhagens dentro de Potamotrygonidae parece não ter sido acompanhada pela diversificação das linhagens parasitas, resultando no padrão de distribuição encontrado para membros de Rhinebothroides.

As três espécies de Rhinebothroides para as quais há um número elevado de hospedeiros R. glandularis, R. venezuelensis e $R$. freitasi - apresentam também distribuição biogeográfica ampla, incluindo rios das Bacias Amazônica e do Prata (Marques \& Brooks, 2003; esse estudo). 
Aparentemente, essa ampla distribuição só é possível pelo fato destas espécies terem sido capazes de colonizar um número maior de espécies de hospedeiro. A distribuição biogeográfica e de hospedeiros de $R$. venezuelensis é um caso ilustrativo. Esta espécie é encontrada somente nas válvulas espirais de Potamotrygon motoro na Bacia do Prata. No entanto, sua distribuição na Bacia Amazônica não abrange somente esta espécie. Rhinebothroides venezuelensis também é amostrada em espécies de potamotrigonídeos com distribuição restrita a essa bacia como $P$. orbignyi, além de quatro espécies não descritas de Potamotrygon. Das espécies em fase de descrição, duas ocorrem no Rio Tarauacá, uma no Rio Tapajós e outra no Alto Solimões, esta última vivendo em simpatria com P. motoro. A capacidade de colonização de múltiplos hospedeiros resulta, portanto, na expansão da distribuição biogeográfica desta linhagem parasita.

A recuperação de padrões de especificidade parasitária dependem do conhecimento taxonômico tanto pra os parasitas como para seus respectivos hospedeiros e o entendimento dos processos que geram esses padrões dependem do conhecimento filogenético de ambas entidades. Nosso conhecimento destes dois componentes (i.e., conhecimento taxonômico e filogenético) é incipiente. No entanto, assumindo que os padrões de especificidade de tetrafilídeos marinhos não estão relacionados com nenhum artefato taxonômico, e que de fato difere do que observamos em potamotrigonídeos, estes podem estar relacionados tanto com a história como com a diversidade de habitats ocupados pelos diferentes hospedeiros. A diversidade de linhagens de elasmobrânquios encontrada no sistema marinho é sem dúvida muito maior do que aquela observada para o sistema fluvial na América do Sul (Lovejoy, 1996; de Carvalho et al., 2004; Nelson, 2006). Consequentemente, a diversidade de habitats ocupados por essas linhagens também é superior àquela utilizada por potamotrigonídeos. Uma vez que elasmobrânquios de água doce ocupam um espectro menor de habitats, as oportunidades de colonização de novos hospedeiros pelas linhagens parasitas podem se tornar mais frequentes (Adamson \& Caira, 1994, Poulin, 2007). Fatores históricos também poderiam ser responsáveis pelos padrões diferenciados observados nesses dois 
sistemas. Quando comparada às linhagens marinhas, a diversificação das linhagens de potamotrigonídeos é recente (Lovejoy et al., 1998) em comparação com as linhagens marinhas (Heinecke et al., 2009), o que em parte poderia responder pelos baixos níveis de especificidade observados para os parasitas desse sistema; assumindo que quanto mais longo for o tempo de associação entre parasitas e hospedeiros, maior será a especificidade. No entanto, alguns estudos tem questionado essa premissa, cujos resultados indicam inexisitir tendência ao generalismo ou a altos graus de especificidade em relação ao tempo de associação (Poulin et al., 2006). Associações históricas podem resultar em diferentes graus de especificidade mesmo em parasitas proximamente relacionados filogeneticamente (Poulin et al., 2006). Sendo assim, fatores ecológicos devem influenciar a diversificação e os padrões de especificidade em parasitas de elasmobrânquios.

Existe ainda a possibilidade de que os padrões de especificidade encontrados para esses dois sistemas sejam na verdade similares, e que as divergências observadas atualmente sejam reflexo do esforço amostral disponível para cada um deles. A representatividade amostral deste estudo inclui uma família bastante diversificada de elasmobrânquios, cujas espécies estão amplamente distribuídas no continente e frequentemente encontram-se vivendo em simpatria. Estudos abordando a fauna parasitária de hospedeiros marinhos são caracterizados por coletas dispersas pelo planeta, sem a centralização de esforços na amostragem em um grupo particular de hospedeiro e/ou a preocupação de obter um número representativo de determinada espécie (parasita e/ou hospedeiro). Esta estratégia oportunista, pulveriza as amostras de parasitas em inúmeros táxons que representam, de forma geral, a diversidade de elasmobrânquios que se conhece até o momento, sem que estas amostras possam fornecer dados sobre a variabilidade das espécies de parasitas e pode determinar os padrões de especificidade reconhecidos para este sistema. Para testar essa possibilidade, é necessário amostrar um grupo de elasmobrânquios marinhos com algumas características similares ao que encontramos em potamotrigonídeos, isto é, um grupo monofilético, com razoável diversidade que apresente algumas linhagens vivendo em simpatria. 


\section{Relações filogenéticas de $\underline{\text { Rhinebothroides e grupos relacionados }}$}

As relações filogenéticas da ordem Tetraphyllidea têm recebido nos últimos anos considerável atenção por parte dos parasitologistas que, por um lado, buscam compreender os processos históricos responsáveis pelas associações com seus hospedeiros e os níveis de especificidade exibidos por membros deste grupo (Caira et al., 2001; Caira \& Jensen, 2001) e/ou, por outro, procuram propor esquemas taxonômicos mais adequados diante do acúmulo de evidências que apontam para a para/polifilía da própria ordem, bem como seus grupos internos (Olson et al., 1999; Caira et al., 2001; Caira \& Jensen, 2001; Healy et al., 2009). Com estes objetivos, diversas hipóteses filogenéticas foram geradas para o grupo nas últimas décadas, baseadas em dados morfológicos (Caira et al., 2001) e moleculares (Olson et al., 1999; Healy et al., 2009). Comuns a todas essas hipóteses são a para/polifilía da ordem e o reconhecimento de que a classificação dos níveis ordinais e subordinais dentro de Cestoda (Khalil et al., 1994) requer revisão. Dentro deste contexto, a divisão de Tetraphyllidea em oito famílias proposta por Euzet (1994) tem sido frequentemente contestada (mesmo que implicitamente), devido a constante resolução polifilética de Onchobothriidae e Phyllobothriidae, duas famílias mais diversas da ordem. Na expectativa de acomodar os resultados destas investigações e propor esquemas taxonômicos cada vez mais congruentes com relações de parentesco, Healy et al. (2009) propuseram a elevação da subfamília Rhinebothriinae, cujos membros consistentemente resultam em um grupo monofilético, ao nível de ordem. Segundo estes autores, nesta nova ordem devem ser inseridas espécies que apresentem botrídios pedunculados em seu escólex, representados pelos gêneros Anthocephalum, Echeneibothrium, Rhabdotobothrium, Rhinebothrium, Rhinebothroides, Scalithrium, Spongiobothrium, Rhodobothium, além de 4 gêneros e um rhinebothriídeo não descritos.

Embora haja suporte molecular e sinapomorfias morfológicas putativas para Rhinebothriidea, a circunscrição e/ou status monofilético de seus gêneros ainda aguarda 
refinamento. Dentro deste contexto, o gênero Rhinebothrium talvez seja a entidade taxonômica que mereça maior atenção devido à evidente polifilía do gênero e a associação de várias de suas espécies com outros gêneros atribuídos à Rhinebothriidea, incluindo Rhinebothroides.

Associação filogenética entre membros de Rhinebothrium e Rhinebothroides tornou-se evidente desde os estudos de Reyda (2007), focados na taxonomia e relações filogenéticas entre membros de Rhinebothrium parasitas de potamotrigonídeos. Posteriormente, Healy et al. (2009) apresentaram hipóteses filogenéticas para membros de Phyllobothriidae, incluindo representantes de Rhinebothroides e Rhinebothrium marinhos e dulcícolas. Embora ambos os estudos indiquem a polifilía de Rhinebothrium, a baixa representatividade taxonômica em suas filogenias impediu decisões taxonômicas que resultassem na fragmentação do conceito atual de Rhinebothrium em dois ou mais gêneros. Isso se deve ao fato de que estudos recentes têm procurado obter melhor resolução filogenética para a ordem Tetraphyllidea (Healy et al., 2009. Olson et al., 1999; Caira \& Jensen, 2001) e grupos relacionados (Caira et al., 2001), na expectativa de refinar sua taxonomia com base em grupos naturais (i.e. monofiléticos). Entretanto, estudos que focam em níveis taxonômicos menos inclusivos (i.e. gêneros) ainda são escassos, exceto pelos estudos de Reyda (2007) para Rhinebothrium e Brooks e colaboradores (Brooks et al., 1981a; Brooks \& Amato, 1992; Zamparo et al., 1999) os quais propuseram hipóteses para as relações de parentesco entre membros de Rhinebothroides.

A monofilía do gênero Rhinebothroides não foi demonstrada até o momento, embora a presença de lobos ovarianos assimétricos seja considerada uma sinapomorfia putativa para o grupo (Mayes et al., 1981; Marques \& Brooks, 2003). Neste estudo, a monofilía de Rhinebothroides foi recuperada em $27,7 \%$ do espaço de parâmetros analisado, sugerindo que este clado é bastante dependente de parâmetros arbitrários de alinhamento. A parafilía de Rhinebothroides é resultado da inserção do clado I (Fig. 4) junto às suas linhagens, um clado representado por espécies de Rhinebothrium parasitas de potamotrigonídeos. 
Este é o primeiro estudo que utiliza dados moleculares para abordar as relações filogenéticas entre as linhagens do gênero Rhinebothroides. Atualmente existem 3 hipóteses filogenéticas para os membros deste gênero (Figuras 15A-C). A primeira delas foi proposta por Brooks et al. (1981a) baseada em 7 caracteres morfológicos e postulava a existência de dois clados irmãos dentro do gênero (Fig. 15A). Em um deles, $R$. circularisi era basal a (R. moralarai $+R$. venezuelensis) e no outro R. scorzai era basal a ( $R$. freitasi $+R$. glandularis). Posteriormente, Brooks \& Amato (1992) reavaliaram as relações de parentesco de Rhinebothroides considerando 9 caracteres morfológicos e a inserção da nova espécie descrita na publicação, $R$. mclennanae. A topologia apresentada pelos autores não difere, em essência, daquela proposta por Brooks et al. (1981a), exceto pela posição da espécie recém descrita como espécie irmã de $R$. glandularis (Fig. 15B); uma vez que ambas compartilham a presença de células glandulares próximas a região do poro genital (Figs. 7B e 15). Finalmente, Zamparo et al. (1999), a partir da descrição da suposta espécie-irmã de Rhinebothroides (Pararhinebothroides hobergi, parasita de Urobatis tumbesensis), re-avaliaram a polarização dos caracteres utilizados por Brooks \& Amato (1992) e apresentaram uma topologia que pouco difere daquela obtida anteriormente (Brooks \& Amato, 1992), exceto pela posição de $R$. scorzai, que resultou basal ao clado ( $R$. circularisi( $R$. moralarai+ $R$. venezuelensis)) (Fig. 15C).
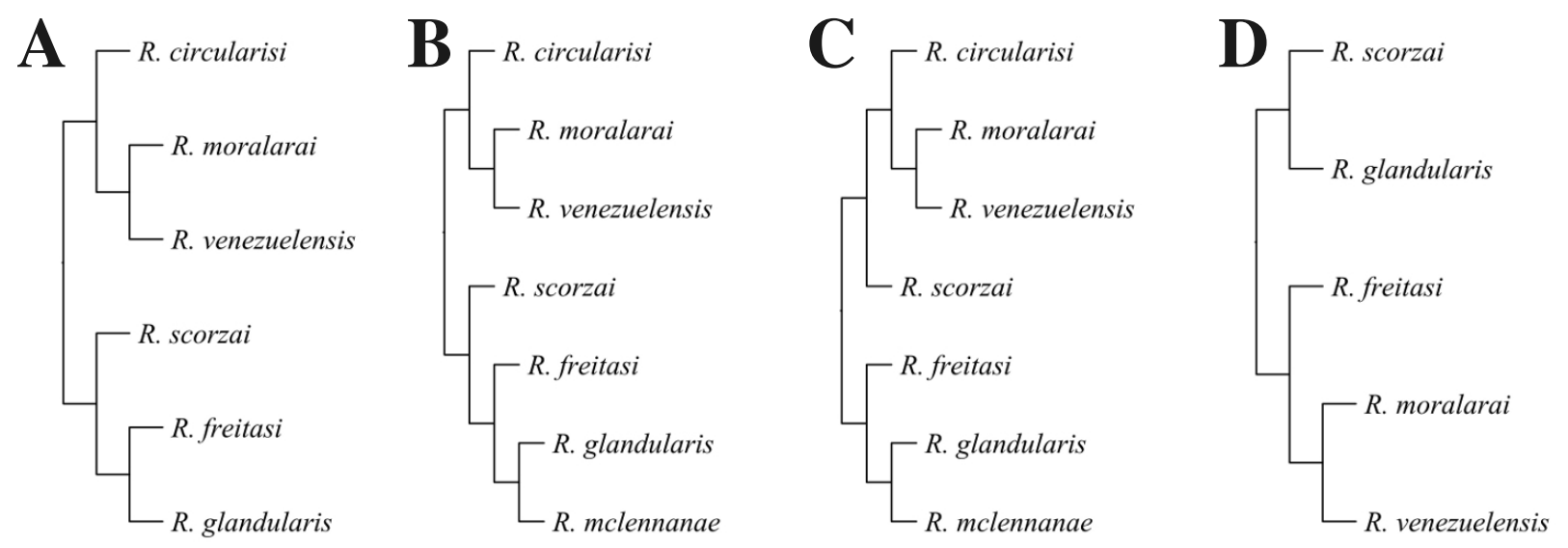

Figura 15. Hipóteses filogenéticas disponíveis para Rhinebothroides. A. Hipótese proposta por Brooks et al. (1981a). B. Hipótese apresentada por Brooks \& Amato (1992). C. Relações filogenéticas definidas por Zamparo et al. (1999). D. Hipótese filogenética baseada em dados moleculares realizada neste estudo. 
O resultado obtido neste estudo não corrobora as hipóteses propostas anteriormente. Apenas o clado composto por $R$. moralarai e $R$. venezuelensis foi recuperado nas topologias propostas anteriormente (Fig. 15A-D). Essas discrepâncias, como veremos abaixo, muito provavelmente estão relacionadas com os caracteres morfológicos utilizados por estes autores. Tais caracteres foram codificados na ausência de informações que permitissem avaliar a variabilidade interespecífica de cada terminal gerando estados de caráter que não podem ser justificados com base no que se sabe atualmente sobre a morfologia das espécies válidas atribuídas ao gênero.

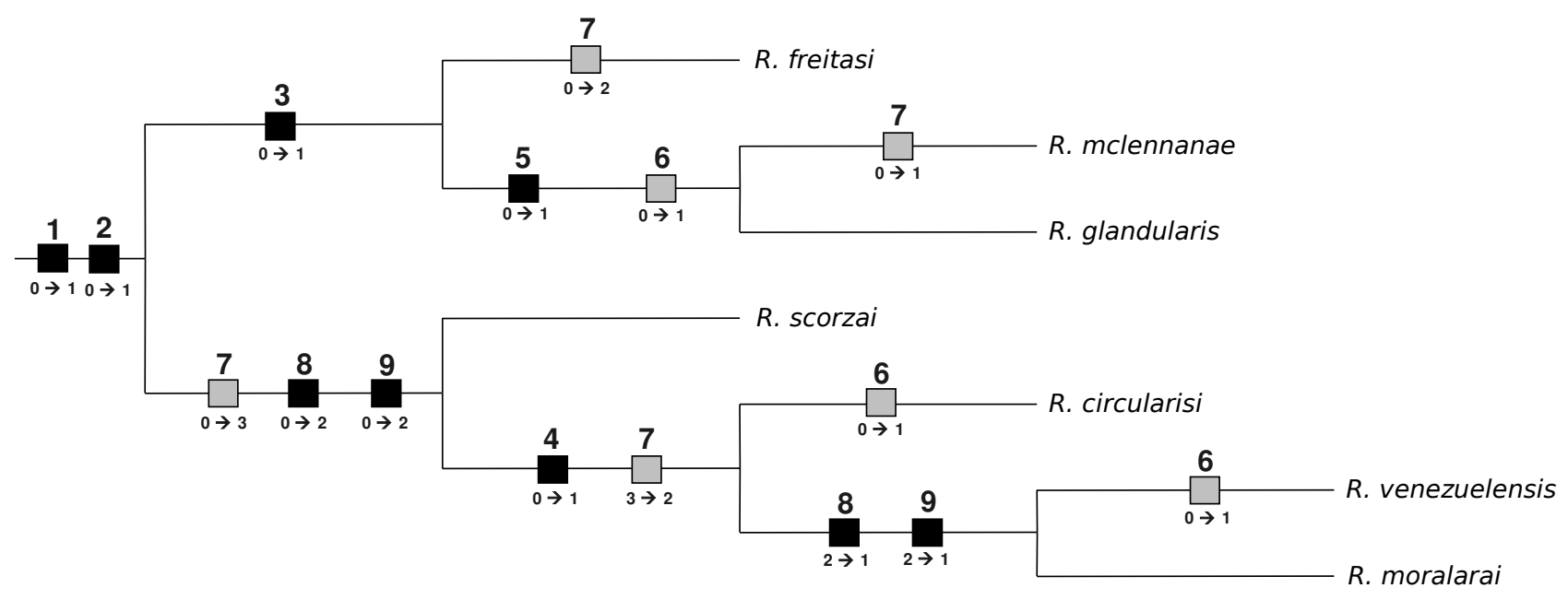

Figura 16. Otimização dos caracteres propostos por Zamparo et al. (1999). 1 - vaso deferente: 0, vaso deferente não expandido; 1 , vaso deferente expandido formando a vesícula seminal externa. 2 - lobos ovarianos: 0 , lobos ovarianos simétricos; 1 , lobos ovarianos assimétricos. 3 - distribuição da vitelária: 0 , vitelária interrompida ao nível do poro genital; 1, vitelária não interrompida ao nível do poro genital. 4 - lobo poral do ovário: 0 , lobo poral se estende além da margem posterior do saco do cirro; 1 , lobo poral se estende até a margem posterior do saco do cirro. 5 - células glandulares próximas ao poro genital: 0 , ausentes; 1 , presentes. 6 - condição do estróbilo: 0 , acraspedoto; 1 , craspedoto. 7 - número de testículos por proglótide: 0 , média de 39-45; 1 , média de 31; 2, média de 53-55; 3, média de 77-80. 8 número de lóculos por botrídio: 0, 69-79; 1, 49-59; 2, 41-45. 9 - comprimento máximo do saco do cirro: 0, 300 - 400 $\mu \mathrm{m} ; 1$, menor que $200 \mu \mathrm{m} ; 2$, maior que $500 \mu \mathrm{m}$.

A otimização da matriz de dados morfológicos na topologia proposta por Zamparo et al. $(1999)^{1}$ pode ser utilizada para discutir alguns dos caracteres escolhidos por esses autores, bem

1 Esta hipótese é aqui adotada como referência uma vez que ela representa a última versão da matriz de dados de Brooks et al. (1981a). A otimização de caracteres apresentados por Zamparo et al. (1999:538, Figura 5) está errada, o que foi verificado após a otimização da matriz usando os parâmetros de default de TNT (versão 1.1, Goloboff et al., 2000). Desta forma, a discussão apresentada aqui é baseada nesta reanálise dos dados cuja distribuição de caracteres na topologia é apresentada na Figura 16. 
como revelar alguns possíveis motivos das discrepâncias topológicas entre dados morfológicos e moleculares (Figs. 15A-D e 16). Como foi discutido acima, o único componente comum entre estas hipóteses é a estreita relação de parentesco entre $R$. venezuelensis e $R$. moralarai. De acordo com a otimização de caracteres morfológicos, estas duas espécies compartilham a presença de 49-59 lóculos por botrídio (caráter $8_{[1]}$ de Zamparo et al., 1999) e comprimento máximo do saco do cirro menor que $200 \mu \mathrm{m}$ de comprimento (caráter $9_{[1]}$ ). A codificação destes caracteres se torna inadequada quando se observa os resultados obtidos por estudos morfológicos baseados em amostras biológicas mais abrangentes biogeograficamente. A análise morfológica realizada por Marques \& Brooks (2003) e por este estudo revela que representantes de $R$. moralarai e $R$. venezuelensis apresentam comprimento máximo do saco do cirro de $550 \mu \mathrm{m}$ (Marques \& Brooks, 2003:1016) e 277 mm (Tabela 9) respectivamente. O número de lóculos por botrídio encontrado para essas duas espécies nominais por Marques \& Brooks (2003:1016) e este estudo (Tabela 9) também difere daquela reportada por Zamparo et al. (1999), sendo 49-63 para $R$. moralarai e 62-86 para $R$. venezuelensis. Vale ressaltar que os valores obtidos para esses caracteres por Marques \& Brooks (2003:1010) e este estudo (Tabelas 9 e 10) se sobrepõem para todas as espécies nominais do gênero.

De certa forma, as topologias morfológicas concordam com os dados moleculares no que diz respeito os complexo Rhinebothroides glandulares. Neste estudo, foi assumido que $R$. glandularis é sinônimo júnior de $R$. mclennanae. Esta última espécie nominal, resulta como grupo-irmão de $R$. glandularis na topologia apresentada por Zamparo et al. (1999) por compartilharem a presença de células glandulares na região do poro genital (caráter $5_{[1]}$ ) - que são conspicuamente coradas durante o processo de preparação de lâminas histológicas - e estróbilo craspedoto (caráter $6_{[1]}$ ). No entanto, enquanto a presença destas células glandulares é incontestável e evidentemente exclusiva para estas espécies nominais, a condição de estrobilização é questionável. Marques \& Brooks (2003) argumentaram que a interpretação da condição do estróbilo é difícil nestes organismos e depende do grau de relaxamento dos espécimes decorrente da fixação do material biológico. A 
análise morfológica realizada neste trabalho revelou que todas as espécies de Rhinebothroides apresentam condição acraspedota, com exceção de $R$. scorzai. Esse caráter, portanto, é uma autapomorfia para essa espécie. Adicionalmente, segundo Zamparo et al. (1999), R. mclennanae possui como autapomorfia a presença de 31 testículos em média (caráter $7_{[1]}$ ). Sem entrar no mérito da codificação proposta para números de testículos propostas para esses autores ${ }^{2}$, Marques \& Brooks (2003:1003, Fig. 7) já demonstraram que para todas as populações de $R$. glandularis há sobreposição de valores para esse caráter. Desta forma, os dados de Zamparo et al. (1999) não justificam a manutenção de $R$. mclennanae como uma espécie válida de Rhinebothroides. O único caráter pertinente a estas espécies nominais que não apresenta problemas de codificação é a presença de células glandulares na região do poro genital, considerada aqui uma autapomorfia para R. glandularis.

Ao contrário das espécies nominais do complexo $R$. glandularis, as hipótese filogenéticas baseadas em dados morfológicos consistentemente sugerem uma certa distância filogenética entre $R$. freitasi e $R$. circularisi, sendo que a primeira foi considerada no presente estudo como sinonímia sênior da segunda. De acordo com dados morfológicos, $R$. freitasi sempre resultou basal ao clado ( $R$. mclennanae $R$. glandularis) ao passo que $R$. circularisi sempre resultou basal ao clado ( $R$. venezuelensis $+R$. moralarai) (Fig. 16). Segundo os dados morfológicos de Zamparo et al. (1999), o clado ( $R$. circularisi ( $R$. venezuelensis $+R$. moralarai)) é sustentado pelo fato de que nestas espécies o lobo poral ovariano não se estende além da margem posterior do saco do cirro (caráter $4_{[1]}$ ) e a presença de 53-55 testículos por proglótide em média (caráter $7_{[2]}$ ). Como foi discutido anteriormente, a codificação do caráter 7 é problemática. Quando avaliamos a forma pela qual o caráter pertinente à posição relativa do lobo poral ovariano foi codificada, encontramos problemas da mesma natureza. Marques \& Brooks (2003) justificaram a sinonímia de $R$. circularisi e $R$. freitasi com base na observação de variação intraespecífica para esse caráter em $R$. freitasi

2 Zamparo et al. (1999) sugerem os seguintes estados para o caráter 7: 0 = média de 39-45 testículos por proglótide; 1 = média de 31 testículos por proglótide; 2 = média de 53-55 testículos por proglótide; 3 = média de 77-80 testículos por proglótide. 
(Marques \& Brooks, 2003:998, Fig. 3) ao passo que este estudo revela variação intraespecífica para o comprimento do lobo poral ovariano para $R$. venezuelensis e $R$. freitasi (Figs. 10 e 12). Temos, portanto que a consistência deste caráter é observada apenas em representantes de $R$. moralarai.

Em outra parte da topologia baseada em dados morfológicos (Fig. 16), o clado (R. freitasi (R. mclennanae $+R$. glandularis)) é sustentado pela ausência de interrupção da vitelária perto do poro genital (caráter $3_{[2]}$ ). No entanto, Zamparo et al. (1999) aparentemente codificaram erroneamente este caráter. As observações realizadas por Marques \& Brooks (2003) revelaram que apenas $R$. scorzai exibe esse caráter e, embora a morfologia de $R$. scorzai não tenha sido estudada em detalhes no presente estudo, o exame preliminar de novos espécimes e da série tipo de todas as espécies nominais de Rhinebothroides corroboram as observações de Marques \& Brooks (2003). Conclui-se que o posicionamento de $R$. freitasi e $R$. circularisi resultam de caracteres morfológicos inadequadamente definidos e/ou codificados.

A espécie nominal $R$. circularisi distancia-se ainda mais de $R$. freitasi pela posição basal de $R$. scorzai relativa ao clado ( $R$. circularisi ( $R$. venezuelensis $+R$. moralarai)) (Fig. 16) nas filogenia baseadas em dados morfológicos. Esta parte da topologia é sustentada pela presença de 77-80 testículos por proglótide (caráter $7_{[3]}$ ), 41-45 lóculos por botrídio (caráter $8_{[2]}$ ) e saco do cirro maior que $500 \mu \mathrm{m}$ (caráter $9_{[2]}$ ). Nenhum destes caracteres possui codificação justificada pelas variações encontradas para estes atributos morfológicos dentro de Rhinebothroides (Marques \& Brooks, 2003). Desta forma, tanto a posição de R. scorzai, bem como a distância filogenética entre R. circularisi e $R$. freitasi não possui suporte morfológico confiável.

Os trabalhos realizados por esses autores deram início aos estudos de tetrafilídeos parasitas de potamotrigonídeos. São trabalhos exploratórios que se propuseram a documentar a diversidade parasitária desse sistema. Consequentemente, a codificação dos caracteres utilizados na taxonomia de Rhinebothroides foi baseada em um número limitado de indivíduos e populações. Adicionalmente, as relações filogenéticas do gênero com os demais grupos dentro de Tetraphyllidea 
eram ainda completamente desconhecidas.

Trabalhos recentes mostram que Rhinebothroides está proximamente relacionado a membros de Rhinebothrium (Healy et al., 2009, Reyda, 2007), principalmente das linhagens de água doce. A topologia apresentada na Figura 4 recupera esta associação (clado I, Fig. 4). Healy et al. (2009) incluíram alguns espécimes de ambientes dulcícolas de várias partes do mundo, sendo dois deles parasitas de potamotrigonídeos: um espécime de Rhinebothroides e um espécime de Rhinebothrium, ambos coletados no Rio Madre de Dios, Peru (referidos como Rhinebothroides cf. freitasi e Rhinebothrium sp.8 em Healy et al., 2009). Como resultado, os espécimes da América do Sul formaram um clado, no qual o espécime de Rhinebothrium dulcícola se mostrou mais proximamente relacionado ao espécime de Rhinebothroides do que aos seus congêneres marinhos (Healy, 2006; Healy; et al., 2009; Reyda, 2007). Este é somente um dentre inúmeros clados que apontam para a polifilía de Rhinebothrium. A associação entre linhagens de Rhinebothrium (clado I, Fig. 4) e Rhinebothroides parasitas de potamotrigonídeos foi obtida em 100\% do espaço de topologias analisado neste estudo, sugerindo que este clado independe de parâmetros arbitrários de alinhamento. A polifilía de Rhinebothrium, como encontrada nesse estudo (Fig. 4), bem como o que observou Healy et al. (2009), deixa claro que algumas linhagens de filobothriídeos atualmente atribuídas a Rhinebothrium deveriam ser alocadas em outros gêneros. Nesse contexto, as associações entre os clados de Rhinebothroides e Rhinebothrium (clado I) de água-doce sugerem que seus representantes poderiam ser alocados em um único gênero, independente das diferenças morfológicas observadas. No entanto, membros de Rhinebothroides são diagnosticados morfologicamente pela presença de lobos ovarianos assimétricos, uma característica que não está presente em nenhum membro de Rhinebothrium. Consequentemente, a expansão do conceito atual de Rhinebothroides para acomodar algumas linhagens de Rhinebothrium resultaria na perda do único caráter que serve como diagnose morfológica para Rhinebothroides. Decisões taxonômicas supra-específicas estão além do escopo deste trabalho e aparentam ser prematuras neste momento 
em decorrência da representatividade taxonômica de linhagens marinhas neste estudo filogenético.

Independente da cautela taxonômica adotada neste estudo, os resultados apresentados têm impacto imediato nos protocolos de inferência biogeográficas de Brooks et al. (1981b, e autores subsequentes) que utilizaram dados parasitológicos para propor hipóteses de colonização do sistema fluvial Neotropical e relações de parentesco entre potamotrigonídeos e linhagens de elasmobrânquios marinhos. Brooks et al. (1981b) consideraram as linhagens dulcícolas de Rhinebothrium e Rhinebothroides, e consequentemente suas relações de parentesco com tetrafilídeos marinhos, como linhagens distintas e não relacionadas entre si. Para cada um destes gêneros foi derivado um cladograma de área independente. Os resultados deste estudo sugerem que os membros de água doce de Rhinebothrium e Rhinebothroides formam um único clado e portando uma única peça de evidência biogeográfica.

O uso de dados parasitológicos para inferir a biogeografia histórica de potamotrigonídeos tem sofrido críticas nos últimos anos. O trabalho pioneiro de Brooks et al. (1981b) foi severamente criticado (Caira 1990, 1994), especialmente com respeito a clareza da metodologia aplicada e suas respectivas inferências biogeográficas (Lovejoy, 1997, Lovejoy et al.,1998; Marques, 2000). Os padrões de colonização propostos por Brooks et al. (1981b) não são corroborados pela hipótese filogenética proposta por Lovejoy (1996). Lovejoy (1997) observa que a metodologia empregada pelos autores na reconstrução do cladograma de áreas não foi especificada na publicação, gerando dúvidas com relação às inferências decorrentes desta hipótese. Brooks et al. (1981b) postula a monofilía de Potamotrygonidae baseando-se na recuperação da monofilía dos diversos grupos de helmintos por eles utilizados. Lovejoy (1997) ressalta que a monofilía do grupo não deveria se basear somente na monofilía de seus parasitas e sua distribuição biogeográfica. O padrão filogenético encontrado por Brooks et al. (1981b) poderia ser o resultado de múltiplos cenários coevolutivos possíveis que assumem diferentes eventos de associação histórica, como por exemplo a colonização de novos hospedeiros (i.e. host-switching) e extinção (Lovejoy, 1997). 
A taxonomia da maior parte dos grupos de helmintos utilizados por Brooks et al. (1981b) ainda está sendo refinada em decorrência de novos estudos que contemplam o exame de novos esforços de coleta e documentação da fauna de tetrafilídeos parasitas de potamotrigonídeos (e.g., Cardoso Jr., em preparação, para Acanthobothrium; Marques et al., 2003, Luchetti et al., 2008 e Luchetti, em preparação para Potamotrygonocestus; Reyda, 2007, para Rhinebothrium de potamotrigonídeos) e elasmobrânquios marinhos (Fyler, 2009, para Acanthobothrium; Healy, 2006, Healy et al., 2009, para Rhinebothrium e Rhinebothriinae). Desta forma, é desejável que tenhamos uma melhor compreensão da diversidade destes grupos antes que possamos contemplá-los em análises biogeográficas.

Este é primeiro trabalho que contemplou o uso de dados moleculares e morfológicos na sistemática de Rhinebothroides. A análise morfológica realizada neste trabalho revela que a variabilidade intraespecífica encontrada nos diferentes caracteres é muito maior do que se acreditava. Os resultados aqui apresentados questionam as práticas taxonômicas tradicionais que se valem do uso de caracteres morfológicos que se apresentaram contínuos de posse de amostras mais representativas e propõe a circunscrição de espécies com base em grupos monofiléticos que apresentem coesão morfológica definida por características discretas. Como consequência, são reconhecidas apenas cinco das oito espécies nominais já descritas para o gênero. Os resultados indicam que linhagens dulcícolas de Rhinebothrium são filogeneticamente próximas de Rhinebothroides, e que a adequação da taxonomia de Rhinebothrium poderá implicar na re-diagnose de Rhinebothroides no futuro. A compreensão das relações entre essas duas linhagens e dos membros de Phyllobothriidae depende de maior representatividade taxonômica em estudos filogenéticos e somente após a obtenção de hipóteses filogenéticas mais representativas essas mudanças taxonômicas devem ser implementadas. 


\section{Conclusões}

- Pela primeira vez na história taxonômica de Rhinebothroides as espécies são definidas pela circunscrição morfológica e molecular de grupos monofiléticos.

- A conjunção destes dados morfológicos e moleculares permitiu a melhor compreensão dos limites de variação morfológica das linhagens de Rhinebothroides, principalmente no que se refere àqueles caracteres tradicionalmente utilizados na taxonomia do grupo.

- As espécies de Rhinebothroides consideradas válidas (i.e., R. glandularis, $R$. freitasi, $R$. moralarai, R. scorzai e $R$. venezuelensis) neste estudo, foram definidas pela congruência morfológica entre representantes de 5 clados recuperados pela análise filogenética de dois genes nucleares (ITS-1 e 28S) e um gene mitocondrial e o material tipo disponível para 8 espécies nominais do gênero.

- A filogenia de Rhinebothroides apresentada difere das hipóteses anteriores baseadas em dados morfológicos em decorrência de codificação inadequada de caracteres morfológicos que não contemplaram os níveis de variação morfológica encontradas neste grupo.

- A forte associação filogenética entre membros de Rhinebothroides e Rhinebothrium parasitas de potamotrigonídeos sugere que o status taxonômico deste gênero deverá ser revista. Para tanto, é necessário que haja uma hipótese filogenética para Phyllobothriidae que possua maior representatividade taxonômica do que os estudos disponíveis até o momento.

- Membros de Rhinebothroides exibem um padrão de baixa especificidade ao hospedeiro, quando comparado aos padrões de especificidade observados em parasitas de elasmobrânquios marinhos. Esse padrão é congruente com outros grupos de helmintos parasitas de potamotrigonídeos (i.e., Acanthobothrium, Potamotrygonocestus e Rhinebothrium).

- Os diferentes padrões de especificidade observados para parasitas de elasmobrânquios marinhos e potamotrigonídeos podem ser um artefato amostral dos grupos marinhos ou o resultado dos diferentes níveis de diversidade ecológica entre estes dois sistemas. 


\section{Resumo}

Membros do gênero Rhinebothroides são parasitas exclusivos de potamotrigonídeos, elasmobrânquios de água doce endêmicos da região Neotropical. Atualmente, seis espécies são reconhecidas para este gênero dentre as oito espécies nominais disponíveis. A taxonomia de Rhinebothroides é convoluta, pois a maioria de suas espécies são diagnosticadas por caracteres morfométricos e merísticos definidos por estudos que desconsideram a variabilidade intraespecífica destas linhagens. A ampla distribuição de algumas espécies, bem como seus padrões generalistas de especificidade - padrão este discrepante em relação à tetrafilídeos marinhos - sugere a existência de complexos de espécies que requerem melhor refinamento taxonômico. Este estudo visa refinar a taxonomia de um destes complexos - Rhinebothroides freitasi, no qual estão inseridas outras 3 especies nominais ( $R$. campbelli, R. circularisi, $R$. venezuelensis) cujas circunscrições são ambíguas. Neste estudo, partiu-se da premissa de que a conjunção de dados moleculares e morfológicos pode elucidar a taxonomia deste complexo. Com este objetivo, dados moleculares para os genes 28S, ITS-1 e COI foram compilados para 57 haplótipos de Rhinebothroides representando todas as espécies válidas para o gênero e a ampla distribuição biogeográfica no gênero nas bacias hidrográficas brasileiras. A otimização direta das sequências nucleotídicas destes haplótipos concatenadas com outros 26 terminais que incluem linhagens de tetrafilídeos marinhos e de água doce, resultou em cinco clados de Rhinebothroides que possuem morfologia congruente com a série tipo de cinco espécies nominais. Desta forma, este estudo reconhece cinco espécies de

Rhinebothroides como válidas: $R$. glandularis, $R$. freitasi, R. moralarai, $R$. scorzai e $R$. venezuelensis. Dentre as espécies do complexo R. freitasi, os dados morfológicos compilados para 400 indivíduos permitiu delimitar os níveis de variabilidade morfológica de $R$. freitasi e $R$. venezuelensis. A representatividade biogeográfica e de hospedeiros contemplada neste estudo revela que, ao contrário das linhagens de tetrafilídeos marinhos, membros de Rhinebothroides possuem baixa especificidade aos seus hospedeiros. 


\begin{abstract}
Members of Rhinebothroides are parasites of the Neotropical freshwater stingrays of the family Potamotrygonidae. To date, six species are recognized for the genus within which there are eight nominal species available. The taxonomy of Rhinebothroides is confusing, since most of its species are currently diagnosed by morphometric and meristic characters that have been defined by studies that disregarded the intraspecific variability of its lineages. The widespread distribution of some species, as well as their relaxed host specificity - pattern which differs from what has been documented for marine tetraphyllideans - suggests the existence of species complexes that require taxonomic refinement. This study aims at refining the taxonomy of one of these complexes Rhinebothroides freitasi, in which are included other three nominal species (R. campbelli, $R$. circularisi, $R$. venezuelensis) circumscribed ambiguously. In this study, it has been assumed that the combination of molecular and morphological data can shed some light on the taxonomic status of this complex. Within this framework, molecular data were compiled for 28S, ITS-1, and COI for 57 haplotypes of Rhinebothroides representing all currently valid species within the genus and their biogeographical distribution along the major Brazilian river basins. The direct optimization of nucleotide sequences from these haplotypes, simultaneously analised with 26 terminals which included marine and freshwater lineages of tetraphyllideans, generated a phylogenetic hypothesis that recognized five major clades within Rhinebothroides. Each of these clades are morphologically congruent with the type series of five nominal species. Therefore, this study recognizes five valid species within Rhinebothroides: R. glandularis, R. freitasi, R. moralarai, R. scorzai, and $R$. venezuelensis. Within the $R$. freitasi complex, the compiled morphological data for $\sim 400$ specimens provided a robust assessment of intraspecific variability for $R$. freitasi and $R$. venezuelensis. The biogeographic and host extensive sampling available for this study reveals that members of Rhinebothroides show low host specificity, as opposed to the marine tetraphyllidean lineages.
\end{abstract}




\section{Literatura Citada}

Aagesen, L. 2005. Direct optimization, affine gap costs, and node stability. Molecular Phylogenetics and Evolution 36: 641-653.

Aagesen, L.; Pettersen, G. \& Seberg, O. 2005. Sequence length variation, indel costs, and congruence in sensitivity analysis. Cladistics $21: 15-30$.

Adamson, M.L. 1981. Development and transmission of Gyrinicola batrachiensis (Walton, 1929) Adamson, 1981 (Pharynngononidae, Oxyuroidea). Canadian Journal of Zoology 59: 1351-1367.

Adamson, M.L. \& Caira, J.N. 1994. Evolutionary factors influencing the nature of parasite specificity. Parasitology 109: S85-S95.

Belyaeva, M. \& Taylor, D.J. 2009. Cryptic species within the Chydorus sphaericus species complex (Crustacea: Cladocera) revealed by molecular markers and sexual stage morphology. Molecular Phylogenetics and Evolution 50: 534-546.

Bickford, D.; Lohman, D.J.; Sodhi, N.S.; Ng, P.K.L.; Meier, R.; Winker, K.; Ingram, K.K. \& Das, I. 2007. Cryptic species as a window on diversity and conservation. Trends in Ecology and Evolution 23: 148-155.

Brant, S.V. \& Ortí, G. 2003. Evidence for gene flow in parasitic nematodes between two host species of shrews. Molecular Ecology 12: 2853-2859.

Brooks, D.R. 1992. Origins, diversification, and historical structure of the helminth fauna inhabiting neotropical freshwater stingrays (Potamotrygonidae). Journal of Parasitology 78: 588-595.

Brooks, D.R. \& Amato, J.F.R. 1992. Cestode parasites in Potamotrygon motoro (Matterer) (Chondrichthyes: Potamotrygonidae) from Southwestern Brazil, including Rhinebothroides mclennanae n. sp. (Tetraphyllidea: Phyllobothriidae), and a revised host-parasite checklist for helminths inhabiting neotropical freshwater stingrays. Journal of Parasitology 78: 393-398.

Brooks, D.R. \& Thorson, T.B. 1976. Two tetraphyllidean cestodes from the freshwater stingray Potamotrygon magdalenae Duméril, 1852 (Chondrichthyes: Potamotrygonidae) from Colombia. 
Journal of Parasitology 62: 943-947.

Brooks, D.R.; Mayes, M.A. \& Thorson, T.B.. 1981a. Systematic review of cestodes infecting freshwater stingrays (Chondrichthyes: Potamotrygonidae) including four new species from Venezuela. Proceeding of the Helminthological Society of Washington 48: 43-64.

Brooks, D.R.; Thorson, T.B. \& Mayes. M.A. 1981b. Freshwater stingrays (Potamotrygonidae) and their helminth parasites: Testing hypotheses of evolution and coevolution. In: Advances in cladistics: Proceedings of the first meeting of the Willi Hennig Society, V. A. Funk and D. R. Brooks, (eds.). New York Botanical Garden, New York, p. 147-175.

Caira, J. N. 1990. Metazoan parasites as indicators of elasmobranch biology. In: Elasmobranchs as living resources: Advances in the biology, ecology, systematics, and behavior, and the status of the fisheries, NOAA Technical Report 90, H. L. Pratt, Jr., S. H. Gruber and T. Taniuchi, (eds.). p. $71-96$.

Caira, J.N. 1994. Parascript: Paragon or parody. Review of Parascript: Parasites and the Language of Evolution, by D. R. Brooks and D. A. McLennan. BioScience 44: 771- 773.

Caira, J.N. \& Jensen, K. 2001. An investigation of the co-evolutionary relationships between onchobothriid tapeworms and their elasmobranch hosts. International Journal for Parasitology 31: 960-975.

Caira, J.N. 2010. Tetraphyllidea In: Global Cestode Database. http://web2.uconn.edu/tapeworm/index.php. Acessado em Janeiro/Fevereiro, 2010.

Caira, J.N.; Jensen, K. \& Healy, C.J. 2001. Interrelationships among tetraphyllidean and lecanicephalidean cestodes. In: Interrelationships of the Platyhelminthes, Littlewood, D.T.J. \& Bray, R. (eds.). Taylor \& Francis, London, p. 135-158.

Calvo, M.; Templado, J.; Oliverio, M. \& Machordom, A. 2009. Hidden Mediterranean biodiversity: molecular evidence for a cryptic species complex within the reef building vermetid gastropod Dendropoma petraeum (Mollusca: Caenogastropoda). Biological Journal of the Linnean Society 
96: 898-912.

Campbell, R.A. \& Beveridge, I. 2002. The genus Acanthobothrium (Cestoda: Tetraphyllidea:Onchobothriidae) parasitic in Australian elasmobranch fishes. Invertebrate Systematics 16: 237-344.

Cardoso Jr., M. em preparação. Diversidade do gênero Acanthobothrium van Beneden, 1850, parasitas de potamotrigonídeos (Myliobatiformes, Potamotrygonidae). Dissertação de mestrado. Universidade de São Paulo.

Chervy, L. 2009. Unifed terminology for cestode microtriches: a proposal from the International Workshops on Cestode Systematics in 2002-2008. Folia Parasitologica 56(3): 199-230.

Criscione, C.D.; Poulin, R. \& Blouin, M.S. 2005. Molecular ecology of parasites: elucidating ecological and microevolutionary processes. Molecular Ecology 14: 2247-2257.

Daniels, S.R.; Picker, M.D.; Cowlin, R.M. \& Hamer, M.L. 2009. Unravelling evolutionary lineages among South African velvet worms (Onychophora: Peripatopsis) provides evidence for widespread cryptic speciation. Biological Journal of the Linnean Society 97: 200-216.

de Carvalho, M. R.; Lovejoy, N.R. \& Rosa, R.S. 2003. Family Potamotrygonidae (River Stingrays). In: Check list of the freshwater fishes of South and Central America, R. E. Reis, S. O. Kullander, C. J. Ferraris, Jr (Organizadores). EDIPUCRS, Porto Alegre, Brasil, p. 22-28.

de Carvalho, M.R.; Maisey, J.G. \& Grande, L. 2004. Freshwater stingrays of the Green River formation of Wyoming (early eocene), with the description of a new genus and species and an analysis of its phylogenetic relationships (Chondrichthyes: Myliobatiformes). Bulletin of the American Museum of Natural History 284, 136pp.

de Meeûs, T.; Michalakis, Y. \& Renaud, F. 1998. Santa Rosalia revisited: or why are there so many kinds of parasites in 'The Garden of Earthly Delights'? Parasitology Today 14: 10-13.

Detwiller, J.T.; Bos, D.H. \& Minchella, D.J. (in press). Revealing the secret lives of cryptic species: Examining the phylogenetic relationships of echinostome parasites in North America. Molecular 
Phylogenetics and Evolution. 10pp. doi:10.1016/j.ympev.2010.01.004.

Deynat, P. 2006. Potamotrygon marinae n. sp., une nouvelle espéce de raies d'eau douce de Guyane (Myliobatiformes, Potamotrygonidae). Comptes Rendus Biologies. 329: 483-493.

Dowton, M. \& Austin, A.D. 2002. Increased congruence does not necessarily indicate increased phylogenetic accuracy - the behavior of the Incongruence Length Difference Test in mixedmodel analyses. Systematic Biology 51(1): 19-31.

Edgecombe,G.D. \& Giribet, G. 2009. Phylogenetics of scutigeromorph centipede Myriapoda: Chilopoda) with implications for species delimitation and historical biogeography of the Australian and New Caledonian faunas. Cladistics 25: 406-427.

Euzet, L. and Combes, C. 1980. Les problemes de l'espece chez les animaux parasites. In: Les problemes de l'espece dans le regne animal. Memoirs de la Societe Zoologique de France. 3: 239-285.

Euzet, L. 1994. Order Tetraphyllidea Carus, 1863. In: Keys to the cestode parasites of vertebrates, L. F. Khalil, A. Jones and R. A. Bray, (eds.). CAB International, Wallingford, Inglaterra, p. 149-194.

Ewing, B. \& Green, P.1998. Basecalling of automated sequencer traces using phred. II. Error probabilities. Genome Research 8: 186-194

Ewing, B.; Hillier, L.; Wendl, M. \& Green, P.1998. Basecalling of automated sequencer traces using phred. I. Accuracy assessment. Genome Research 8: 175-185.

Frost, D.R.; Rodrigues, M.T.; Grant, T. \& Titus, T.A. 2001. Phylogenetics of the lizard genus Tropidurus (Squamata: ropiduridae: Tropidurinae): direct optimization, descriptive efficiency, and sensitivity analysis of congruence between molecular data and morphology. Molecular Phylogenetics and Evolution 21(3): 352-371.

Fyler, C.A. 2009. Systematics, biogeography and character evolution in the tapeworm genus Acanthobothrium van Beneden, 1850. Tese de Doutorado. University of Connecticut. Storrs, Connecticut, EUA. xiii+182pp. 
Giribet, G. 2001. Exploring the behavior of POY, a program for direct optimization of molecular data. Cladistics 17: 60-70.

Giribet, G. \& Edgecombe, G.D. 2006. Conflict between datasets and phylogeny of centipedes: an analysis based on seven genes and morphology. Proceedings of the Royal Society B 273: 531538.

Giribet, G.; Edgecombe, G.D. \& Wheeler, W.C. 2001. Arthropod phylogeny based on eight molecular loci and morphology. Nature 413: 157-161.

Goloboff, P.A.; Farris, J.S. \& Nixon, K.C. 2008. TNT, a free program for phylogenetic analysis. Cladistics 24: 774-786.

Goodman, S.M.; Maminira, C.P.; Bradman, H.M.; Christidis, L.; \& Appleton, B. 2009b. The use of molecular phylogenetic and morphological tools to identify cryptic and paraphyletic species: examples from the diminutive long-fingered bats (Chiroptera: Miniopteridae: Miniopterus) on Madagascar. American Museum Novitates 3669: 1-34.

Goodman, S.M.; Maminira, C.P.; Weyeneth, N.; Bradman, H.M.; Christidis, L.; Ruedi, M. \& Appleton, B. 2009a. The use of molecular and morphological characters to resolve the taxonomic identity of cryptic species: the case of Miniopterus manavi (Chiroptera, Miniopteridae). Zoologica Scripta 38: 339-363.

Gordon, D.; Abajian, C. \& Green P. 1998. Consed: A graphical tool for sequence finishing. Genome Reasearch 8: 195-202.

Gordon, D.; Desmarais, C. \& Green, P. 2001. Automated finishing with Autofinish. Genome Research 11: 614-625.

Hall, T.A. 1999. BioEdit: a user-friendly biological sequence alignment editor and analysis. Program for Windows 95/98/NT. Nucleic Acid Symposium 41: 95-98.

Healy, C.J. 2006. A revision of selected Tetraphyllidea (Cestoda): Caulobothrium, Rhabdotobothrium, Rhinebothrium, Scalithrium, and Spongiobothrium. Tese de Doutorado. 
University of Connecticut. Storrs, Connecticut, EUA. xiv+327pp.

Healy, C.J.; Caira, J.N.; Jensen, K.; Webster, B.L. \& Littlewood, D.T.J. 2009. Proposal for a new tapeworm order, Rhinebothriidea. International Journal for Parasitology 39: 497-511.

Heinicke, M.P.; Naylor, G.J.P. \& Hedges, S.B. 2009. Cartilaginous fishes (Chondrichthyes). In: The timetree of life. Hedges S. B. \& Kumar S. (eds.) Oxford University Press, New York. pp 320-327. Ivanov, V.A. 2004. A new species of Rhinebothroides Mayes, Brooks \& Thorson, 1981 (Cestoda: Tetraphyllidea) from the ocellate river stingray in Argentina, with amended descriptions of two other species of the genus. Systematic Parasitology 58: 159-174.

Jex, A.R.; Schneider, M.A. \& Cribb, T.H. 2006. The importance of host ecology in thelastomatoid (Nematoda: Oxyurida) host specificity. Parasitology International 55:169-174.

Jousson, O.; Bartoli, P. \& Pawlowski, J. 2000. Cryptic speciation among intestinal parasites (Trematoda: Digenea) infecting sympatric host fishes (Sparidae). Journal of Evolutionay Biology $13 ; 778-785$.

Khalil, L.F., Jones, A. \& Bray, R.A. (eds.), 1994. Keys to the Cestode Parasites of Vertebrates. CAB International, Wallingford, U.K.

Lake, J.A. 1991. The order of sequence alignment can bias the selection of tree topology. Molecular Biology and Evolution 8(3): 378-385.

Leung, T.L.F.; Keeney, D.B. \& Poulin, R. 2009. Cryptic species complexes in manipulative echinostomatid trematodes: when two become six. Parasitology 136: 241-252.

Lopéz-Neyra, C. R. \& Díaz-Ungría, C. 1958. Cestodes de Venezuela.V. Cestodes de Vertebrados Venezolanos (segunda nota). Nova Cientia 23: 1-41.

Lovejoy, N.R. 1996. Systematics of myliobatoid elasmobranchs: with emphasis on the phylogeny and historical biogeography of neotropical freshwater stingrays (Potamotrygonidae: Rajiformes). Zoological Journal of the Linnean Society 117: 207-257.

Lovejoy, N.R. 1997. Stingrays, parasites, and Neotropical biogeography: a closer look at Brooks et 
al.'s hypotheses concerning the origins of Neotropical freshwater rays (Potamotrygonidae). Systematic Biology 46: 218-230.

Lovejoy, N.R; Bermingham, E. \& Martin, A.P. 1998. Marine incursion into South America. Nature 396: 421-422.

Luchetti, N.M. em preparação. Sistemática de Potamotrygonocestus Brooks \& Thorson, 1976 (Eucestoda: Tetraphyllidea), parasitas de potamotrigonídeos (Myliobatiformes, Potamotrygonidae). Dissertação de mestrado. Universidade de São Paulo.

Luchetti, N.M.; Marques, F.P.L. \& Charvet-Almeida, P. 2008. A new species of Potamotrygonocestus Brooks \& Thorson, 1976 (Eucestoda: Tetraphyllidea) from Plesiotrygon iwamae Rosa, Castello \& Thorson (Mylliobatoidea: Potamotrygonidae) and a redescription of Potamotrygonocestus chaoi Marques, Brooks \& Araujo, 2003. Systematic Parasitology 70: 131-142.

Marlier, G. 1967. Ecological studies on some lakes of the Amazon Valley. Amazoniana 1: 91-115.

Marques, F. P. L. 2000. Evolution of Neotropical freshwater stingrays and their parasites: Taking into account space and time. Tese de Doutorado, University of Toronto, Ontario, Canada, xx+322 pp.

Marques, F.P.L. \& Brooks, D.R. 2003. Taxonomic Revision of Rhinebothroides (Eucestoda: Tetraphyllidea: Phyllobothriidae), parasites of Neotropical freshwater stingrays (Rajiformes: Myliobatoidei: Potamotrygonidae). Journal of Parasitology 89(5): 994-1017.

Marques, F.P.L. \& Domingues, M. V. (Eds.). 2006. In: Banco de dados do Laboratório Helmintologia Evolutiva, Universidade de São Paulo. Acessado múltiplas vezes no endereço http://www.ib.usp.br/hpc.

Marques, F.P.L.; Brooks, D.R. \& Araújo, M.L.G. 2003. Systematics and phylogeny of Potamotrygonocestus (Platyhelminthes: Neodermata: Eucestoda: Tetraphyllidea: Onchobothriidae) with descriptions of three new species from freshwater potamotrygonids 
(Myliobatoidei: Potamotrygonidae). Zoologia Scripta 32: 367-396.

Mayes, M. A., Brooks, D.R. \& Thorson, T.B. 1981. Two new tetraphyllidean cestodes from Potamotrygon circularis Garman (Chondrichthyes: Potamotrygonidae) in the Itacuaí River, Brazil. Proceedings of the Helminthological Society of Washington 48: 38-42.

Mickevich, M.F. \& Farris, J.S. 1981. The implications of congruence in Menidia. Systematic Zoology 30: 351-370.

Morrison, D.A. \& Ellis, J.T. 1997. Effects of nucleotide sequence alignment on phylogeny estimation: a case study of 18s rDNAs of Apicomplexa. Molecular Biology and Evolution 14: $428-441$.

Nelson, J. S. 2006. Fishes of the World. Quarta edição. John Wiley \& Sons, Hoboken, New Jersey. $601 \mathrm{pp}$.

Olson, P.D.; Ruhnke, T.R.; Sanney, J. \& Hudson, T. 1999. Evidence for host-specific clades of tetraphyllidean tapeworms (Platyhelminthes: Eucestoda) revealed by analysis of $18 \mathrm{~S}$ ssrDNA. International Journal for Parasitology 29: 1465-1476.

Page, R.D.M. \& Charleston, M.A. 1998. Trees within trees: phylogeny and historical associations. Trends in Ecology \& Evolution 13: 356-359.

Pfenninger, M. \& Schwenk, K. 2007. Cryptic animal species are homogeneously distributed among taxa and biogeographical regions. BMC Evolutionary Biology 7: 121.

Phillips, A.; Janies, D. \& Wheeler, W.C. 2000. Multiple sequence alignment in phylogenetic analysis. Molecular Phylogenetics and Evolution 16(3): 317-330.

Poulin, R. \& Keeney, D.B. 2007. Host specificity under molecular and experimental scrutiny. TRENDS in Parasitology 24: 24-28.

Poulin, R. \& Morand, S. 2000. The Diversity of Parasites. The Quarterly Review of Biology 75(3): 277-293.

Poulin, R. 2007. Evolutionary Ecology of Parasites. Princeton University Press, New Jersey, 
$\mathrm{x}+332 \mathrm{p}$

Poulin, R.; Krasnov, B.R.; Shenbrot, G.I.; Mouillot, D. \& Khokhlova, I.S. 2006. Evolution of host specificity in fleas: Is it directional and irreversible? International Journal for Parasitology 36: 185-191.

Ramirez, M.J. 2006. Further problems with the incongruence length difference test: “hypercongruence” effect and multiple comparisons. Cladistics 22: 289-295.

Randhawa, H.S.; Saunders, G.W. \& Burt. M.D.B. 2007. Establishment of the onset of host specificity in four phyllobothriid tapeworm species (Cestoda: Tetraphyllidea) using a molecular approach. Parasitology 134:1291-1300.

Rego, A. A. 1979. Contribuição ao conhecimento dos helmintos de raias fluviais Paratrygonidae. Revista Brasileira de Biologia 39: 879-890.

Rembaut, A. 2007. Figtree v1.3.1. In http://tree.bio.ed.ac.uk/software/figtree/. Acessado em Dezembro, 2009.

Reyda, F.B. 2007. Patterns of diversity and host specificity in the cestodes Neotropical freshwater stingrays. Tese de Doutorado. University of Connecticut. Storrs, Connecticut, EUA. xiv+217pp.

Reyda, F.B. \& Marques, F.P.L. em preparação. Species boundaries in Neotropical freshwater lineages of Rhinebothrium (Eucestoda: Tetraphyllidea) parasites of Potamotrygonidae (Rajiformes: Myliobatoidei).

Rosas-Valdez, R.; Choudhury, A.; Ponce de Léon, G.P. 2004. Phylogenetic analysis on genera of Corallobothriinae (Cestoda: Proteocephalidea) from North American ictalurid fishes, using partial sequences of the 28S ribosomal gene. Journal of Parasitology 90: 1123-1127.

Sanders, J. 2009. Program note: Cladescan, a program for automated phylogenetic sensitivity analysis. Cladistics 25: 1-3.

Swofford, D.L. 2002. PAUP*. Phylogenetic Analysis Using Parsimony (*and Other Methods), 4.0 edn, Sinauer, Sunderland, MA. 
Thompson, J.D.; Higgins, D.G. \& Gibson, T.J. 1994. CLUSTAL W: improving the sensitivity of progressive multiple sequence alignment through sequence weighting, position-specific gap penalties and weight matrix choice. Nucleic Acids Research 22(22): 4673-4680.

Varón, A.; Vinha, L.S.; \& Wheeler, W.C. 2009. POY version 4: phylogenetic analysis using dynamic homologies. Cladistics 25: 1-14.

Wagner, W. H., Jr. 1961. Problems in the classification of ferns. In: "Recent Advances in Botany I," Univ. of Toronto Press, Toronto. pp. 841-844.

Wheeler, W.C. 1995. Sequence alignment, parameter sensitivity, and the phylogenetic analysis of molecular data. Systematic Biology 44(3): 321-331.

Wheeler, W.C. 1996. Optimization alignment: The end of multiple sequence alignment in phylogenetics? Cladistics 12: 1-9.

Wheeler, W.C. 2001. Homology and the optimization of DNA sequence data. Cladistics 17: 3-11.

Wheeler, W.C. 2003. Implied alignment: a synapomorphy-based multiple-sequence alignment method and its use in cladogram search. Cladistics 19: 261-268.

Wheeler, W.C. \& Hayashi, C.Y. 1998. The phylogeny of the extant Chelicerate orders. Cladistics 14: 173-192.

Wilcox, D., Dove, B., McDavis, D., \& Greer, D. (1995-2002). Freeware distribuído por http://ddsdx.uthscsa.edu/dig/dowload.html.

Zamparo, D., Brooks, D.R. \& Barriga, R. 1999. Pararhinebothroides hobergi n. gen. n. sp. (Eucestoda: Tetraphyllidea) in Urobatis tumbesensis (Chondrichthyes: Myliobatiformes) from Coastal Ecuador. Journal of Parasitology 85: 534-539. 


\section{ANEXO A}

Modelo de comandos de execução (scripts) utilizados em POY

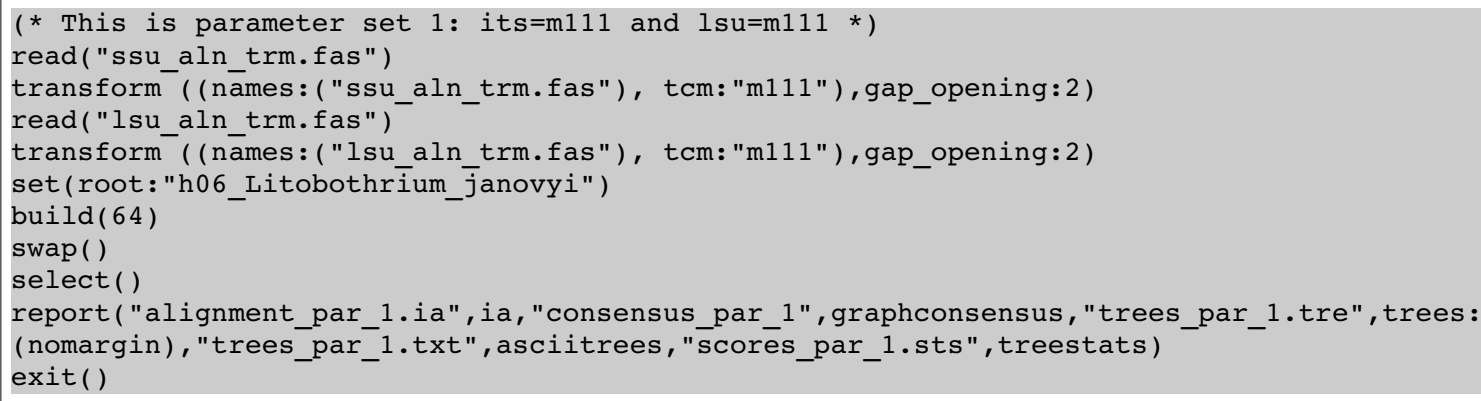


ANEXO B

Arquivo em formato NEXUS para computar comprimentos de ramos em uma das 18 topologias geradas em POY

\#NEXUS

[Veronica M. Bueno, Fevereiro de 2010]

begin data;

dimensions ntax=83 nchar $=1905$;

format datatype=dna matchchar $=$ gap=- interleave missing=N;

MATRIX

options gapmode=newstate;

r094 rhoides negro spnGGGAACTGCTATGTAACCTCT---C--GGACCGCTGGTCATGG-TGGTCCACAACC-

ATTTC GGTGGGGTGCCTATTTGCCCTATACTCCCAGGCGTGCTCGCCAGTCGTGGCAGCTTAACTGCTGTCACGGCA-

TCGGCCAGTCCACACCGGAGCGGCAATGCAGTACATGTGCCGGAAGGTATGTGTGCAAGGTATAAGAT-A-

TTGGCACCACCATATGCCTACGCCCCACTATGCGCCCTTGTCTTTTACACTTACCATACAGGTAGTGTGTGAGT-

-GTACGCGTGTTGGTGTAT-

TCCGGCACAAGTGCTACTATTACT-ACTA---

TCTGTGCAAAACGCGTGGTCGGCATTAACTTGTCG-ACTGTGCGCGGTTCTCATGAGCGTGGTTGGCTATCTT--

GCCTGGTAGTCAATGCGTCTTGTGCAGAGCTGGAAGAGCCCAGCACCGAAGCCTGCGGCAGGTTTGCTGTTAGGCAATGTGGTGTTTGGGTCGGCTCGCG GGATTGCCACTCCACTCGAAGTCCAGCATTGAGTATGGTTT-

CTGGATTTGGCCCAGAGAGGGTGAAAGGCCCGTACGGGTGGAGGTGTCAGACAGGTGAGGCAGTCCTCTAGGCCGGCCTTAGAGTCGGGTTGTTTGGGAA TGCAGCCCAAAGCGGGTGGTAAACTCCATCCAAGGCTAAATACTAGCACGAGTCCGATAGCAAACAAGTACCGTGAGGGAAAGTTGAAAAGTACTTTGAA GAGAGAGTAAACAGTACGTGAAACCGCATGCAGGTAAACGGGTGGCGTCAAGCTGCACGCCCAGAGGATTCAGCCGGTTAGAGTGTGTCTATGCGCTTG-CGTATGAATGGGCCAGAGTAGGGCG----TGGTAGTCCGCTGGAAGACAGCGGGCCCTGCCGCAAGGTGGGGATGTG------TGAGCCGGGTGGAAGCCGGAGCACGCTATCCGTC--TGTGGGGCCGTCTAGCCGGTGCACTTTCTCTGT--

GGTGGACACCACGACCGGTGGAACTGCCAGTCTGCTGTGGTCGAGTCGTGTTCGGTTGGTCCTTGT-GGCTAGTTGGGCGCGAT---CACGGGCAACCTTGGTGAACGGCGTTGGCGTGGTCTCTCGG--------GGGCATGCCTTCGTGTTATCGGTAGCCAGTTGTCTGAACGGGCCTGCCTCGCGATTGTTCTAGCCGTCGTG---

GGGTGGTCTGGTGGGCCATGGTGGTAGGAATAACTGTGCAGGGCACTGGAGTGTTCGGCCTCGAATGCAGCCAGCACGCACGCTAGTAGTGT-----TGTTGC---G---

ATGTGGGTGCTCTCGTGGTCTGCCTGGTGCCGGGTCTGATTGTCGTGTTGCCTGCGCAAAGAAATTTTTAGAGCCTTATTATAATGTTATAAGTACTGAT TGTTATAAATTTTTAATTACAAATCATGGTATCATAATGATTTTTTTCTTTATAATGCCTATATTAATAGGAGGGTTTGGTAATTATTTAATTCCCTTAT TATGCGGTTTGTCTGATTTAAATTTACCTCGTTTAAAAGCATTAAGTGCTTGATTGTTGTTACCTTCTATCGTTTTTTTAGTAATAAGCATGTGTTTAGG GGCAGGGATAGGCTGAACTTTTTATCCTCCTTTATCTTCCAGTCTATTTGAAGGAAGTAAGGGTGTGGATTTTTTGATGTTTTCTCTACATTTGGCTGGT GTGTCTAGTATTTTTAGCTCTATTAATTTTATCTGTACTTTGTATACTGCCTTTAGTGGTAGTTTGGCGTCTCGAAGGTCAATAATTTTATGGGC 19Rhinebothrium_sp_1_worm_3

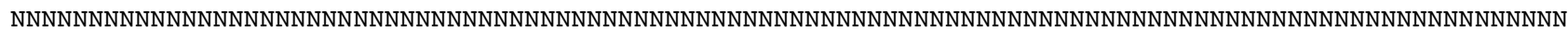

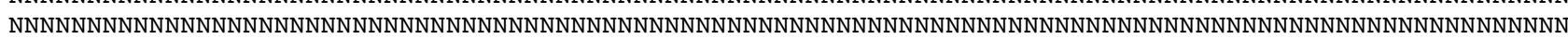
NNNNNNNNNNNNNNNNNNNNNNNNNNNNNNNNNNNNNNNNNNNNNNNNNNNNNNNNNNNNNNNNNNNNNNNNNNNNNNNNNNNNNNNNNNNNNNNNNNNN

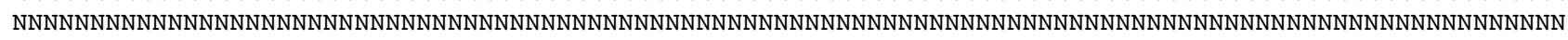
NNNNNNNNNNNNNNNNNNNNNNNNNNNNNNNNNNNNNNNNNNNNNNNNNNNNNNNNNNNNNNNNNNNNNNNNNNNNNNNNNNNNNNNNNNNNNNNNNNNN NNNNNNNNNNNNNNNNNNNNNNGGAAGAGCCCAGCACCGAAGCCTGCGGTAGCTTTACTGTTAGGCAATGTGGTGTTTGGGTCGGCTCGCGGGATTGCCA CTCCACTCGAAGTCCAGCATTGAGTATGGTTT-

CTGGATTTGGCCCAGAGAGGGTGAAAGGCCCGTACGGGTGGAGGTATCAGACAAGTGAGGCAATTCACTAGGCCGGCCTTAGAGTCGGGTTGTTTGGGAA TGCAGCCCAAAGTGGGTGGTAAACTCCATCCAAGGCTAAATACTAGCACGAGTCCGATAGCAAACAAGTACCGTGAGGGAAAGTTGAAAAGTACTTTGAA GAGAGAGTAAACAGTACGTGAAACCGCATGCAGGTAAACGGGTGGCGTCAAGCTGCACGCCCAGAGGATTCAGCCGGTTAGAGTGTAGT-

TATGCGCTTG-CGTGTCAACAGGCCAGAGTAAGGCG----TGGTAGACCGCTGGAAGACAGTGGGCCCTGCCGCAAGGTGGGGATGTG-----TTTAGCCGGGTGGACGCCGGAGCACGCTATCCGTC--TGTTGGGCCTACTAGCCGGTGCACTTTCTCTGT--

GGTGGACACCACGACCGGTGGGACTGCCAGTCTGCTATGGTCAAGTCGTATTCGGTTGGTCCTTGT-GGCTAACTGGGTGCGAT---CACGGGCAAACTTGGTGAACGGCGTTGACGTGCTCTC----TTGA----GGGTGTGTCTTCGTGTTATCGGTAACCAGTTGTCTTAACGGGCCTGCCTTACGATTGTTCTAGCCGTCGTA---

GGGTGGTCTGGTGGACCATGGTGGTAAGAATAACTGTGCAGGGCACCGGAGTTTTCGGCCTCAAATGCAGCCAGCATGCACGCTAGTAGTGT-----GT---T---

GCCAATATGGGTGCTCTCGTGGTCTGCCTGGTGCCGGGTCTGATTGTCGTGTTGCCTACGCAAAGAAATTTTTGGAGCCGTACTATAATGTTATTAGTAC GGACTGTTATAAATTTTTAATTACTAATCATGGTATTATAATGATTTTTTTCTTTATAATGCCTATTTTGATAGGCGGTTTTGGTAATTATTTGATTCCA TTACTTTGTGGTTTATCTGATTTAAATCTACCCCGTTTAAAAGCACTCAGAGCTTGGTTGTTGTTGCCTTCAGCTCTTTTTTTGGTGGTGAGTATGTGTT TAGGGGCTGGTATAGGTTGGACTTTCTATCCTCCGTTATCTTCTAGATTATTTGAAGGGAGTAAGGGGGTAGATTTTTTAATGTTTTCGTTGCATTTAGC AGGAATTTCTAGTATTTTTAGGTCTATTAAATTTATTTGTACTTTGTATACTGCTTTTAGTGATAGTTTGGCAGCACGTAGATGTATTATACTATGGTC r015_Rfulbrighti_marajo_orbignyi

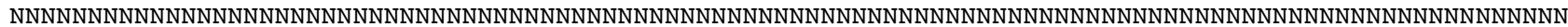

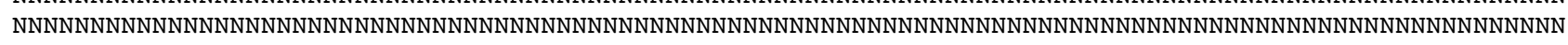

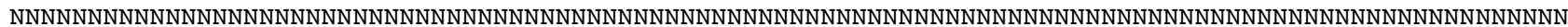

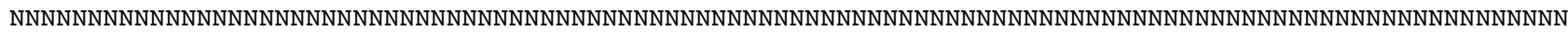

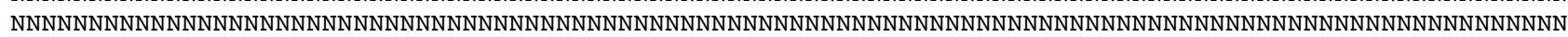
NNNNNNNNNNNNNNNNNNNNNNNNNNNNNNNNNNNNNNNNNGCCTGCGGTAGTTTTACTGTTAGGCAATGTGGTGTTTGGGCCGGCTCGCAGGATTGCCA CTTCACTCGAAGTCCAGCATTGAGTATGGTCCACTGGATTTGGCCCAGAGAGGGTGAAAGGCCCGTACGGGTGGAGGTTTCAGACAAGTGAGGCAATTCA CTAGGCCGGCCTTAGAGTCGGGTTGTTTGGGAATGCAGCCCAAAGTGGGTGGTAAACTCCATCCAAGGCTAAATACTAGCACGAGTCCGATAGCAAACAA GTACCGTGAGGGAAAGTTGAAAAGTACTTTGAAGAGAGAGTAAACAGTACGTGAAACCGCATGCAGGTAAACGGGTGGCGTCAAGCTGCACGCCCAGAGG ATTCAGCCGGTTAGAGTGTAGT-TATGCGCTTG-CGTGTCGAACGGCCAGTGTAAGATT----

GGCTAGTCCACTGGAAGACAGTGGGCCCTGCCGCAAGGTGGGG-TGTG-----T-GTACCGGGTGGAAGCCGGAGCACGCTAGCCGTC-TGTTGGGCCATCTAGCCGGTGCACTTTCTCTGT-- 
GGTGGACACCACGACCGGTGGTACTGCCAGTCTGCTATGGTCAAGTCGTATTCGGTTGGTCCTTGT-GGCCTACTGGGTGCGAT---CACGGACAAACTCGGTGAACGGCGTTGACGTGCTCTT-------CCCAGGGTATGTCTTCGTGATATCGGTAACCGGTTGTCTTAACGGGCCTGCCTTACGATTGTTCCAGTCGTCCTA---

GGGTGGTCTGGTGGACCATGGTGGTAAGAATAACTGTGCAGGGCACCGGAGTTTTCGGCCTCAAATGCAGCCAGCATGCACGCTGGTAGTGT-----

TC----------

GTGTGGGTGCTCTCGTGGCCTGCCTGGTGCCGAGTCTGATTGTCGTGTTGCCTGCGCAAAGAAATTTTTAGAGCCGTATTATAAAGTAATTAATACGGAC TGTTATAAATTTTTAATTACTAATCATGGTATTATTATGATTTTCTTTTTTATAATGCCTATTTTAATCGGCGGGTTTGGTAACTATTTAATACCCTTGT TAGCGGGGTTATCTGATTTAAATTTGCCACGTTTAAAAGCATTGAGTGCTTGACTTTTACTGCCCTCTGTGGTTTTTTTGTTAATAAGTATGTGTCTTGG TGCTGGTATTGGTTGGACCTTTTATCCTCCCTTATCTTCCGTGGCTTTTGAGGGCAGTAAGGGTGTTGATTTTTTAATGTTTTCTTTGCATTTAGCGGGG GTGTCTAGAATTTTAGTTCTATAAATTTTATCTGTACCTTGTATACTGCTTTTAGCGGTAGGTTATCCTCACGCGGTTCTATTATTTTGTGGTC r049 gld uppersol mot GGGAACCGCTATGTAATCTAT---CTGGGACTGCCCGTCATGG-

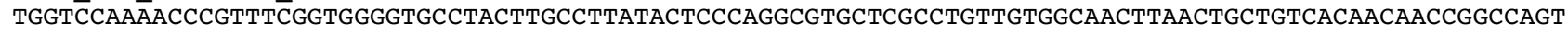
CCACACCGGAGCGGCATATTAGTACACGTGTCA-AAG---CGTGTGCAAGGTATAAGAACA-

TTGGCACTACCATATGCCTACGCCCCGCTATGCGCCСTTGTCTTTTACACTTACCATACGGATAGTGTGTATGT-----------------------------------------GT--GTGTGTTAGTGTAT-

GCTAGCATTACTACTACTACTG--

TCTGTGCAAAACGCACGGGGAGCATTAACTTGCTGTACTGTGTGTGGTTCTCATGAGCGTACTTGGTTACCTT--

GCCTGGGTGCCATTGCGTCTTGTGCAGAGCTGGAAGAGCCCAGCACCGAAGCCTGCGGTAGCTTTACTGTTAGGCAATGTGGTGTTTGGGCCGGCTCGCG GGGTTGCCACTCCACTCGAAGTCCAGCATTGAGTATGGTTT-

CTGGATTTGGCCCAGAGAGGGTGAAAGGCCCGTACGGGTGGAGGTTTCAGACAAGTGAGGCAATTCACTAGGCCGGCCTTAGAGTCGGGTTGTTTGGGAA TGCAGCCCAAAGTGGGTGGTAAACTCCATCCAAGGCTAAATACTAGCACGAGTCCGATAGCAAACAAGTACCGTGAGGGAAAGTTGAAAAGTACTTTGAA GAGAGAGTAAACAGTACGTGAAACCGCATGCAGGTAAACGGGTGGCGTCAAGCTGCACGCCCAGAGGATTCAGCCGGTTAGAGTGTAGTTATGCGCTTG-CGTATCAAAGGGCCAGAGTAAGGCG----TGGTAGTCCGCTGGAAGACAGCGGGCCCTGCCGCAAGGTGGGGATGTG-----TAAGCCGGGTGGATGCCGGAGCACGCTATCCGTC--TGGAGGGCCGTCTAGCCGGTGCACTTTCTCTGT--

GGTGGACACCACGACCGGTGGAACTGCCAGTCTGCTATGGTCAAGTCGTGTTCGGTTGGTCCTTGT-GGCTAGCTGGGCGCGAT---CACGGGCAAATTTGGTGAACGGCGTTGATGTGCCCTC--_--_----GGGTATGTCTTCGTGTTATCGGTAACCAGTTGTCTTAACGGGCCTGCCTTACGATTGTTCTAGCCGTCGTA---

GGGTGGTCTGGTGGGCCATAGTGGTAAGAATAACTGTGCAGGGCACCGGAGTTTTCGGCCTCAAACGCAGCCAGCATGCACGCTAGTAGTGT----TG---C--TG---

ATGTGGGTGCTCTCGTGGTCTGCCTGGTGCCGGGTCTGATTGTCGTGTTGCCTACGCAAAGAAATTTTTGGAGCCTTACTATAATGTGATTAGTACGGAT TGTTATAATTTTTTAATTACTAAACATGGTATTATAATGATTTTCTTTTTTATAATGCCTATTTTAATAGGGGGGTTTGGTAATTATTTAATTCCTCTAT TAAGGGGTTTGTCTGATTTAAATTTACCTCGTTTAAAAGCACTGAGTGCTTGGTTGCTTTTACCTTCTGCTGTATTCTTAGTCATTAGAATGTGCTTAGG TGCTGGTATAGGTTGAACTTTTTATCCTCCTTTGTCTTCTAGTGTTTTTGAGGGTAGTAAGGGTGTAGATTTTTTAATGTTTTCATTGCATTTGGCCGGT GTCTCTAGTATATTTAGTTCTATTAATTTTATATGTACTTTGTACACTGCTTTTAGTGGTAGGTTGGCTTCTCGTAGTTCAATTGTATTATGAGC r199_gld_lagonovo_mot GGGAACCGCTATGTAATCTAT---CTGGGACTGCCCGTCATGG-

TGGTC $\bar{C}$ AA $\bar{A}$ ACCCGTTTCGGTGGGGTGCCTACTTGCCTTATACTCCCAGGCGTGCTCGCCTGTTGTGGCAACTTAACTGCTGTCACAACAACCGGCCAGT CCACACCGGAGCGGCATATTAGTACACGTGTCA-AAG---CGTGTGCAAGGTATAAGAACA-

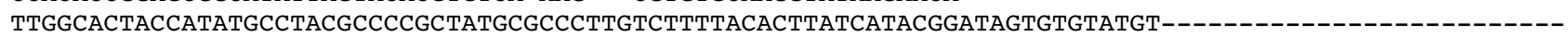
----------------GT--GTGTGTTAGTGTAT-

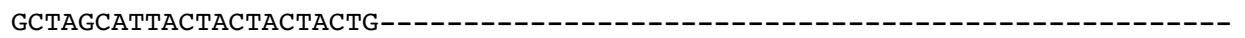

TCTGTGCAAAACGCACGGCGAGCATTAACTTGCTGTACTGTGTGTGGTTCTCATGAGCGTACTTGGTTACCTT--

GCCTGGGTGCCATTGCGTCTTGTGCAGAGCTNNNNNNNNNNNNNNNNNNNNNNNNNNNNNNNNNNNNNNNNNNNNNNNNNNNNNNNNNNNNNNNNNNNNN NNNTTGCCACTCCACTCGAAGTCCAGCATTGAGTATGGTTT-

CTGGATTTGGCCCAGAGAGGGTGAAAGGCCCGTACGGGTGGAGGTTTCAGACAAGTGAGGCAATTCACTAGGCCGGCCTTAGAGTCGGGTTGTTTGGGAA TGCAGCCCAAAGTGGGTGGTAAACTCCATCCAAGGCTAAATACTAGCACGAGTCCGATAGCAAACAAGTACCGTGAGGGAAAGTTGAAAAGTACTTTGAA GAGAGAGTAAACAGTACGTGAAACCGCATGCAGGTAAACGGGTGGCGTCAAGCTGCACGCCCAGAGGATTCAGCCGGTTAGAGTGTAGT-

TATGCGCTTG-CGTATCAAAGGGCCAGAGTAAGGCG----TGGTAGTCCGCTGGAAGACAGCGGGCCCTGCCGCAAGGTGGGGATGTG-----TAAGCCGGGTGGATGCCGGAGCACGCTATCCGTC--TGGAGGGCCGTCTAGCCGGTGCACTTTCTCTGT--

GGTGGACACCACGACCGGTGGAACTGCCAGTCTGCTATGGTCAAGTCGTGTTCGGTTGGTCCTTGT-GGCTAGCTGGGCGCGAT---CACGGGCAAATTTGGTGAACGGCGTTGATGTGCCCTC---------GGGTATGTCTTCGTGTTATCGGTAACCAGTTGTCTTAACGGGCCTGCCTTACGATTGTTCTAGCCGTCGTA---

GGGTGGTCTGGTGGGCCATAGTGGTAAGAATAACTGTGCAGGGCACCGGAGTTTTCGGCCTCAAACGCAGCCAGCATGCACGCTAGTAGTGT-----

TG---C--TG---

ATGTGGGTGCTCTCGTGGTCTGCCTGGTGCCGGGTCTGATTGTCGTGTTGCCTACGCAAAGAAATTTTTGGAGCCTTACTATAATGTGATTAGTACAGAT TGTTATAATTTTCTGATTACTAAACATGGTATTATAATGATTTTCTTTTTTATAATGCCTATTTTAATAGGGGGGTTTGGTAACTATTTAATTCCTTTAT TAAGAGGTTTGTCCGATTTAAATTTGCCTCGTTTAAAAGCTTTGAGTGCTTGATTGCTTTTACCTTCTGCTGTATTTTTAGTGATTAGTATGTGTTTAGG TGCTGGTATAGGTTGAACTTTCTATCCTCCTTTGTCTTCTAGTGTTTTTGAGGGTAGTAAGGGTGTAGACTTTTTAATGTTTTCATTACATTTGGCCGGT GTTTCTAGTATATTTAGTTCTATTAATTTATATGTACTTTGTATACTGCCTTTAGTGGTAGGTTGGCTTCTCGTAGTTCAATTGTATTATGAGC r247_frt_xingu_leop GGGAACTGCTATGTAACCTCT---C--GGACTGCCCGTCATGG-TGGTCCACAACC-

АTTTCGGTGGGGTGC CTACTTGCCCTATACTCCCAGGCGTGCTCGCCAGTCGTGGCAACTTAACTGCTGTCACGGCAATCGGCCAGTCCACACCGGAGCG GCAATCCAGTACATGTGCCGCAAGGTACGTGTGCGAGGTATAAGAA-A-

TTGGCACCACCATATGCCTACGCCCCACTATGCGCCСTTGTCTTTTACACTTATCATACAGGTAGTGTGTGAGT--------------------------------------GTACGCGTGTTGGTGTAA-

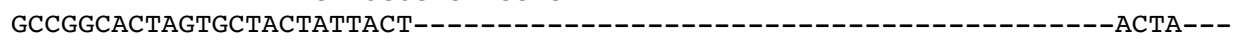

TCTGTGCAAAACGCATGGTCGGCATTAACTTGTTCGACTGTGTGCGGTTCTCATGAGCGTGGTTGGCTATCTT--

GCCTGGTAGCCGATGCGTCTTGTGCAGAGCTGGAAGAGCCCAGCACCGAAGCCTGCGGCAGGTTTGCTGTTAGGCAATGTGGTGTTTGGGTCGGCTCGCG GGATTGCCACTCCACTCGAAGTCCAGCATTGAGTATGGTTT-

CTGGATTTGGCCCAGAGAGGGTGAAAGGCCCGTACGGGTGGAGGTATCAGACAAGTGAGGCAATTCACTAGGCCGGCCTTAGAGTCGGGTTGTTTGGGAA TGCAGCCCAAAGCGGGTGGTAAACTCCATCCAAGGCTAAATACTAGCACGAGTCCGATAGCAAACAAGTACCGTGAGGGAAAGTTGAAAAGTACTTTGAA GAGAGAGTAAACAGTACGTGAAACCGCATGCAGGTAAACGGGTGGCGTCAAGCTGCACGCCCAGAGGATTCAGCCGGTTAGAGTGTATC-

TATGCGCTTG-CGTATAAATGGGCCAGAGTAAGGCG----TGGTAGTCCGCTGGTAGACAGCGGGCCCTGCCGCAAGGTGGGGATGTG-----CAAGCCGGGTGGATGCCGGAGCACGCTATCCGTC--TGTGGGGCCGTCTAGCCGGTGCACTTTCTCTGT--

GGTGGACACCACGACCGGTGGAACTGCCAGTCTGCTGTGGCCAAGTCGTGTTCGGTTCGTCCTTGT-GGCGAACTGGGCGCGAT---CACGGGCAACCTTGGTGAACGGCGTTGATGTGCCCTC----------GGGTATGTCTTCGTGTTATCGGTAGCCAGTTGTCTTAACGGGCCTGCCTTGCGATTGTTCTAGCCGTCGTA---

GGGTGGTCTGGTGGGCCATGGTGGTAAGAATAACTGTGCAGGGCACCGGAGTGTTCGGCCTCAAATGCAGCCAGCATGCACGCTAGTAGTGT-----

TG---C---G---

ATGTGGGTGCTCTCGTGGTCTGCCTGGTGCCGGGTCTGATTGTCGTGTTGCCTGCGCAAAGAAATTTTTGGAGCCTTACTATAATGTTATAAGTACAGAT 
TGTTATAАATTTTAАTTACTAATCACGGTATTATAATGATTTTCTTTTTTATAATGCСTATTTTAATCGGTGGATTTGGCAATTATTTAATCCTTTGT TATGTGGTTTATCTGATTTAAATTTACCTCGGTTAAAAGCATTGAGTGCTTGATTATTATTGCCTTCTGCTGTTTTTTTAGTAATAAGTATGTGTTTAGG GGCAGGGGTAGGTTGGACTTTTTACCCCССTTTATCTTCAAGTTTATTTGAGGGTAGGAAGGGGGTAGATTTTTTAATGTTTTCTTTACATTTAGCAGGA GTTTCTAGTATTTTTAGTTCTATAAATTTTATTTGCACTCTATATACTGCTTTTAGTAGTAGTTTGGCGTCTCGAAGTTCGATAATATTATGGGC r06_scorzai_marajo_spmar1 GGGAACTGCTATGTA-CAACAATACTCGGACCGCTCGTCATAG-TGGTCTGCTACCATTT'CGGTGGGGTGCCTATTTGCCCTATACTCCCAGGCGTGCTCGCCAGCTGCGGCAACTTAACTGCTGCCACAGCAAGAGGCCAGTCCACACCGGAGCG GCAAACCAGTACATGTGTCGCAAG---CGTGTGCAAGGTATAAGAA-A-

TTGGCACTACCATATGCCTACGCCCCACTATGCGCCCCTGTCTTTTACACTTACTATACGGGTAGTGTGTGTGTATGTGAGTGTGTGTGTGTGTGTGTGT GTGTGCGTGTGTGTATGTATGTGTGTGGGTGTATGTCAGCATTACTACTACTACTACTACTACCACCACCACCACTAC---------

TACTACTACTACTACTACTA---

TCTGTGCAAAACGNNNNNNNNNNNNNNNNNNNNNNNNNNNNNNNNNNNNNNNNNNNNNNNNNNNNNNNNNNNNNNNNNNNNNNNNNNNNNNNNNNNNNNN

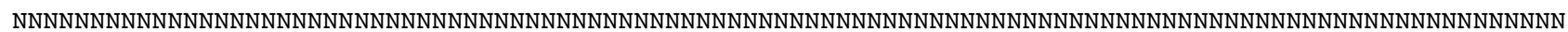

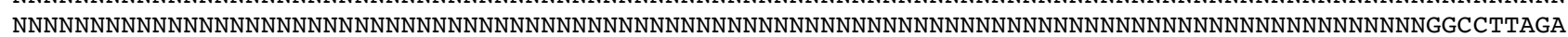
GTCGGGTTGCTTGGGAATGCAGCCCAAAGTGGGTGGTAAACTCCATCCAAGGCTAAATACTAGCACGAGTCCGATAGCAAACAAGTACCGTGAGGGAAAG TTGAAAAGTACTTTGAAGAGAGAGTAAACAGTACGTGAAACCGCATGCAGGTAAACGGGTGGCGTCAAGCTGCACGCCCAGAGGATTCAGCCGGTTAGAG TGTAGT-TATGCGCTTG-CGTATCGAAGGGCCAGAGTAAAGCGCGCGTGGTAGTCCGCTGGAAGACAGCGGGCCCTGCCGCAAGGTGGGGATGTG----T-AAGCCGGGTGGAAGCCGGAGCACGCTATCCGTC--TGCGGGGCCGTCTAGCCGGTGCACTTTCTCTGT--

GGTGGACACCACGACCGGTGGAACTGCCAGTCTGCTATGGTCAAGTCGTGTTCGGTTGGTCCTTGT-GGCGAACTGGGCGCGAT---CACGGGCAAATTTGGTGAACGGCGTTGATGTGCCCTC-----------GGGTGCGTCTTCGTGCTATCGGTAGCCAGTTGTCTTAACGGGCCTGCCTTACGATTGTTCTAGCCGTCGTA---

GGGTGGTCTGGTGGGCCGTAGTGGTAAGAATAACTGTGCAGGGCACTGGAGTTATCGGCCTCAAACGCAGCCAGCATGCACGCTAGTAGTGTGTCCCTG$--\mathrm{G}---\mathrm{T}---$

ATGTGGGTGCTCTCGTGGTCTGCCTGGTGCCGGGTCTGATTGTCGTGTTGCCTACGCAAAGAAATTTTTAGAACCTTACTATAATGTTATTAGTACTGAT TGTTATAAATTTTTGATTACTAATCATGGTATTATAATGATCTTTTTTTTTATAATGCСTATTTTAATTGGTGGGTTTGGTAATTATTTAATCCCTTTAT TATGTGGTTTATCTGATTTAAACTTACCACGTTTAAACGCGCTTAGTGCTTGGTTACTTTTACCTTCTGTGTTATTTTTAGTTATAAGAATGTGTTTAGG GGCCGGGGTGGGTTGAACTTTTTATCCTCCCTTAGCTTCCAGTGTATTTGAGGGGAGTAAGGGTGTAGACTTTTTAATGTTTTCTTTACACTTAGCGGGA GTTTCTAGAATTTTTAGCTCTATTAATTTTATTTGTACTTTACACACTGCCTTTAGGGGTAATTTAGCTTCTCGTAGTTCTATTGTATTATGGGC r093 frt negro spn GGGAACTGCTATGTAACCTCT---C--GGACTGCCCGTCATGG-TGGTCCACAACC-

АTTT $\bar{C} G$ GTGGGTGC $\bar{C}$ TACTTGCCCTATACTCCCAGGCGTGCTCGCCAGTCGTGGCAACTTAACTGCTGTCACGGCAATCGGCCAGTCCACACCGGAGCG GCAATCCAGTACATGTGCCGCAAGGTACGTGTGCGAGGTATAAGAA-A-

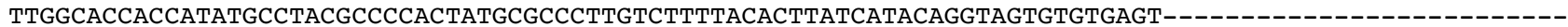
----------------GTACGCGTGTTGGTGTAA-

GCCGGCACTAGTGCTACTATTACT-_-_-

TCTGTGCAAAACGCATGGTCGGCATTAACTTGTTCGACTGTGTGCGGTTCTCATGAGCGTGGTTGGCTATCTT--

GCCTGGTAGCCGATGCGTCTTGTGCAGAGCTNNNNNNNNNNNNNNNNNNNNNNNNNNNNNNNNNNNNNNNNNNNNNNNNNNNNNNNNNNNNNNNNNNNNN NNNTTGCCACTCCACTCGAAGTCCAGCATTGAGTATGGTTT-

CTGGATTTGGCCCAGAGAGGGTGAAAGGCCCGTACGGGTGGAGGTATCAGACAAGTGAGGCAATTCACTAGGCCGGCCTTAGAGTCGGGTTGTTTGGGAA TGCAGCCCAAAGCGGGTGGTAAACTCCATCCAAGGCTAAATACTAGCACGAGTCCGATAGCAAACAAGTACCGTGAGGGAAAGTTGAAAAGTACTTTGAA GAGAGAGTAAACAGTACGTGAAACCGCATGCAGGTAAACGGGTGGCGTCAAGCTGCACGCCCAGAGGATTCAGCCGGTTAGAGTGTATC-

TATGCGCTTG-CGTATAAATGGGCCAGAGTAAGGCG----TGGTAGTCCGCTGGCAGACAGCGGGCCCTGCCGCAAGGTGGGGATGTG-----CAAGCCGGGTGGATGCCGGAGCACGCTATCCGTC--TGTGGGGCCGTCTAGCCGGTGCACTTTCTCTGT--

GGTGGACACCACGACCGGTGGAACTGCCAGTCTGCTGTGGCCAAGTCGTGTTCGGTTCGTCCTTGT-GGCGAACTGGGCGCGAT---CACGGGCAACCTTGGTGAACGGCGTTGATGTGCCCTC---------GGGTATGTCTTCGTGTTATCGGTAGCCAGTTGTCTTAACGGGCCTGCCTTGCGATTGTTCTAGCCGTCGTA---

GGGTGGTCTGGTGGGCCATGGTGGTAAGAATAACTGTGCAGGGCACCGGAGTGTTCAGCCTCAAATGCAGCCAGCATGCACGCTAGTAGTGT----TG---C---G---

ATGTGGGTGCTCTCGTGGTCTGCCTGGTGCCGGGTCTGATTGTCGTGTTGCCTGCGCAAAGAAATTTTTGGAGCCTTATTATAATGTTATTAGTGCAGAT TGTTATAAATTTTTAATTACTAACCATGGTATTATAATGATTTTTTTCTTTATAATGCCTATTTTAATAGGTGGCTTTGGTAATTATTTGATTCCTTTAT TGTGTGGGTTATCTGATCTAAATTTACCTCGTTTAAAAGCATTGAGTGCTTGATTGTTACTGCCTTCCGCTGTTTTTTTAGTAATAAGCATGTGTTTAGG AGCGGGGGTAGGTTGAACTTTTTATCCTCCTTTATCTTCGAGTTTATTTGAGAGTAGAAAGGGTGTGGATTTTTTAATGTTTTCTTTACATTTAGCAGGA GTTTCTAGTATTTTTAGTTCTATAAATTTTATTTGTACGTTATATACTGCTTTTAGGGGTAGTTTGGCGTCTCGAAGTTCGATAGTATTATGGGC r118_frt_salob_flk GGGAACTGCTATGTAACCTCT---C--GGACTGCCGGTCATGG-TGGTCCACAACC-

ATTTCGGTGGGGTGC CTACTTGCCCTATACTCCCAGGCGTGCTCGCCAGTCGTGGCAACTTAACTGCTGTCACGGCAATCGGCCAGTCCACACCGGAGCG GCAATCCAGTACATGTGCCGCAAGGTACGTGTGCGAGGTATAAGAA-

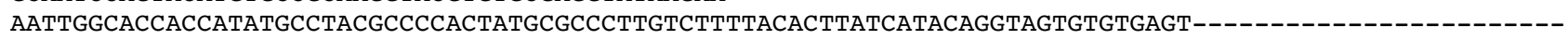
- - - - - - - - - - -

GCCGGCACTAGTGCTACTATGACT---

TCTGTGCAAAACGCATGGTCGGCATTAACTTGTTCGACTGTGTGCGGTTCTCATGAGCGTGGTTGGCTATCTT--

GCCTGGTAGTCGATGCGTCTTGTGCAGAGCTNNNNNNNNNNNNNNNNNNNNNNNNNNNNNNNNNNNNNNNNNNNNNNNNNNNNNNNNNNNNNNNNNNNNN

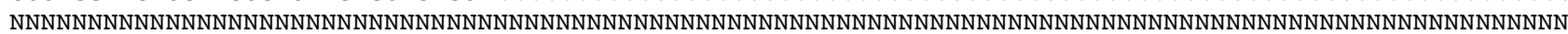

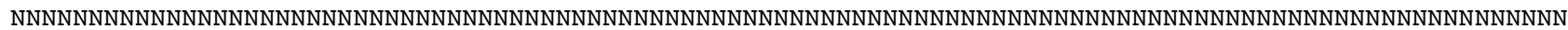

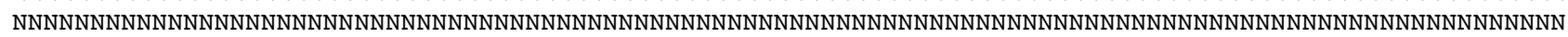

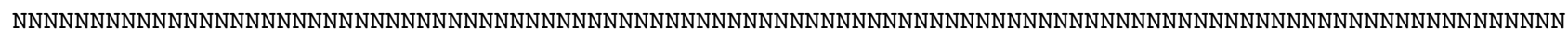

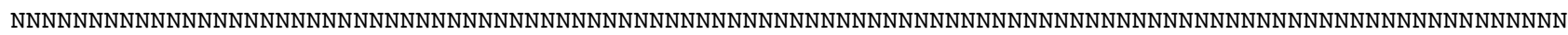

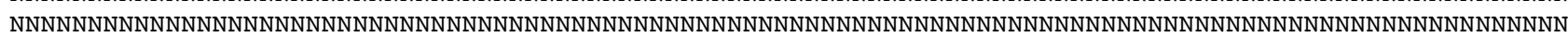

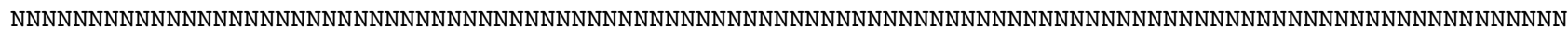

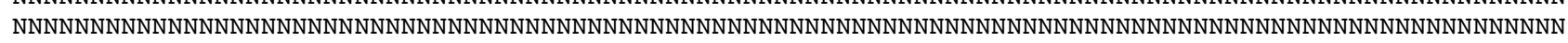

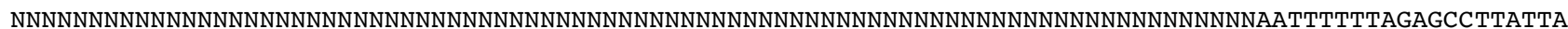
TAATGTTATTAGTACAGATTGTTATAAATTTTTAATTACTAACCATGGTATAATAATGATTTTTTTCTTTATAATGCCTATCTTAATAGGGGGATTTGGT AATTATTTGATTCCTTTATTGTGTGGCCTGTCAGATTTAAATTTACCACGTTTAAAAGCATTGAGTGCTTGATTGTTACTGCCTTCTGCAGTTTTTTTGA TAATAAGAATGTGTTTAGGGGCAGGGATAGGTTGAACTTTTTATCCACCTTTATCTTCAAGTTTATTTGAAGGGAGTAAGGGTGTAGATTTTTTGATGTT TTCATTACATTTGGCTGGTGTTTCTAGAATTTTTAGTTCTATAAATTTTATCTGTACTTTATATACTGCTTTTAGAGGTAGTTTGGCGTCTCGGAGTTCT ATAGTCTTATGAGC

r030_gld_lagonovo_mot GGGAACCGCTATGTAATCTAT---CTGGGACTGCCCGTCATGG-

TGGT $\bar{C}$ CAA $\bar{A} A C C C G T T T \bar{C} G$ TGGGGTGCCTACTTGCCTTATACTCCCAGGCGTGCTCGCCTGTTGTGGCAACTTAACTGCTGTCACAACAACCGGCCAGT CCACACCGGAGCGGCATATTAGTACACGTGTCA-AAG---CGTGTGCAAGGTATAAGAACA-

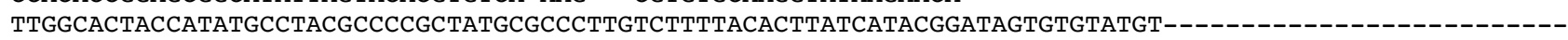
------_-_----_---GT--GTGTGTTAGTGTAT- 
GCTAGCATTACTACTACTACTG-

TCTGTGCAAAACGCACGGCGAGCATTAACTTGCTGTACTGTGTGTGGTTCTCATGAGCGTACTTGGTTACCTT--

GCCTGGGTGCCATTGCGTCTTGTGCAGAGCTNNNNNNNNNNNNNNNNNNNNNNNNNNNNNNNNNNNNNNNNNNNNNNNNNNNNNNNNNNNNNNNNNNNNN NNNTTGCCACTCCACTCGAAGTCCAGCATTGAGTATGGTTT-

CTGGATTTGGCCCAGAGAGGGTGAAAGGCCCGTACGGGTGGAGGTTTCAGACAAGTGAGGCAATTCACTAGGCCGGCCTTAGAGTCGGGTTGTTTGGGAA TGCAGCCCAAAGTGGGTGGTAAACTCCATCCAAGGCTAAATACTAGCACGAGTCCGATAGCAAACAAGTACCGTGAGGGAAAGTTGAAAAGTACTTTGAA GAGAGAGTAAACAGTACGTGAAACCGCATGCAGGTAAACGGGTGGCGTCAAGCTGCACGCCCAGAGGATTCAGCCGGTTAGAGTGTAGT-

TATGCGCTTG-CGTATCAAAGGGCCAGAGTAAGGCG----TGGTAGTCCGCTGGAAGACAGCGGGCCCTGCCGCAAGGTGGGGATGTG-----TAAGCCGGGTGGATGCCGGAGCACGCTATCCGTC--TGGAGGGCCGTCTAGCCGGTGCACTTTCTCTGT--

GGTGGACACCACGACCGGTGGAACTGCCAGTCTGCTATGGTCAAGTCGTGTTCGGTTGGTCCTTGT-GGCTAGCTGGGCGCGAT---CACGGGCAAATTTGGTGAACGGCGTTGATGTGCCCTC----------GGGTATGTCTTCGTGTTATCGGTAACCAGTTGTCTTAACGGGCCTGCCTTACGATTGTTCTAGCCGTCGTA---

GGGTGGTCTGGTGGGCCATAGTGGTAAGAATAACTGTGCAGGGCACCGGAGTTTTCGGCCTCAAACGCAGCCAGCATGCACGCTAGTAGTGT----TG---C--TG---

ATGTGGGTGCTCTCGTGGTCTGCCTGGTGCCGGGTCTGATTGTCGTGTTGCCTACGCAAAGAAATTTTTGGAGCCTTATTATAATGTGATTAGTACAGAT TGTTATAATTTTCTGATTACTAAACATGGTATTATAATGATTTTCTTTTTTATAATGCСTATTTTAATAGGGGGGTTTGGTAACTATTTAATTCCTTTAT TAAGAGGTTTGTCCGATTTAAATTTGCCTCGTTTAAAAGCTTTGAGTGCTTGATTGCTTTTACCTTCTGCTGTATTTTTAGTGATTAGTATGTGTTTAGG TGCTGGTATAGGTTGAACTTTCTATCCTCCTTTGTCTTCTAGTGTTTTTGAGGGTAGTAAGGGTGTAGACTTTTTAATGTTTTCATTACATTTGGCTGGT GTTTCTAGTATATTTAGTTCTATTAATTTTATATGTACTTTGTATACTGCCTTTAGTGGTAGGTTGGCTTCTCGTAGTTCAATTGTATTATGAGC r250_rhoides_negro_spnGGGAACTGCTATGTAACCTCT---C--GGACTGCCCGTCATGGATGGTCCACAACC-

АTTTCGTGGGGTGCCTACTTGCCCTATACTCCCAGGCGTGCTCGCCAGTCGTGGCAACTTAACTGCTGTCACGGCAATCGGCCAGTCCACACCGGAGCG GCAATCCAGTACATGTGCCGCAAGGTACGTGTGCGAGGTATAAGAA-A-

TTGGCACCACCATATGCCTACGCCCCACTATGCGCCСTTGTCTTTTACACTTATCATACAGGTAGTGTGTGAGT---------------------------------------GTACGCGTGTTGGTGTAA-

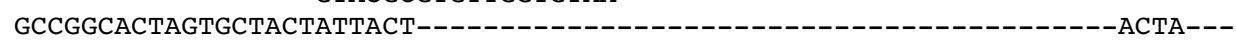

TCTGTGCAAAACGCATGGTCGGCATTAACTTGTTCGACTGTGTGCGGTTCTCATGAGCGTGGTTGGCTATCTT--

GCCTGGTAGCCGATGCGTCTTGTGCAGAGCTNNNNNNNNNNNNNNNNNNNNNNNNNNNNNNNNNNNNNNNNNNNNNNNNNNNNNNNNNNNNNNNNNNNNN NNNTTGCCACTCCACTCGAAGTCCAGCATTGAGTATGGTTT-

CTGGATTTGGCCCAGAGAGGGTGAAAGGCCCGTACGGGTGGAGGTATCAGACAAGTGAGGCAATTCACTAGGCCGGCCTTAGAGTCGGGTTGTTTGGGAA TGCAGCCCAAAGCGGGTGGTAAACTCCATCCAAGGCTAAATACTAGCACGAGTCCGATAGCAAACAAGTACCGTGAGGGAAAGTTGAAAAGTACTTTGAA GAGAGAGTAAACAGTACGTGAAACCGCATGCAGGTAAACGGGTGGCGTCAAGCTGCACGCCCAGAGGATTCAGCCGGTTAGAGTGTATC-

TATGCGCTTG-CGTATAAATGGGCCAGAGTAAGGCG----TGGTAGTCCGCTGGTAGACAGCGGGCCCTGCCGCAAGGTGGGGATGTG-----CAAGCCGGGTGGATGCCGGAGCACGCTATCCGTC--TGTGGGGCCGTCTAGCCGGTGCACTTTCTCTGT--

GGTGGACACCACGACCGGTGGAACTGCCAGTCTGCTGTGGCCAAGTCGTGTTCGGTTCGTCCTTGT-GGCGAACTGGGCGCGAT---CACGGGCAACCTTGGTGAACGGCGTTGATGTGCCCTC-----------GGGTATGTCTTCGTGTTATCGGTAGCCAGTTGTCTTAACGGGCCTGCCTTGCGATTGTTCTAGCCGTCGTA---

GGGTGGTCTGGTGGGCCATGGTGGTAAGAATAACTGTGCAGGGCACCGGAGTGTTCAGCCTCAAATGCAGCCAGCATGCACGCTAGTAGTGT----TG---C---G---

ATGTGGGTGCTCTCGTGGTCTGCCTGGTGCCGGGTCTGATTGTCGTGTTGCCTGCGCAAAGAAATTTTTGGAGCCTTATTATAATGTTATTAGTACAGAT TGTTATAAATTTTTAATTACTAACCATGGTATTATAATGATTTTTTTCTTTATAATGCCTATTTTAATAGGTGGCTTTGGTAATTATTTGATTCCTTTAT TGTGTGGGTTATCTGATTTAAATTTACCTCGTTTAAAAGCATTGAGTGCTTGATTGTTACTGCCTTCCGCTGTTTTTTTAGTAATAAGTATGTGTTTAGG AGCGGGAGTAGGTTGAACTTTTTATCCTCCTTTATCTTCGAGTTTATTTGAGAGTAGAAAGGGTGTGGATTTTTTAATGTTTTCTTTACATTTAGCAGGA GTTTCTAGTATTTTTAGTTCTATAAATTTATTTGTACGTTATATACTGCTTTTAGGGGTAGTTTGGCGTCTCGGAGTTCGATAGTATTATGGGC CH10_Rhinebothrium_megacanthocephalus_LRP3901

NNNNNNNNNNNNNNNNNNNNNNNNNNNNNNNNNNNNNNNNNNNNNNNNNNNNNNNNNNNNNNNNNNNNNNNNNNNNNNNNNNNNNNNNNNNNNNNNNNNN

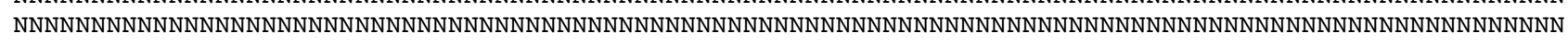

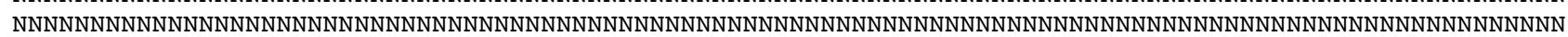

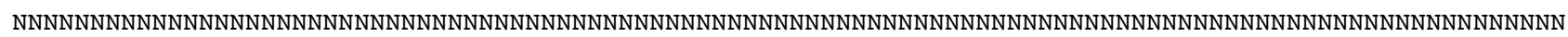

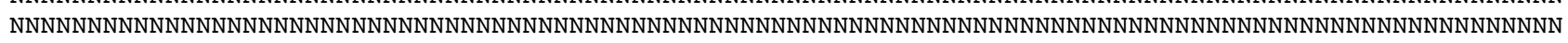
NNNNNNNNNNNNNNNNNNNNNNGGAAGAGCCCAGCACCGAAGCCTGCGGTAGCTTTACTGTTAGGCAATGTGGTGTTTGGGTCGGCTCGCGGGATTGCCA CTCCACTCGAAGTCCAGCATTGAGTATGGTCCACTGGATTTGGCCCAGAGAGGGTGAAAGGCCCGTACGGGTGGAGGTTTCAGACAAGTGAGGCAATTCA CTAGGCCGGCCTTAGAGTCGGGTTGTTTGGGAATGCAGCCCAAAGTGGGTGGTAAACTCCATCCAAGGCTAAATACTAGCACGAGTCCGATAGCAAACAA GTACCGTGAGGGAAAGTTGAAAAGTACTTTGAAGAGAGAGTAAACAGTACGTGAAACCGCATGCAGGTAAACGGGTGGCGTCAAGCTGTACGCCCGGAGG ATTCAGCCGGTTAGAGTGTAGT-CATGCGCTTG-CGCATCGAAAGGCCAGTGTAAGCAT----

GGGTAGTCTACTGGAAGACAGTGGGCCCTGCCGCAAGGTGGGGACGTG-----C-GTACCGGGTGGAAGCCGGAGCACGCTATCCGTC--

TGTTGGGCCATCTAGCCGGTGCACTTTCTCCGT--

GGTGGACACCACGACCGGTGGAACTGCCAGTCTGCTGTAGCCAAGTCGTGTCCGGTTGGTCCCTGT-GGCCTACGGGGCACGAT---CACGGGCAAACTCGGTGAACGGCGTTGGTGCGTCCTC----------GGGCGCGTCTTCGTGTTATCGGTAACCGGTTGTCTTAACGGGCCTGCCTCGCGAGTGTTTTAGCCGTCGTG---

GGGTGGTCTGGTGGGCTACAGTGGTAAGAATAACTGTGCAGGGCATCGGAGTTCTCGGCCTCAATTGCAGTCGGCATGCACGCTAGAAGTGT-----

GA---TTG-G---

ATGCTGGCGCTCTCGCTGCCTGCCTGGTGTCGGGTCTGATTGTCGTGTTGCCTGCGAAAAGAAATTTTTAGAGCCTTATTATAATTTAATTAGCTCTGAC TGTTATAAATTTTAATTACTAATCATGGCATTATAATGATATTCTTTTTTTTGATGCCTATTCTTATAGGCGGGTTTGGTAATTATTTATTACCTCTGT TATGTGGTTTGTCTGATTTAAATTTGCCTCGATTAAAAGCATTGAGTGCATGATTATTGTTACCTTCCATGGTTTTTTTAATTGTGAGTATGTGTTTAGG GGCAGGTATTGGGTGAACTTTTTATCCACCTTTATCTGCCAGTTTATTTTCAGGCAGAAAGGGTGTAGATTTTTTGATGATATCATTACATCTTGCAGGT GTTTCAAGTATTTTTGGATCTATTAAATTTATCTGCACACTTTATAGTGCATTTAGCGGGAGTTTAGCATCACGTAGTTCTATTGTGTTGTGATC r09_scorzai_marajo_motGGGAACTGCTATGTAACAACAATACTCGGACCGCTCGTCATAG-TGGTCTGCTACC-

ATTT̄CGGTGGGGTGCCTATTTGCCTATACTCCCAGGCGTGCTCGCCAGCTGCGGCAACTTAACTGCTGCCACAGCAAGAGGCCAGTCCACACCGGAGCG GCAAACCAGTACATGTGTCGCAAG---CGTGTGCAAGGTATAAGAA-A-

TTGGCACTACCATATGCCTACGCCCCACTATGCGCCCCTGTCTTTTACACTTACTATACGGGTAGTGTGTGTGTATGTGAGTGTGTGTGTGTGTGTGTGC GTGCGTGCGTGTTGGTATGTAGGTGTGCTGGTGTAT-GCCAGCATTACTACTACTACTACTGCTACCACCACCACCAC---------

TACTACTACTACTACTACTA---

TCTGTGCAAAACGNNNNNNNNNNNNNNNNNNNNNNNNNNNNNNNNNNNNNNNNNNNNNNNNNNNNNNNNNNNNNNNNNNNNNNNNNNNNNNNNNNNNNNN

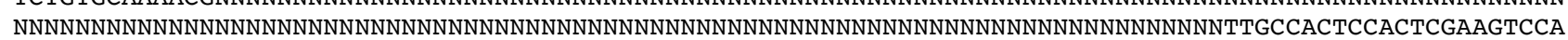
GCATTGAGTATGGTTT-

CTGGATTTGGCCCAGAGAGGGTGAAAGGCCCGTACGGGTGGAGGTGTCAGACAAGTGAGGCAATTCACTAGGCCGGCCTTAGAGTCGGGTTGCTTGGGAA TGCAGCCCAAAGTGGGTGGTAAACTCCATCCAAGGCTAAATACTAGCACGAGTCCGATAGCAAACAAGTACCGTGAGGGAAAGTTGAAAAGTACTTTGAA 
GAGAGAGTAAACAGTACGTGAAACCGCATGCAGGTAAACGGGTGGCGTCAAGCTGCACGCCCAGAGGATTCAGCCGGTTAGAGTGTAGTTATGCGCTTG-CGTATCGAAGGGCCAGAGTAAAGCGCGCGTGGTAGTCCGCTGGAAGACAGCGGGCCCTGCCGCAAGGTGGGGATGTG-----TAAGCCGGGTGGAAGCCGGAGCACGCTATCCGTC--TGCGGGGCCGTCTAGCCGGTGCACTTTCTCTGT--

GGTGGACACCACGACCGGTGGAACTGCCAGTCTGCTATGGTCAAGTCGTGTTCGGTTGGTCCTTGT-GGCGAACTGGGCGCGAT---CACGGGCAAATTTGGTGAACGGCGTTGATGTGCCCTC-----------GGGTGCGTCTTCGTGCTATCGGTAGCCAGTTGTCTTAACGGGCCTGCCTTACGATTGTTCTAGCCGTCGTA---

GGGTGGTCTGGTGGGCCGTAGTGGTAAGAATAACTGTGCAGGGCACTGGAGTTATCGGCCTCAAACGCAGCCAGCATGCACGCTAGTAGTGTGTCCCTG$--\mathrm{G}---\mathrm{T}---$

ATGTGGGTGCTCTCGTGGTCTGCCTGGTGCCGGGTCTGATTGTCGTGTTGCCTACGCAAAGAAATTTTTAGAACCTTACTATAATGTTATTAGTACTGAT TGTTATAAATTTTGATTACTAATCATGGTATTATAATGATTTTTTTTTTTATAATGCCTATTTTAATTGGTGGGTTTGGTAATTATTTAATTCCTTTAT TATGTGGTTTATCTGATTTAAACTTACCACGTTTAAACGCGCTTAGTGCTTGGTTACTTTTACCTTCTGTGTTATTTTTAGTTATAAGAATGTGTTTAGG GGCTGGGGTAGGTTGAACTTTTTATCCTCCCTTAGCTTCCAGTGCATTTGAGGGGAGTAAGGGTGTAGACTTTTTAATGTTTTCTTTACACTTAGCGGGG GTTTCTAGAATTTTAGCTCTATTAATTTTATTTGTACTTTACACACTGCCTTTAGGGGTAATTTAGCTTCTCGTAGTTCTATTGTATTATGGGC 15Rhinebothrium_copianullum_worm_1

NNNNNNNNNNNNNNNNNNNNNNNNNNNNNNNNNNNNNNNNNNNNNNNNNNNNNNNNNNNNNNNNNNNNNNNNNNNNNNNNNNNNNNNNNNNNNNNNNNNN

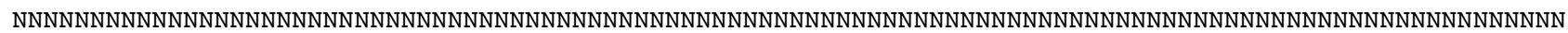

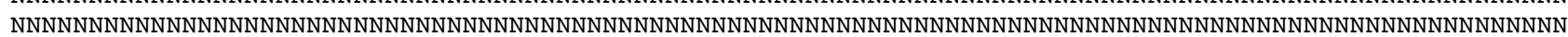

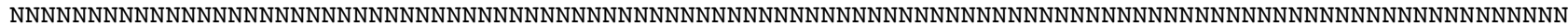

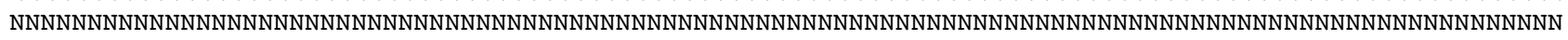
NNNNNNNNNNNNNNNNNNNNNNGGAAGAGCCCAGCACCGAAGCCTGCGGTAGCTTTACTGTTAGGCAATGTGGTGTTTGGGTCGGCTCGCGGGATTGCCA CTCCACTCGAAGTCCAGCATTGAGTATGGTTT-

CTGGATTTGGCCCAGAGAGGGTGAAAGGCCCGTACGGGTGGAGGTATCAGACAAGTGAGGCAATTCACTAGGCCGGCCTTAGAGTCGGGTTGTTTGGGAA TGCAGCCCAAAGTGGGTGGTAAACTCCATCCAAGGCTAAATACTAGCACGAGTCCGATAGCAAACAAGTACCGTGAGGGAAAGTTGAAAAGTACTTTGAA GAGAGAGTAAACAGTACGTGAAACCGCATGCAGGTAAACGGGTGGCGTCAAGCTGCACGCCCAGAGGATTCAGCCGGTTAGAGTGTAGT-

TATGCGCTTG-CGTGTCGACAGGCCAGAGTAAGGCG----TGGTAGACCGCTGGAAGACAGTGGGCCCTGCCGCAAGGTGGGGATGTG-----

TTTAGCCGGGTGGACGCCGGAGCACGCTATCCGTC--TGTTGGGCCTACTAGCCGGTGCACTTTCTCTGT--

GGTGGACACCACGACCGGTGGGACTGCCAGTCTGCTATGGTCAAGTCGTATTCGGTTGGTCCTTGT-GGCTTACTGGGTGCGAT---CACGGGCAAACTTGGTGAACGGCGTTGACGTGCTCTC----TTGA----GGGTGTGTCTTCGTGTTATCGGTAGCCAGTTGTCTTAACGGGCCTGCCTTACGATTGTTCTAGCCGTCGTA---

GGGTGGTCTGGTGGACCATGGTGGTAAGAATAACTGTGCAGGGCACCGGAGTTTTCGGCCTCAAATGCAGCCAGCATGCACGCTAGTAGTGT-----

GT---T---

GCCAATGTGGGTGCTCTCGTGGTCTGCCTGGTGCCGGGTCTGATTGTCGTGTTGCCTACGCAAAGAAATTTTTAGAGCCATATTATAATGTTATTAGAAC AGATTGTTATAATTTTTAATTACTAACCACGGTATAATAATGATTTTTTTTTTCATAATGCCTATTTTAATAGGGGGTTTTGGTAATTATTTAATACCT CTATTGTGTGGTTTATCTGATTTAAACTTACCACGCTTAAAAGCTCTTAGAGCTTGGTTGTTACTGCCTTCTGCTGTTTTTTTAGTTGTGAGCATGTGTT TGGGTGCAGGAGTAGGATGAACCTTTTATCCTCСTTTATCTTCTAGTTTATTTGAAGGCAGTAAGGGAGTAGACTTTTTAATGTTTTCATTGCATTTAGC TGGGGTTTCCAGAATTTTAAGTCTATAAATTTTATGTGTACTTTATATACAGCTTTTAGTGATAGATTAGCATCACGTAGTTGTATTATATTATGGTC 25Rhinebothrium_sp_1_worm_11

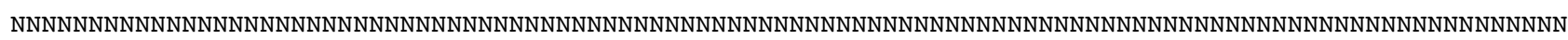

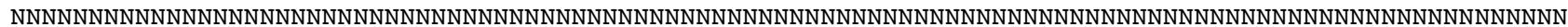

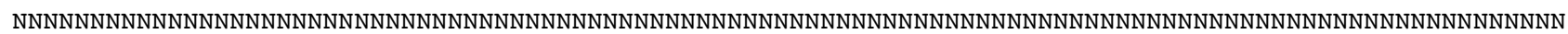

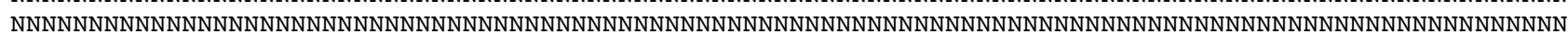

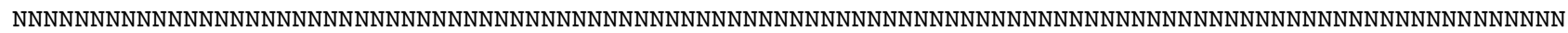
NNNNNNNNNNNNNNNNNNNNNNGGAAGAGCCCAGCACCGAAGCCTGCGGTAGCTTTACTGTTAGGCAATGTGGTGTTTGGGTCGGCTCGCGGGATTGCCA CTCCACTCGAAGTCCAGCATTGAGTATGGTTT-

CTGGATTTGGCCCAGAGAGGGTGAAAGGCCCGTACGGGTGGAGGTATCAGACAAGTGAGGCAATTCACTAGGCCGGCCTTAGAGTCGGGTTGTTTGGGAA TGCAGCCCAAAGTGGGTGGTAAACTCCATCCAAGGCTAAATACTAGCACGAGTCCGATAGCAAACAAGTACCGTGAGGGAAAGTTGAAAAGTACTTTGAA GAGAGAGTAAACAGTACGTGAAACCGCATGCAGGTAAACGGGTGGCGTCAAGCTGCACGCCCAGAGGATTCAGCCGGTTAGAGTGTAGTTATGCGCTTG-CGTGTCAACAGGCCAAAGTAAGGCG----TGGTAGACCGCTGGAAGACAGTGGGCCCTGCCGCAAGGTGGGGATGTG----TTTAGCCGGGTGGACGCCGGAGCACGCTATCCGTC--TGTTGGGCCTACTAACCGGTGCACTTTCTCTGT--

GGTGGACACCACGACCGGTGGGACTGCCAGTCTGCTATGGTCAAGTCGTATTCGGTTGGTCCTTGT-GGCTAACTGGGTGCGAT---CACGGGCAAACTTGGTGAACGGCGTTGACGTGCTCTC----TTGA----GGGTGTGTCTTCGTGTTATCGGTAACCAGTTGTCTTAACGGGCCTGCCTTACGATTGTTCTAGCCGTCGTA---

GGGTGGTCTGGTGGACCATGGTGGTAAGAATAACTGTGCAGGGCACCGGAGTTTTCGGCCTCAAATGCAGCCAGCATGCACGCTAGTAGTGT----GT---T---

GCCAATATGGGTGCTCTCGTGGTCTGCCTGGTGCCGGGTCTGATTGTCGTGTTGCCTACGCAAAGAAATTTTTAGAGCCGTACTATAATGTTATTAGTAC GGACTGCTATAAATTTTTAATTACTAATCATGGTATTATAATGATTTTTTTCTTTATAATGCCTATTTTGATAGGAGGTTTTGGTAATTATTTGATTCCA TTACTTTGTGGTTTATCCGATTTAAATCTACCTCGTTTAAAAGCACTTAGAGCTTGGTTGTTGTTGCCTTCAGCTCTTTTTTTGGTGGTGAGCATGTGCT TAGGGGCTGGTATAGGTTGGACTTTTTATCCTCCTTTATCTTCTAGATTATTTGAAGGTAGTAAGGGGGTAGATTTTTTAATGTTTTCGTTGCATTTAGC AGGAATTTCTAGTATTTTTAGGTCTATTAAATTTATTTGTACTTTATATACTGCTTTTAGTGATAGTTTAGCATCACGTAGTTGTATTATATTATGATC r036_gld_jamanxim_tpj1GGGAACCGCTATGTAATCTAT---CTGGGACTGCCCGTCATGG-

TGGTC $\bar{C}$ AA $\bar{A} A C C C G T T T \bar{C} G$ GTGGGTGCCTACTTGCCTTATACTCCCAGGCGTGCTCGCCTGTTGTGGCAACTTAACTGCTGTCACAACAACCGGCCAGT CCACACCGGAGCGGCATATTAGTACACGTGTCA-AAG---CGTGTGCAAGGTATAAGAACA-

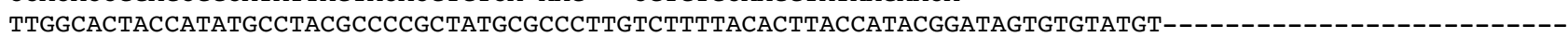
---------------GT--GTGTGTTAGTGTAT-

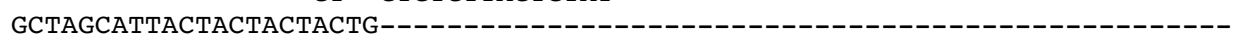

TCTGTGCAAAACGCATGGAGAGCATTAACTTGCTGTACCGTGTGTGGTTCTCATGAGCGTACTTGGTTACCTT--

GCCTGGGTGCCATTGCGTCTTGTGCAGAGCTNNNNNNNNNNNNNNNNNNNNNNNNNNNNNNNNNNNNNNNNNNNNNNNNNNNNNNNNNNNNNNNNNNNNN

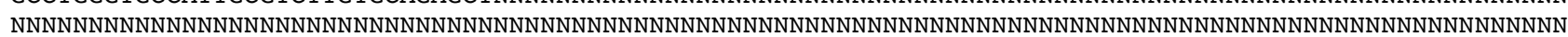
NNNNNNNNNNNNNNNNGGCCTTAGAGTCGGGTTGTTTGGGAATGCAGCCCAAAGTGGGTGGTAAACTCCATCCAAGGCTAAATACTAGCACGAGTCCGAA TAGCAACAAGTACCGTGAGGGAAAGTTGAAAAGTACTTTGAAGAGAGAGTAAACAGTACGTGAAACCGCATGCAGGTAAACGGGTGGCGTCAAGCTGCAC GCCCAGAGGATTCAGCCGGTTAGAGTGTAGT-TATGCGCTTG-CGTATCAAAGGGCCAGAGTAAGGCG----

TGGTAGTCCGCTGGAAGACAGCGGGCCCTGCCGCAAGGTGGGGATGTG-----T-AAGCCGGGTGGATGCCGGAGCACGCTATCCGTC-TGGAGGGCCGTCTAGCCGGTGCACTTTCTCTGT--

GGTGGACACCACGACCGGTGGAACTGCCAGTCTGCTATGGTCAAGTCGTGTTCGGTTGGTCCTTGT-GGCTAGCTGGGCGCGAT---CACGGGCAAATTTGGTGAACGGCGTTGATGTGCCCTC---------GGGTATGTCTTCGTGTTATCGGTAACCAGTTGTCTTAACGGGCCTGCCTTACGATTGTTCTAGCCGTCGTA--- 
GGGTGGTCTGGTGGGCCATAGTGGTAAGAATAACTGTGCAGGGCACCGGAGTTTTCGGCCTCAAACGCAGCCAGCATGCACGCTAGTAGTGT----TG---C--TG---

ATGTGGGTGCTCTCGTGGTCTGCCTGGTGCCGGGTCTGATTGTCGTGTTGCCTACGCAAAGAATTTTTTGGAGCCTTATTATAATGTGATTAGTACAGAT TGTTATAATTTTCTGATTACCAAACATGGTATTATAATGATTTTCTTTTTTATAATGCCTATCTTAATAGGGGGGTTTGGTAATTATTTAATTCCCTTAT TAAGGGGTTTGTCCGATTTAAACTTGCCTCGTTTAAAAGCCTTGAGTGCTTGATTGCTTTTACCTTCTGCTGTATTTTTAGTGATTAGTATGTGTTTAGG TGCTGGTATAGGTTGAACTTTCTATCCTCCTTTGTCTTCTAGTGTTTTTGAGGGGAGTAAGGGTGTAGACTTTTTAATGTTTTCATTGCATTTGGCTGGT GTTTCTAGTATATTTAGTTCTATTAATTTATATGTACTTTGTATACTGCCTTTAGTGGTAGGTTGGCTTCTCGTAGTTCAATTGTATTATGAGC CH4_Scalithrium_sp_LRP3895

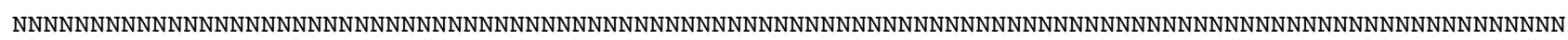

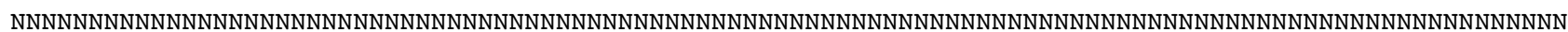

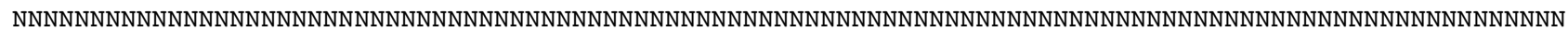

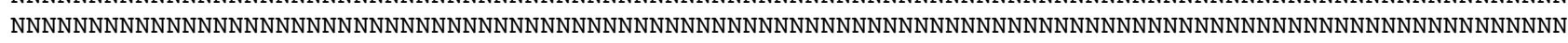
NNNNNNNNNNNNNNNNNNNNNNNNNNNNNNNNNNNNNNNNNNNNNNNNNNNNNNNNNNNNNNNNNNNNNNNNNNNNNNNNNNNNNNNNNNNNNNNNNNNN NNNNNNNNNNNNNNNNNNNNNNGGAAGAGCCCAGCACCGAAGCCTGCGGTAGTTTTACTGTTAGGCAATGTGGTGTTTGGGTCGGCTCGCGGGATTGCCA СTCCACTCGAAGTCCAGCATTGAGTATGGTCCACTGGATTTGGCCCAGAGAGGGTGAAAGGCCCGTACGGGTGGAGGTTTCAGACAAGTAAGGCAATTCA CCAGGCCGGCCTTAGAGTCGGGTTGTTTGAGAATGCAGCCCAAAGTGGGTGGTAAACTCCATCCAAGGCTAAATACTGGCACGAGTCCGATAGCAAACAA GTACCGTGAGGGAAAGTTGAAAAGTACTTTGAAGAGAGAGTAAACAGTACGTGAAACCGCATGCAGGTAAACGGGTGGCGTCAAGCTGCAAGCCCAGAGG ATTCAGCCGGTTAGAGTGTAGT-TACGCGCCTG-CGCGTCAACCAGCCAGTGTAAGATT----

GGGTAGTCCGCTGGAAGACAGTGGGCCCTGCCGCAAGGTGGGGATGTG-----T-GTACCGGGCGGAAGCCGGAGCACGCTGCCTGTC--

TGTTGGGCTGTCTAGCCGGTGCACTTTCTCTGT--

GGTGGACACCACGACCGGTGGGACTGCCAGTCTGCCGTGGCCAAGTCGTGTTCGGTTGGTCCCTGT-GGCCTACTGGATGCGAT---CACGGGCAAACTCGGTGTACGGCGTTGACGCGCTCTC---------_GGTGCGTCTTCGTGTTATCGGGCATCGGTTGTCTTAACGGGCCTGCCTGACGATTGTTGTAGCCGTCGTC---

GGGTGGTCTGGTGGGCCTCGGTGGTAAGAATAACTGTGCAGGGCACCGGAGTTGTCGGCCTCAAATGCAGCCAGCATGCACGCTATAAGTGT-----

TG---T---G---

ATGCGGGTGCTCTCGTTGTCTGCCTGTTGTCGGGTCTGATTGTCGTGTTGCCTGCGCAAAGAACTTTCTGGAGCCGTACTATAATATAATAAGTGTTGAT TGTTATAAATTTTTAATAACGAAACATGGTATTATAATGATTTTTTTCTTTATAATGCCTATCTTAATAGGGGGTTTCGGTAACTATTTAATCCCGTTGC TTTGCGGGTTATCTGATTTAAATTTGCCGCGTTTAAATGCTTTAAGAGCATGGTTGTTGTTACCTTCAATGGTTTTTTTGTTAGTTAGGATGTGTTTAGG CGCGGGTATAGGGTGGACGTTTTATCCGCCTTTATCTTCTAGGGCTTTTACAAGAAGAAAGGGGGTAGATTTTTTAATGTTTTCTTTACATTTGGCTGGT GTTTCTAGTGTTTTTGGTTCAATAAAATTTATTTGTACTTTATACTCTTCATTTAGTGGTAAATTAGGGTCTCGAGGTTCTATAATTTTATGATC r245_frt_xingu_leop GGGAACTGCTATGTAACCTCT---C--GGACTGCCCGTCATGG-TGGTCCACAACC-

АTTTCGGTGGGGTGC CTACTTGCCCTATACTCCCAGGCGTGCTCGCCAGTCGTGGCAACTTAACTGCTGTCACGGCAATCGGCCAGTCCACACCGGAGCG GCAATCCAGTACATGTGCCGCAAGGTACGTGTGCGAGGTATAAGAA-A-

TTGGCACCACCATATGCCTACGCCCCACTATGCGCССTTGTCTTTTACACTTATCATACAGGTAGTGTGTGAGT---------------------------------------GTACGCGTGTTGGTGTAA-

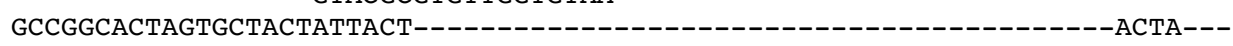

TCTGTGCAAAACGCATGGTCGGCATTAACTTGTTCGACTGTGTGCGGTTCTCATGAGCGTGGTTGGCTATCTT--

GCCTGGTAGCCAATGCGTCTTGTGCAAAGCTNNNNNNNNNNNNNNNNNNNNNNNNNNNNNNNNNNNNNNNNNNNNNNNNNNNNNNNNNNNNNNNNNNNNN NNNTTGCCACTCCACTCGAAGTCCAGCATTGAGTATGGTTT-

CTGGATTTGGCCCAGAGAGGGTGAAAGGCCCGTACGGGTGGAGGTATCAGACAAGTGAGGCAATTCACTAGGCCGGCCTTAGAGTCGGGTTGTTTGGGAA TGCAGCCCAAAGCGGGTGGTAAACTCCATCCAAGGCTAAATACTAGCACGAGTCCGATAGCAAACAAGTACCGTGAGGGAAAGTTGAAAAGTACTTTGAA GAGAGAGTAAACAGTACGTGAAACCGCATGCAGGTAAACGGGTGGCGTCAAGCTGCACGCCCAGAGGATTCAGCCGGTTAGAGTGTATC-

TATGCGCTTG-CGTATAAATGGGCCAGAGTAAGGCG----TGGTAGTCCGCTGGTAGACAGCGGGCCCTGCCGCAAGGTGGGGATGTG-----CAAGCCGGGTGGATGCCGGAGCACGCTATCCGTC--TGTGGGGCCGTCTAGCCGGTGCACTTTCTCTGT--

GGTGGACACCACGACCGGTGGAACTGCCAGTCTGCTGTGGCCAAGTCGTGTTCGGTTCGTCCTTGT-GGCGAACTGGGCGCGAT---CACGGGCAACCTTGGTGAACGGCGTTGATGTGCCCTC----------GGGTATGTCTTCGTGTTATCGGTAGCCAGTTGTCTTAACGGGCCTGCCTTGCGATTGTTCTAGCCGTCGTA---

GGGTGGTCTGGTGGGCCATGGTGGTAAGAATAACTGTGCAGGGCACCGGAGTGTTCGGCCTCAAATGCAGCCAGCATGCACGCTAGTAGTGT-----

TG---C---G---

ATGTGGGTGCTCTCGTGGTCTGCCTGGTGCCGGGTCTGATTGTCGTGTTGCCTGCGCAAAGAAATTTTTGGAGCCTTATTATAATGTTATAAGCACAGAT TGTTATAAATTTTTAATTACTAATCATGGTATTATAATGATTTTCTTTTTTATAATGCCTATTTTAATCGGTGGATTTGGCAATTATTTAATTCCTTTGT TATGTGGTTTATCTGATTTAAAATTACCTCGTTTAAAAGCATTGAGTGCTTGATTATTATTGCCTTCTGCTGTTTTTTTAGTAATAAGTATGTGTTTAGG GGCAGGGGTAGGTTGGACTTTTTACCСTCCTTTATCTTCAAGTTTATTTGAGGGTAGGAAGGGAGTAGATTTTTTAATGTTTTCTTTACACTTAGCAGGA GTTTCTAGTATTTTTAGTTCTATAAATTTTATTTGCACTTTATATACTGCTTTTAGCGGTAGTTTGGCGTCTCGAAGTTCGATAATATTATGAGC r119 frtsalob flk GGGAACTGCTATGTAACCTCT---C--GGACTGCTGGTCATGG-TGGTCCACAACC-

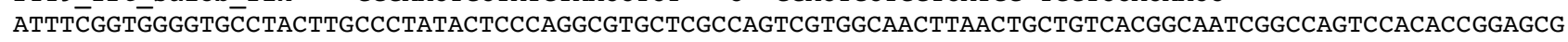
GCAATCCAGTACATGTGCCGCAAGGTACGTGTGCGAGGTATAAGAA-

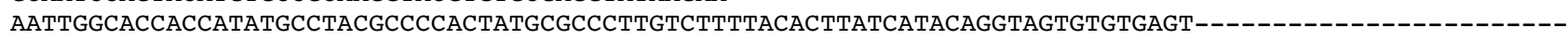
AATTGGCACCACCATATGCCTACGCCCCACTATGCGCCCTT

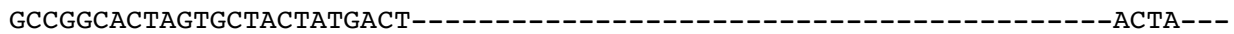

TCTGTGCAAAACGCATGGTCGGCATTAACTTGTTCGACTGTGTGCGGTTCTCATGAGCGTGGTTGGCTATCTT--

GCCTGGTAGTCGATGCGTCTTGTGCAGAGCTGGAAGAKCCCAGCACCGAAGCCTGCGGCAGGTTTGCTGTTAGGCAATGTGGTGTTTGGGTCGGCTCGCG GGATTGCCACTCCACTCGAAGTCCAGCATTGAGTATGGTTT-

CTGGATTTGGCCCAGAGAGGGTGAAAGGCCCGTACGGGTGGAGGTATCAGACAAGTGAGGCAATTCACTAGGCCGGCCTTAGAGTCGGGTTGTTTGGGAA TGCAGCCCAAAGCGGGTGGTAAACTCCATCCAAGGCTAAATACTAGCACGAGTCCGATAGCAAACAAGTACCGTGAGGGAAAGTTGAAAAGTACTTTGAA GAGAGAGTAAACAGTACGTGAAACCGCATGCAGGTAAACGGGTGGCGTCAAGCTGCACGCCCAGAGGATTCAGCCGGTTAGAGTGTATC-

TATGCGCTTG-CGTATAAATGGGCCAGAGTAAGGCG----TGGTAGTCCGCTGGTAGACAGCGGGCCCTGCCGCAAGGTGGGGATGTG-----C-

AAGCCGGGTGGATGCCGGAGCACGCTATCCGTC--TGTGGGGCCGTCTAGCCGGTGCACTTTCTCTGT--

GGTGGACACCACGACCGGTGGAACTGCCAGTCTGCTGTGGTCAAGTCGTGTTCGGTTGGTCCTTGT-GGCGAACTGGGCGCGAT---CACGGGCAACCTTGGTGAACGGCGTTGATGTGCCCTC-----------GGGTATGTCTTCGTGTTATCGGTAGCCAGTTGTCTTAACGGGCCTGCCTTGCGATTGTTCTAGCCGTCGTA---

GGGTGGTCTGGTGGGCCATGGTGGTAAGAATAACTGTGCAGGGCACCGGAGTGTTCGGCCTCAAATGCAGCCAGCATGCACGCTAGTAGTGT-----

TG---C---G---

ATGTGGGTGCTCTCGTGGTCTGCCTGGTGCCGGGTCTGATTGTCGTGTTGCCTGCGCAAAGAATTTTTTAGAGCCTTATTATAATGTTATTAGTACAGAT TGTTATAAATTTTAATTACTAACCATGGTATAATAATGATTTTTTTCTTTATAATGCCTATCTTAATAGGGGGATTTGGTAATTATTTGATTCCTTTAT TGTGTGGCTTGTCAGATTTAAATTTACCACGTTTAAAAGCATTAAGTGCTTGATTGTTACTGCCTTCTGCAGTTTTTTTGATAATAAGTATGTGTTTAGG GGCAGGAATAGGTTGAACTTTTTATCCACCTTTATCTTCAAGTTTATTTGAAGGGAGTAAGGGTGTAGATTTTTTGATGTTTTCATTACATTTGGCTGGT 
GTTTCTAGAАTTTTAGTTCTATAAATTTTATTTGTACTTTATATACTGCTTTTAGAGGTAGTTTGGCGTCTCGAAGTTCTATAGTCTTGTGAGC r243 gld toc toc2 GGGAACCGCTATGTAATCTAT---CTGGGACTGCCCGTCATGG-

TGGTC CAA $\bar{A} A C C \bar{C} G T T T C G G T G G G G T G C C T A C T T G C C T T A T A C T C C C A G G C G T G C T C G C C T G T T G T G G C A A C T T A A C T G C T G T C A C A A C A A C C G G C C A G T$ CCACACCGGAGCGGCATATTAGTACACGTGTCA-AAG---CGTGTGCAAGGCATAAGAACA-

TTGGCACTACCATATGCCTACGCCCCGCTATGCGCCCTTGTCTTTTACACTTACCATACGGATGGTGTGTATG----------------------------------------GT--GTGTGTTAGTGTAT-

GCTAGCATTACTACTACTACTG----------------0-1

TCTGTGCAAAACGCATGGAGAGCATTAACTTGCTGTACCGTGTGTGGTTCTCATGAGCGTACTTGGTTACCTT--

GCCTGGGTGCCATTGCGTCTTGTGCAGAGCTNNNNNNNNNNNNNNNNNNNNNNNNNNNNNNNNNNNNNNNNNNNNNNNNNNNNNNNNNNNNNNNNNNNNN

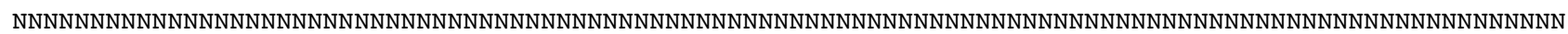

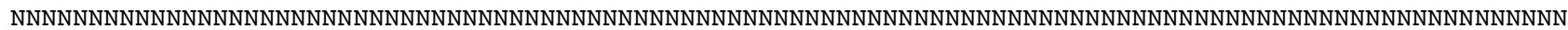

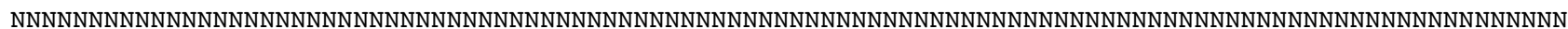

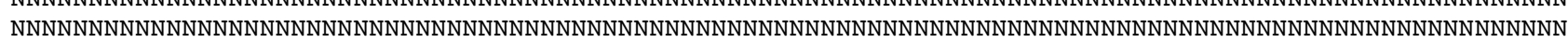

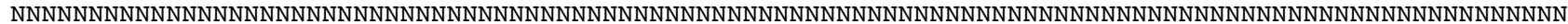

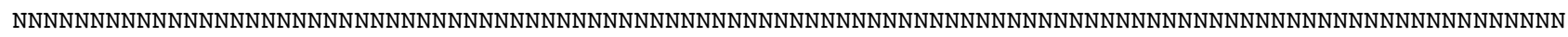

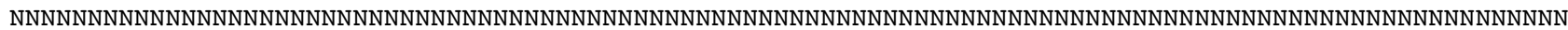

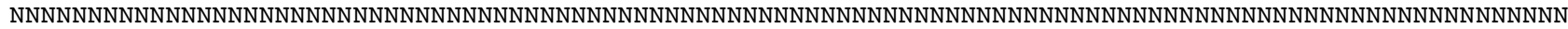
NNNNNNNNNNNNNNNNNNNNNNNNNNNNNNNNNNNNNNNNNNNNNNNNNNNNNNNNNNNNNNNNNNNNNNNNNNNNNNNNAATTTTTTAGAGCCTTATTA TAATGTGATTAGTACAGATTGTTACAATTTTCTGATTACTAAACATGGTATTATAATGATTTTCTTTTTTATAATGCCTATTTTAATAGGAGGGTTTGGT AАСTATTTAATTCCTTTATTAAGGGGTTTGTCCGATTTAAATTTGCCTCGATTAAAAGCCTTGAGTGCTTGGTTGCTTTTACCTTCTGCTGTATTCTTAG TGATTAGTATGTGTTTAGGTGCTGGTATAGGTTGAACTTTTTATCCTCCTTTGTCTTCTAGTGTTTTTGAGGGTAGTAAGGGTGTAGACTTTTTGATGTT TTCCTTGCATTTGGCTGGTGTTTCTAGTATATTTAGTTCTATTAATTTTATATGTACTTTGTATACTGCCTTTAGTGGTAGGTTGGCTTCTCGTAGTTCA ATTGTATTATGAGC

r123 frt cuiaba brac GGGAACTGCTATGTAACCTCT---C--GGACTGCCGGTCATGG-TGGTCCACAACC-

АTTT $\bar{C}$ GGTGGGGTGC $\bar{C}$ TACTTGCCCTATACTCCCAGGCGTGCTCGCCAGTCGTGGCAACTTAACTGCTGTCACGGCAATCGGCCAGTCCACACCGGAGCG GCAATCCAGTACATGTGCCGCAAGGTACGTGTGCGAGGTATAAGAA-

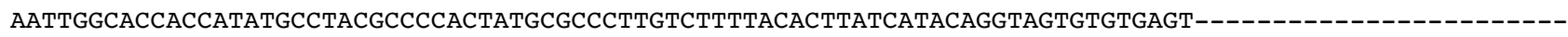
-----------------GTACGCGTGTTGGTGTAT-

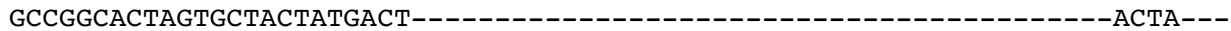

TCTGTGCAAAACGCATGGTCGGCATTAACTTGTTCGACTGTGTGCGGTTCTCATGAGCGTGGTTGGCTATCTT--

GCCTGGTAGTCGATGCGTCTTGTGCAGAGCTGGAAGAGCCCAGCACCGAAGCCTGCGGCAGGTTTGCTGTTAGGCAATGTGGTGTTTGGGTCGGCTCGCG GGATTGCCACTCCACTCGAAGTCCAGCATTGAGTATGGTTT-

CTGGATTTGGCCCAGAGAGGGTGAAAGGCCCGTACGGGTGGAGGTATCAGACAAGTGAGGCAATTCACTAGGCCGGCCTTAGAGTCGGGTTGTTTGGGAA TGCAGCCCAAAGCGGGTGGTAAACTCCATCCAAGGCTAAATACTAGCACGAGTCCGATAGCAAACAAGTACCGTGAGGGAAAGTTGAAAAGTACTTTGAA GAGAGAGTAAACAGTACGTGAAACCGCATGCAGGTAAACGGGTGGCGTCAAGCTGCACGCCCAGAGGATTCAGCCGGTTAGAGTGTATCTATGCGCTTG-CGTATAAATGGGCCAGAGTAAGGCG----TGGTAGTCCGCTGGTAGACAGCGGGCCCTGCCGCAAGGTGGGGATGTG-----CAAGCCGGGTGGATGCCGGAGCACGCTATCCGTC--TGTGGGGCCGTCTAGCCGGTGCACTTTCTCTGT--

GGTGGACACCACGACCGGTGGAACTGCCAGTCTGCTGTGGTCAAGTCGTGTTCGGTTGGTCCTTGT-GGCGAACTGGGCGCGAT---CACGGGCAACCTTGGTGAACGGCGTTGATGTGCCCTC-----------GGGTATGTCTTCGTGTTATCGGTAGCCAGTTGTCTTAACGGGCCTGCCTTGCGATTGTTCTAGCCGTCGTA---

GGGTGGTCTGGTGGGCCATGGTGGTAAGAATAACNNNNNNNNNNNNNNNNNNNNNNNNNNNNNNNNNNNNNNNNNNNNNNNNNNNNNNNNNNNNNNNNNN NNNNNNNNNNNNNNNNNNNNNNNNNNNNNNNNNNNNNNNNNNNNNNNNNNNNNNNNNNNNNNNNNNNNNNNAATTTTTTAGAGCCTTATTATAATGTTAT TAGTACAGATTGTTATAAATTTTTAATTACTAACCATGGTATAATAATGATTTTTTTCTTTATAATGCCTATCTTAATAGGGGGATTTGGTAATTATTTG АTTCСTTTATTGTGTGGCCTGTCAGATTTAAATTTACCACGTTTAAAAGCATTGAGTGCTTGATTGTTACTGCCTTCTGCAGTTTTTTTGATAATAAGAA TGTGTTTAGGGGCAGGGATAGGTTGAACTTTTTATCCACСTTTATCTTCAAGTTTATTTGAAGGGAGTAAGGGTGTAGATTTTTTGATGTTTTCATTACA TTTGGCAGGTGTTTCTAGAATTTTTAGTTCTATAAATTTTATCTGTACTTTATATACTGCTTTTAGAGGTAGTTTGGCGTCTCGGAGTTCTATAGTCTTA TGAGC

r238 gld toc orb GGGAACCGCTATGTAATCTAT---CTGGGACTGCCCGTCATGG-

TGGTC $\bar{C}$ AA $\bar{A} A C C \bar{C} G T T T C G G T G G G G T G C C T A C T T G C C T T A T A C T C C C A G G C G T G C T C G C C T G T T G T G G C A A C T T A A C T G C T G T C A C A A C A A C C G G C C A G T$ CCACACCGGAGCGGCATATTAGTACACGTGTCA-AAG---CGTGTGCAAGGCATAAGAACA-

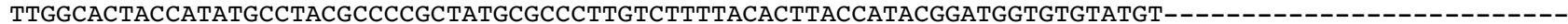
---------------GT--GTGTGTTAGTGTAT-

GCTAGCATTACTACTACTACTG-_-_-_-_-_-_-

TCTGTGCAAAACGCATGGAGAGCATTAACTTGCTGTACCGTGTGTGGTTCTCATGAGCGTACTTGGTTACCTT--

GCCTGGGTGCCATTGCGTCTTGTGCAGAGCTNNNNNNNNNNNNNNNNNNNNNNNNNNNNNNNNNNNNNNNNNNNNNNNNNNNNNNNNNNNNNNNNNNNNN

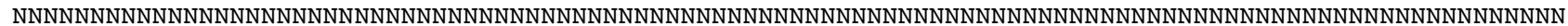

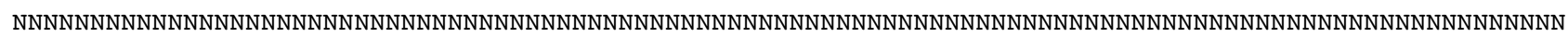
NNNNNNNNNNNNNNNNNNNNNNNNNNNNNNNNNNNNNNNNNNNNNNNNNNNNNNNNNNNNNNNNNNNNNNNNNNNNNNNNNNNNNNNNNNNNNNNNNNNN

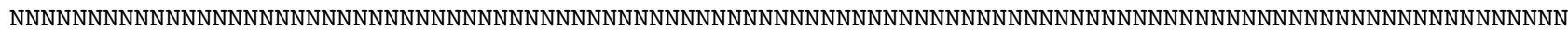

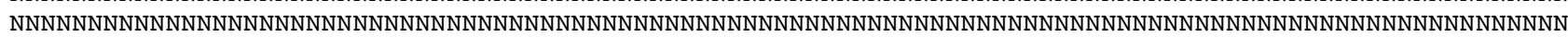

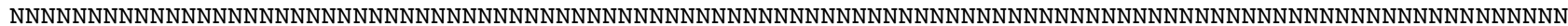

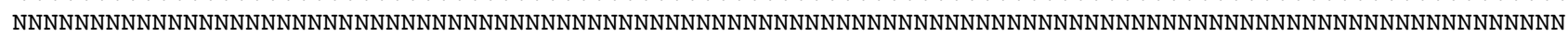

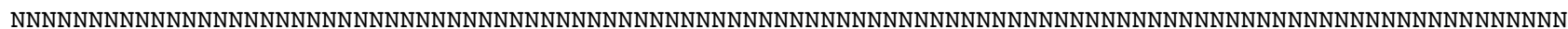
NNNNNNNNNNNNNNNNNNNNNNNNNNNNNNNNNNNNNNNNNNNNNNNNNNNNNNNNNNNNNNNNNNNNNNNNNNNNNNNNAATTTTTTAGAGCCTTATTA TAATGTGATTAGTACAGATTGTTACAATTTTCTGATTACTAAACATGGTATTATAATGATTTTCTTTTTTATAATGCCTATTTTAATAGGGGGGTTTGGT AАСTATTTAATTCCTTTATTAAGGGGTTTGTCCGATTTAAATTTGCCTCGATTAAAAGCCTTGAGTGCTTGGTTGCTTTTACCTTCTGCTGTATTCTTAG TGATTAGTATGTGTTTAGGTGCTGGTATAGGTTGAACTTTTTATCCTCCTTTGTCTTCTAGTGTTTTTGAGGGTAGTAAGGGTGTAGACTTTTTGATGTT TTCCTTGCATTTGGCTGGTGTTTCTAGTATATTTAGTTCTATTAATTTTATATGTACTTTGTATACTGCCTTTAGTGGTAGGTTGGCTTCTCGTAGTTCA ATTGTATTATGAGC

r237_gld_toc_toc2 GGGAACCGCTATGTAATCTAT---CTGGGACTGCCCGTCATGG-

TGGTC $\bar{C}$ AA $\bar{A} A C C \bar{C} G T T T C G G T G G G G T G C C T A C T T G C C T T A T A C T C C C A G G C G T G C T C G C C T G T T G T G G C A A C T T A A C T G C T G T C A C A A C A A C C G G C C A G T$ CCACACCGGAGCGGCATATTAGTACACGTGTCA-AAG---CGTGTGCAAGGCATAAGAACA-

TTGGCACTACCATATGCCTACGCCCCGCTATGCGCCСTTGTCTTTTACACTTACCATACGGATGGTGTGTATGT-_-_-_-_-_-_-_-_-_-_-_-_-_ ----------------GT--GTGTGTTAGTGTAT-

GCTAGCATCACTACTACTACTG--

TCTGTGCAAAACGCATGGAGAGCATTAACTTGCTGTACCGTGTGTGGTTCTCATGAGCGTACTTGGTTACCTT--

GCCTGGGTGCCATTGCGTCTTGTGCAGAGCTNNNNNNNNNNNNNNNNNNNNNNNNNNNNNNNNNNNNNNNNNNNNNNNNNNNNNNNNNNNNNNNNNNNNN

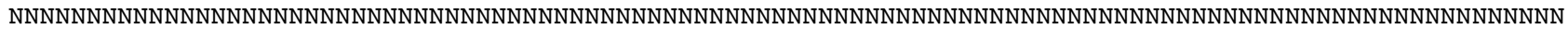




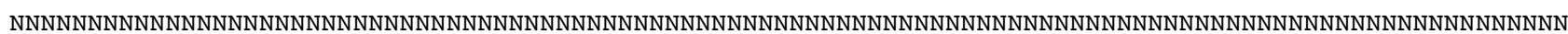

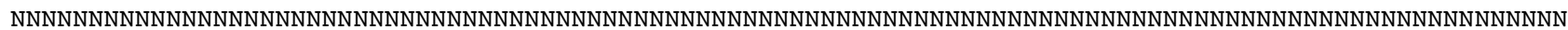

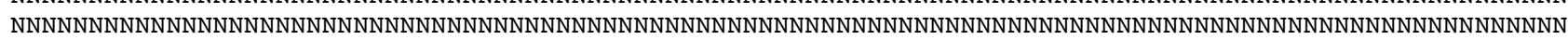
NNNNNNNNNNNNNNNNNNNNNNNNNNNNNNNNNNNNNNNNNNNNNNNNNNNNNNNNNNNNNNNNNNNNNNNNNNNNNNNNNNNNNNNNNNNNNNNNNNNN

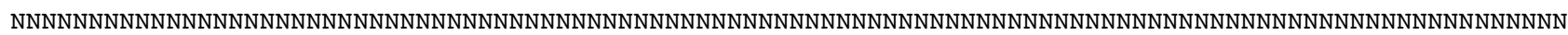

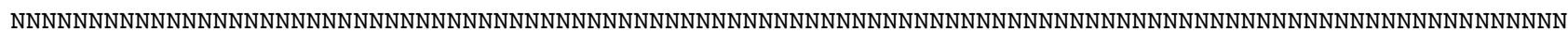

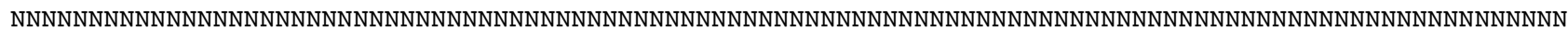

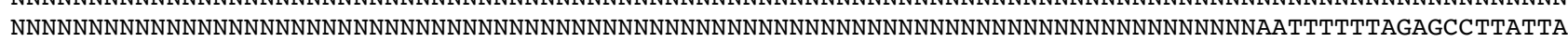
TAATGTGATTAGTACAGATTGTTACAATTTTCTGATTACTAAACATGGTATTATAATGATTTTCTTTTTTATAATGCCTATTTTAATAGGGGGGTTTGGT AACTATTTAATTCCTTTATTAAGGGGTTTGTCCGATTTAAATTTGCCTCGATTAAAAGCCTTGAGTGCTTGGTTGCTTTTACCTTCTGCTGTATTCTTAG TGATTAGTATGTGTTTAGGTGCTGGTATAGGTTGAACTTTTTATCCTCCTTTGTCTTCTAGTGTTTTTGAGGGTAGTAAGGGTGTAGACTTTTTGATGTT TTCCTTGCATTTGGCTGGTGTTTCTAGTATATTTAGTTCTATTAATTTTATATGTACTTTGTATACTGCCTTTAGTGGTAGGTTGGCTTCTCGTAGTTCA ATTGTATTATGAGC

r096 moral negro spn GGGAACTGCTATGTAACCTCT---C--GGACCGCTGGTCATGG-TGGTCCACAACCATTT $\bar{C} G G T G G \bar{G}$ GTGCCTATTTGCCCTATACTCCCAGGCGTGCTCGCCAGTCGTGGCAGCTTAACTGCTGTCACGGCATCGGCCAGTCCACACCGGAGCGGCAATGCAGTACATGTGCCGGAAGGTATGTGTGCAAGGTATAAGAT-ATTGGCACCACCATATGCCTACGCCCCACTATGCGCCCTTGTCTTTTACACTTACCATACAGGTAGTGTGTGAGT ----------GTACGCGTGTTGGTGTAT-

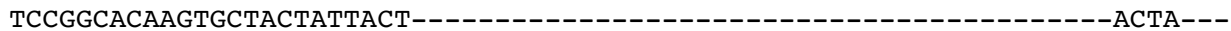
TCTGTGCAAAACGCGTGGTCGGCATTAACTTGTCG-ACTGTGCGCGGTTCTCATGAGCGTGGTTGGCTATCTT-GCCTGGTAGTCAATGCGTCTTGTGCAGAGCTNNNNNNNNNNNNNNNNNNNNNNNNNNNNNNNNNNNNNNNNNNNNNNNNNNNNNNNNNNNNNNNNNNNNN NNNTTGCCACTCCACTCGAAGTCCAGCATTGAGTATGGTTT-

CTGGATTTGGCCCAGAGAGGGTGAAAGGCCCGTACGGGTGGAGGTGTCAGACAGGTGAGGCAGTCCTCTAGGCCGGCCTTAGAGTCGGGTTGTTTGGGAA TGCAGCCCAAAGCGGGTGGTAAACTCCATCCAAGGCTAAATACTAGCACGAGTCCGATAGCAAACAAGTACCGTGAGGGAAAGTTGAAAAGTACTTTGAA GAGAGAGTAAACAGTACGTGAAACCGCATGCAGGTAAACGGGTGGCGTCAAGCTGCACGCCCAGAGGATTCAGCCGGTTAGAGTGTGTCTATGCGCTTG-CGTATGAATGGGCCAGAGTAGGGCG----TGGTAGTCCGCTGGAAGACAGCGGGCCCTGCCGCAAGGTGGGGATGTG-----TGAGCCGGGTGGAAGCCGGAGCACGCTATCCGTC--TGTGGGGCCGTCTAGCCGGTGCACTTTCTCTGT--

GGTGGACACCACGACCGGTGGAACTGCCAGTCTGCTGTGGTCGAGTCGTGTTCGGTTGGTCCTTGT-GGCTAGCTGGGCGCGAT---CACGGGCAACCTTGGTGAACGGCGTTGGCGTGGTCTCTCGG--------GGGCATGCCTTCGTGTTATCGGTAGCCAGTTGTCTGAACGGGCCTGCCTCGCGATTGTTCTAGCCGTCGTG---

GGGTGGTCTGGTGGGCCATGGTGGTAGGAATAACTGTGCAGGGCACTGGAGTGTTCGGCCTCGAATGCAGCCAGCACGCACGCTAGTAGTGT------

TGTTGC---G---

ATGTGGGTGCTCTCGTGGTCTGCCTGGTGCCGGGTCTGATTGTCGTGTTGCCTGCGCAAAGAAATTTTTAGAACCTTATTATAATGTTATAAGTACTGAT TGTTATAAATTTTTAATTACAAATCATGGTATCATAATGATTTTTTTCTTTATAATGCCTATATTAATAGGAGGGTTTGGTAATTATTTAATTCCCTTAT TATGCGGTTTGTCTGATTTAAATTTACCTCGTTTAAAAGCATTAAGTGCTTGATTGTTGTTACCTTCTATCGTTTTTTTAGTAATAAGCATGTGTTTAGG GGCAGGGATAGGCTGAACTTTTTATCCTCCTTTATCTTCCAGTCTATTTGAAGGAAGTAAGGGTGTGGATTTTTTGATGTTTTCTCTACATTTGGCTGGT GTGTCTAGTATTTTTAGCTCTATTAATTTTATCTGTACTTTGTATACTGCCTTTAGTGGTAGTTTGGCGTCTCGAAGGTCAATAATTTTATGGGC r019_Rfulbrighti_marajo_orbignyi

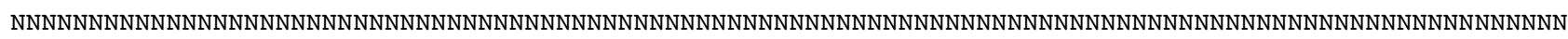

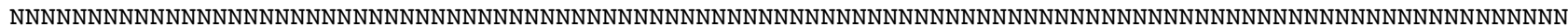

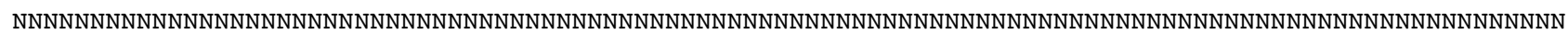

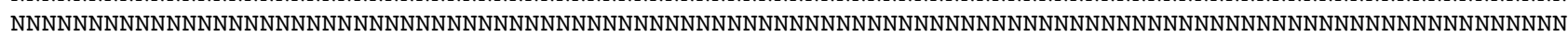

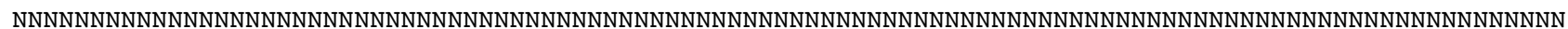

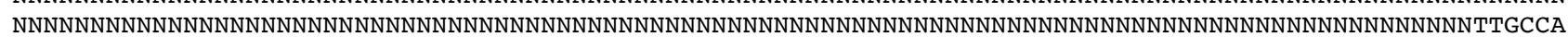
СTTCACTCGAAGTCCAGCATTGAGTATGGTCCACTGGATTTGGCCCAGAGAGGGTGAAAGGCCCGTACGGGTGGAGGTTTCAGACAAGTGAGGCAATTCA CTAGGCCGGCCTTAGAGTCGGGTTGTTTGGGAATGCAGCCCAAAGTGGGTGGTAAACTCCATCCAAGGCTAAATACTAGCACGAGTCCGATAGCAAACAA GTACCGTGAGGGAAAGTTGAAAAGTACTTTGAAGAGAGAGTAAACAGTACGTGAAACCGCATGCAGGTAAACGGGTGGCGTCAAGCTGCACGCCCAGAGG ATTCAGCCGGTTAGAGTGTAGT-TATGCGCTTG-CGTGTCGAACGGCCAGTGTAAGATT----

GGCTAGTCCACTGGAAGACAGTGGGCCCTGCCGCAAGGTGGGG-TGTG-----T-GTACCGGGTGGAAGCCGGAGCACGCTAGCCGTC-TGTTGGGCCATCTAGCCGGTGCACTTTCTCTGT--

GGTGGACACCACGACCGGTGGTACTGCCAGTCTGCTATGGTCAAGTCGTATTCGGTTGGTCCTTGT-GGCCTACTGGGTGCGAT---CACGGACAAACTCGGTGAACGGCGTTGACGTGCTCTT----_--_CCCAGGGTATGTCTTCGTGATATCGGTAACCGGTTGTCTTAACGGGCCTGCCTTACGATTGTTCCAGTCGTCCTA---

GGGTGGTCTGGTGGACCATGGTGGTAAGAATAACTGTGCAGGGCACCGGAGTTTTCGGCCTCAAATGCAGCCAGCATGCACGCTGGTAGTGT-----TC---------

GTGTGGGTGCTCTCGTGGCCTGCCTGGTGCCGAGTCTGATTGTCGTGTTGCCTGCGCAAAGAAATTTTTAGAGCCGTATTATAAAGTAATTAATACAGAC TGTTATAAATTTTTAATTACTAATCATGGTATTATTATGATTTTCTTTTTTATAATGCCTATTTTAATCGGCGGGTTTGGTAATTATTTAATACCCTTGT TAGCGGGGTTATCTGATTTAAATTTGCCACGTTTAAAAGCATTGAGTGCTTGACTTTTACTGCCCTCTGTGGTTTTTTTGTTAATAAGTATGTGTCTTGG TGCTGGTATTGGTTGGACCTTTTATCCTCCCTTATCTTCTGTGGCTTTTGAGGGCAGTAAGGGTGTTGATTTTTTAATGTTTTCTTTGCATTTAGCGGGG GTGTCTAGAATTTTTAGTTCTATAAATTTTATCTGTACCTTGTATACTGCTTTTAGCGGTAGGTTATCTTCACGCGGTTCTATTATTTTGTGGTC 03Rhinebothrium_paratrygoni

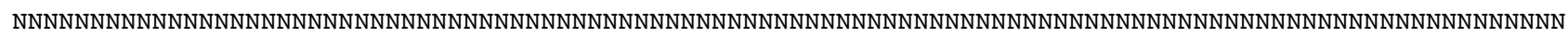

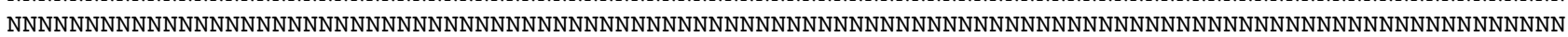

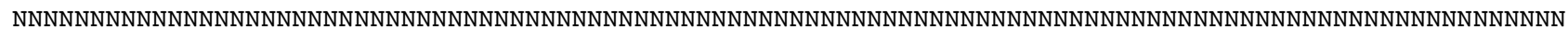

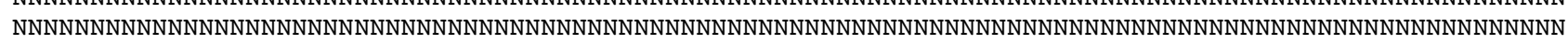
NNNNNNNNNNNNNNNNNNNNNNNNNNNNNNNNNNNNNNNNNNNNNNNNNNNNNNNNNNNNNNNNNNNNNNNNNNNNNNNNNNNNNNNNNNNNNNNNNNNN NNNNNNNNNNNNNNNNNNNNNNGGAAGAGCCCAGCACCGAAGCCTGCGGTAGTTTTACTGTTAGGCAATGTGGTGTTTGGGTCGGCCTGCGGGATTGCCA CTCCACTCGAAGTCCAGCATTGAGTATGGTTT-

CTGGATTTGGCCCAGAGAGGGTGAAAGGCCCGTACGGGTGGAGGTGTCAGACAAGTGAGGCAATTCACTAGGCCGGCCTTAGAGTCGGGTTGTTTGGGAA TGCAGCCCAAAGTGGGTGGTAAACTCCATCCAAGGCTAAATACTAGCACGAGTCCGATAGCAAACAAGTACCGTGAGGGAAAGTTGAAAAGTACTTTGAA GAGAGAGTAAACAGTACGTGAAACCGCATGCAGGTAAACGGGTGGCGTCAAGCTGCACGCCCAGAGGATTCAGCCGGTTAGAGTGTAGT-

TATGCGCTTG-CGTGTCAACAGGCCAGTGTAAGGCG----TGGTAGTCCACTGGAAGACAGTGGGCCCTGCCGCAAGGCGGGGATGTG------TAAGCCGGGTGGATGCCGGAGCACACTATCCGTCC-TAGGGGGCCTACTAGCCGGTGCACTTTCTCTGT--

GGTGGACACCACGACCGGTGGAACTGCCAGTCTGCTATGGTCAAGTCGTGTTCGGTTGGTCCTTGT-GGCTAACTGGGTGCGAT---CACGGGCAAATTTGGCGAACGGCGTTGACGTGCTCTC--------_GGGTGTGTCTTCGTGTTATCGGTAGCCAGTTGCCTTAACGGGCCTGCCTTGCGATTGTTCTAGCCGTCGTATATGGGTGGTCTGGTGGACCTTAGTGGTAAGAATAACTGTGCAGGGCACCGGAGTTTTCGGCCTCAAATGCAGCCGGCATGCACGCTAGTA 
GTGT-----GT---T---

GCCTATGTGGGTGCTCTCGTGGTCTGCCTGGTGCCGGGTCTGATTGTCGTGTTGCCTGCGCAAAGAAATTTTTAGAACCCTATTATAATGTGATTAGGAC GGATTGTTATAAATTTTTAATTACTAACCACGGTATTATAATGATTTTTTTCTTTATTATGCCTATTTTAATAGGCGGGTTTGGTAATTATCTTATACCT CTGTTATGTGGGTTGTCTGACCTGAATTTACCACGTTTAAAAGCTTTAAGGGCTTGGTTGCTTTTACCGTCTACAGTTTTTCTTATTACGAGTATGTGTT TAGGTGCGGGAGTAGGTTGAACATTTTATCCTCCTTTATCCTCTAGTTTATTTGAAGGTAGTAAGGGTGTTGACTTTTTGATGTTTTCATTGCATTTAGC AGGGGTGTCTAGAATTTTTAGTTCTATTAATTTTATATGCACCTTATACACAGCTTTTAGTGGGAGATTGGCTTCCCGTAGATCTATAATTCTTTGGGC r201_gld_lagonovo_mot GGGAACCGCTATGTAATCTAT---CTGGGACTGCCCGTCATGG-

TGGTCCAAAAACCCGTTTC GGTGGGTGCCTACTTGCCTTATACTCCCAGGCGTGCTCGCCTGTTGTGGCAACTTAACTGCTGTCACAACAACCGGCCAGT CCACACCGGAGCGGCATATTAGTACACGTGTCA-AAG---CGTGTGCAAGGTATAAGAACA-

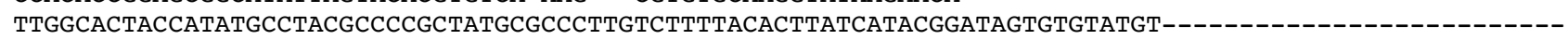
----------------GT--GTGTGTTAGTGTAT-

GCTAGCATTACTACTACTACTG--------

TCTGTGCAAAACGCACGGCGAGCATTAACTTGCTGTACTGTGTGTGGTTCTCATGAGCGTACTTGGTTACCTT--

GCCTGGGTGCCATTGCGTCTTGTGCAGAGCTNNNNNNNNNNNNNNNNNNNNNNNNNNNNNNNNNNNNNNNNNNNNNNNNNNNNNNNNNNNNNNNNNNNNN NNNTTGCCACTCCACTCGAAGTCCAGCATTGAGTATGGTTT-

CTGGATTTGGCCCAGAGAGGGTGAAAGGCCCGTACGGGTGGAGGTTTCAGACAAGTGAGGCAATTCACTAGGCCGGCCTTAGAGTCGGGTTGTTTGGGAA TGCAGCCCAAAGTGGGTGGTAAACTCCATCCAAGGCTAAATACTAGCACGAGTCCGATAGCAAACAAGTACCGTGAGGGAAAGTTGAAAAGTACTTTGAA GAGAGAGTAAACAGTACGTGAAACCGCATGCAGGTAAACGGGTGGCGTCAAGCTGCACGCCCAGAGGATTCAGCCGGTTAGAGTGTAGT-

TATGCGCTTG-CGTATCAAAGGGCCAGAGTAAGGCG----TGGTAGTCCGCTGGAAGACAGCGGGCCCTGCCGCAAGGTGGGGATGTG------TAAGCCGGGTGGATGCCGGAGCACGCTATCCGTC--TGGAGGGCCGTCTAGCCGGTGCACTTTCTCTGT--

GGTGGACACCACGACCGGTGGAACTGCCAGTCTGCTATGGTCAAGTCGTGTTCGGTTGGTCCTTGT-GGCTAGCTGGGCGCGAT---CACGGGCAAATTTGGTGAACGGCGTTGATGTGCCCTC------_----_GGGTATGTCTTCGTGTTATCGGTAACCAGTTGTCTTAACGGGCCTGCCTTACGATTGTTCTAGCCGTCGTA---

GGGTGGTCTGGTGGGCCATAGTGGTAAGAATAACTGTGCAGGGCACCGGAGTTTTCGGCCTCAAACGCAGCCAGCATGCACGCTAGTAGTGT------

TG---C--TG---

ATGTGGGTGCTCTCGTGGTCTGCCTGGTGCCGGGTCTGATTGTCGTGTTGCCTACGCAAAGAAATTTTTGGAGCCTTACTATAATGTGATTAGTACAGAT TGTTATAATTTTCTGATTACTAAACATGGTATTATAATGATTTTCTTTTTTATAATGCCTATTTTAATAGGGGGGTTTGGTAACTATTTAATTCCTTTAT TAAGAGGTTTGTCCGATTTAAATTTGCCTCGTTTAAAAGCTTTGAGTGCTTGATTGCTTTTACCTTCTGCTGTATTTTTAGTGATTAGTATGTGTTTAGG TGCTGGTATAGGTTGAACTTTCTATCCTCCTTTGTCTTCTAGTGTTTTTGAGGGTAGTAAGGGTGTAGACTTTTTAATGTTTTCATTACATTTGGCCGGT GTTTCTAGTATATTTAGTTCTATTAATTTTATATGTACTTTGTATACTGCCTTTAGTGGTAGGTTGGCTTCTCGTAGTTCAATTGTATTATGAGC r052 vnz uppersol mot GGGAACTGCTATGTAACCTCT---C--GGACCGCTGGTCATGG-TGGTCCACAACC-

ATTTC̄GGTGGGGTGCCTĀCTTGCCCTATACTCCCAGGCGTGCTCGCCAGTCGTGGCAACTTAACTGCTGTCGCGGCAATCGGCCAGTCCACACCGGAGCG GCAATGCAGTACATGTGTCGGAAGGCACGTGTGCGAGGTATAAGAA-A-

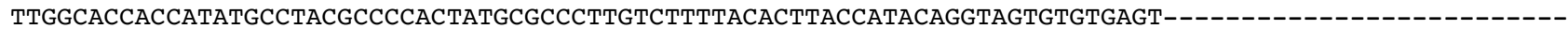
------------GTACGCGTGTTGGTGTAT-

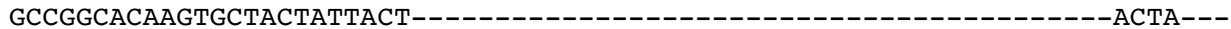

TCTGTGCAAAACGCATGGTCGGCATTGACTTGTTGTACTGTGCGCGGTTCTCATGAGCGTGGTTGGCTATCTTTTGCCTGGTAGCCGATGCGTCTTGTGC AGTTCTGGAAGAGCCCAGCACCGAAGCCTGCGGCAGGTTTGCTGTTAGGCAATGTGGTGTTTGGGTCGGCTCGCGGGATTGCCACTCCACTCGAAGTCCA GCATTGAGTATGGTTT-

CTGGATTTGGCCCAGAGAGGGTGAAAGGCCCGTACGGGTGGAGGTGTCAGACAAGTGAGGCAATTCACTAGGCCGGCCTTAGAGTCGGGTTGTTTGGGAA TGCAGCCCAAAGCGGGTGGTAAACTCCATCCAAGGCTAAATACTAGCACGAGTCCGATAGYAAACAAGTACCGTGAGGGAAAGTTGAAAAGTACTTTGAA GAGAGAGTAAACAGTACGTGAAACCGCATGCAGGTAAACGGGTGGCGTCAAGCTGCACGCCCAGAGGATTCAGCCGGTTAGAGTGTATCTATGCGCTTG-CGTATAAAAGGGCCAGAGTAAGGCG----TGGTAGTCCGCTGGCAGACAGCGGGCCCTGCCGCAAGGTGGGGATGTG------TAAGCCGGGTGGATGCCGGAGCACGCTATCCGTC--TGTGGGGCCGTCTAGCCGGTGCACTTTCTCTGT--

GGTGGACACCACGACCGGTGGAACTGCCAGTCTGCTGTGGTCAAGTCGTGTTCGGTTGGTCCTTGT-GGCGAACTGGGCGCGAT---CACGGGCAACCTTGGTGAACGGCGTTGATGTGCCCTC---_-_-----GGGTATGTCTTCGTGTTATCGGTAGCCAGTTGTCTTAACGGGCCTGCCTTGCGATTGTTCTAGCCGTCGTA---

GGGTGGTCTGGTGGGCCATGGTGGTAAGAATAACTGTGCAGGGCACCGGAGTGTTCGGCCTCAAATGCAGCCAGCATGCACGCTAGTAGTGT------

TG---C---G---

ATGTGGGTGCTCTCGTGGTCTGCCTGGTGCCGGGTCTGATTGTCGTGTTGCCTGCGCAAAGAAATTTTTAGAGCCTTATTATAATGTTATTAGTACAGAT TGTTATAAATTTTTAATTACTAATCATGGTATTATAATGATTTTTTTCTTTATAATGCCCATTTTAATAGGTGGTTTTGGTAATTATTTAATTCCTTTGT TGTGTGGTTTGTCGGATTTAAATCTACCTCGCTTGAAAGCATTAAGTGCTTGGTTGTTACTGCCTTCTGCAGTTTTTTTAGTAATTAGTATGTGTTTGGG AGCAGGTATAGGTTGGACTTTTTATCCTCCTCTTTCTTCAAGTTTATTTGAGGGTAGAAAGGGTGTAGATTTTTTGATGTTTTCATTACATTTGGCGGGA GTTTCTAGTATTTTTAGTTCTATAAATTTTATTTGTACTTTGTATACTGCTTTCAGAGGTAGGTTAGCGTCTCGAAGTTCTATAGTATTATGGGC r050 gld uppersol mot GGGAACCGCTATGTAATCTAT---CTGGGACTGCCCGTCATGG-

TGGTCCAAĀACCCGTTTC $\bar{C} G G T G G G G T G C C T A C T T G C C T T A T A C T C C C A G G C G T G C T C G C C T G T T G T G G C A A C T T A A C T G C T G T C A C A A C A A C C G G C C A G T$ CCACACCGGAGCGGCATATTAGTACACGTGTCA-AAG---CGTGTGCAAGGTATAAGAACA-

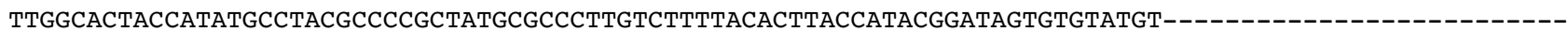
------------------GT--GTGTGTTAGTGTAT-

GCTAGCATTACTACTACTACTG--

TCTGTGCAAAACGCACGGGGAGCATTAACTTGCTGTACTGTGTGTGGTTCTCATGAGCGTACTTGGTTACCTT-

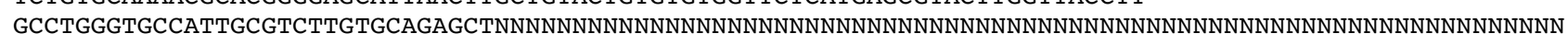

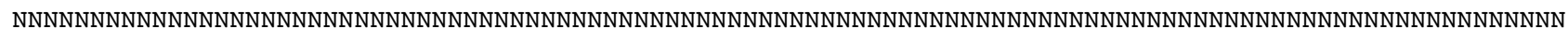
NNNNNNNNNNNNNNNNGGCCTTAGAGTCGGGTTGTTTGGGAATGCAGCCCAAAGTGGGTGGTAAACTCCATCCAAGGCTAAATACTAGCACGAGTCCGAT AGCAAACAAGTACCGTGAGGGAAAGTTGAAAAGTACTTTGAAGAGAGAGTAAACAGTACGTGAAACCGCATGCAGGTAAACGGGTGGCGTCAAGCTGCAC GCCCAGAGGATTCAGCCGGTTAGAGTGTAGT-TATGCGCTTG-CGTATCAAAGGGCCAGAGTAAGGCG----

TGGTAGTCCGCTGGAAGACAGCGGGCCCTGCCGCAAGGTGGGGATGTG-----T-AAGCCGGGTGGATGCCGGAGCACGCTATCCGTC-TGGAGGGCCGTCTAGCCGGTGCACTTTCTCTGT--

GGTGGACACCACGACCGGTGGAACTGCCAGTCTGCTATGGTCAAGTCGTGTTCGGTTGGTCCTTGT-GGCTAGCTGGGCGCGAT---CACGGGCAAATTTGGTGAACGGCGTTGATGTGCCCTC----_-----_GGGTATGTCTTCGTGTTATCGGTAACCAGTTGTCTTAACGGGCCTGCCTTACGATTGTTCTAGCCGTCGTA---

GGGTGGTCTGGTGGGCCATAGTGGTAAGAATAACTGTGCAGGGCACCGGAGTTTTCGGCCTCAAACGCAGCCAGCATGCACGCTAGTAGTGT----TG---C--TG---

ATGTGGGTGCTCTCGTGGTCTGCCTGGTGCCGGGTCTGATTGTCGTGTTGCCTACGCAAAGAAATTTTTGGAGCCTTACTATAATGTGATTAGTACGGAT TGTTATAATTTTTTAATTACTAAACATGGTATTATAATGATTTTCTTTTTTATAATGCCTATTTTAATAGGGGGGTTTGGTAATTATTTAATTCCTCTAT TAAGGGGTTTGTCTGATTTAAATTTACCTCGTTTAAAAGCACTGAGTGCTTGGTTGCTTTTACCTTCTGCTGTATTCTTAGTCATTAGAATGTGCTTAGG TGCTGGTATAGGTTGAACTTTTTATCCTCCTTTGTCTTCTAGTGTTTTTGAGGGTAGTAAGGGTGTAGATTTTTTAATGTTTTCATTGCATTTGGCCGGT GTCTCTAGTATATTTAGTTCTATTAATTTTATATGTACTTTGTACACTGCTTTTAGTGGTAGGTTGGCTTCTCGTAGTTCAATTGTATTATGAGC 
r186_gld_jamanxim_tpj1GGGAACCGCTATGTAATCTAT---CTGGGACTGCCCGTCATGG-

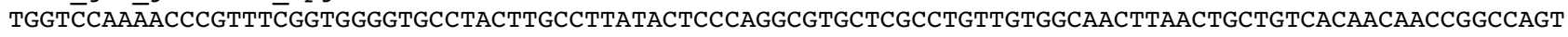
CCACACCGGAGCGGCATATTAGTACACGTGTCA-AAG---CGTGTGCAAGGTATAAGAACA-

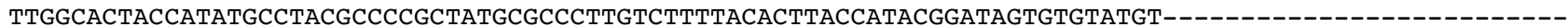
----------------GT--GTGTGTTAGTGTAT-

GCTAGCATTACTACTACTACTG-

TCTGTGCAAAACGCATGGAGAGCATTAACTTGCTGTACCGTGTGTGGTTCTCATGAGCGTACTTGGTTACCTT--

GCCTGGGTGCCATTGCGTCTTGTGCAGAGCTNNNNNNNNNNNNNNNNNNNNNNNNNNNNNNNNNNNNNNNNNNNNNNNNNNNNNNNNNNNNNNNNNNNNN NNNNNNNNNNNNNNNNNNNNNNNNNNNNNNNNNNNNNNNNNNNNNNNNNNNNNNNNNNNNNNNNNNNNNNNNNNNNNNNNNNNNNNNNNNNNNNNNNNNN NNNNNNNNNNNNNNNNGGCCTTAGAGTCGGGTTGTTTGGGAATGCAGCCCAAAGTGGGTGGTAAACTCCATCCAAGGCTAAATACTAGCACGAGTCCGAT AGCAAACAAGTACCGTGAGGGAAAGTTGAAAAGTACTTTGAAGAGAGAGTAAACAGTACGTGAAACCGCATGCAGGTAAACGGGTGGCGTCAAGCTGCAC GCCCAGAGGATTCAGCCGGTTAGAGTGTAGT-TATGCGCTTG-CGTATCAAAGGGCCAGAGTAAGGCG----

TGGTAGTCCGCTGGAAGACAGCGGGCCCTGCCGCAAGGTGGGGATGTG-----T-AAGCCGGGTGGATGCCGGAGCACGCTATCCGTC-TGGAGGGCCGTCTAGCCGGTGCACTTTCTCTGT--

GGTGGACACCACGACCGGTGGAACTGCCAGTCTGCTATGGTCAAGTCGTGTTCGGTTGGTCCTTGT-GGCTAGCTGGGCGCGAT---CACGGGCAAATTTGGTGAACGGCGTTGATGTGCCCTC-----------GGGTATGTCTTCGTGTTATCGGTAACCAGTTGTCTTAACGGGCCTGCCTTACGATTGTTCTAGCCGTCGTA---

GGGTGGTCTGGTGGGCCATAGTGGTAAGAATAACTGTGCAGGGCACCGGAGTTTTCGGCCTCAAACGCAGCCAGCATGCACGCTAGTAGTGT----TG---C--TG---

ATGTGGGTGCTCTCGTGGTCTGCCTGGTGCCGGGTCTGATTGTCGTGTTGCCTACGCAAAGAATTTTTTGGAGCCTTATTATAATGTGATTAGTACAGAT TGTTATAATTTTCTGATTACCAAACATGGTATTATAATGATTTTCTTTTTTATAATGCСTATCTTAATAGGGGGGTTTGGTAATTATTTAATTCCCTTAT TAAGGGGTTTGTCCGATTTAAACTTGCCTCGTTTAAAAGCCTTGAGTGCTTGATTGCTTTTACCTTCTGCTGTATTTTTAGTGATTAGTATGTGTTTAGG TGCTGGTATAGGTTGAACTTTCTATCCTCCTTTGTCTTCTAGTGTTTTTGAGGCGAGTAAGGGTGTAGACTTTTTAATGTTTTCATTGCATTTGGCTGGT GTTTCTAGTATATTTAGTTCTATTAATTTTATATGTACTTTGTATACTGCCTTTAGTGGTAGGTTGGCTTCTCGTAGTTCAATTGTATTATGAGC r095_rhoides_negro_spnGGGAACTGCTATGTAACCTCT---C--GGACCGCTGGTCATGG-TGGTCCACAACCАTTTC̄GGTGGGGTGCCTATTTGCCCTATACTCCCAGGCGTGCTCGCCAGTCGTGGCAGCTTAACTGCTGTCACGGCATCGGCCAGTCCACACCGGAGCGGCAATGCAGTACATGTGCCGGAAGGTATGTGTGCAAGGTATAAGAT-A-

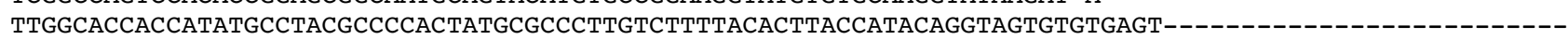

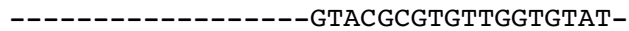

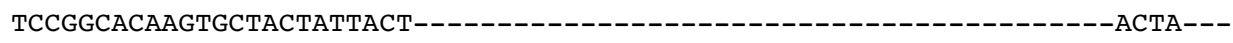

TCTGTGCAAAACGCGTGGTCGGCATTAACTTGTCG-ACTGTGCGCGGTTCTCATGAGCGTGGTTGGCTATCTT--

GCCTGGTAGTCAATGCGTCTTGTGCAGAGCTGGAAGAGCCCAGCACCGAAGCCTGCGGCAGGTTTGCTGTTAGGCAATGTGGTGTTTGGGTCGGCTCGCG GGATTGCCACTCCACTCGAAGTCCAGCATTGAGTATGGTTT-

CTGGATTTGGCCCAGAGAGGGTGAAAGGCCCGTACGGGTGGAGGTGTCAGACAGGTGAGGCAGTCCTCTAGGCCGGCCTTAGAGTCGGGTTGTTTGGGAA TGCAGCCCAAAGCGGGTGGTAAACTCCATCCAAGGCTAAATACTAGCACGAGTCCGATAGCAAACAAGTACCGTGAGGGAAAGTTGAAAAGTACTTTGAA GAGAGAGTAAACAGTACGTGAAACCGCATGCAGGTAAACGGGTGGCGTCAAGCTGCACGCCCAGAGGATTCAGCCGGTTAGAGTGTGTC-

TATGCGCTTG-CGTATGAATGGGCCAGAGTAGGGCG----TGGTAGTCCGCTGGAAGACAGCGGGCCCTGCCGCAAGGTGGGGATGTG-----TGAGCCGGGTGGAAGCCGGAGCACGCTATCCGTC--TGTGGGGCCGTCTAGCCGGTGCACTTTCTCTGT--

GGTGGACACCACGACCGGTGGAACTGCCAGTCTGCTGTGGTCGAGTCGTGTTCGGTTGGTCCTTGT-GGCTAGTTGGGCGCGAT---CACGGGCAACCTTGGTGAACGGCGTTGGCGTGGTCTCTCGG-------GGGCATGCCTTCGTGTTATCGGTAGCCAGTTGTCTGAACGGGCCTGCCTCGCGATTGTTCTAGCCGTCGTG---

GGGTGGTCTGGTGGGCCATGGTGGTAGGAATAACTGTGCAGGGCACTGGAGTGTTCGGCCTCGAATGCAGCCAGCACGCACGCTAGTAGTGT----TGTTGC---G---

ATGTGGGTGCTCTCGTGGTCTGCCTGGTGCCGGGTCTGATTGTCGTGTTGCCTGCGCAAAGAAATTTTTAGAGCCTTATTATAATGTTATAAGTACTGAT TGTTATAAATTTTTAATTACAAATCATGGTATCATAATGATTTTTTTCTTTATAATGCCTATATTAATAGGAGGGTTTGGTAATTATTTAATTCCCTTAT TATGCGGTTTGTCTGATTTAAATTTACCTCGTTTAAAAGCATTAAGTGCTTGATTGTTGTTACCTTCTATCGTTTTTTTAGTAATAAGCATGTGTTTAGG GGCAGGGATAGGCTGAACTTTTTATCCTCCTTTATCTTCCAGTCTATTTGAAGGAAGTAAGGGTGTGGATTTTTTGATGTTTTCTCTACATTTGGCTGGT GTGTCTAGTATTTTTAGCTCTATTAATTTATCTGTACTTTGTATACTGCCTTTAGTGGTAGTTTGGCGTCTCGAAGGTCAATAATTTTATGGGC r016_Rfulbrighti_marajo_orbignyi

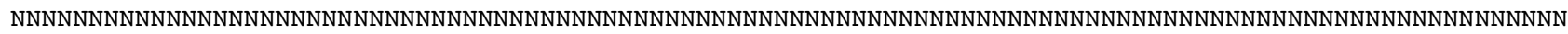

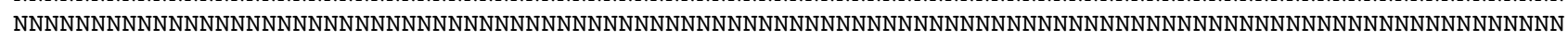

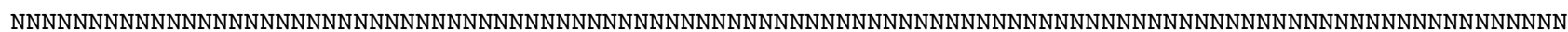

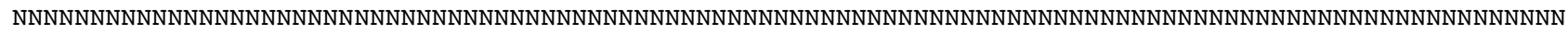

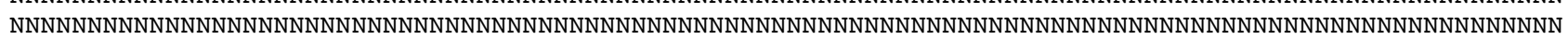
NNNNNNNNNNNNNNNNNNNNNNGGAAGAGCCCAGCACCGAAGCCTGCGGTAGTTTTACTGTTAGGCAATGTGGTGTTTGGGCCGGCTCGCAGGATTGCCA CTTCACTCGAAGTCCAGCATTGAGTATGGTCCACTGGATTTGGCCCAGAGAGGGTGAAAGGCCCGTACGGGTGGAGGTTTCAGACAAGTGAGGCAATTCA CTAGGCCGGCCTTAGAGTCGGGTTGTTTGGGAATGCAGCCCAAAGTGGGTGGTAAACTCCATCCAAGGCTAAATACTAGCACGAGTCCGATAGCAAACAA GTACCGTGAGGGAAAGTTGAAAAGTACTTTGAAGAGAGAGTAAACAGTACGTGAAACCGCATGCAGGTAAACGGGTGGCGTCAAGCTGCACGCCCAGAGG ATTCAGCCGGTTAGAGTGTAGT-TATGCGCTTG-CGTGTCGAACGGCCAGTGTAAGATT----

GGCTAGTCCACTGGAAGACAGTGGGCCCTGCCGCAAGGTGGGG-TGTG-----T-GTACCGGGTGGAAGCCGGAGCACGCTAGCCGTC--

TGTTGGGCCATCTAGCCGGTGCACTTTCTCTGT--

GGTGGACACCACGACCGGTGGTACTGCCAGTCTGCTATGGTCAAGTCGTATTCGGTTGGTCCTTGT-GGCCTACTGGGTGCGAT---CACGGACAAACTCGGTGAACGGCGTTGACGTGCTCTT------_CCAGGGTATGTCTTCGTGATATCGGTAACCGGTTGTCTTAACGGGCCTGCCTTACGATTGTTCCAGTCGTCCTA---

GGGTGGTCTGGTGGACCATGGTGGTAAGAATAACTGTGCAGGGCACCGGAGTTTTCGGCCTCAAATGCAGCCAGCATGCACGCTGGTAGTGT-----

TC-----------

GTGTGGGTGCTCTCGTGGCCTGCCTGGTGCCGAGTCTGATTGTCGTGTTGCCTGCGCAAAGAAATTTTTAGAGCCGTATTATAAAGTAATTAATACAGAC TGTTATAAATTTTAATTACTAATCATGGCATTATTATGATTTTCTTTTTTATAATGCCTATTTTAATCGGCGGGTTTGGTAATTATTTAATACCCTTGT TAGCAGGGTTATCTGATTTAAATTTGCCACGTTTAAAAGCGTTGAGTGCTTGACTTTTACTGCCCTCTGTAGTTTTTTTGTTAATAAGTATGTGTCTTGG TGCTGGTATTGGTTGGACTTTTTATCCTCCCTTATCTTCTGTGGCTTTTGAGGGCAGTAAGGGTGTTGATTTTTTAATGTTTTCTCTGCATTTAGCGGGG GTGTCTAGAATTTTAGTTCTATAAATTTTATCTGTACCTTGTATACTGCTTTTAGCGGTAGGTTATCCTCACGTGGTTCTATTATTTTGTGGTC 16Rhinebothrium_copianullum_worm_2

NNNNNNNNNNNNNNNNNNNNNNNNNNNNNNNNNNNNNNNNNNNNNNNNNNNNNNNNNNNNNNNNNNNNNNNNNNNNNNNNNNNNNNNNNNNNNNNNNNNN

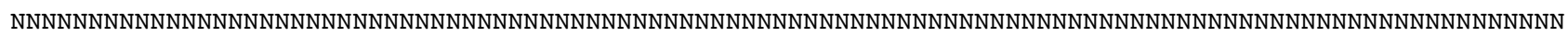

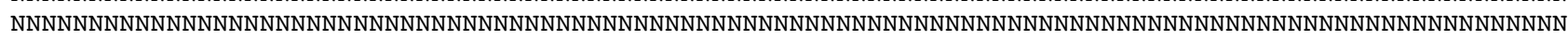

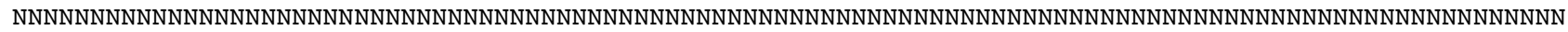




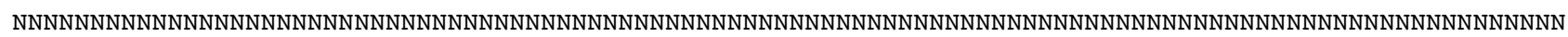
NNNNNNNNNNNNNNNNNNNNNNGGAAGAGCCCAGCACCGAAGCCTGCGGTAGCTTTACTGTTAGGCAATGTGGTGTTTGGGTCGGCTCGCGGGATTGCCA CTCCACTCGAAGTCCAGCATTGAGTATGGTTT-

CTGGATTTGGCCCAGAGAGGGTGAAAGGCCCGTACGGGTGGAGGTATCAGACAAGTGAGGCAATTCACTAGGCCGGCCTTAGAGTCGGGTTGTTTGGGAA TGCAGCCCAAAGTGGGTGGTAAACTCCATCCAAGGCTAAATACTAGCACGAGTCCGATAGCAAACAAGTACCGTGAGGGAAAGTTGAAAAGTACTTTGAA GAGAGAGTAAACAGTACGTGAAACCGCATGCAGGTAAACGGGTGGCGTCAAGCTGCACGCCCAGAGGATTCAGCCGGTTAGAGTGTAGT-

TATGCGCTTG-CGTGTCGACAGGCCAGAGTAAGGCG----TGGTAGACCGCTGGAAGACAGTGGGCCCTGCCGCAAGGTGGGGATGTG----TTTAGCCGGGTGGACGCCGGAGCACGCTATCCGTC--TGTTGGGCCTACTAGCCGGTGCACTTTCTCTGT--

GGTGGACACCACGACCGGTGGGACTGCCAGTCTGCTATGGTCAAGTCGTATTCGGTTGGTCCTTGT-GGCTTACTGGGTGCGAT---CACGGGCAAACTTGGTGAACGGCGTTGACGTGCTCTC----TTGA----GGGTGTGTCTTCGTGTTATCGGTAGCCAGTTGTCTTAACGGGCCTGCCTTACGATTGTTCTAGCCGTCGTA---

GGGTGGTCTGGTGGACCATGGTGGTAAGAATAACTGTGCAGGGCACCGGAGTTTTCGGCCTCAAATGCAGCCAGCATGCACGCTAGTAGTGT------

GT---T---

GCCAATGTGGGTGCTCTCGTGGTCTGCCTGGTGCCGGGTCTGATTGTCGTGTTGCCTACGCAAAGAAATTTTTAGAGCCTTATTATAATGTTATTAGAAC AGATTGTTATAATTTTTTAATTACTAACCACGGTATAATAATGATTTTTTTTTTCATAATGCCTATTTTAATAGGGGGTTTTGGTAATTATTTAATACCT TTATTGTGTGGTTTATCTGATTTAAACTTACCACGCTTAAAAGCTCTTAGAGCTTGGTTGTTACTGCCTTCTGCTGTTTTTTTAGTTGTGAGCATGTGTT TGGGTGCAGGAGTAGGATGAACCTTTTATCCTCCTTTATCTTCTAGTTTATTTGAAGGCAGTAAGGGAGTAGACTTTTTAATGTTTTCATTGCATTTAGC TGGGGTTTCCAGAATTTTTAGGTCTATAAATTTTATGTGTACTTTATATACAGCTTTTAGTGATAGATTAGCATCACGTAGTTGTATTATATTATGGTC r116 vnz salob mot GGGAACTGCTATGTAACCTCT---C--GGACCGCTGGTCATGG-TGGTCCACAACC-

ATTT'CGGTGGGGTGC̄CTACTTGCCCTATACTCCCAGGCGTGCTCGCCAGTCGTGGCAACTTAACTGCTGTCACGGCAATCGGCCAGTCCACACCGGAGCG GCAATGCAGTACATGTGTCGGAAGGCACGTGTGCGAGGTATAAGAA-A-

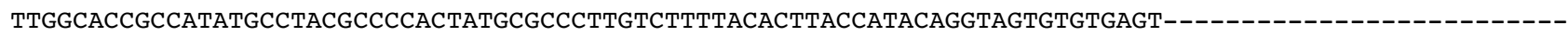
-----------GTACGCGTGTTGGTGTAT-

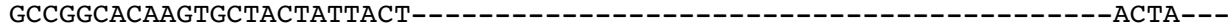

TCTGTGCAAAACGCATGGTCGGCATTAACGTGTTGTACTGTGCGCGGTTCTCATGAGCGTGGTTGGCTATCTTTTGCCTGGTAGCCGATGCGTCTTGTGC AGAGCTNNNNNNNNNNNNNNNNNNNNNNNNNNNNNNNNNNNNNNNNNNNNNNNNNNNNNNNNNNNNNNNNNNNNNNNNNNNNNNNNNNNNNNNNNNNNNN

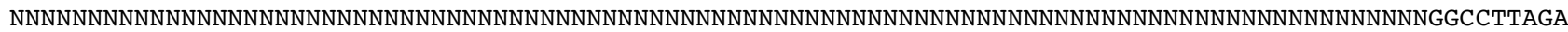
GTCGGGTTGTTTGGGAATGCAGCCCAAAGCGGGTGGTAAACTCCATCCAAGGCTAAATACTAGCACGAGTCCGATAGCWWACAAGTACCGTGAGGGAAAG TTGAAAAGTACTTTGAAGAGAGAGTGRACAGTACGTGAAACCGCATGCAGGTAAACGGGTGGCGTCAAGCTGCACGCCCAGAGGATTCAGCCGGTTAGAG TGTATC-TATGCGCTTG-CGTATAAATGGGCCAGAGTAAGGCG----TGGTAGTCCGCTGGTAGACAGCGGGCCCTGCCGCAAGGTGGGGATGTG-----C-AAGCCGGGTGGATGCCGGAGCACGCTATCCGTC--TGTGGGGCCGTCTAGCCGGTGCACTTTCTCTGT--

GGTGGACACCACGACCGGTGGAACTGCCAGTCTGCTGTGGCCAAGTCGTGTTCGGTTCGTCCTTGT-GGCGAACTGGGCGCGAT---CACGGGCAACCTTGGTGAACGGCGTTGATGTGCCCTC-----------_GGGTATGTCTTCGTGTTATCGGTAGCCAGTTGTCTTAACGGGCCTGCCTTGCGATTGTTCTAGCCGTCGTA---

GGGTGGTCTGGTGGGCCATGGTGGTAAGAATAACTGTGCAGGGCACCGGAGTGTTCGGCCTCAAATGCAGCCAGCATGCACGCTAGTAGTGT-----TG---C---G---

ATGTGGGTGCTCTCGTGGTCTGCCTGGTGCCGGGTCTGATTGTCGTGTTGCCTGCGCAAAGAAATTTTTAGAGCCTTATTATAATGTTATTAGTACAGAT TGTTATAAATTTTTAATTACTAATCATGGTATTATAATGATTTTTTTCTTTATAATGCCTATTTTAATAGGTGGTTTTGGTAATTATTTAATTCCTTTGC TGTGTGGTTTATCAGATTTAAATTTGCCTCGTTTAAAAGCATTAAGTGCTTGGTTGTTATTACCTTCTGCAGTTTTTTTAATAATAAGTATGTGCTTGGG AGCAGGAATAGGTTGGACTTTTTATCCTCCTTTATCTTCTAGTTTATTTGAAGGTAGAAAGGGGGTAGATTTTTTGATGTTTTCGTTACATTTAGCAGGG GTTTCTAGTATTTTTAGTTCTATAAATTTTATTTGTACTCTATACACTGCTTTTAGGGGTAGTTTAGCATCTCGGAGTTCTATAGTATTATGGGC r108_frt_cuiaba_brac GGGAACTGCTATGTAACCTCT---C--GGACTGCTGGTCATGG-TGGTCCACAACCATTTC CGTGGGGTGCCTACTTGCCCTATACTCCCAGGCGTGCTCGCCAGTCGTGGCAACTTAACTGCTGTCACGGCAATCGGCCAGTCCACACCGGAGCG GCAATCCAGTACATGTGCCGCAAGGTGCGTGTGCGAGGTATAAGAA-

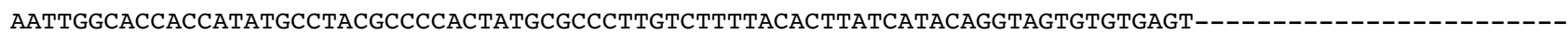

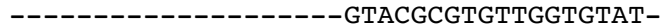

GCCGGCACTAGTGCTACTATGACT---

TCTGTGCAAAACGCATGGTCGGCATTAACTTGTTCGACTGTGTGCGGTTCTCATGAGCGTGGTTGGCTATCTT--

GCCTGGTAGTCGATGCGTCTTGTGCAGAGCTNNNNNNNNNNNNNNNNNNNNNNNNNNNNNNNNNNNNNNNNNNNNNNNNNNNNNNNNNNNNNNNNNNNNN

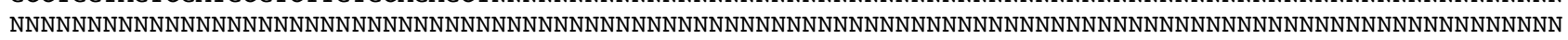
NNNNNNNNNNNNNNNNGGCCTTAGAGTCGGGTTGTTTGGGAATGCAGCCCAAAGCGGGTGGTAAACTCCATCCAAGGCTAAATACTAGCACGAGTCCGAT AGCAAACAAGTACCGTGAGGGAAAGTTGAAAAGTACTTTGAAGAGAGAGTAAACAGTACGTGAAACCGCATGCAGGTAAACGGGTGGCGTCAAGCTGCAC GCCCAGAGGATTCAGCCGGTTAGAGTGTATC-TATGCGCTTG-CGTATAAATGGGCCAGAGTAAGGCG-----

TGGTAGTCCGCTGGTAGACAGCGGGCCCTGCCGCAAGGTGGGGATGTG-----C-AAGCCGGGTGGATGCCGGAGCACGCTATCCGTC--

TGTGGGGCCGTCTAGCCGGTGCACTTTCTCTGT--

GGTGGACACCACGACCGGTGGAACTGCCAGTCTGCTGTGGTCAAGTCGTGTTCGGTTGGTCCTTGT-GGCGAACTGGGCGCGAT---CACGGGCAACCTTGGTGAACGGCGTTGATGTGCCCTC----------GGGTATGTCTTCGTGTTATCGGTAGCCAGTTGTCTTA-CGGGCCTGCCTTGCGATTGTTCTASCC-TCGTA---GGGTGGTCTGGTGGGCCATGGTGGTAGAAT--

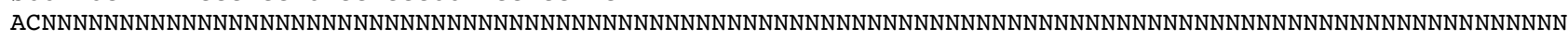
NNNNNNNNNNNNNNNNNNNNNNNNNNNNNNNNNNNNNNNAATTTTTTAGAGCCTTATTATAATGTTATTAGTACAGATTGTTATAAATTTTTAATTACTA ATCATGGTATAATAATGATTTTTTTCTTTATAATGCCTATCTTAATAGGGGGATTTGGTAATTATTTGATTCCTTTATTGTGTGGCTTGTCAGATTTAAA TTTACCACGTTTAAAAGCATTAAGTGCTTGATTGTTACTGCCTTCTGCAGTTTTTTTGATAATAAGTATGTGTTTAGGGGCAGGAATAGGTTGAACTTTT TATCCGCCTTTATCTTCAAGTTTATTTGAAGGGAGTAAGGGTGTAGATTTTTTGATGTTTTCATTACATTTGGCTGGTGTTTCTAGAATTTTTAGTTCTA TAAATTTTATTTGTACTTTATATACTGCTTTTAGAGGTAGTTTGGCGTCTCGAAGTTCTATAGTCTTGTGAGC 05Rhinebothrium_sp_2_worm_2

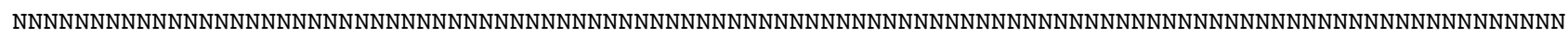

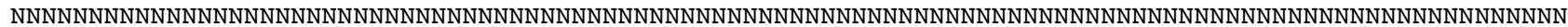

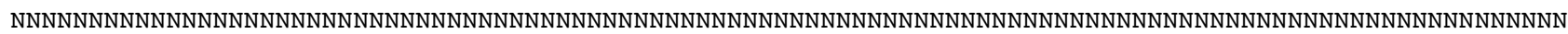

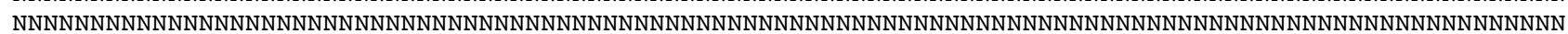

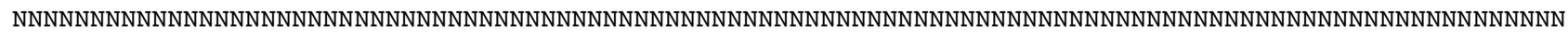
NNNNNNNNNNNNNNNNNNNNNNGGAAGAGCCCAGCACCGAAGCCTGCGGTAGTTTTACTGTTAGGCAATGTGGTGTTTGGGTCGGCCTGCGGGATTGCCA CTCCACTCGAAGTCCAGCATTGAGTATGGTTT-

CTGGATTTGGCCCAGAGAGGGTGAAAGGCCCGTACGGGTGGAGGTGTCAGACAAGTGAGGCAATTCACTAGGCCGGCCTTAGAGTCGGGTTGTTTGGGAA TGCAGCCCAAAGTGGGTGGTAAACTCCATCCAAGGCTAAATACTAGCACGAGTCCGATAGCAAACAAGTACCGTGAGGGAAAGTTGAAAAGTACTTTGAA GAGAGAGTAAACAGTACGTGAAACCGCATGCAGGTAAACGGGTGGCGTCAAGCTGCACGCCCAGAGGATTCAGCCGGTTAGAGTGTAGTTATGCGCTTG-CGTGTCAACAGGCCAGTGTAAGGCG----TGGTAGTCCGCTGGAAGACAGTGGGCCCTGCCGCAAGGCGGGGATGTG------TAAGCCGGGTGGATGCCGGAGCACACTATCCGTCCCTGGGGGGCACCTTAGCCGGTGCACTTTCTCTGT-- 
GGTGGACACCACGACCGGTGGAACTGCCAGTCTGCTATGGTCAAGTCGTGTTCGGTTGGTCCTTGT-GGCTAACTGGGTGCGAT---CACGGGCAAATTTGGCGAACGGCGTTGACGTGCTCTC-----------GGGTGTGTCTTCGTGTTATCGGTAGCCAGTTGCCTTAACGGGCCTGCCTTGCGATTGTTCTAGCCGTCGTATATGGGTGGTCTGGTGGACCTTAGTGGTAAGAATAACTGTGCAGGGCACCGGAGTTTTCGGCCTCAAATGCAGCCGGCATGCACGCTAGTA GTGT-----GT---T---

GCCTATGTGGGTGCTCTCGTGGTCTGCCTGGTGCCGGGTCTGATTGTCGTGTTGCCTGCGCAAAGAAATTTTTAGAACCCTATTATAATGTGATTAGGAC GGATTGTTATAAATTTTTAATTACTAACCACGGTATTATAATGATTTTTTTCTTTATTATGCCTATTTTAATAGGCGGGTTTGGTAATTATCTTATACCT CTGTTATGTGGGTTGTCTGACCTGAATTTACCACGTTTAAAAGCTTTAAGGGCTTGGTTGCTTTTACCGTCTACAGTTTTTCTTATTACGAGTATGTGTT TAGGTGCGGGGGTAGGTTGAACATTTTATCCTCCTTTATCTTCTAGTTTATTTGAAGGTAGTAAGGGTGTTGACTTTTTGATGTTTTCATTGCATTTAGC AGGGGTGTCTAGAATTTTAGCTCTATTAATTTTATATGCACCTTATACACAGCTTTTAGTGGGAGATTGGCTTCCCGTAGATCTATAATTCTTTGGGC r102_frt_negro_schr GGGAACTGCTATGTAACCTCT---C--GGACTGCCCGTCATGG-TGGTCCACAACC-

АTTT $\bar{C}$ GGT $\overline{G G G G T G \bar{C}}$ TACTTGCCCTATACTCCCAGGCGTGCTCGCCAGTCGTGGCAACTTAACTGCTGTCACGGCAATCGGCCAGTCCACACCGGAGCG GCAATCCAGTACATGTGCCGCAAGGTACGTGTGCGAGGTATAAGAA-A-

TTGGCACCACСATATGCCTACGCCCCACTATGCGCCСTTGTCTTTTACACTTATCATACAGGTAGTGTGTGAGT-------------------------- - - - - - - - - - - GTACGCGTGTTGGTGTAA-

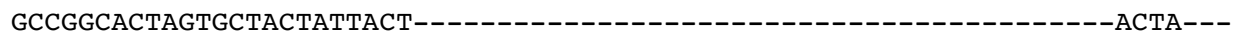

TCTGTGCAAAACGCATGGTCGGCATTAACTTGTTCGACTGTGTGCGGTTCTCATGAGCGTGGTTGGCTATCTT--

GCCTGGTAGCCGATGCGTCTTGTGCAGAGCTNNNNNNNNNNNNNNNNNNNNNNNNNNNNNNNNNNNNNNNNNNNNNNNNNNNNNNNNNNNNNNNNNNNNN NNNTTGCCACTCCACTCGAAGTCCAGCATTGAGTATGGTTT-

CTGGATTTGGCCCAGAGAGGGTGAAAGGCCCGTACGGGTGGAGGTATCAGACAAGTGAGGCAATTCACTAGGCCGGCCTTAGAGTCGGGTTGTTTGGGAA TGCAGCCCAAAGCGGGTGGTAAACTCCATCCAAGGCTAAATACTAGCACGAGTCCGATAGCAAACAAGTACCGTGAGGGAAAGTTGAAAAGTACTTTGAA GAGAGAGTAAACAGTACGTGAAACCGCATGCAGGTAAACGGGTGGCGTCAAGCTGCACGCCCAGAGGATTCAGCCGGTTAGAGTGTATC-

TATGCGCTTG-CGTATAAATGGGCCAGAGTAAGGCG----TGGTAGTCCGCTGGTAGACAGCGGGCCCTGCCGCAAGGTGGGGATGTG-----CAAGCCGGGTGGATGCCGGAGCACGCTATCCGTC--TGTGGGGCCGTCTAGCCGGTGCACTTTCTCTGT--

GGTGGACACCACGACCGGTGGAACTGCCAGTCTGCTGTGGCCAAGTCGTGTTCGGTTCGTCCTTGT-GGCGAACTGGGCGCGAT---CACGGGCAACCTTGGTGAACGGCGTTGATGTGCCCTC----------GGGTATGTCTTCGTGTTATCGGTAGCCAGTTGTCTTAACGGGCCTGCCTTGCGATTGTTCTAGCCGTCGTA---

GGGTGGTCTGGTGGGCCATGGTGGTAAGAATAACTGTGCAGGGCACCGGAGTGTTCGGCCTCAAATGCAGCCAGCATGCACGCTAGTAGTGT-----

TG---C---G---

ATGTGGGTGCTCTCGTGGTCTGCCTGGTGCCGGGTCTGATTGTCGTGTTGCCTGCGCAAAGNNNNNNNNNNNNNNNNNNNNNACTGTTATTAGCTCAGAT TGTTATAAATTTTAATTACTAATCATGGCATTATAATGATTTTTTTTTTTATAATGCCTATTTTGATAGGTGGTTTTGGTAATTACTTAATTCCTTTAT TATGTGGCTTATCTGATTTAAATTTACCTCGTTTAAAAGCATTAAGTGCTTGATTATTATTGCCTTCTGCTGTTTTTTTAATAGTAAGTATGTGTTTAGG TGCAGGAATAGGTTGGACTTTTTATCCTCCTTTATCTTCTAGTTTATTTGAAGGTAGAAAGGGTGTAGATTTTTTAATGTTTTCTCTACATTTGGCAGGA GTTTCTAGTATTTTTAGTTCTATAAATTTTATTTGTACTTTATATACTGCTTTTAATGGTAGTTTAGCATCTCGAAGTTCGATAGTGTTATGATC r035 gld jamanxim tpj1GGGAACCGCTATGTAATCTAT---CTGGGACTGCCCGTCATGG-

TGGT $\bar{C}$ CAA $\bar{A}$ ACCCGTTTCGGTGGGGTGCCTACTTGCCTTATACTCCCAGGCGTGCTCGCCTGTTGTGGCAACTTAACTGCTGTCACAACAACCGGCCAGT CCACACCGGAGCGGCATATTAGTACACGTGTCA-AAG---CGTGTGCAAGGTATAAGAACA-

TTGGCACTACCATATGCCTACGCCCCGCTATGCGCCCTTGTCTTTTACACTTACCATACGGATAGTGTGTATGT----------------------------------------GT--GTGTGTTAGTGTAT-

GCTAGCATTACTACTACTACTG-

TCTGTGCAAAACGCATGGAGAGCATTAACTTGCTGTACCGTGTGTGGTTCTCATGAGCGTACTTGGTTACCTT--

GCCTGGGTGCCATTGCGTCTTGTGCAGAGCTNNNNNNNNNNNNNNNNNNNNNNNNNNNNNNNNNNNNNNNNNNNNNNNNNNNNNNNNNNNNNNNNNNNNN

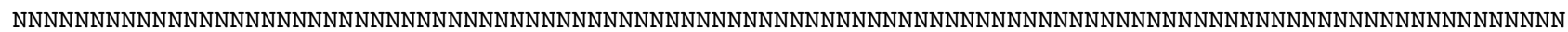
NNNNNNNNNNNNNNNNGGCCTTAGAGTCGGGTTGTTTGGGAATGCAGCCCAAAGCGGGTGGTAAACTCCATCCAAGGCTAAATACTAGCACGAGTCCGAT AGCAAACAAGTACCGTGAGGGAAAGTTGAAAAGTACTTTGAAGAGAGAGTAAACAGTACGTGAAACCGCATGCAGGTAAACGGGTGGCGTCAAGCTGCAC GCCCAGAGGATTCAGCCGGTTAGAGTGTAGT-TATGCGCTTG-CGTATCAAAGGGCCAGAGTAAGGCG----

TGGTAGTCCGCTGGAAGACAGCGGGCCCTGCCGCAAGGTGGGGATGTG-----T-AAGCCGGGTGGATGCCGGAGCACGCTATCCGTC--

TGGAGGGCCGTCTAGCCGGTGCACTTTCTCTGT--

GGTGGACACCACGACCGGTGGAACTGCCAGTCTGCTATGGTCAAGTCGTGTTCGGTTGGTCCTTGT-GGCTAGCTGGGCGCGAT--_CACGGGCAAATTTGGTGAACGGCGTTGATGTGCCCTC----_-----GGGTATGTCTTCGTGTTATCGGTAACCAGTTGTCTTAACGGGCCTGCCTTACGATTGTTCTAGCCGTCGTA---

GGGTGGTCTGGTGGGCCATAGTGGTAAGAATAACTGTGCAGGGCACCGGAGTTTTCGGCCTCAAACGCAGCCAGCATGCACGCTAGTAGTGT-----

TG---C--TG---

ATGTGGGTGCTCTCGTGGTCTGCCTGGTGCCGGGTCTGATTGTCGTGTTGCCTACGCAAAGNNNNNNNNNNNNNNNNNNNNNNNNNNNNNNNNNNNNNNN NNNNNNNNNNNNNNNNNNNNNNNNNNNNNNNNNNNAGTGGTTTTCTTTTTTATAATGCCTATCTTAATAGGGGGGTTTGGTAATTATTTAATTCCCTTAT TAAGGGGTTTGTCCGATTTAAACTTGCCTCGTTTAAAAGCCTTGAGTGCTTGATTGCTTTTACCTTCTGCTGTATTTTTAGTGATTAGTATGTGTTTAGG TGCTGGTATAGGTTGAACTTTCTATCCTCCTTTGTCTTCTAGTGTTTTTGAGGGGAGTAAGGGTGTAGACTTTTTAATGTTTTCATTGCATTTGGCTGGT GTTTCTAGTATATTTAGTTCTATTAATTTTATATGTACTTTGTATACTGCCTTTAGTGGTAGGTTGGCTTCTCGTAGTTCAATTGTATTATGAGC 26Rhinebothrium_sp_1_worm_12

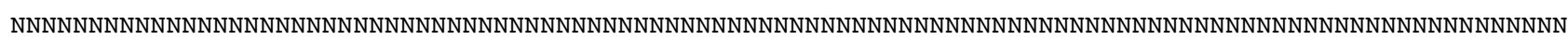

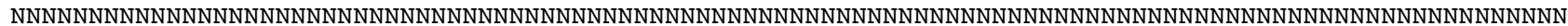

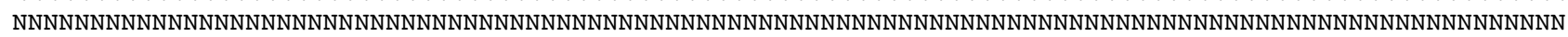

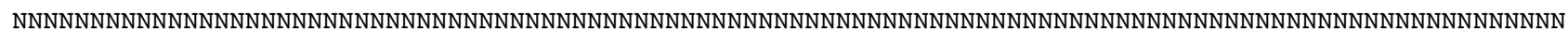

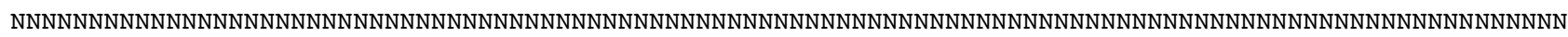
NNNNNNNNNNNNNNNNNNNNNNGGAAGAGCCCAGCACCGAAGCCTGCGGTAGCTTTACTGTTAGGCAATGTGGTGTTTGGGTCGGCTCGCGGGATTGCCA CTCCACTCGAAGTCCAGCATTGAGTATGGTTT-

CTGGATTTGGCCCAGAGAGGGTGAAAGGCCCGTACGGGTGGAGGTATCAGACAAGTGAGGCAATTCACTAGGCCGGCCTTAGAGTCGGGTTGTTTGGGAA TGCAGCCCAAAGTGGGTGGTAAACTCCATCCAAGGCTAAATACTAGCACGAGTCCGATAGCAAACAAGTACCGTGAGGGAAAGTTGAAAAGTACTTTGAA GAGAGAGTAAACAGTACGTGAAACCGCATGCAGGTAAACGGGTGGCGTCAAGCTGCACGCCCAGAGGATTCAGCCGGTTAGAGTGTAGTTATGCGCTTG-CGTGTCAACAGGCCAGAGTAAGGCG----TGGTAGACCGCTGGAAGACAGTGGGCCCTGCCGCAAGGTGGGGATGTG----TTTAGCCGGGTGGACGCCGGAGCACGCTATCCGTC--TGTTGGGCCTACTAGCCGGTGCACTTTCTCTGT--

GGTGGACACCACGACCGGTGGGACTGCCAGTCTGCTATGGTCAAGTCGTATTCGGTTGGTCCTTGT-GGCTAACTGGGTGCGAT---CACGGGCAAATTTGGTGAACGGCGTTGACGTGCTCTC----TTGA----GGGTGTGTCTTCGTGTTATCGGTAACCAGTTGTCTTAACGGGCCTGCCTTACGATTGTTCTAGCCGTCGTA---

GGGTGGTCTGGTGGACCATGGTGGTAAGAATAACTGTGCAGGGCACCGGAGTTTTCGGCCTCAAATGCAGCCAGCATGCACGCTAGTAGTGT-----GT---T---

GCCAATATGGGTGCTCTCGTGGTCTGCCTGGTGCCGGGTCTGATTGTCGTGTTGCCTACGCAAAGAAATTTTTAGAGCCGTACTATAATGTTATTAGTAC GGACTGCTATAAATTTTTAATTACTAATCATGGTATTATAATGATTTTTTTCTTTATAATGCCTATTTTGATAGGAGGTTTTGGTAATTATTTGATTCCA 
TTACTTTGTGGTTTATCCGATTTAAATCTACCTCGTTTAAAAGCACTTAGAGCTTGGTTGTTGTTGCCTTCAGCTCTTTTTTTGGTGGTGAGCATGTGCT TAGGGGCTGGTATAGGTTGGACTTTTTATCCTCСTTTATCTTCTAGATTATTTGAAGGTAGTAAGGGGGTAGATTTTTTAATGTTTTCGTTGCATTTAGC AGGAATTTCTAGTATTTTAAGTCTATTAAATTTATTTGTACTTTGTATACTGCTTTTAGTGATAGTTTAGCATCACGTAGTTGTATTATATTATGATC r053_vnz_uppersol_mot GGGAACTGCTATGTAACCTCT---C--GGACCGCTGGTCATGG-TGGTCCACAACC-

АTTT $\bar{C} G G T \bar{G} G G G T C C T \bar{A} C T T G C C C T A T A C T C C C A G G C G T G C T C G C C A G T C G T G G C A A C T T A A C T G C T G T C G C G G C A A T C G G C C A G T C C A C A C C G G A G C G$ GCAATGCAGTACATGTGTCGGAAGGCACGTGTGCGAGGTATAAGAA-A-

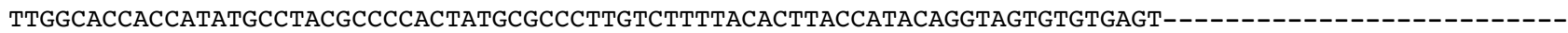
---------------GTACGCGTGTTGGTGTAT-

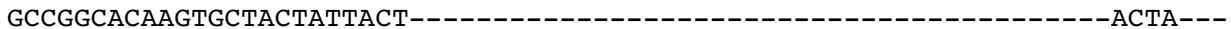

TCTGTGCAAAACGCATGGTCGGCATTGACTTGTTGTACTGTGCGCGGTTCTCATGAGCGTGGTTGGCTATCTTTTGCCTGGTAGCCGATGCGTCTTGTGC AGAGCTGGAAGAGCCCAGCACCGAAGCCTGCGGCAGGTTTGCTGTTAGGCAATGTGGTGTTTGGGTCGGCTCGCGGGATTGCCACTCCACTCGAAGTCCA GCATTGAGTATGGTTT-

CTGGATTTGGCCCAGAGAGGGTGAAAGGCCCGTACGGGTGGAGGTGTCAGACAAGTGAGGCAATTCACTAGGCCGGCCTTAGAGTCGGGTTGTTTGGGAA TGCAGCCCAAAGCGGGTGGTAAACTCCATCCAAGGCTAAATACTAGCACGAGTCCGATAGCAAACAAGTACCGTGAGGGAAAGTTGAAAAGTACTTTGAA GAGAGAGTAAACAGTACGTGAAACCGCATGCAGGTAAACGGGTGGCGTCAAGCTGCACGCCCAGAGGATTCAGCCGGTTAGAGTGTATC-

TATGCGCTTG-CGTATAAAAGGGCCAGAGTAAGGCG----TGGTAGTCCGCTGGCAGACAGCGGGCCCTGCCGCAAGGTGGGGATGTG-----T-

AAGCCGGGTGGATGCCGGAGCACGCTATCCGTC--TGTGGGGCCGTCTAGCCGGTGCACTTTCTCTGT--

GGTGGACACCACGACCGGTGGAACTGCCAGTCTGCTGTGGTCAAGTCGTGTTCGGTTGGTCCTTGT-GGCGAACTGGGCGCGAT---CACGGGCAACCTTGGTGAACGGCGTTGATGTGCCCTC-----------GGGTATGTCTTCGTGTTATCGGTAGCCAGTTGTCTTAACGGGCCTGCCTTGCGATTGTTCTAGCCGTCGTA---

GGGTGGTCTGGTGGGCCATGGTGGTAAGAATAACTGTGCAGGGCACCGGAGTGTTCGGCCTCAAATGCAGCCAGCATGCACGCTAGTAGTGT-----

TG---C---G---

ATGTGGGTGCTCTCGTGGTCTGCCTGGTGCCGGGTCTGATTGTCGTGTTGCCTGCGCAAAGAAATTTTTAGAGCCTTATTATAATGTTATTAGTACAGAT TGTTATAAАTTTTTAATTACTAATCATGGTATTATAATGATTTTTTTCTTTATAATGCCCATTTTAATAGGTGGTTTTGGTAATTATTTAATTCCTTTGT TGTGTGGTTTGTCGGATTTAAATCTACCTCGCTTGAAAGCATTAAGTGCTTGGTTGTTACTGCCTTCTGCAGTTTTTTTAGTAATTAGTATGTGTTTGGG AGCAGGTATAGGTTGGACTTTTTATCCTCCTCTTTCTTCAAGTTTATTTGAGGGTAGAAAGGGTGTAGATTTTTTGATGTTTTCATTACATTTGGCGGGA GTTTCTAGTATTTTTAGTTCTATAAATTTTATTTGTACTTTGTATACTGCTTTCAGAGGTAGGTTAGCGTCTCGAAGCTCTATAGTATTATGGGC r08 scorzai marajo motGGGAACTGCTATGTAACAACAATACTCGGACCGCTCGTCATAG-TGGTCTGCTACC-

АTTT̄CGGTGGGĞTGCCTATTTGCCCTATACTCCCAGGCGTGCTCGCCAGCTGCGGCAACTTAACTGCTGCCACAGCAAGAGGCCAGTCCACACCGGAGCG GCAAACCAGTACATGTGTCGCAAG---CGTGTGCAAGGTATAAGAA-A-

TTGGCACTACCATATGCCTACGCCCCACTATGCGCCCCTGTCTTTTACACTTACTATACGGGTAGTGTGTGTGTATGTGAGTGTGTGTGTGTGTGTGTGT GTGCGTGCGTGTGTGTATGTATGTGTGCGTGTGTGT-GTCAGCAATAATACTAACAATACCGAGAGCTCCCCCCCCCC---------

СССТАСАAСТАТАACTATA---

TCTGTGTGAAACANNNNNNNNNNNNNNNNNNNNNNNNNNNNNNNNNNNNNNNNNNNNNNNNNNNNNNNNNNNNNNNNNNNNNNNNNNNNNNNNNNNNNNN

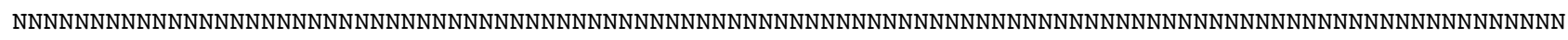
NNNNNNNNNNNNNNNNNNNNNNNNNNNNNNNNNNNNNNNNNNNNNNNNNNNNNNNNNNNNNNNNNNNNNNNNNNNNNNNNNNNNNNNNNNNGGCCTTAGA GTCGGGTTGCTTGGGAATGCAGCCCAAAGTGGGTGGTAAACTCCATCCAAGGCTAAATACTAGCACGAGTCCGATAGCAAACAAGTACCGTGAGGGAAAG TTGAAAAGTNCTTTGAAGAGAGAGTAAACAGTACGTGAAACCGCATGCAGGTAAACGGGTGGCGTCAAGCTGCACGCCCAGAGGATTCAGCCGGTTAGAG TGTAGT-TATGCGCTTG-CGTATCGAAGGGCCAGAGTAAAGCGCGCGTGGTAGTCCGCTGGAAGACAGCGGGCCCTGCCGCAAGGTGGGGATGTG----T-AAGCCGGGTGGAAGCCGGAGCACGCTATCCGTC--TGCGGGGCCGTCTAGCCGGTGCACTTTCTCTGT--

GGTGGACACCACGACCGGTGGAACTGCCAGTCTGCTATGGTCAAGTCGTGTTCGGTTGGTCCTTGT-GGCGAACTGGGCGCGAT---CACGGGCAAATTTGGTGAACGGCGTTGATGTGCCCTC-----------GGGTGCGTCTTCGTGCTATCGGTAGCCAGTTGTCTTAACGGGCCTGCCTTACGATTGTTCTAGCCGTCGTA---

GGGTGGTCTGGTGGGCCGTAGTGGTAAGAATAACTGTGCAGGGCACTGGAGTTATCGGCCTCAAACGCAGCCAGCATGCACGCTAGTAGTGTGTCCCTG$--\mathrm{G}---\mathrm{T}---$

ATGTGGGTGCTCTCGTGGTCTGCCTGGTGCCGGGTCTGATTGTCGTGTTGCCTACGCAAAGAAATTTTTAGAACCTTACTATAATGTTATTAGTACTGAT TGTTATAAATTTTGATTACTAATCATGGTATTATAATGATTTTTTTTTTTATAATGCCTATTTTAATTGGTGGGTTTGGTAATTATTTAATTCCTTTAT TATGTGGTTTATCTGATTTAAACTTACCACGTTTAAACGCGCTTAGTGCTTGGTTACTTTTACCTTCTGTGTTATTTTTAGTTATAAGAATGTGTTTAGG GGCTGGGGTAGGTTGAACTTTTTATCCTCCCTTAGCTTCCAGTGCATTTGAGGGGAGTAAGGGTGTAGACTTTTTAATGTTTTCTTTACACTTAGCGGGG GTTTCTAGAATTTTAGCTCTATTAATTTTATTTGTACTTTACACACTGCCTTTAGGGGTAATTAGCTTCTCGTAGTTCTATTGTATTATGGGC 28Rhinebothrium_sp_1_worm_14

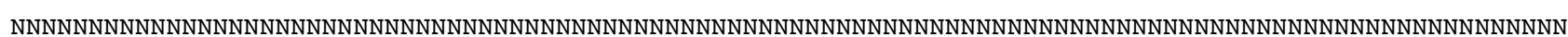

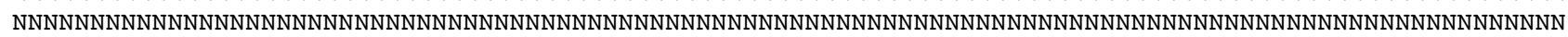

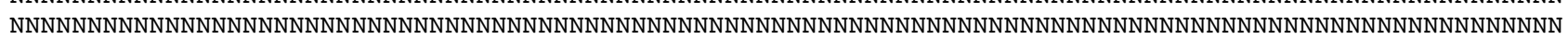

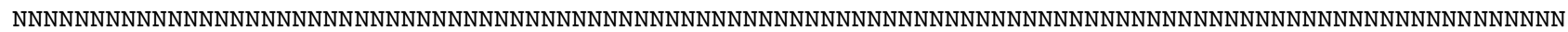

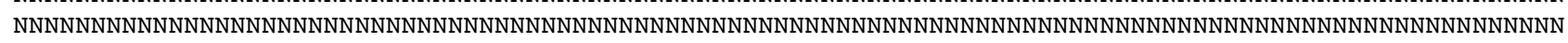
NNNNNNNNNNNNNNNNNNNNNNGGAAGAGCCCAGCACCGAAGCCTGCGGTAGCTTTACTGTTAGGCAATGTGGTGTTTGGGTCGGCTCGCGGGATTGCCA CTCCACTCGAAGTCCAGCATTGAGTATGGTTT-

CTGGATTTGGCCCAGAGAGGGTGAAAGGCCCGTACGGGTGGAGGTATCAGACAAGTGAGGCAATTCACTAGGCCGGCCTTAGAGTCGGGTTGTTTGGGAA TGCAGCCCAAAGTGGGTGGTAAACTCCATCCAAGGCTAAATACTAGCACGAGTCCGATAGCAAACAAGTACCGTGAGGGAAAGTTGAAAAGTACTTTGAA GAGAGAGTAAACAGTACGTGAAACCGCATGCAGGTAAACGGGTGGCGTCAAGCTGCACGCCCAGAGGATTCAGCCGGTTAGAGTGTAGT-

TATGCGCTTG-CGTGTCAACAGGCCAGAGTAAGGCG----TGGTAGACCGCTGGAAGACAGTGGGCCCTGCCGCAAGGTGGGGATGTG-----

TTTAGCCGGGTGGACGCCGGAGCACGCTATCCGTC--TGTTGGGCCTACTAGCCGGTGCACTTTCTCTGT--

GGTGGACACCACGACCGGTGGGACTGCCAGTCTGCTATGGTCAAGTCGTATTCGGTTGGTCCTTGT-GGCTAACTGGGTGCGAT---CACGGGCAAATTTGGTGAACGGCGTTGACGTGCTCTC----TTGA----GGGTGTGTCTTCGTGTTATCGGTAACCAGTTGTCTTAACGGGCCTGCCTTACGATTGTTCTAGCCGTCGTA---

GGGTGGTCTGGTGGACCATGGTGGTAAGAATAACTGTGCAGGGCACCGGAGTTTTCGGCCTCAAATGCAGCCAGCATGCACGCTAGTAGTGT-----

GT---T---

GCCAATATGGGTGCTCTCGTGGTCTGCCTGGTGCCGGGTCTGATTGTCGTGTTGCCTACGCAAAGAAATTTTTGGAGCCGTATTATAATGTTATTGGTAC GGATTGTTATAAATTTTTAATTACTAATCATGGTATTATAATGATTTTTTTCTTTATAATGCCTATTTTGATAGGTGGTTTTGGTAATTATTTGATTCCA TTACTTTGTGGTTTATCTGATTTAAATTTACCCCGTTTAAAAGCACTTAGAGCTTGGTTGTTGTTGCCATCAGCTCTTTTTTTGGTGGTGAGTATGTATT TAGGGGCTGGTATAGGTTGGACTTTTTATCCTCCATTATCTTCTAGATTATTTGAAGGTAGTAAGGGGGTAGATTTTTTAATGTTTTCGTTGCATTTAGC AGGAATTTCTAGTATTTTTAGGTCTATTAAATTTATTTGTACCTTGTATACTGCTTTTAGTGATAGTTTAGCATCACGTAGGTGTATTATATTATGATC r031 gld lagonovo mot GGGAACCGCTATGTAATCTAT---CTGGGACTGCCCGTCATGG-

TGGTC CAA $\bar{A}$ ACCCGTTTCGGTGGGGTGCCTACTTGCCTTATACTCCCAGGCGTGCTCGCCTGTTGTGGCAACTTAACTGCTGTCACAACAAACGGCCAGT CCACACCGGAGCGGCATATTAGTACACGTGTCA-AAG---CGTGTGCAAGGTATAAGAACA-

TTGGCACTACCATATGCCTACGCCCCGCTATGCGCCСTTGTCTTTTACACTTATCATACGGATAGTGTGTATGT------------------------- 
-----------------GT--GTGTGTTAGTGTAT-

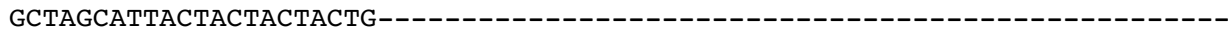

TCTGTGCAAAACGCACGGCGAGCATTAACTTGCTGTACTGTGTGTGGTTCTCATGAGCGTACTTGGTTACCTT--

GCCTGGGTGCCATTGCGTCTTGTGCAGAGCTNNNNNNNNNNNNNNNNNNNNNNNNNNNNNNNNNNNNNNNNNNNNNNNNNNNNNNNNNNNNNNNNNNNNN NNNTTGCCACTCCACTCGAAGTCCAGCATTGAGTATGGTTT-

CTGGATTTGGCCCAGAGAGGGTGAAAGGCCCGTACGGGTGGAGGTTTCAGACAAGTGAGGCAATTCACTAGGCCGGCCTTAGAGTCGGGTTGTTTGGGAA TGCAGCCCAAAGTGGGTGGTAAACTCCATCCAAGGCTAAATACTAGCACGAGTCCGATAGCAAACAAGTACCGTGAGGGAAAGTTGAAAAGTACTTTGAA GAGAGAGTAAACAGTACGTGAAACCGCATGCAGGTAAACGGGTGGCGTCAAGCTGCACGCCCAGAGGATTCAGCCGGTTAGAGTGTAGTTATGCGCTTG-CGTATCAAAGGGCCAGAGTAAGGCG----TGGTAGTCCGCTGGAAGACAGCGGGCCCTGCCGCAAGGTGGGGATGTG-----TAAGCCGGGTGGATGCCGGAGCACGCTATCCGTC--TGGAGGGCCGTCTAGCCGGTGCACTTTCTCTGT--

GGTGGACACCACGACCGGTGGAACTGCCAGTCTGCTATGGTCAAGTCGTGTTCGGTTGGTCCTTGT-GGCTAGCTGGGCGCGAT---CACGGGCAAATTTGGTGAACGGCGTTGATGTGCCCTC-----------GGGTATGTCTTCGTGTTATCGGTAACCAGTTGTCTTAACGGGCCTGCCTTACGATTGTTCTAGCCGTCGTA---

GGGTGGTCTGGTGGGCCATAGTGGTAAGAATAACTGTGCAGGGCACCGGAGTTTTCGGCCTCAAACGCAGCCAGCATGCACGCTAGTAGTGT-----

TG---C--TG---

ATGTGGGTGCTCTCGTGGTCTGCCTGGTGCCGGGTCTGATTGTCGTGTTGCCTACGCAAAGAAATTTTTGGAGCCTTACTATAATGTGATTAGTACAGAT TGTTATAATTTTCTGATTACTAAACATGGTATTATAATGATTTTCTTTTTTATAATGCCTATTTTAATAGGGGGGTTTGGTAACTATTTAATTCCTTTAT TAAGAGGTTTGTCCGATTTAAATTTGCCTCGTTTAAAAGCTTTGAGTGCTTGATTGCTTTTACCTTCTGCTGTATTTTTAGTGATTAGTATGTGTTTAGG TGCTGGTATAGGTTGAACTTTCTATCCTCCTTTGTCTTCTAGTGTTTTTGAGGGTAGTAAGGGTGTAGACTTTTTAATGTTTTCATTACATTTGGCCGGT GTTTCTAGTATATTTAGTTCTATTAATTTTATATGTACTTTGTATACTGCCTTTAGAGGTAGGTTGGCTTCTCGTAGTTCAATTGTATTATGAGC AF286930_Litobothrium_janovyi

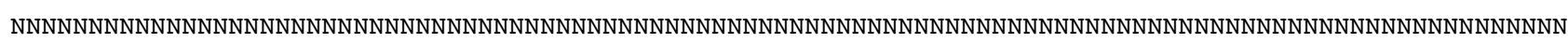

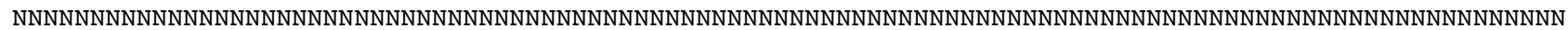

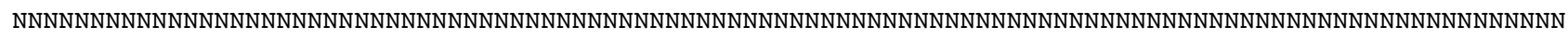
NNNNNNNNNNNNNNNNNNNNNNNNNNNNNNNNNNNNNNNNNNNNNNNNNNNNNNNNNNNNNNNNNNNNNNNNNNNNNNNNNNNNNNNNNNNNNNNNNNNN

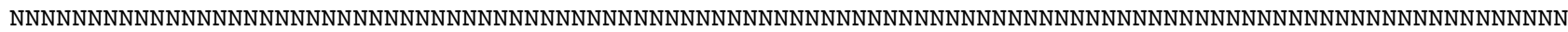
NNNNNNNNNNNNNNNNNNNNNNGGAATAGCCCAGCACCGAAGCCTGCGGCAGGTTTGCTGTTAKGCAATGTGGTGTTTGGGTCGGCTTATGGGATTGCCA CTCCATTCGAAGTCCAGCATTGAGTATGGTACCCTGGATTTGGCCCAGAGAGGGTGAAAGGCCCGTACGAGTGGATGTATCAGACATGTAAGGCAATTCA CCAGGCCGGCCTTAGAGTCGGGTTGTTTGGGAATGCAGCCCAAAGTGGGTGGTAAACTCCATCCAAGGCTAAATACTAGCACGAATCCGATAGCGAACAA GTACCGTGAGGGAAAGTTGAAAAGTACTTTGAAGAGAGAGTAAACAGTACGTGAAACCGCATGCAGGTAAACGGGTGGCGTCAAGCTGTAAGCCCAGAGG ATTCAGTCGGTTAGGATGTAGTGTATGCGCCTGGCGCATCGAGAGGTCAGAGTAAGATT----

GGGTAATCTGCTGGTAAACAGCAGGCTCAGCCGCAAGGTTGGGATATG-----T-GTACCGGGTGGTTGCCGGAGCATGTTACCCGTC--

TGTTGGACCACCTAGCCGGTGCACTTCCTCTGTTTGGTGAACACCACGACCGGTGGTATTGCCAGTCTGCTATAGTCAAGTCGTGTTCAGCTGGTACTTG T-GCTAGTTGGATTGCGATGATCACAGGCAAATT-CGGTGAACGGTGTAGAGGTGTT--T---------

CGGCACTTTTGCATGTTATCGGACACTGGTTGTC--AACGGGTCTGTTTAGTGATTGTTGTA-GTCGTCGCT---

AGATGGCCTGGTGGATTATGGTGGTAAGAATAACTGTGCAAGGCACCGGAGTTATCGGTCTCTAATGCAGCCTACATGCACGCTACAAGTGA----AC-----------ATG-

GGGTGTTGTTGCAGCCTGCCTGTTATTGGGTCTGATTGTCGTGTTGCCTGCGCAAAGNNNNNNNNNNNNNNNNNNNNNNNNNNNNNNNNNNNNNNNNNNN

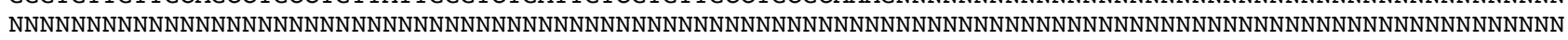

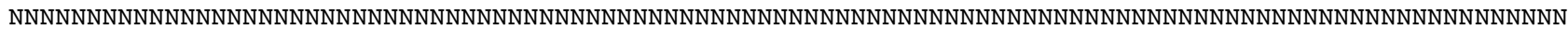

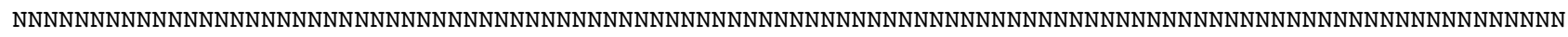

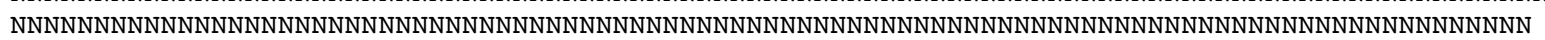
06Rhinebothrium_sp_2_worm_3

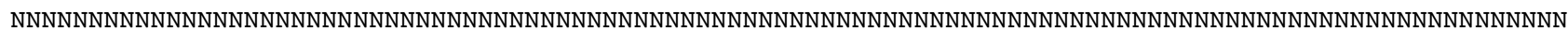

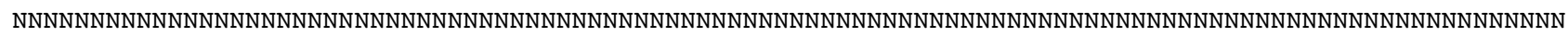

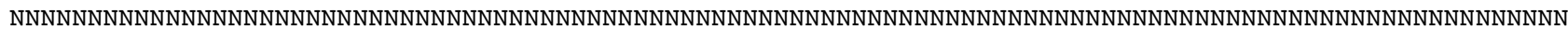

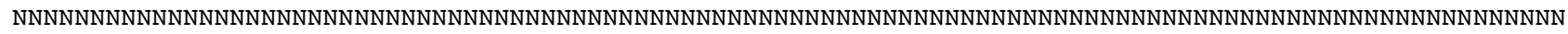

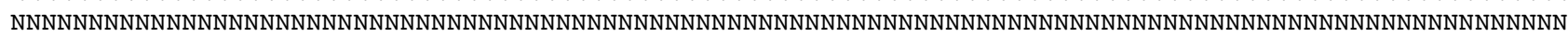
NNNNNNNNNNNNNNNNNNNNNNGGAAGAGCCCAGCACGTAAGCCTGCGGTAGTTTTACTGTTAGGCAATGTGGTGTTTGGGTCGGCCTGCGGGATTGCCA CTCCACTCGAAGTCCAGCATTGAGTATGGTTT-

CTGGATTTGGCCCAGAGAGGGTGAAAGGCCCGTACGGGTGGAGGTGTCAGACAAGTGAGGCAATTCACTAGGCCGGCCTTAGAGTCGGGTTGTTTGGGAA TGCAGCCCAAAGTGGGTGGTAAACTCCATCCAAGGCTAAATACTAGCACGAGTCCGATAGCAAACAAGTACCGTGAGGGAAAGTTGAAAAGTACTTTGAA GAGAGAGTAAACAGTACGTGAAACCGCATGCAGGTAAACGGGTGGCGTCAAGCTGCACGCCCAGAGGATTCAGCCGGTTAGAGTGTAGT-

TATGCGCTTG-CGTGTCAACAGGCCAGTGTAAGGCG----TGGTAGTCCACTGGAAGACAGTGGGCCCTGCCGCAAGGCGGGGATGTG-----TAAGCCGGGTGGATGCCGGAGCACACTATCCGTCC-TAGGGGGCCTACTAGCCGGTGCACTTTCTCTGT--

GGTGGACACCACGACCGGTGGAACTGCCAGTCTGCTATGGTCAAGTCGTGTTCG-TTGGTCCTTGT-GGCTAACTGGGTGCGAT---CACGGGCAAATTTGGCGAACGGCGTTGACGTGCTCTC----------

GGGTGTGTCTTCGTGTTATCGGTAGCCAGTTGCCTTAACGGGCCTGCCTTGCGATTGTTCTATGCCGTCGTATATGGGTGGTCTGGTGGACCTTAGTGGT AAGAATAACTGTGCAGGGCACCGGAGTTTTCGGCCTCAAATGCAGCCGGCATGCACGCTAGTAGTGT-----GT---T---GCCTATGTGGGTGCTCTCTGGTCTGCCTGGTGCCGGGTCTGATTGTCGTGTTGCCTGCGCAAAGAAATTTTTAGAACCCTATTATAATGTGATTAGGACGGATTGTTATAAATTTTA АTTACTAACCACGGTATTATAATGATTTTTTTCTTTATTATGCCTATTTTAATAGGCGGGTTTGGTAATTATCTTATACCTCTGTTATGTGGGTTGTCTG ACCTGAATTTACCACGTTTAAAAGCTTTAAGGGCTTGGTTGCTTTTACCGTCTACAGTTTTTCTTATTACGAGTATGTGTTTAGGTGCGGGAGTAGGTTG AACATTTTATCCTCCTTTATCTTCTAGTTTATTTGAAGGTAGTAAGGGTGTTGACTTTTTGATGTTTTCATTGCATTTAGCAGGGGTGTCTAGAATTTT AGTTCTATTAATTTATATGCACCTTATACACAGCTTTTAGTGGGAGATTGGCTTCCCGTAGATCTATAATTCTTTGGGC r092_rhoides_negro_spnGGGAACTGCTATGTAACCTCT---C--GGACCGCTGGTCATGG-TGGTCCACAACCАTTTC̄GGTGGGGTGCCTATTTGCCCTATACTCCCAGGCGTGCTCGCCAGTCGTGGCAGCTTAACTGCTGTCACGGCATCGGCCAGTCCACACCGGAGCGGCAATGCAGTACATGTGCCGGAAGGTATGTGTGCAAGGTATAAGAT-ATTGGCACCACCATATGCCTACGCCCCACTATGCGCCCTTGTCTTTTACACTTACCATACAGGTAGTGTGTGAG -----------------GTACGCGTGTTGGTGTAT-

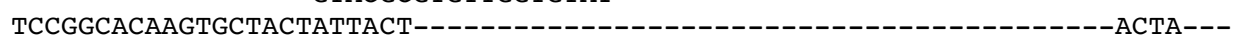
TCTGTGCAAAACGCGTGGTCGGCATTAACTTGTCG-ACTGTGCGCGGTTCTCATGAGCGTGGTTGGCTATCTT--

GCCTGGTAGTCAATGCGTCTTGTGCAGAGCTGGAAGAGCCCAGCACCGAAGCCTGCGGCAGGTTTGCTGTTAGGCAATGTGGTGTTTGGGTCGGCTCGCG GGATTGCCACTCCACTCGAAGTCCAGCATTGAGTATGGTTT-

CTGGATTTGGCCCAGAGAGGGTGAAAGGCCCGTACGGGTGGAGGTGTCAGACAGGTGAGGCAGTCCTCTAGGCCGGCCTTAGAGTCGGGTTGTTTGGGAA TGCAGCCCAAAGCGGGTGGTAAACTCCATCCAAGGCTAAATACTAGCACGAGTCCGATAGCAAACAAGTACCGTGAGGGAAAGTTGAAAAGTACTTTGAA GAGAGAGTAAACAGTACGTGAAACCGCATGCAGGTAAACGGGTGGCGTCAAGCTGCACGCCCAGAGGATTCAGCCGGTTAGAGTGTGTC- 
TATGCGCTTG-CGTATGAATGGGCCAGAGTAGGGCG----TGGTAGTCCGCTGGAAGACAGCGGGCCCTGCCGCAAGGTGGGGATGTG-----TGAGCCGGGTGGAAGCCGGAGCACGCTATCCGTC--TGTGGGGCCGTCTAGCCGGTGCACTTTCTCTGT--

GGTGGACACCACGACCGGTGGAACTGCCAGTCTGCTGTGGTCGAGTCGTGTTCGGTTGGTCCTTGT-GGCTAGTTGGGCGCGAT---CACGGGCAACCTTGGTGAACGGCGTTGGCGTGGTCTCTCGG--------GGGCATGCCTTCGTGTTATCGGTAGCCAGTTGTCTGAACGGGCCTGCCTCGCGATTGTTCTAGCCGTCGTG---

GGGTGGTCTGGTGGGCCATGGTGGTAGGAATAACTGTGCAGGGCACTGGAGTGTTCGGCCTCGAATGCAGCCAGCACGCACGCTAGTAGTGT----TGTTGC---G---

ATGTGGGTGCTCTCGTGGTCTGCCTGGTGCCGGGTCTGATTGTCGTGTTGCCTGCGCAAAGAAATTTTTAGAGCCTTATTATAATGTTATAAGTACTGAT TGTTATAAATTTTTAATTACAAATCATGGTATCATAATGATTTTTTTCTTTATAATGCCTATATTAATAGGAGGGTTTGGTAATTATTTAATTCCCTTAT TATGCGGTTTGTCTGATTTAAATTTACCTCGTTTAAAAGCATTAAGTGCTTGATTGTTGTTACCTTCTATCGTTTTTTTAGTAATAAGCATGTGTTTAGG GGCAGGGATAGGCTGAACTTTTTATCCTCCTTTATCTTCCAGTCTATTTGAAGGAAGTAAGGGTGTGGATTTTTTGATGTTTTCTCTACATTTGGCTGGT GTGTCTAGTATTTTTAGCTCTATTAATTTTATCTGTACTTTGTATACTGCCTTTAGTGGTAGTTTGGCGTCTCGAAGGTCAATAATTTTATGGGC r046 gld jamanxim tpj1GGGAACCGCTATGTAATCTAT---CTGGGACTGCCCGTCATGG-

TGGT $\bar{C}$ CAA AACCCGTTTC CCACACCGGAGCGGCATATTAGTACACGTGTCA-AAG---CGTGTGCAAGGTATAAGAACA-

TTGGCACTACCATATGCCTACGCCCCGCTATGCGCССTTGTCTTTTACACTTACCATACGGATAGTGTGTATGT-----------------------------------------GT--GTGTGTTAGTGTAT-

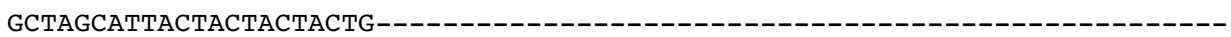

TCTGTGCAAAACGCATGGAGAGCATTAACTTGCTGTACCGTGTGTGGTTCTCATGAGCGTACTTGGTTACCTT--

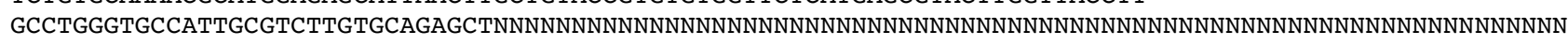

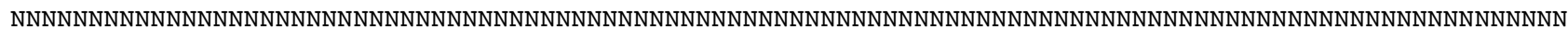
NNNNNNNNNNNNNNNNGGCCTTAGAGTCGGGTTGTTTGGGAATGCAGCCCAAAGTGGGTGGTAAACTCCATCCAAGGCTAAATACTAGCACGAGTCCGAT AGCAAACAAGTACCGTGAGGGAAAGTTGAAAAGTACTTTGAAGAGAGAGTAAACAGTACGTGAAACCGCATGCAGGTAAACGGGTGGCGTCAAGCTGCAC GCCCAGAGGATTCAGCCGGTTAGAGTGTAGT-TATGCGCTTG-CGTATCAAAGGGCCAGAGTAAGGCG----

TGGTAGTCCGCTGGAAGACAGCGGGCCCTGCCGCAAGGTGGGGATGTG-----T-AAGCCGGGTGGATGCCGGAGCACGCTATCCGTC-TGGAGGGCCGTCTAGCCGGTGCACTTTCTCTGT--

GGTGGACACCACGACCGGTGGAACTGCCAGTCTGCTATGGTCAAGTCGTGTTCGGTTGGTCCTTGT-GGCTAGCTGGGCGCGAT---CACGGGCAAATTTGGTGAACGGCGTTGATGTGCCCTC---------GGGTATGTCTTCGTGTTATCGGTAACCAGTTGTCTTAACGGGCCTGCCTTACGATTGTTCTAGCCGTCGTA---

GGGTGGTCTGGTGGGCCATAGTGGTAAGAATAACTGTGCAGGGCACCGGAGTTTTCGGCCTCAAACGCAGCCAGCATGCACGCTAGTAGTGT-----

TG---C--TG---

ATGTGGGTGCTCTCGTGGTCTGCCTGGTGCCGGGTCTGATTGTCGTGTTGCCTACGCAAAGAATTTTTTGGAGCCTTATTATAATGTGATTAGTACAGAT TGTTATAATTTTCTGATTACCAAACATGGTATTATAATGATTTTCTTTTTTATAATGCCTATCTTAATAGGGGGGTTTGGTAATTATTTAATTCCCTTAT TAAGGGGTTTGTCCGATTTAAACTTGCCTCGTTTAAAAGCCTTGAGTGCTTGATTGCTTTTACCTTCTGCTGTATTTTTAGTGATTAGTATGTGTTTAGG TGCTGGTATAGGTTGAACTTTCTATCCTCCTTTGTCTTCTAGTATTTTTGAGGGGAGTAAGGGTGTAGACTTTTTAATGTTTTCATTGCATTTGGCTGGT GTTTCTAGTATATTTAGTTCTATTAATTTTATATGTACTTTGTATACTGCCTTTAGTGGTAGGTTGGCTTCTCGTAGTTCAATTGTATTATGAGC 42Rhinebothrium_sp_4_worm_3

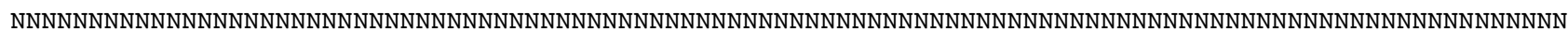

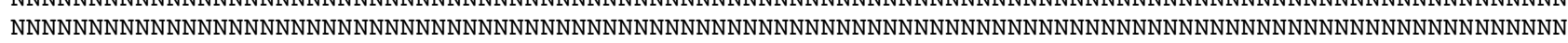

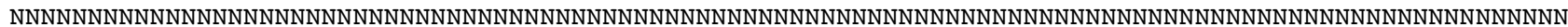

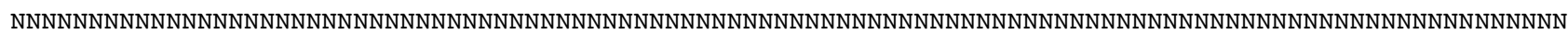
NNNNNNNNNNNNNNNNNNNNNNNNNNNNNNNNNNNNNNNNNNNNNNNNNNNNNNNNNNNNNNNNNNNNNNNNNNNNNNNNNNNNNNNNNNNNNNNNNNNN NNNNNNNNNNNNNNNNNNNNNNGGAAGAGCCCAGCACCGAAGCCTGCGGTAGCTTTACTGTTAGGCAATGTGGTGTTTGGGTCGGCTCGCGGGATTGCCA CTCCACTCGAAGTCCAGCATTGAGTATGGTTT-

CTGGATTTGGCCCAGAGAGGGTGAAAGGCCCGTACGGGTGGAGGTGTCAGACAAGTGAGGCAATTCACTAGGCCGGCCTTAGAGTCGGGTTGTTTGGGAA TGCAGCCCAAAGTGGGTGGTAAACTCCATCCAAGGCTAAATACTAGCACGAGTCCGATAGCAAACAAGTACCGTGAGGGAAAGTTGAAAAGTACTTTGAA GAGAGAGTAAACAGTACGTGAAACCGCATGCAGGTAAACGGGTGGCGTCAAGCTGCACGCCGAGAGTATTCAGCCGGTTAGAGTGTAGT-

TATGCGCTTG-CGTGTCGACAGGCCAGAGTAAGGCG----

TGGTAGTCCGCTGGAAGACAGTGGGCCCTGCCGCGAGGTGGGGATGTGCTTTTTTGTGCCGGGTGGAAGCCGGAGCACGCTATCCGTC-TGTTGGGCCTACTAGCCGGTGCACTTACTCTCT--

GGTGGACACCACGACCGGTGGGACTGCCAGTCTGCTATGGTCAATTCGTGTTCGGTTGGTCCTTGT-GGCTTACTGGGTGCGAT---

CACGGGCGAACAGTGGCGAACGGCGTTGACGTGCTCTC----TTGA----

GGGTGTGTCTTCGTGTTATCGGTAGCCAGTCGTCTTAACGGACCTGCCTTGCGGTTGTTCTA-GCCGTCGTA---

GGGTGGTCTGGTGGACCTTAGTGGTAGGAATAACTGTGCAGGGCACCGGAGTTGTCGGCCTCAAATGCGGCCAGCATGCACGCTAGTAGTGT-----

GT---T---

GCCCATGTGGGTGCTCGCGTGGCCTGCCTGGTGCCGGGTCTGATTGTCGTGTTGCCTACGCAAAGAAATTTTTGGAGCCTTATTACAATGTTATAAGAAC CGATTGTTATAAATTTTTAATCACGAAACATGGTATTATAATGATTTTTTTCTTTATAATGCCTATCTTAATAGGGGGGTTTGGTAATTATTTAATACCT СTTTTATGCGGTTTATCTGACTTAAATTTACCTCGGTTAAATGCATTGAGGGCTTGGCTATTATTACCTTCTGCTGTTTTTTTAGTAGTTAGCATGTATT TAGGAGCAGGTATAGGTTGGACCTTTTATCCTCCTTTGTCTTCAAGAATGTTTGAGGTAAGTCGTGGTGTTGATTTTTTAATGTTTTCTTTACACTTAGC CGGTGTTTCAAGTATTTTTAGTTCTATAAACTTTATTTGTACATTATACACTGCTTTTACTAATAGATTAGCTTCACGTAGAAGCATAATTTTATGATC r122_gld_cuiaba_brac GGGAACCGCTATGTAACTTCT---CTCGGACTGCCCGTCATGG-

TGGTC CAAĀACCCGTTTCGGTGGGGTGCCTACTTGCCTTATACTCCCAGGCGTGCTCGCCAGTTGTGGCAACTTAACTGCTGTCACAACAATCGGCCAGT CCACACCGGAGCGGCATATTAGTACACGTGTGA-AAG---CGTGTGCAAGGTATAAGAACA-

TTGGCACTACCATATGCCTACGCCCСАCTATGCGCCСTTGTCTTTTACACTTATCATACGGATAGTCTGTATGT-_-_-_-_-_-_-_-_-_-_-_---------------GT--GTGTGTTAGCGTAT-

GCTAGCATTACTACTACTACTG----

TCTGTGCAAAACGCATGGTCAGCATTAACTTGCTGTACTGTGTGTGGTTCTCATGAGCGTAGTTGGCTACCTT--

GCCTGGGTGCCATTGCGTCTTGTGCAGAGCTGGAAGAGCCCAGCACCGAAGCCTGCGGTAGCTTTACTGTTAGGCAATGTGGTGTTTGGGCCGGCTCGCG GGATTGCCACTCCACCCGAAGTCCAGCATTGAGTATGGTAT-

CTGGATTTGGCCCAGAGAGGGTGAAAGGCCCGTACGGGTGGAGGTTTCAGACAAGTGAGGCAATTCACTAGGCCGGCCTTAGAGTCGGGTTGTTTGGGAA TGCAGCCCAAAGTGGGTGGTAAACTCCATCCAAGGCTAAATACTAGCACGAGTCCGATAGCAAACAAGTACCGTGAGGGAAAGTTGAAAAGTACTTTGAA GAGAGAGTAAACAGTACGTGAAACCGCATGCAGGTAAACGGGTGGCGTCAAGCTGCACGCCCAGAGGATTCAGCCGGTTAGAGTGTAGT-

TATGCGCTTG-CGTATCAAAGGGCCAGAGTAAGGCG----TGGTAGTCCGCTGGAAGACAGCGGGCCCTGCCGCAAGGTGGGGATGTG-----TAAGCCGGGTGGATGCCGGAGCACGCTATCCGTC--TGGAGGGCCGTCTAGCCGGTGCACTTTCTCTGT--

GGTGGACACCACGACCGGTGGAACTGCCAGTCTGCTATGGTCAAGTCGTGTTCGGTTGGTCCTTGT-GGCTAGCTGGGCGCGAT---CACGGGCAACTTTGGTGAACGGCGTTGATGTGCCCTC---------_GGGTATGTCTTCGTGTTATCGGTAACCAGTTGTCTTAACGGGCCTGCCTTACGATTGTTCTAGCCGTCGTA--- 
ATGTGGGTGCTCTCGTGGTCTGCCTGGTGCCGGGTCTGATTGTCGTGTTGCCTACGCAAAGAATTTTTTAGAGCCTTATTATAATGTGATTAGCACAGAT TGTTATAATTTTTTGATTACTAATCATGGTATTATAATGATTTTCTTTTTTATAATGCCTATTTTAATAGGGGGGTTTGGTAATTATTTAATTCCTTTAT TAAGTGGTTTATCTGATTTAAATTTACCTCGCCTAAAAGCATTGAGTGCTTGGTTGTTGTTACCTTCTGCTGTGTTTTTGGTGGTTAGGATGTGTTTAGG GGCTGGAATAGGTTGGACTTTTTATCCTCСTTTGTCTTCTAGTGTTTTTGAGGGCAGTAAGGGGGTAGATTTTTTAATGTTTTCTTTACATTTGGCGGGT GTTTCTAGCATATTTAGTTCTATTAАTTTTATTTGTACTTTATATACTGCTTTTAGTGGANNNNNNNNNNNNNNNNNNNNNNNNNNNNNNNNNNN r241_frt_toc_toc2

NNNNNNNNNNNNNNNNNNNNNNNNNNNNNNNNNNNNNNNNNNNNNNNNNNNNNNNNNNNNNNNNNNNNNNNNNNNNNNNNNNNNNNNTCCCAGGCGTGCT CGCCAGTCGTGGCAACTTAACTGCTGTCACGGCAATCGGCCAGTCCACACCGGAGCGGCAATCCAGTACATGTGCCGCAAGGTACGTGTGCGAGGTATAA GAA-A-

TTGGCACCACСАTATGCCTACGCCCСАCTATGCGCССTTGTCTTTTACACTTATCATACAGGCAGTGTGTGAGT----------------------------------------GTACGCGTGTTGGTGTAA-

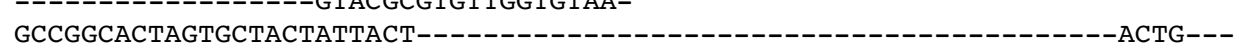

TCTGTGCAAAACGCATGGTCGGCATTAACTTGTTCGACTGTGTGCGGTTCTCATGAGCGTGGTTGGCTATCTT--

GCCTGGTAGCCGATGCGTCTTGTGCAGAGCTNNNNNNNNNNNNNNNNNNNNNNNNNNNNNNNNNNNNNNNNNNNNNNNNNNNNNNNNNNNNNNNNNNNNN NNNTTGCCACTCCACTCGAAGTCCAGCATTGAGTATGGTTT-

CTGGATTTGGCCCAGAGAGGGTGAAAGGCCCGTACGGGTGGAGGTATCAGACAAGTGAGGCAATTCACTAGGCCGGCCTTAGAGTCGGGTTGTTTGGGAA TGCAGCCCAAAGCGGGTGGTAAACTCCATCCAAGGCTAAATACTAGCACGAGTCCGATAGCAAACAAGTACCGTGAGGGAAAGTTGAAAAGTACTTTGAA GAGAGAGTAAACAGTACGTGAAACCGCATGCAGGTAAACGGGTGGCGTCAAGCTGCACGCCCAGAGGATTCAGCCGGTTAGAGTGTATC-

TATGCGCTTG-CGTATAAATGGGCCAGAGTAAGGCG----TGGTAGTCCGCTGGTAGACAGCGGGCCCTGCCGCAAGGTGGGGATGTG-----CAAGCCGGGTGGATGCCGGAGCACGCTATCCGTC--TGTGGGGCCGTCTAGCCGGTGCACTTTCTCTGT--

GGTGGACACCACGACCGGTGGAACTGCCAGTCTGCTGTGGCCAAGTCGTGTTCGGTTCGTCCTTGT-GGCGAACTGGGCGCGAT---CACGGGCAACCTTGGTGAACGGCGTTGATGTGCCCTC----------GGGTATGTCTTCGTGTTATCGGTAGCCAGTTGTCTTAACGGGCCTGCCTTGCGATTGTTCTAGCCGTCGTA---

GGGTGGTCTGGTGGGCCATGGTGGTAAGAATAACTGTGCAGGGCACCGGAGTGTTCGGCCTCAAATGCAGCCAGCATGCACGCTAGTAGTGT-----

TG---C---G---

ATGTGGGTGCTCTCGTGGTCTGCCTGGTGCCGGGTCTGATTGTCGTGTTGCCTGCGCAAAGAAATTTTTGGAGCCTTATTATAACGTTATTAGTACAGAT TGTTATAAATTTTTAATTACTAACCATGGTATTATAATGATTTTCTTTTTTATAATGCCTATTTTAATAGGTGGTTTTGGTAATTATTTAATTCCTTTGT TATGTGGTTTATCTGACTTAAACTTACCTCGTTTAAAAGCATTGAGTGCTTGATTGTTATTGCCTTCTGCTGTTTTTTTAGTAATAAGTATGTGCTTAGG AGCAGGGATAGGCTGGACTTTTTATCCTCCTTTATCTTCGAGTTTATTTGAGGGTAGAAAGGGTGTAGATTTTTTAATGTTTTCTTTGCATTTAGCAGGA GTTTCTAGTATTTTTAGCTCTATAAATTTTATTTGTACTTTATACACCGCTTTTAGTGGTAGTTTAGCGTCTCGAAGTTCGAGTANNNNNNNNNN r054_frt_jamanxim_tpj1GGGAACTGCTATGTAACCTCT---C--GGACTGCCCGTCATGG-TGGTCCACAACC-

ATTT $\bar{C} G$ TTGGGTGCCTACTTGCCCTATACTCCCAGGCGTGCTCGCCAGTCGTGGCAACTTAACTGCTGTCACGGCAATCGGCCAGTCCACACCGGAGCG GCAATCCAGTACATGTGCCGCAAGGTACGTGTGCGAGGTATAAGAA-A-

TTGGCACCACСATATGCCTACGCCCCACTATGCGCССTTGTCTTTTACACTTATCATACAGGTAGTGTGTGAGT----------------------------------------GTACGCGTGTTGGTGTAA-

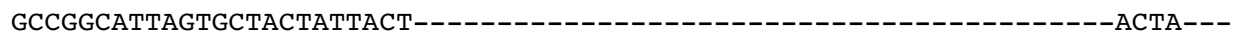

TCTGTGCAAAACGCATGGTCGGCATTAACTTGTTCGACTGTGTGCGGTTCTCATGAGCGTGGTTGGCTATCTT--

GCCTGGTAGCCGATGCGTCTTGTGCAGAGCTNNNNNNNNNNNNNNNNNNNNNNNNNNNNNNNNNNNNNNNNNNNNNNNNNNNNNNNNNNNNNNNNNNNNN

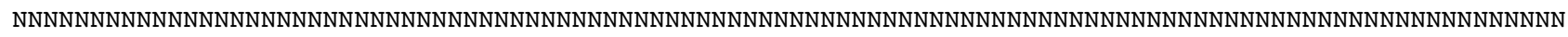

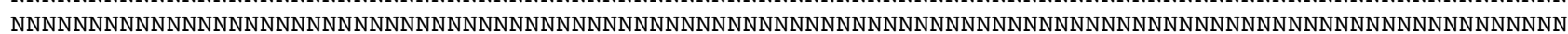

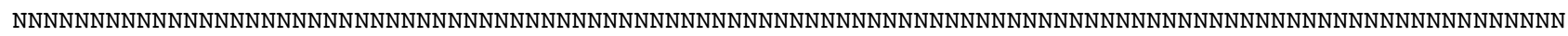

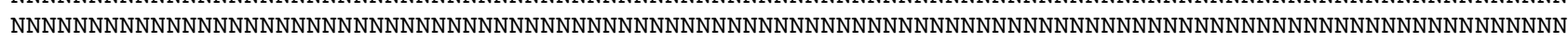

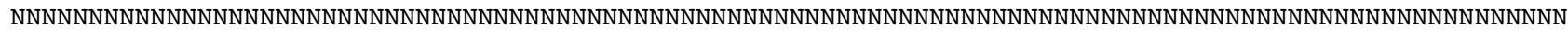

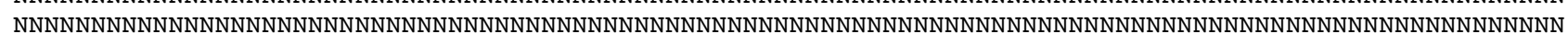

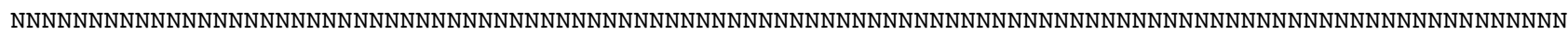

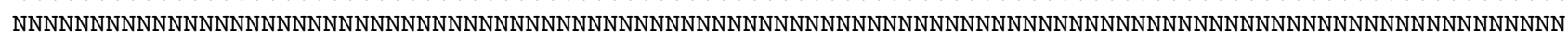

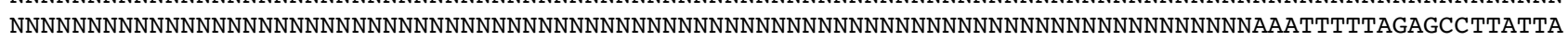
TAATGTTATTAGTACAGATTGTTATAAATTTTTAATTACTAATCATGGTATTATAATGATTTTTTTCTTTATAATGCCTATTTTAATAGGGGGGTTTGGT АATTATTTAATCCCTTTATTATGTGGTTTATCTGATTTAAATTTACCTCGCTTAAAAGCATTGAGTGCTTGATTGTTGTTACCATCTGCCGTTTTTTTAA TAATAAGTATGTGTTTAGGGGCAGGGGTAGGTTGAACTTTTTATCCCCССTTATCTTCTAGTTTATTTGAGGGTAGAAAGGGTGTAGATTTTTTAATGTT TTCTTTACATTTGGCAGGGGTTTCTAGTATTTTTAGTTCTATAAATTTTATTTGTACTTTGTATACTGCTTTTAGTGGTAGTCTCGCGTCGCGAAGTTCG ATAGTATTATGAGC

38Rhinebothrium_sp_1_worm_20

NNNNNNNNNNNNNNNNNNNNNNNNNNNNNNNNNNNNNNNNNNNNNNNNNNNNNNNNNNNNNNNNNNNNNNNNNNNNNNNNNNNNNNNNNNNNNNNNNNNN

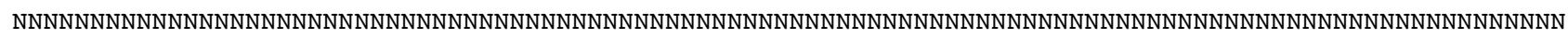

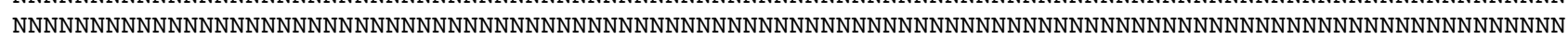

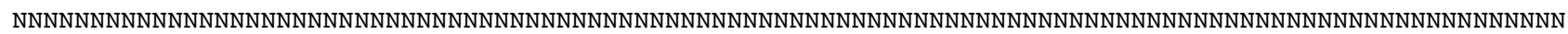
NNNNNNNNNNNNNNNNNNNNNNNNNNNNNNNNNNNNNNNNNNNNNNNNNNNNNNNNNNNNNNNNNNNNNNNNNNNNNNNNNNNNNNNNNNNNNNNNNNNN NNNNNNNNNNNNNNNNNNNNNNGGAAGAGCCCAGCACCGAAGCCTGCGGTAGCTTTACTGTTAGGCAATGTGGTGTTTGGGTCGGCTCGCGGGATTGCCA CTCCACTCGAAGTCCAGCATTGAGTATGGTTT-

CTGGATTTGGCCCAGAGAGGGTGAAAGGCCCGTACGGGTGGAGGTATCAGACAAGTGAGGCAATTCACTAGGCCGGCCTTAGAGTCGGGTTGTTTGGGAA TGCAGCCCAAAGTGGGTGGTAAACTCCATCCAAGGCTAAATACTAGCACGAGTCCGATAGCAAACAAGTACCGTGAGGGAAAGTTGAAAAGTACTTTGAA GAGAGAGTAAACAGTACGTGAAACCGCATGCAGGTAAACGGGTGGCGTCAAGCTGCACGCCCAGAGGATTCAGCCGGTTAGAGTGTAGTTATGCGCTTG-CGTGTCAACAGGCCAGAGTAAGGCG----TGGTAGACCGCTGGAAGACAGTGGGCCCTGCCGCAAGGTGGGGATGTG----TTTAGCCGGGTGGACGCCGGAGCACGCTATCCGTC--TGTTGGGCCTACTAGCCGGTGCACTTTCTCTGT--

GGTGGACACCACGACCGGTGGGACTGCCAGTCTGCTATGGTCAAGTCGTATTCGGTTGGTCCTTGT-GGCTAACTGGGTGCGAT---CACGGGCAAACTTGGTGAACGGCGTTGACGTGCTCTC----TTGA----GGGTGTGTCTTCGTGTTATCGGTAACCAGTTGTCTTAACGGGCCTGCCTTACGATTGTTCTAGCCGTCGTA---

GGGTGGTCTGGTGGACCATGGTGGTAAGAATAACTGTGCAGGGCACCGGAGTTTTCGGCCTCAAATGCAGCCAGCATGCACGCTAGTAGTGT-----

GT---T---

GCCAATATGGGTGCTCTCGTGGTCTGCCTGGTGCCGGGTCTGATTGTCGTGTTGCCTACGCAAAGAAATTTTTAGAGCCGTACTATAATGTTATTAGTAC GGACTGTTATAAATTTTAATTACTAATCATGGTATTATAATGATTTTTTTCTTTATAATGCCTATTTTGATAGGGGGTTTTGGTAATTATTTGATTCCG TTACTTTGTGGTTTATCCGATTTAAATCTACCCCGTTTAAAAGCACTTAGAGCTTGGTTGTTATTGCCTTCAGCTCTTTTTTTGGTGGTGAGCATGTGTT TAGGGGCTGGTATAGGTTGGACTTTTTATCCTCСTTTATCTTCTAGATTATTTGAAAGTAGTAAGGGGGTAGATTTTTTAATGTTTTCGTTGCATTTAGC 

35Rhinebothrium_sp_3_worm_2

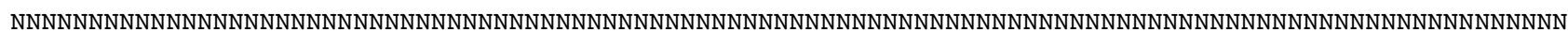

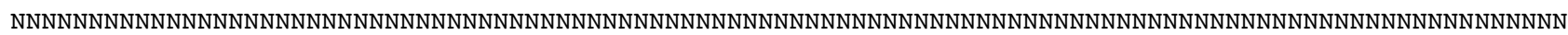

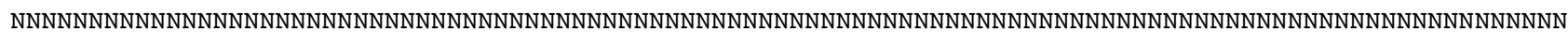

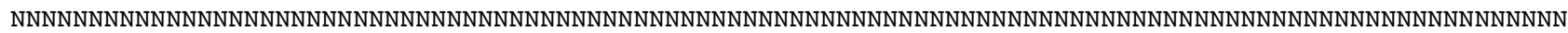

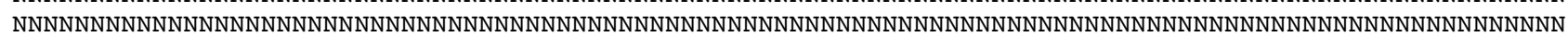
NNNNNNNNNNNNNNNNNNNNNNGGAAGAGCCCAGCACCGAAGCCTGCGGTAGCTTTACTGTTAGGCAATGTGGTGTTTGGGTCGGCTCGCGGGATTGCCA CTCCACTCGAAGTCCAGCATTGAGTATGGTTT-

CTGGATTTGGCCCAGAGAGGGTGAAAGGCCCGTACGGGTGGAGGTATCAGACAAGTGAGGCAATTCACTAGGCCGGCCTTAGAGTCGGGTTGTTTGGGAA TGCAGCCCAAAGTGGGTGGTAAACTCCATCCAAGGCTAAATACTAGCACGAGTCCGATAGCAAACAAGTACCGTGAGGGAAAGTTGAAAAGTACTTTGAA GAGAGAGTAAACAGTACGTGAAACCGCATGCAGGTAAACGGGTGGCGTCAAGCTGCACGCCCAGAGGATTCAGCCGGTTAGAGTGTAGT-

TATGCGCTTG-CGTGTCAACAGGCCAGAGTAAGGCG----TGGTAGACCGCTGGAAGACAGTGGGCCCTGCCGCAAGGTGGGGATGTG----TTTAGCCGGGTGGACGCCGGAGCACGCTATCCGTC--TGTTGGGCCTACTAGCCGGTGCACTTTCTCTGT--

GGTGGACACCACGACCGGTGGGACTGCCAGTCTGCTATGGTCAAGTCGTATTCGGTTGGTCCTTGT-GGCTAACTGGGTGCGAT---CACGGGCAAACTTGGTGAACGGCGTTGACGTGCTCTC----TTGA----GGGTGTGTCTTCGTGTTATCGGTAACCAGTTGTCTTAACGGGCCTGCCTTACGATTGTTCTAGCCGTCGTA---

GGGTGGTCTGGTGGACCATGGTGGTAAGAATAACTGTGCAGGGCACCGGAGTTTTCGGCCTCAAATGCAGCCAGCATGCACGCTAGTAGTGT-----

GT---T---

GCCAATATGGGTGCTCTCGTGGTCTGCCTGGTGCCGGGTCTGATTGTCGTGTTGCCTACGCAAAGAAATTTTTAGAGCCGTACTATAATGTTATTAGTAC AGACTGCTATAAATTTTAATTACTAATCATGGTATTATAATGATTTTTTTCTTTATAATGCCTATTTTGATAGGAGGTTTTGGTAATTATTTGATTCCA TTACTTTGTGGTTTATCCGATTTAAATCTACCTCGTTTAAAAGCACTTAGAGCTTGGTTGTTGTTGCCTTCAGCTCTTTTTTTGGTGGTGAGCATGTGCT TAGGGGCTGGTATAGGTTGGACTTTTTATCCTCСTTTATCTTCTAGATTATTTGAAGGTAGTAAGGGGGTAGATTTTTTAATGTTTTCGTTGCATTTAGC AGGAATTTCTAGTATTTTTAGGTCTATTAAATTATTTGTACTTTGTATACTGCTTTTAGTGATAGTTTAGCATCACGTAGTTGTATTATATTATGATC 31Rhinebothrium_sp_1_worm_17

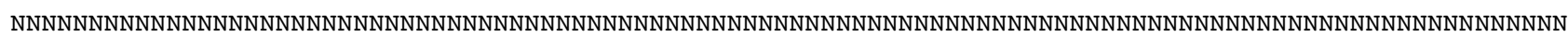

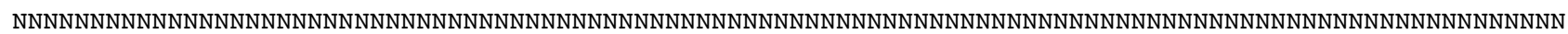

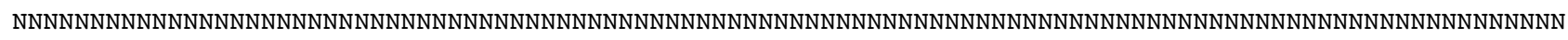

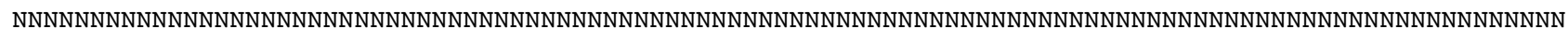

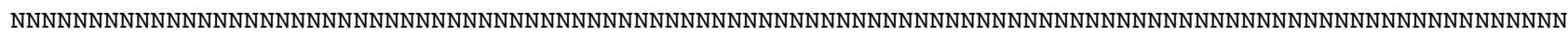
NNNNNNNNNNNNNNNNNNNNNNNNNNNNNNNNNNNNNNNAAGCCTGCGGTAGCTTTACTGTTAGGCAATGTGGTGTTTGGGTCGGCTCGCGGGATTGCCA CTCCACTCGAAGTCCAGCATTGAGTATGGTTT-

CTGGATTTGGCCCAGAGAGGGTGAAAGGCCCGTACGGGTGGAGGTATCAGACAAGTGAGGCAATTCACTAGGCCGGCCTTAGAGTCGGGTTGTTTGGGAA TGCAGCCCAAAGTGGGTGGTAAACTCCATCCAAGGCTAAATACTAGCACGAGTCCGATAGCAAACAAGTACCGTGAGGGAAAGTTGAAAAGTACTTTGAA GAGAGAGTAAACAGTACGTGAAACCGCATGCAGGTAAACGGGTGGCGTCAAGCTGCACGCCCAGAGGATACAGCCGGTTAGAGTGTAGTTATGCGCTTG-CGTGTCAACAGGCCAGAGTAAGGCG----TGGTAGACCGCTGGAAGACAGTGGGCCCTGCCGCAAGGTGGGGATGTG----TTTAGCCGGGTGGACGCCGGAGCACGCTATCCGTC--TGTTGGGCCTACTAGCCGGTGCACTTTCTCTGT--

GGTGGACACCACGACCGGTGGGACTGCCAGTCTGCTATGGTCAAGTCGTATTCGGTTGGTCCTTGT-GGCTAACTGGATGCGAT---CACGGGCAAACTTGGTGAACGGCGTTGACGTGCTCTC----TTGA----GGGTGTGTCTTCGTGTTATCGGTAACCAGTTGTCTTAACGGGCCTGCCTTACGATTGTTCTAGCCGTCGTA---

GGGTGGTCTGGTGGACCATGGTGGTAAGAATAACTGTGCAGGGCACCGGAGTTTTCGGCCTCAAATGCAGCCAGCATGCACGCTAGTAGTGT-----

GT---T---

GCCAATATGGGTGCTCTCGTGGTCTGCCTGGTGCCGGGTCTGATTGTCGTGTTGCCTACGCAAAGAAATTTTTGGAGCCGTATTATAATGTTATTAGTAC GGACTGTTATAAATTTTTAATTACTAATCACGGTATTATAATGATTTTTTTCTTTATAATGCCTATTCTGATAGGTGGTTTTGGCAATTATTTGATTCCA TTACTTTGTGGCTTATCCGATTTAAATCTACCTCGCTTAAAAGCGCTTAGAGCTTGGTTGTTATTGCCTTCGGCTCTTTTTTTGGTGGTGAGTATGTGTT TAGGGGCTGGTATAGGTTGGACTTTTTATCCTCCACTATCTTCTAGATTATTTGAAAGCAGTAAGGGGGTAGATTTTTTAATGTTTTCGTTGCATTTAGC AGGTATTTCTAGTATTTTTAGGTCTATTAAATTTATTTGTACCTTGTATACTTCTTTTAGTGATAGTTTAGCATCACGTAGCTGTATTATACTATGATC 18Rhinebothrium_sp_1_worm_2

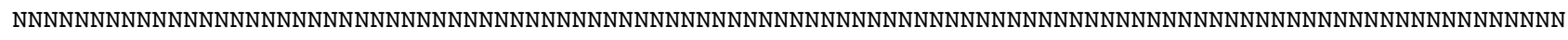

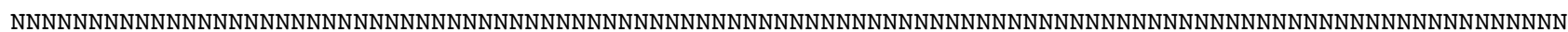

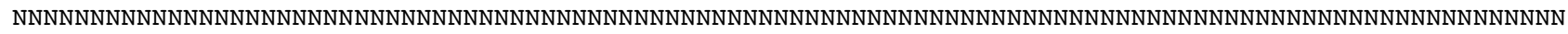

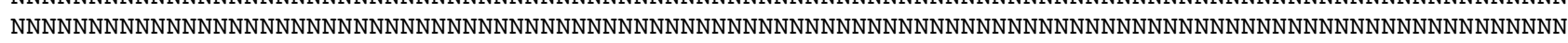

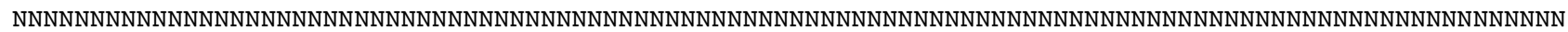
NNNNNNNNNNNNNNNNNNNNNNGGAAGAGCCCAGCACCGAAGCCTGCGGTAGCTTTACTGTTAGGCAATGTGGTGTTTGGGTCGGCTCGCGGGATTGCCA CTCCACTCGAAGTCCAGCATTGAGTATGGTTT-

CTGGATTTGGCCCAGAGAGGGTGAAAGGCCCGTACGGGTGGAGGTATCAAACAAGTGAGGGAATTCACTAGGCCGGCCTTAGAGTCGGGTTGTTGGGGAA TGCAGCCCAAAGTGGGTGGTAAACTCCATCCAAGGCTAAATACTACCACGAGTCCGATAGCAAACAATTACCGTGAGGGAAAGTTGAAAAGTACCTTGAA GAGAGAGTAAACAGTACGTGAAACCGCATGCAGGTAAACGGGTGGCGTCAAGCTGCACGCCCAGAGGATTCAGCCGGTTAGAGTGTAGT-

TATGCGCTTG-CGTGTCAACAGGCCAGAGTAAGGCG----TGGTAGACCGCTGGAAGACAGTGGGCCCTGCCGCAAGGTGGGGATGTG----TTTAGCCGGGTGGACGCCGGAGCACGCTATCCGTC--TGTTGGGCCTACTAGCCGGTGCACTTTCTCTGT--

GGTGGACACCACGACCGGTGGGACTGCCAGTCTGCTATGGTCAAGTCGTATTCGGTTGGTCCTTGT-GGCTAACTGGGTGCGAT---CACGGGCAAACTTGGTGAACGGCGTTGACGTGCTCTC----TTGA---_GGGTGTGTCTTCGTGTTATCGGTAACCAGTTGTCTTAACGGGCCTGCCTTACGATTGTTCTAGCCGTCGTA---

GGGTGGTCTGGTGGACCATGGTGGTAAGAATAACTGTGCAGGGCACCGGAGTTTTCGGCTCCAAATGCAGCCAGCATGCACGCTAGTAGTGT-----

GT---T---

GCCAATATGGGTGCTCTCGTGGTCTGCCTGGTGCCGGGTCTGATTGTCGTGTTGCCTACGCAAAGAAATTTTTGGAGCCATACTATAATGTTATTAGTAC GGACTGTTATAAATTTTTAATTACTAATCATGGTATTATAATGATTTTTTTCTTTATAATGCCTATTTTGATAGGTGGTTTTGGTAATTATTTGATTCCG TTACTTTGTGGTTTATCTGATTTAAATCTACCCCGTTTAAAAGCACTCAGAGCTTGGTTGTTGTTGCCTTCAGCTCTTTTTTTGGTGGTGAGTATGTGTT TAGGGGCTGGTATAGGTTGGACTTTCTATCCTCCGTTATCTTCTAGATTATTTGAAGGGAGTAAGGGGGTAGATTTTTTAATGTTTTCGTTGCATTTAGC AGGAATTTCTAGTATTTTTAGGTCTATTAAATTTATTTGTACTTTGTATACTGCTTTTAGTGATAGTTTAGCAGCACGTAGATGTATTATATTATGATC r242_frt_toc_toc2 GAGAACTGCTATGTAACCTCT---C--GGACTGCCCGTCATGG-TGGTCCACAACC-

ATTTCGGTGGGGTGCCTACTTGCCCTATACTCCCAGGCGTGCTCGCCAGTCGTGGCAACTTAACTGCTGTCACGGCAATCGGCCAGTCCACACCGGAGCG GCAATCCAGTACATGTGCCGCAAGGTACGTGTGCGAGGTATAAGAA-A-

TTGGCACCACCATATGCCTACGCCCCACTATGCGCCCTTGTCTTTTACACTTATCATACAGGCAGTGTGTGAT--------------------------------------GTACGCGTGTTGGTGTAA- 


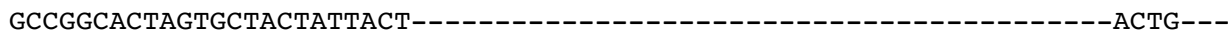

TCTGTGCAAAACGCATGGTCGGCATTAACTTGTTCGACTGTGTGCGGTTCTCATGAGCGTGGTTGGCTATCTT--

GCCTGGTAGCCGATGCGTCTTGTGCAGAGCTNNNNNNNNNNNNNNNNNNNNNNNNNNNNNNNNNNNNNNNNNNNNNNNNNNNNNNNNNNNNNNNNNNNNN NNNTTGCCACTCCACTCGAAGTCCAGCATTGAGTATGGTTT-

CTGGATTTGGCCCAGAGAGGGTGAAAGGCCCGTACGGGTGGAGGTATCAGACAAGTGAGGCAATTCACTAGGCCGGCCTTAGAGTCGGGTTGTTTGGGAA TGCAGCCCAAAGCGGGTGGTAAACTCCATCCAAGGCTAAATACTAGCACGAGTCCGATAGCAAACAAGTACCGTGAGGGAAAGTTGAAAAGTACTTTGAA GAGAGAGTAAACAGTACGTGAAACCGCATGCAGGTAAACGGGTGGCGTCAAGCTGCACGCCCAGAGGATTCAGCCGGTTAGAGTGTATC-

TATGCGCTTG-CGTATAAATGGGCCAGAGTAAGGCG----TGGTAGTCCGCTGGTAGACAGCGGGCCCTGCCGCAAGGTGGGGATGTG-----CAAGCCGGGTGGATGCCGGAGCACGCTATCCGTC--TGTGGGGCCGTCTAGCCGGTGCACTTTCTCTGT--

GGTGGACACCACGACCGGTGGAACTGCCAGTCTGCTGTGGCCAAGTCGTGTTCGGTTCGTCCTTGT-GGCGAACTGGGCGCGAT---CACGGGCAACCTTGGTGAACGGCGTTGATGTGCCCTC-----------GGGTATGTCTTCGTGTTATCGGTAGCCAGTTGTCTTAACGGGCCTGCCTTGCGATTGTTCTAGCCGTCGTA---

GGGTGGTCTGGTGGGCCATGGTGGTAAGAATAACTGTGCAGGGCACCGGAGTGTTCGGCCTCAAATGCAGCCAGCATGCACGCTAGTAGTGT----TG---C---G---

ATGTGGGTGCTCTCGTGGTCTGCCTGGTGCCGGGTCTGATTGTCGTGTTGCCTGCGCAAAGAAATTTTTGGAGCCTTATTATAACGTTATTAGTACAGAT TGTTATAAАTTTTTAАTTACTAACCATGGTATTATAATGATTTTCTTTTTTATAATGCСTATTTTAATAGGTGGTTTTGGTAATTATTTAATTCCTTTGT TATGTGGTTTATCTGACTTAAATTTACCTCGTTTAAAAGCATTGAGTGCTTGATTGTTATTGCCTTCTGCTGTTTTTTTAGTAATAAGTATGTGTTTAGG AGCAGGGATAGGCTGGACTTTTTATCCTCCTTTATCTTCGAGTTTATTTGAGGGTAGAAAGGGTGTAGATTTTTTAATGTTTTCTTTGCACTTAGCAGGA GTTTCTAGTATTTTTAGCTCTATAAATTTTATTTGTACTTTATACACCGCTTTTAGTGGTAGTTTGGCGTCTCGAAGTTCGATAATATTATGGGC r048_gld_uppersol_mot GGGAACCGCTATGTAATCTAT---CTGGGACTGCCCGTCATGG-

TGGTC $\bar{C}$ AA $\bar{A} A C C C G T T \bar{C} G G T G G G G T G C C T A C T T G C C T T A T A C T C C C A G G C G T G C T C G C C T G T T G T G G C A A C T T A A C T G C T G T C A C A A C A A C C G G C C A G T$ CCACACCGGAGCGGCATATTAGTACACGTGTCA-AAG---CGTGTGCAAGGTATAAGAACA-

TTGGCACTACCATATGCCTACGCCCCGCTATGCGCCCTTGTCTTTTACACTTACCATACGGATAGTGTGTATGT---------------------------------------GT--GTGTGTTAGTGTAT-

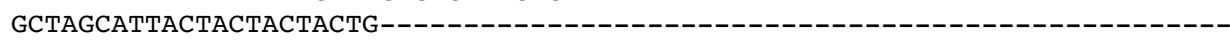

TCTGTGCAAAACGCACGGGGAGCATTAACTTGCTGTACTGTGTGTGGTTCTCATGAGCGTACTTGGTTACCTT--

GCCTGGGTGCCATTGCGTCTTGTGCAGAGCTGGAAGAGCCCAGCACCGAAGCCTGCGGTAGCTTTACTGTTAGGCAATGTGGTGTTTGGGCCGGCTCGCG GGGTTGCCACTCCACTCGAAGTCCAGCATTGAGTATGGTTT-

CTGGATTTGGCCCAGAGAGGGTGAAAGGCCCGTACGGGTGGAGGTTTCAGACAAGTGAGGCAATTCACTAGGCCGGCCTTAGAGTCGGGTTGTTTGGGAA TGCAGCCCAAAGTGGGTGGTAAACTCCATCCAAGGCTAAATACTAGCACGAGTCCGATAGCAAACAAGTACCGTGAGGGAAAGTTGAAAAGTACTTTGAA GAGAGAGTAAACAGTACGTGAAACCGCATGCAGGTAAACGGGTGGCGTCAAGCTGCACGCCCAGAGGATTCAGCCGGTTAGAGTGTAGT-

TATGCGCTTG-CGTATCAAAGGGCCAGAGTAAGGCG----TGGTAGTCCGCTGGAAGACAGCGGGCCCTGCCGCAAGGTGGGGATGTG-----TAAGCCGGGTGGATGCCGGAGCACGCTATCCGTC--TGGAGGGCCGTCTAGCCGGTGCACTTTCTCTGT--

GGTGGACACCACGACCGGTGGAACTGCCAGTCTGCTATGGTCAAGTCGTGTTCGGTTGGTCCTTGT-GGCTAGCTGGGCGCGAT---CACGGGCAAATTTGGTGAACGGCGTTGATGTGCCCTC----------GGGTATGTCTTCGTGTTATCGGTAACCAGTTGTCTTAACGGGCCTGCCTTACGATTGTTCTAGCCGTCGTA---

GGGTGGTCTGGTGGGCCATAGTGGTAAGAATAACTGTGCAGGGCACCGGAGTTTTCGGCCTCAAACGCAGCCAGCATGCACGCTAGTAGTGT-----

TG---C--TG---

ATGTGGGTGCTCTCGTGGTCTGCCTGGTGCCGGGTCTGATTGTCGTGTTGCCTACGCAAAGAAATTTTTGGAGCCTTACTATAATGTGATTAGTACGGAT TGTTATAATTTTTTAATACTAAACATGGTATTATAATGATTTTCTTTTTTATAATGCCTATTTTAATAGGGGGGTTTGGTAATTATTTAATTCCTCTAT TAAGGGGTTTGTCTGATTTAAATTTACCTCGTTTAAAAGCACTGAGTGCTTGGTTGCTTTTACCTTCTGCTGTATTCTTAGTCATTAGAATGTGCTTAGG TGCTGGTATAGGTTGAACTTTTTATCCTCCTTTGTCTTCTAGTGTTTTTGAAGGTAGTAAGGGTGTAGATTTTTTAATGTTTTCATTGCATTTGGCCGGT GTCTCTAGTATATTTAGTTCTATTAATTTTATATGTACTTTGTACACTGCTTTTAGTGGTAGGTTGGCTTCTCGTAGTTCAATTGTATTATGAGC r117_vnz_salob_mot_GGGAACTGCTATGTAACCTCT---C--GGACCGCTGGTCATGG-TGGTCCACAACC-

АTTTCGGTGGGGTGC CTACTTGCCCTATACTCCCAGGCGTGCTCGCCAGTCGTGGCAACTTAACTGCTGTCACGGCAATCGGCCAGTCCACACCGGAGCG GCAATGCAGTACATGTGTCGGAAGGCACGTGTGCGAGGTATAAGAA-A-

TTGGCACCGCCATATGCCTACGCCCCACTATGCGCCCTTGTCTTTTACACTTACCATACAGGTAGTGTGTGAGT--------------------------------------GTACGCGTGTTGGTGTAT-

GCCGGCACAAGTGCTACTATTACT-_-_-

TCTGTGCAAAACGCATGGTCGGCATTAACGTGTTGTACTGTGCGCGGTTCTCATGAGCGTGGTTGGCTATCTTTTGCCTGGTAGCCGATGCGTCTTGTGC AGAGCTNNNNNNNNNNNNNNNNNNNNNNNNNNNNNNNNNNNNNNNNNNNNNNNNNNNNNNNNNNNNNNNNNNNNNNNNNNNNNNNNNNNNNNNNNNNNNN

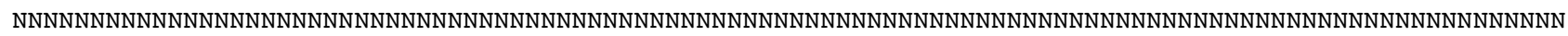

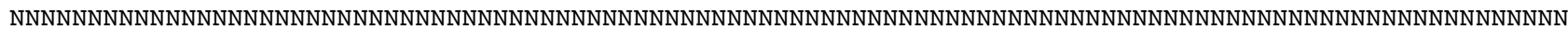

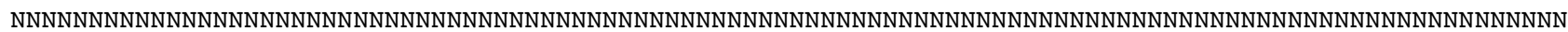

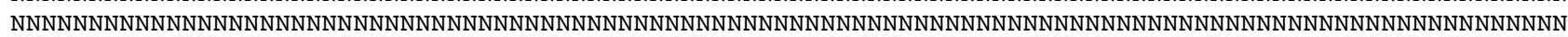

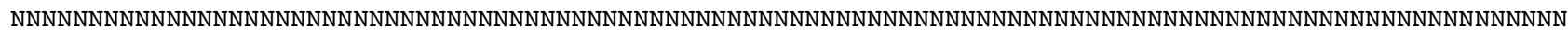

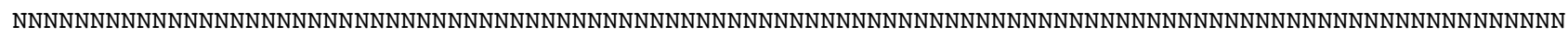

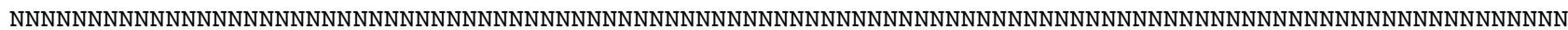

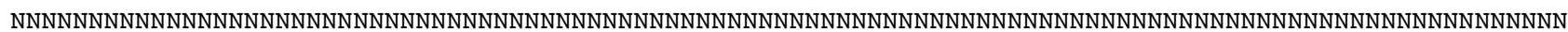

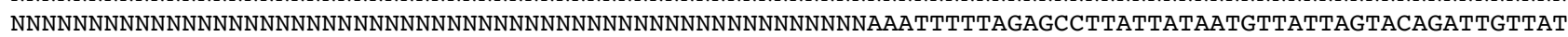
АAАTTTTTAАTTACTAATCATGGTATTATAATGATTTTTTTCTTTATAATGCСTATTTTAATAGGTGGTTTTGGTAATTATTTAATTCCTTTGCTGTGTG GTTTATCAGATTTAAATTTGCCTCGTTTAAAAGCATTAAGTGCTTGGTTGTTATTACCTTCTGCAGTTTTTTTAATAATAAGTATGTGCTTGGGAGCAGG AATAGGTTGGACTTTTTATCCTCСTTTATCTTCTAGTTTATTTGAAGGTAGAAAGGGGGTAGATTTTTTGATGTTTTCGTTACATTTAGCAGGGGTTTCT AGTATTTTTAGTTCTATAAATTTATTTGTACTCTGTACACTGCTTTTAGGGGTAGTTTAGCATCTCGGAGTTCTATAGTATTATGGGC r04_scorzai_marajo_spmar1

NNNNNNNNNNNNNNNNNNNNNNNNNNNNNNNNNNNNNNNNNNNNNNNNNNNNNNNNNNNNNNNNNNNNNNNNNNNNNNNNNNNNNNNTCCCAGGCGTGCT CGCCAGCTGCGGCAACTTAACTGCTGCCACAGCAAGAGGCCAGTCCACACCGGAGCGGCAAACCAGTACATGTGTCGCAAG---

CGTGTGCAAGGTATAAGAA-A-

TTGGCACTACCATATGCCTACGCCCCACTATGCGCCCCTGTCTTTTACACTTACTATACGGGTAGTGTGTGTGTATGTGAGTGTGTGTGTGTGTGTGCG-TGCGTGCGTGTTGGTATGTAGGTGTGCTGGTGTAT-ACCAGCATTACTACTACTACTACTGCTACCACCACCACCAC---------

TACTACTACTACTACTACTA---

TCTGTGCAAAACGNNNNNNNNNNNNNNNNNNNNNNNNNNNNNNNNNNNNNNNNNNNNNNNNNNNNNNNNNNNNNNNNNNNNNNNNNNNNNNNNNNNNNNN

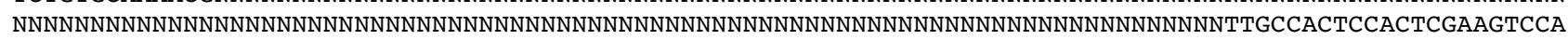
GCATTGAGTATGGTTT-

CTGGATTTGGCCCAGAGAGGGTGAAAGGCCCGTACGGGTGGAGGTGTCAGACAAGTGAGGCAATTCACTAGGCCGGCCTTAGAGTCGGGTTGCTTGGGAA TGCAGCCCAAAGTGGGTGGTAAACTCCATCCAAGGCAAAATACTAGCACGAGTCCGATAGCAAACAAGTACCGTGAGGGAAAGTTGAAAAGTACTTTGAA GAGAGAGTAAACAGTACGTGAAACCGCATGCAGGTAAACGGGTGGCGTCAAGCTGCACGCCCAGAGGATTCAGCCGGTTAGAGTGTAGT- 
TATGCGCTTG-CGTATCGAAGGGCCAGAGTAAAGCGCGCGTGGTAGTCCGCTGGAAGACAGCGGGCCCTGCCGCAAGGTGGGGATGTG-----TAAGCCGGGTGGAAGCCGGAGCACGCTATCCGTC--TGCGGGGCCGTCTAGCCGGTGCACTTTCTCTGT--

GGTGGACACCACGACCGGTGGAACTGCCAGTCTGCTATGGTCAAGTCGTGTTCGGTTGGTCCTTGT-GGCGAACTGGGCGCGAT---CACGGGCAAATTTGGTGAACGGCGTTGATGTGCCCTC--_---_---_GGGTGCGTCTTCGTGCTATCGGTAGCCAGTTGTCTTAACGGGCCTGCCTTACGATTGTTCTAGCCGTCGTA---

GGGTGGTCTGGTGGGCCGTAGTGGTAAGAATAACTGTGCAGGGCACTGGAGTTATCGGCCTCAAACGCAGCCAGCATGCACGCTAGTAGTGTGTCCCTG$--\mathrm{G}---\mathrm{T}---$

ATGTGGGTGCTCTCGTGGTCTGCCTGGTGCCGGGTCTGATTGTCGTGTTGCCTACGCAAAGAAATTTTAGAACCTTACTATAATGTTATTAGTACTGAT TGTTATAAATTTTTGATTACTAATCATGGTATTATAATGATTTTTTTTTTTATAATGCCTATTTTAATTGGTGGGTTTGGTAATTATTTAATTCCTTTAT TATGTGGTTTATCTGATTTAAACTTACCACGTTTAAACGCGCTTAGTGCTTGGTTACTTTTACCTTCTGTGTTATTTTTAGTTATAAAAATGTGTTTAGG GGCTGGGGTAGGTTGAACTTTTTATCCTCCCCTAGCTTCCAGTGCATTTGAGGGGAGTAAGGGTGTAGACTTTTTAATGTTTTCTTTACACTTAGCGGGG GTTTCTAGAATTTTAGCTCTATTAATTTTATTTGTACTTTACACACTGCCTTTAGGGGTAATTTAGCTTCTCGTAGTTCTATTGTATTATGGGC r209_frt_tp_tpj1

NNNNNNNNNNNNNNNNNNNNNNNNNNNNNNNNNNNNNNNNNNNNNNNNNNNNNNNNNNNNNNNNNNNNNNNNNNNNNNNNNNNNNNNTCCCAGGCGTGCT CGCCAGTCGTGGCAACTTAACTGCTGTCACGGCAATCGGCCAGTCCACACCGGAGCGGCAATCCAGTACATGTGCCGCAAGGTACGTGTGCGAGGTATAA GAA-A-

TTGGCACCACСАTATGCCTACGCCCCACTATGCGCCССTGTCTTTTACACTTATCATACAGGTAGTGTGTGAGT---------------------------------------GTACGCGTGTTGGTGTAA-

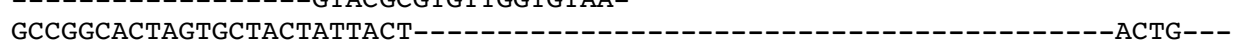

TCTGTGCAAAACGCATGGTCGGCATTGACTTGTTCGACTGTGTGCGGTTCTCATGAGCGTGGTTGGCTATCTT--

GCCTGGTAGCCGATGCGTCTTGTGCAGAGCTGCGAKASCCCAGCACCGAAGCCTGCGGCAGGTTTGCTGTTAGGCAATGTGGTGTTTGGGTCGGCTCGCG GGATTGCCACTCCACTCGAAGTCCAGCATTGAGTATGGTTT-

CTGGATTTGGCCCAGAGAGGGTGAAAGGCCCGTACGGGTGGAGGTATCAGACAAGTGAGGCAATTCACTAGGCCGGCCTTAGAGTCGGGTTGTTTGGGAA TGCAGCCCAAAGCGGGTGGTAAACTCCATCCAAGGCTAAATACTAGCACGAGTCCGATAGCAAACAAGTACCGTGAGGGAAAGTTGAAAAGTACTTTGAA GAGAGAGTAAACAGTACGTGAAACCGCATGCAGGTAAACGGGTGGCGTCAAGCTGCACGCCCAGAGGATTCAGCCGGTTAGAGTGTATC-

TATGCGCTTG-CGTATAAATGGGCCAGAGTAAGGCG----TGGTAGTCCGCTGGYAGACAGCGGGCCCTGCCGCAAGGTGGGGATGTG-----CAAGCCGGGTGGATGCCGGAGCACGCTATCCGTC--TGTGGGGCCGTCTAGCCGGTGCACTTTCTCTGT--

GGTGGACACCACGACCGGTGGAACTGCCAGTCTGCTGTGGCCAAGTCGTGTTCGGTTGGTCCTTGT-GGCGAACTGGGCGCGAT---CACGGGCAACCTTGGTGAACGGCGTTGATGTGCCCTC----------GGGTATGTCTTCGTGTTATCGGTAGCCAGTTGTCTTAACGGGCCTGCCTTGCGATTGTTCTAGCCGTCGTA---

GGGTGGTCTGGTGGGCCATGGTGGTAAGAATAACTGTGCAGGGCACCGGAGTGTTCGGCCTCAAATGCAGCCAGCATGCACGCTAGTAGTGT-----

TG---C---G---

ATGTGGGTGCTCTCGTGGTCTGCCTGGTGCCGGGTCTGATTGTCGTGTTGCCTGCGCAAAGAAATTTTTAGAGCCTTATTATAATGTTATTAGTACAGAT TGTTATAAATTTTTAATTACTAATCATGGTATTATAATGATTTTTTTCTTTATAATGCCTATTTTAATAGGTGGTTTTGGTAATTATTTAATTCCTTTAT TATGTGGTTTATCTGATTTAAATTTACCTCGCTTAAAAGCATTGAGTGCTTGATTATTGTTACCTTCTGCCGTTTTTTTAGTAATAAGCATGTGTTTAGG GGCAGGGATAGGTTGGACTTTTTATCCACCCTTATCTTCTAGCTTATTTGAGGGTAGAAAGGGTGTAGATTTTTTAATGTTTTCTTTACATTTGGCAGGG АTTTCTAGTATTTTTAGTTCTATAAATTTTATTTGTACTTTGTATACTGCATTTAGTGGTAGTCTCGCGTCGCGAAGTTCGATAGTATTATGAGC 32Rhinebothrium_sp_1_worm_18

NNNNNNNNNNNNNNNNNNNNNNNNNNNNNNNNNNNNNNNNNNNNNNNNNNNNNNNNNNNNNNNNNNNNNNNNNNNNNNNNNNNNNNNNNNNNNNNNNNNN

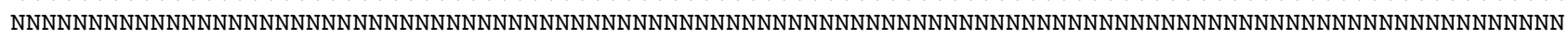

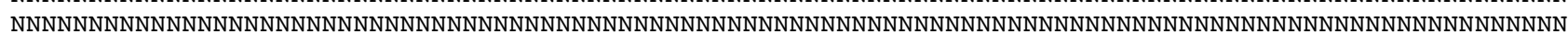

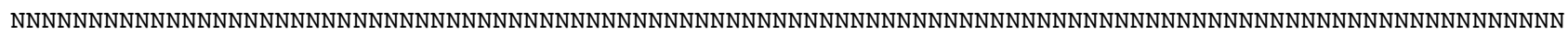

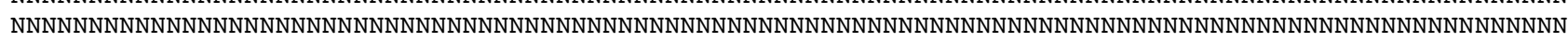
NNNNNNNNNNNNNNNNNNNNNNGGAAGAGCCCAGCACCGAAGCCTGCGGTAGCTTTACTGTTAGGCAATGTGGTGTTTGGGTCGGCTCGCGGGATTGCCA CTCCACTCGAAGTCCAGCATTGAGTATGGTTT-

CTGGATTTGGCCCAGAGAGGGTGAAAGGCCCGTACGGGTGGAGGTATCAGACAAGTGAGGCAATTCACTAGGCCGGCCTTAGAGTCGGGTTGTTTGGGAA TGCAGCCCAAAGTGGGTGGTAAACTCCATCCAAGGCTAAATACTAGCACGAGTCCGATAGCAAACAAGTACCGTGAGGGAAAGTTGAAAAGTACTTTGAA GAGAGAGTAAACAGTACGTGAAACCGCATGCAGGTAAACGGGTGGCGTCAAGCTGCACGCCCAGAGGATTCAGCCGGTTAGAGTGTAGT-

TATGCGCTTG-CGTGTCAACAGGCCAAAGTAAGGCG----TGGTAGACCGCTGGAAGACAGTGGGCCCTGCCACAAGGTGGGGATGTG----TTTAGCCGGGTGGACGCCGGAGCACGCTATCCGTC--TGTTGGGCCTACTAACCGGTGCACTTTCTCTGT--

GGTGGACACCACGACCGGTGGGACTGCCAGTCTGCTATGGTCAAGTTGTATTCGGTTGGTCCTTGT-GGCTAACTGGGTGCGAT---CACGGGCAAACTTGGTGAACGGCGTTGACGTGCTCTC----TTGA----GGGTGTGTCTTCGTGTTATCGGTAACCAGTTGTCTTAACGGGCCTGCCTTACGATTGTTCTAGCCGTCGTA---

GGGTGGTCTGGTGGACCATGGTGGTAAGAATAACTGTGCAGGGCACCGGAGTTTTCGGCCTCAAATGCAGCCAGCATGCACGCTAGTAGTGT-----

GT---T---

GCCAATATGGGTGCTCTCGTGGTCTGCCTGGTGCCGGGTCTGATTGTCGTGTTGCCTACGCAAAGAAATTTTTAGAGCCGTATTATAATGTTATTAGTAC GGATTGTTATAAATTTTTAATTACTAACCATGGCATCATAATGATTTTTTTCTTTATAATGCCTATCTTAATAGGAGGCTTTGGTAACTATTTAATACCG TTACTTTGTGGTCTATCTGATTTAAATTTACCGCGCTTAAAAGCTTTAAGAGCTTGGTTGTTACTGCCTTCGGCTCTTTTTTTAGTGGTGAGTATGTTCC TAGGTGCAGGCGTAGGTTGGACTTTTTATCCTCCATTATCTTCTAGTTTATTTGAGGGCAGTAAGGGGGTGGATTTTTTAATGTTTTCATTGCACTTGGC AGGTATTTCTAGAATTTTCAGGTCTATTAATTTTATTTGTACCTTGTATACTGCTTTTACGGAGAGCTTAGCATCACGCAGTTGTATTATATTATGGTC r077 frt negro schr GGGAACTGCTATGTAACCTCT---C--GGACTGCCCGTCATGG-TGGTCCACAACC-

ATTT $\bar{C}$ GGTGGGGTC $\bar{C}$ CTACTTGCCCTATACTCCCAGGCGTGCTCGCCAGTCGTGGCAACTTAACTGCTGTCACGGCAATCGGCCAGTCCACACCGGAGCG GCAATCCAGTACATGTGCCGCAAGGTACGTGTGCGAGGTATAAGAA-A-

TTGGCACCACCATATGCCTACGCCCCGCTATGCGCCСTTGTCTTTTACACTTATCATACAGGTAGTGTGTGAGT-------------------------

GCCGGCACTAGTGCTACTATTACT--_-_-

TCTGTGCAAAACGNNNNNNNNNNNNNNNNNNNNNNNNNNNNNNNNNNNNNNNNNNNNNNNNNNNNNNNNNNNNNNNNNNNNNNNNNNNNNNNNNNNNNNN

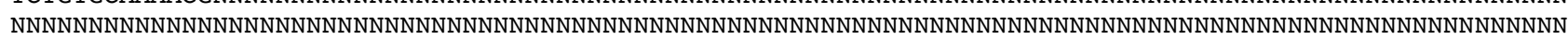

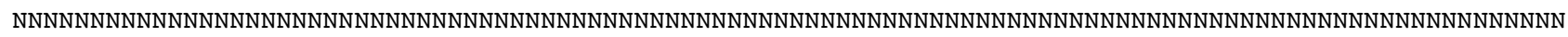

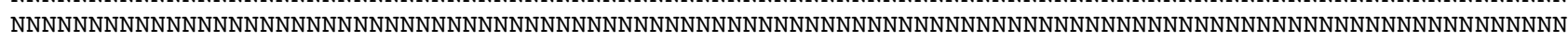

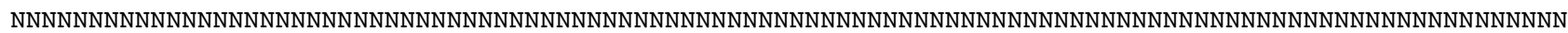

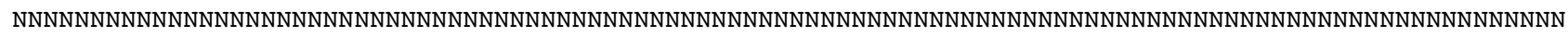

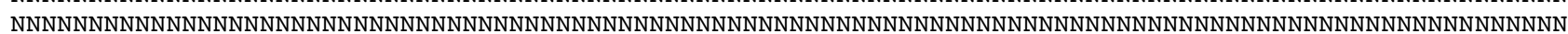

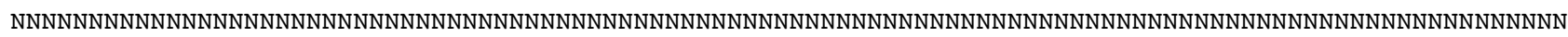

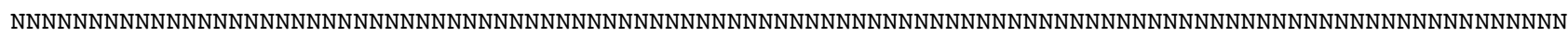

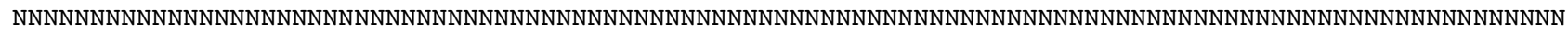


NNNNNNNNNNNNNNNNNNNNNNNNNNNNNNNNNNNNNNNNNNNNNNNNNNNNNNNAAATTTTTGGAGCCTTATTATAATGTTATTAGCTCAGATTGTTAT AAATTTTTAATTACTAATCATGGCATTATAATGATTTTTTTTTTTATAATGCCTATTTTGATAGGTGGTTTTGGTAATTATTTAATTCCTTTATTATGTG GCTTATCCGATTTAAATTTACCTCGTTTAAAAGCATTAAGTGCTTGATTATTATTGCCTTCTGCTGTTTTTTTAGTAGTAAGTATGTGTTTGGGAGCAGG AGTAGGTTGGACTTTTTATCCTCCTTTATCTTCTAGTTTATTTGAAGGTAGAAAGGGTGTAGATTTTTTAATGTTTTCTTTACATTTGGCAGGAGTTTCT AGTATTTTTAGTTCTATAAATTTTATTTGTACTTTATATACTGCTTTTAGTGGTAGTTTAGCATCTCGAAGTTCGATAGTGTTATGATC r018_Rfulbrighti_marajo_orbignyi

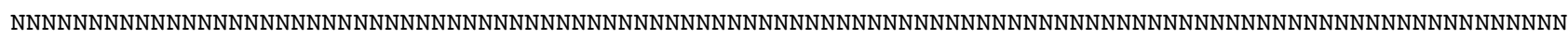

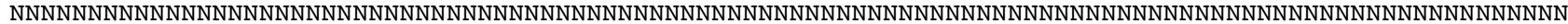

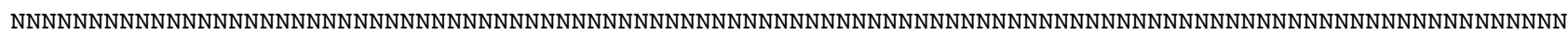

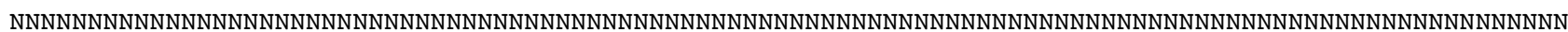

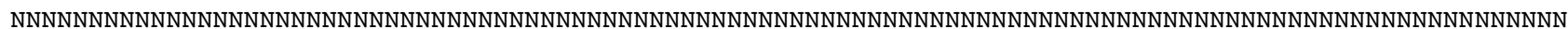

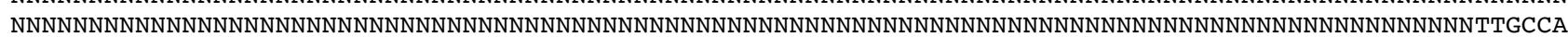
CTTCACTCGAAGTCCAGCATTGAGTATGGTCCACTGGATTTGGCCCAGAGAGGGTGAAAGGCCCGTACGGGTGGAGGTTTCAGACAAGTGAGGCAATTCA CTAGGCCGGCCTTAGAGTCGGGTTGTTTGGGAATGCAGCCCAAAGTGGGTGGTAAACTCCATCCAAGGCTAAATACTAGCACGAGTCCGATAGCAAACAA GTACCGTGAGGGAAAGTTGAAAAGTACTTTGAAGAGAGAGTAAACAGTACGTGAAACCGCATGCAGGTAAACGGGTGGCGTCAAGCTGCACGCCCAGAGG ATTCAGCCGGTTAGAGTGTAGT-TATGCGCTTG-CGTGTCGAACGGCCAGTGTAAGATT----

GGCTAGTCCACTGGAAGACAGTGGGCCCTGCCGCAAGGTGGGG-TGTG-----T-GTACCGGGTGGAAGCCGGAGCACGCTAGCCGTC-TGTTGGGCCATCTAGCCGGTGCACTTTCTCTGT--

GGTGGACACCACGACCGGTGGTACTGCCAGTCTGCTATGGTCAAGTCGTATTCGGTTGGTCCTTGT-GGCCTACTGGGTGCGAT---CACGGACAAACTCGGTGAACGGCGTTGACGTGCTCTT------_-_CCAGGGTATGTCTTCGTGATATCGGTAACCGGTTGTCTTAACGGGCCTGCCTTACGATTGTTCCAGTCGTCCTA---

GGGTGGTCTGGTGGACCATGGTGGTAAGAATAACTGTGCAGGGCACCGGAGTTTTCGGCCTCAAATGCAGCCAGCATGCACGCTGGTAGTGT-----TC--------

GTGTGGGTGCTCTCGTGGCCTGCCTGGTGCCGAGTCTGATTGTCGTGTTGCCTGCGCAAAGAAATTTTTAGAGCCGTATTATAAAGTAATTAATACAGAC TGTTATAAATTTTTAATTACTAATCATGGTATTATTATGATTTTCTTTTTTATAATGCCTATTTTAATCGGCGGGTTTGGTAATTATTTAATACCCTTGT TAGCGGGGTTATCTGATTTAAATTTGCCACGTTTAAAAGCGTTGAGTGCTTGACTTTTACTGCCCTCTGTGGTTTTTTTGTTAATAAGTATGTGTCTTGG TGCTGGTATTGGTTGGACCTTTTATCCTCCCTTATCTTCTGTGGCTTTTGAGGGCAGTAAGGGTGTTGATTTTTTAATGTTTTCTTTGCATTTAGCGGGG GTGTCTAGAATTTTTAGTTCTATAAATTTTATCTGTACTTTGTATACTGCTTTTAGCGGTAGGTTATCCTCACGCGGTTCTATTATTTTGTGGTC r239_frt_toc_scob

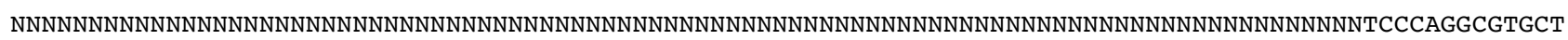
CGCCAGTCGTGGCAACTTAACTGCTGTCACGGCAATCGGCCAGTCCACACCGGAGCGGCAATCCAGTACATGTGCCGCAAGGTACGTGTGCGAGGTATAA GAA-A-

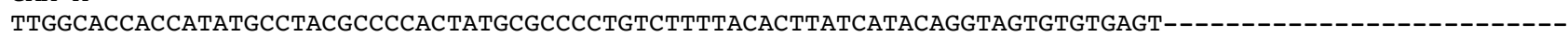
--_---_---_-----GTACGCGTGTTGGTGTAA-

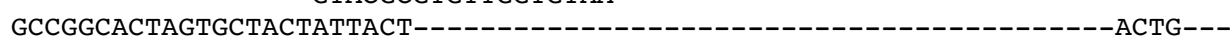

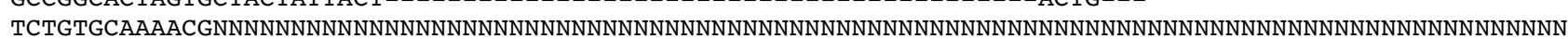

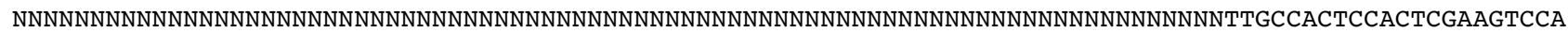
GCATTGAGTATGGTTT-

CTGGATTTGGCCCAGAGAGGGTGAAAGGCCCGTACGGGTGGAGGTATCAGACAAGTGAGGCAATTCACTAGGCCGGCCTTAGAGTCGGGTTGTTTGGGAA TGCAGCCCAAAGCGGGTGGTAAACTCCATCCAAGGCTAAATACTAGCACGAGTCCGATAGCAAACAAGTACCGTGAGGGAAAGTTGAAAAGTACTTTGAA GAGAGAGTAAACAGTACGTGAAACCGCATGCAGGTAAACGGGTGGCGTCAAGCTGCACGCCCAGAGGATTCAGCCGGTTAGAGTGTATC-

TATGCGCTTG-CGTATAAATGGGCCAGAGTAAGGCG----TGGTAGTCCGCTGGCAGACAGCGGGCCCTGCCGCAAGGTGGGGATGTG------CAAGCCGGGTGGATGCCGGAGCACGCTATCCGTC--TGTGGGGCCGTCTAGCCGGTGCACTTTCTCTGT--

GGTGGACACCACGACCGGTGGAACTGCCAGTCTGCTGTGGCCAAGTCGTGTTCGGTTGGTCCTTGT-GGCGAACTGGGCGCGAT---CACGGGCAACCTTGGTGAACGGCGTTGATGTGCCCTC----------GGGTATGTCTTCGTGTTATCGGTAGCCAGTTGTCTTAACGGGCCTGCCTTGCGATTGTTCTAGCCGTCGCA---

GGGTGGTCTGGTGGGCCATGGTGGTAAGAATAACTGTGCAGGGCACCGGAGTGTTCGGCCTCAAATGCAGCCAGCATGCACGCTAGTAGTGT------

TG---C---G---

ATGTGGGTGCTCTCGTGGTCTGCCTGGTGCCGGGTCTGATTGTCGTGTTGCCTGCGCAAAGAAATTTTTAGAGCCTTATTATAACGTTATTAGCACAGAT TGTTATAAATTTTTAATTACTAATCATGGTATTATAATGATTTTTTTCTTTATAATGCCTATTTTAATAGGTGGTTTTGGTAATTATTTAATTCCTTTAT TATGTGGTTTATCTGATTTAAATTTACCTCGTTTAAAAGCATTGAGTGCTTGATTGTTGTTACCTTCTGCTGTTTTTTTAGTAATAAGTATGTGTTTAGG GGCAGGGATAGGTTGGACTTTTTATCCTCCTTTATCTTCTAGTTTATTTGAGGGCAGAAAGGGTGTAGATTTTTTAATGTTTTCTTTACATTTGGCAGGG GTTTCTAGAATTTTTAGTTCTATAAATTTTATTTGTACTTTGTATACTGCTTTTAGTGGTAGTCTTGCCTCGCGAAGTTCGATAGTATTATGAGC r109 gld cuiaba brac GGGAACCGCTATGTAACTTCT---CTCGGACTGCCCGTCATGG-

TGGTCCAAĀACCCGTTTCGGTGGGGTGCCTACTTGCCTTATACTCCCAGGCGTGCTCGCCAGTTGTGGCAACTTAACTGCTGTCACAACAATCGGCCAGT CCACACCGGAGCGGCATATTAGTACACGTGTGA-AAG---CGTGTGCAAGGTATAAGAACA-

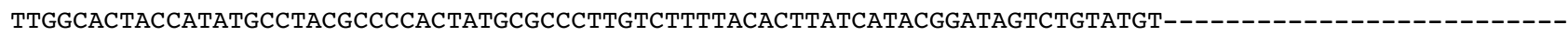
------------GT--GTGTGTTAGCGTAT-

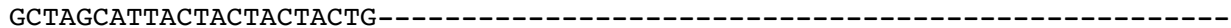

TCTGTGCAAAACGCATGGTCAGCATTAACTTGCTGTACTGTGTGTGGTTCTCATGAGCGTAGTTGGCTACCTT--

GCCTGGGTGCCATTGCGTCTTGTGCAGAGCTNNNNNNNNNNNNNNNNNNNNNNNNNNNNNNNNNNNNNNNNNNNNNNNNNNNNNNNNNNNNNNNNNNNNN

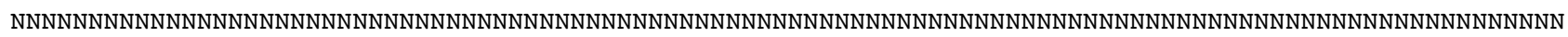
NNNNNNNNNNNNNNNNGGCCTTAGAGTCGGGTTGTTTGGGAATGCAGCCCAAAGTGGGTGGTAAACTCCATCCAAGGCTAAATACTAGCACGAGTCCGAT AGCAAACAAGTACCGTGAGGGAAAGTTGAAAAGTACTTTGAAGAGAGAGTAAACAGTACGTGAAACCGCATGCAGGTAAACGGGTGGCGTCAAGCTGCAC GCCCAGAGGATTCAGCCGGTTAGAGTGTAGT-TATGCGCTTG-CGTATCAAAGGGCCAGAGTAAGGCG----

TGGTAGTCCGCTGGAAGACAGCGGGCCCTGCCGCAAGGTGGGGATGTG------T-AAGCCGGGTGGATGCCGGAGCACGCTATCCGTC-TGGAGGGCCGTCTAGCCGGTGCACTTTCTCTGT--

GGTGGACACCACGACCGGTGGAACTGCCAGTCTGCTATGGTCAAGTCGTGTTCGGTTGGTCCTTGT-GGCTAGCTGGGCGCGAT---CACGGGCAACTTTGGTGAACGGCGTTGATGTGCCCTC------------GGGTATGTCTTCGTGTTATCGGTAACCAGTTGTCTTAACGGGCCTGCCTTACGATTGTTCTAGCCGTCGTA---

GGGTGGTCTGGTGGGCCATAGTGGTAAGAATAACTGTGCAGGGCACCGGAGTGTTCGGCCTCAAAGGCAGCCAGCATGCACGCTAGTAGTGT------

TG---C--TG---

ATGTGGGTGCTCTCGTGGTCTGCCTGGTGCCGGGTCTGATTGTCGTGTTGCCTACGCAAAGAATTTTTTAGAGCCTTATTATAATGTGATTAGCACAGAT TGTTATAATTTTTTGATTACTAATCATGGTATTATAATGATTTTCTTTTTTATAATGCCTATTTTAATAGGGGGGTTTGGTAATTATTTAATTCCTTTAT TAAGTGGTTTATCTGATTTAAATTTACCTCGCCTAAAAGCATTGAGTGCTTGGTTGTTGTTACCTTCTGCTGTGTTTTTGGTGGTTAGGATGTGTTTAGG GGCTGGAATAGGTTGGACTTTTTATCCTCCTTTGTCTTCTAGTGTTTTTGAGGGCAGTAAGGGGGTAGATTTTTTAATGTTTTCTTTACATTTGGCGGGT 
GTTTCTAGCATATTTAGTTCTATTAATTTATTTGTACTTTATATACTGCTTTTAGTGGTAGCTTGGCTTCTCGTAGTTCAATTGTATTGTGGGC r014_Rfulbrighti_marajo_orbignyi

NNNNNNNNNNNNNNNNNNNNNNNNNNNNNNNNNNNNNNNNNNNNNNNNNNNNNNNNNNNNNNNNNNNNNNNNNNNNNNNNNNNNNNNNNNNNNNNNNNNN

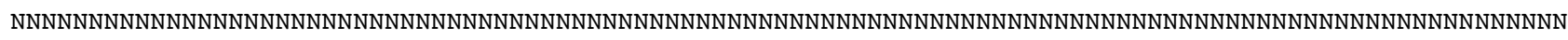

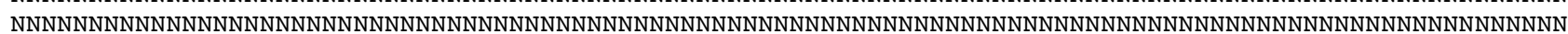

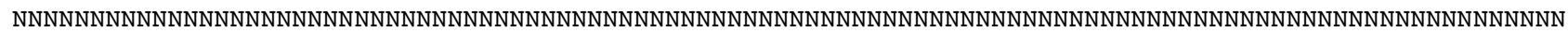

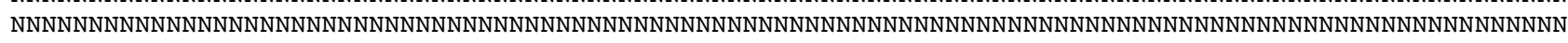
NNNNNNNNNNNNNNNNNNNNNNNNNNNNNNNNNNNNNNNNNGCCTGCGGTAGTTTTACTGTTAGGCAATGTGGTGTTTGGGCCGGCTCGCAGGATTGCCA СTTCACTCGAAGTCCAGCATTGAGTATGGTCCACTGGATTTGGCCCAGAGAGGGTGAAAGGCCCGTACGGGTGGAGGTTTCAGACAAGTGAGGCAATTCA CTAGGCCGGCCTTAGAGTCGGGTTGTTTGGGAATGCAGCCCAAAGTGGGTGGTAAACTCCATCCAAGGCTAAATACTAGCACGAGTCCGATAGCAAACAA GTACCGTGAGGGAAAGTTGAAAAGTACTTTGAAGAGAGAGTAAACAGTACGTGAAACCGCATGCAGGTAAACGGGTGGCGTCAAGCTGCACGCCCAGAGG ATTCAGCCGGTTAGAGTGTAGT-TATGCGCTTG-CGTGTCGAACGGCCAGTGTAAGATT----

GGCTAGTCCACTGGAAGACAGTGGGCCCTGCCGCAAGGTGGGG-TGTG-----T-GTACCGGGTGGAAGCCGGAGCACGCTAGCCGTC--

TGTTGGGCCATCTAGCCGGTGCACTTTCTCTGT--

GGTGGACACCACGACCGGTGGTACTGCCAGTCTGCTATGGTCAAGTCGTATTCGGTTGGTCCTTGT-GGCCTACTGGGTGCGAT---CACGGACAAACTCGGTGAACGGCGTTGACGTGCTCTT-------_CCAGGGTATGTCTTCGTGATATCGGTAACCGGTTGTCTTAACGGGCCTGCCTTACGATTGTTCCAGTCGTCCTA---

GGGTGGTCTGGTGGACCATGGTGGTAAGAATAACTGTGCAGGGCACCGGAGTTTTCGGCCTCAAATGCAGCCAGCATGCACGCTGGTAGTGT-----

TC-----------

GTGTGGGTGCTCTCGTGGCCTGCCTGGTGCCGAGTCTGATTGTCGTGTTGCCTGCGCAAAGAAATTTTTAGAGCCGTATTATAAAGTAATTAATACAGAC TGTTATAAATTTTTAATTACTAATCATGGTATTATTATGATTTTCTTTTTTATAATGCCTATTTTAATCGGCGGGTTTGGTAATTATTTAATACCCTTGT TAGCGGGGTTATCTGATTTAAATTTGCCACGTTTAAAAGCGTTGAGTGCTTGACTTTTACTGCCCTCTGTGGTTTTTTTGTTAATAAGTATGTGTCTTGG TGCTGGTGTTGGTTGGACCTTTTATCCTCCCTTATCTTCTGTGGCTTTTGAGGGCAGTAAGGGTGTTGATTTTTTAATGTTTTCTTTGCATTTAGCGGGG GTGTCTAGAATTTTAGTTCTATAAATTTTATCAGTACCTTGTATACTGCTTTTAGCGGTAGATTATCCTCACGCGGTTCTATTATTTTGTGGTC r103 frt negro schr GGGAACTGCTATGTAACCTCT---C--GGACTGCCCGTCATGG-TGGTCCACAACC-

АTTT $\bar{C}$ GGT $\bar{G}$ GGTG $\bar{C}$ CTACTTGCCCTATACTCCCAGGCGTGCTCGCCAGTCGTGGCAACTTAACTGCTGTCACGGCAATCGGCCAGTCCACACCGGAGCG GCAATCCAGTACATGTGCCGCAAGGTACGTGTGCGAGGTATAAGAA-A-

TTGGCACCACСАTATGCCTACGCCCСАCTATGCGCССTTGTCTTTTACACTTATCATACAGGTAGTGTGTGAGT---------------------------------------GTACGCGTGTTGGTGTAA-

GCCGGCACTAGTGCTACTATTACT--

TCTGTGCAAAACGCATGGTCGGCATTAACTTGTTCGACTGTGTGCGGTTCTCATGAGCGTGGTTGGCTATCTT--

GCCTGGTAGCCGATGCGTCTTGTGCAGAGCTNNNNNNNNNNNNNNNNNNNNNNNNNNNNNNNNNNNNNNNNNNNNNNNNNNNNNNNNNNNNNNNNNNNNN

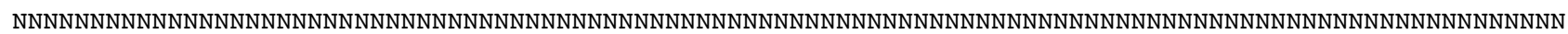
NNNNNNNNNNNNNNNNGGCCTTAGAGTCGGGTTGTTTGGGAATGCAGCCCAAAGCGGGTGGTAAACTCCATCCAAGGCTAAATACTAGCACGAGTCCGAT AGCAAACAAGTACCGTGAGGGAAAGTTGAAAAGTACTTTGAAGAGAGAGTAAACAGTACGTGAAACCGCATGCAGGTAAACGGGTGGCGTCAAGCTGCAC GCCCAGAGGATTCAGCCGGTTAGAGTGTGTC-TATGCGCTTG-CGTATGAATGGGCCAGAGTAAGGCG----

TGGTAGTCCGCTGGCAGACAGCGGGCCCTGCCGCAAGGTGGGGATGTG-----T-AAGCCGGGTGGATGCCGGAGCACGCTATCCGTC--

TGTGGGGCCGTCTAGCCGGTGCACTTTCTCTGT--

GGTGGACACCACGACCGGTGGAACTGCCAGTCTGCTGTGGTCAAGTCGTGTTCGGTTGGTCCTTGT-GGCGAACTGGGCGCGAT---CACGGGCAACCTTGGTGAACGGCGTTGATGTGCCCTC----------_GGGTATGTCTTCGTGTTATCGGTAGCCAGTTGTCTTAACGGGCCTGCCTTGCGATTGTTCTAGCCGTCGTA---

GGGTGGTCTGGTGGGCCATGGTGGTAAGAATAACTGTGCAGGGCACCGGAGTGTTCGGCCTCAAATGCAGCCAGCATGCACGCTAGTAGTGT-----

TG---C---G---

ATGTGGGTGCTCTCGTGGTCTGCCTGGTGCCGGGTCTGATTGTCGTGTTGCCTGCGCAAAGAAATTTTTGGAGCCTTATTATAATGTTATTAGCTCAGAT TGTTATAAATTTTTAATTACTAATCATGGCATTATAATGATTTTTTTTTTTATAATGCCTATTTTGATAGGTGGTTTTGGTAATTATTTAATTCCTTTAT TATGTGGCTTATCCGATTTAAATTTACCTCGTTTAAAAGCATTAAGTGCTTGATTATTATTGCCTTCTGCTGTTTTTTTAGTAGTAAGTATGTGTTTGGG AGCAGGAATAGGTTGGACTTTTTATCCTCCTTTATCTTCTAGTTTATTTGAAGGTAGAAAGGGTGTAGATTTTTTAATGTTTTCTCTACATTTGGCAGGA GTTTCTAGTATTTTTAGTTCTATAAATTTTATTTGTACTTTATATACTGCTTTTAGTAGTAGTTTAGCATCTCGAAGTTCGATAGTGTTGTGATC r249 rhoides negro orbGGGAACTGCTATGTAACCTCT---C--GGACTGCCCGTCATGG-TGGTCCACAACC-

АTTTC $\bar{C}$ GTGGGGTGCCTA $\bar{C} T$ TGCCCTATACTCCCAGGCGTGCTCGCCAGTCGTGGCAACTTAACTGCTGTCACGGCAATCGGCCAGTCCACACCGGAGCG GCAATCCAGTACATGTGCCGCAAGGTACGTGTGCGAGGTATAAGAA-A-

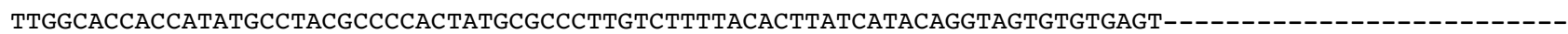
--------------GTACGCGTGTTGGTGTAA-

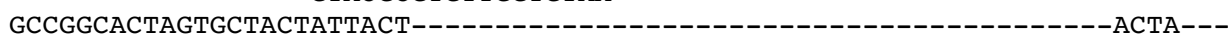

TCTGTGCAAAACGNNNNNNNNNNNNNNNNNNNNNNNNNNNNNNNNNNNNNNNNNNNNNNNNNNNNNNNNNNNNNNNNNNNNNNNNNNNNNNNNNNNNNNN NNNNNNGGAAGAGCCCAGCACCGAAGCCTGCGGCAGGTTTGCTGTTAGGCAATGTGGTGTTTGGGTCGGCTCGCGGGATTGCCACTCCACTCGAAGTCCA GCATTGAGTATGGTTT-

CTGGATTTGGCCCAGAGAGGGTGAAAGGCCCGTACGGGTGGAGGTATCAGACAAGTGAGGCAATTCACTAGGCCGGCCTTAGAGTCGGGTTGTTTGGGAA TGCAGCCCAAAGCGGGTGGTAAACTCCATCCAAGGCTAAATACTAGCACGAGTCCGATAGCAAACAAGTACCGTGAGGGAAAGTTGAAAAGTACTTTGAA GAGAGAGTAAACAGTACGTGAAACCGCATGCAGGTAAACGGGTGGCGTCAAGCTGCACGCCCAGAGGATTCAGCCGGTTAGAGTGTATC-

TATGCGCTTG-CGTATAAATGGGCCAGAGTAAGGCG----TGGTAGTCCGCTGGCAGACAGCGGGCCCTGCCGCAAGGTGGGGATGTG-----CAAGCCGGGTGGATGCCGGAGCACGCTATCCGTC--TGTGGGGCCGTCTAGCCGGTGCACTTTCTCTGT--

GGTGGACACCACGACCGGTGGAACTGCCAGTCTGCTGTGGCCAAGTCGTGTTCGGTTCGTCCTTGT-GGCGAACTGGGCGCGAT---CACGGGCAACCTTGGTGAACGGCGTTGATGTGCCCTC----_----_GGTATGTCTTCGTGTTATCGGTAGCCAGTTGTCTTAACGGGCCTGCCTTGCGATTGTTCTAGCCGTCGTA---

GGGTGGTCTGGTGGGCCATGGTGGTAAGAATAACTGTGCAGGGCACCGGAGTGTTCAGCCTCAAATGCAGCCAGCATGCACGCTAGTAGTGT----TG---C---G---

ATGTGGGTGCTCTCGTGGTCTGCCTGGTGCCGGGTCTGATTGTCGTGTTGCCTGCGCAAAGAAATTTTTGGAGCCTTATTATAATGTTATTAGTGCAGAT TGTTATAAATTTTTAATTACTAACCATGGTATTATAATGATTTTTTTCTTTATAATGCCTATTTTAATAGGTGGCTTTGGTAATTATTTGATTCCTTTAT TGTGTGGGTTATCTGATCTAAATTTACCTCGTTTAAAAGCATTGAGTGCTTGATTGTTACTGCCTTCCGCTGTTTTTTTAGTAACAAGTATGTGTTTAGG AGCGGGAGTAGGTTGAACTTTTTATCCTCCTTTATCTTCGAGTTTATTTGAGAGTAGAAAGGGTGTGGATTTTTTAATGTTTTCTTTACATTTAGCAGGA GTTTCTAGTATTTTTAGTTCTATAAATTTTATTTGTACGTTATATACTGCTTTTAGGGGTAGTTTGGCGTCTCGAAGTTCGATAGTATTATGGGC r051_vnz_uppersol_mot GGGAACTGCTATGTAACCTCT---C--GGACCGCTGGTCATGG-TGGTCCACAACCATTTCGGTGGGGTGCTÄCTTGCCCTATACTCCCAGGCGTGCTCGCCAGTCGTGGCAACTTAACTGCTGTCGCGGCAATCGGCCAGTCCACACCGGAGCG GCAATGCAGTACATGTGTCGGAAGGCACGTGTGCGAGGTATAAGAA-A-

TTGGCACCACCATATGCCTACGCCCCACTATGCGCCСTTGTCTTTTACACTTACCATACAGGTAGTGTGTGAGT---------------------------------------GTACGCGTGTTGGTGTAT- 


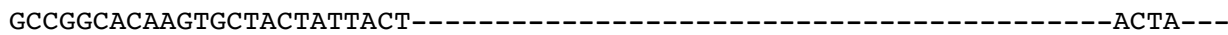

TCTGTGCAAAACGCATGGTCGGCATTGACTTGTTGTACTGTGCGCGGTTCTCATGAGCGTGGTTGGCTATCTTTTGCCTGGTAGCCGATGCGTCTTGTGC

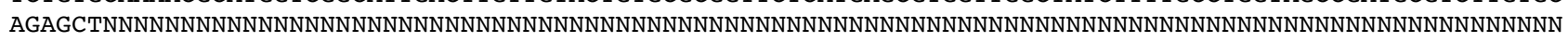

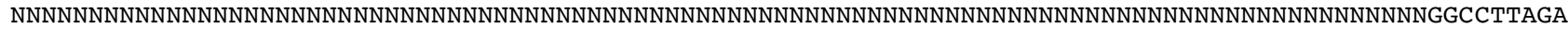
GTCGGGTTGTTTGGGAATGCAGCCCAAAGCGGGTGGTAAACTCCATCCAAGGCTAAATACTAGCACGAGTCCGATAGCAAACAAGTACCGTGAGGGAAAG TTGAAAAGTACTTTGAAGAGAGAGTAAACAGTACGTGAAACCGCATGCAGGTAAACGGGTGGCGTCAAGCTGCACGCCCAGAGGATTCAGCCGGTTAGAG TGTATC-TATGCGCTTG-CGTATAAAAGGGCCAGAGTAAGGCG----TGGTAGTCCGCTGGCAGACAGCGGGCCCTGCCGCAAGGTGGGGATGTG----T-AAGCCGGGTGGATGCCGGAGCACGCTATCCGTC--TGTGGGGCCGTCTAGCCGGTGCACTTTCTCTGT--

GGTGGACACCACGACCGGTGGAACTGCCAGTCTGCTGTGGTCAAGTCGTGTTCGGTTGGTCCTTGT-GGCGAACTGGGCGCGAT---CACGGGCAACCTTGGTGAACGGCGTTGATGTGCCCTC----_-----GGGTATGTCTTCGTGTTATCGGTAGCCAGTTGTCTTAACGGGCCTGCCTTGCGATTGTTCTAGCCGTCGTA---

GGGTGGTCTGGTGGGCCATGGTGGTAAGAATAACTGTGCAGGGCACCGGAGTGTTCGGCCTCAAATGCAGCCAGCATGCACGCTAGTAGTGT------

TG---C---G---

ATGTGGGTGCTCTCGTGGTCTGCCTGGTGCCGGGTCTGATTGTCGTGTTGCCTGCGCAAAGAAATTTTTAGAGCCTTATTATAATGTTATTAGTACAGAT TGTTATAAATTTTTAATTACTAATCATGGTATTATAATGATTTTTTTCTTTATAATGCCCATTTTAATAGGTGGTTTTGGTAATTATTTAATTCCTTTGT TGTGTGGTTTGTCGGATTTAAATCTACCTCGCTTGAAAGCATTAAGTGCTTGGTTGTTACTGCCTTCTGCAGTTTTTTTAGTAATTAGTATGTGTTTGGG AGCAGGTATAGGTTGGACTTTTTATCCTCCTCTTTCTTCAAGTTTATTTGAGGGTAGAAAGGGTGTAGATTTTTTGATGTTTTCATTACATTTGGCGGGA GTTTCTAGTATTTTTAGTTCTATAAATTTTATTTGTACTTTGTATACTGCTTTCAGAGGTAGGTTAGCGTCTCGAAGCTCTATAGTATTATGGGC 17Rhinebothrium_sp_1_worm_1

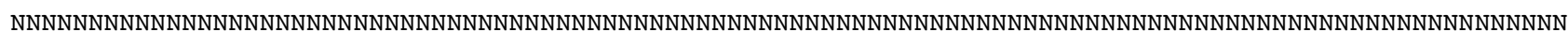

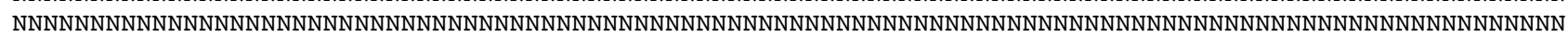

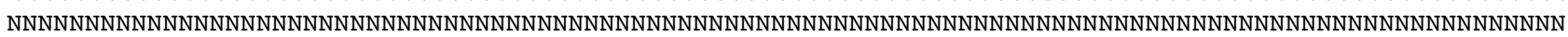

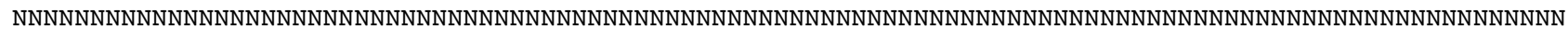

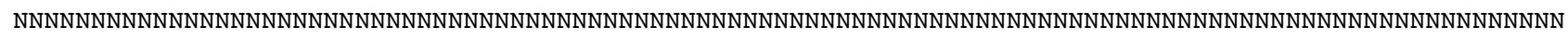
NNNNNNNNNNNNNNNNNNNNNNGGAAGAGCCCAGCACCGAAGCCTGCGGTAGCTTTACTGTTAGGCAATGTGGTGTTTGGGTCGGCTCGCGGGATTGCCA CTCCACTCGAAGTCCAGCATTGAGTATGGTTT-

CTGGATTTGGCCCAGAGAGGGTGAAAGGCCCGTACGGGTGGAGGTATCAGACAAGTGAGGCAATTCACTAGGCCGGCCTTAGAGTCGGGTTGTTTGGGAA TGCAGCCCAAAGTGGGTGGTAAACTCCATCCAAGGCTAAATACTAGCACGAGTCCGATAGCAAACAAGTACCGTGAGGGAAAGTTGAAAAGTACTTTGAA GAGAGAGTAAACAGTACGTGAAACCGCATGCAGGTAAACGGGTGGCGTCAAGCTGCACGCCCAGAGGATTCAGCCGGTTAGAGTGTAGTTATGCGCTTG-CGTGTCAACAGGCCAGAGTAAGGCG----TGGTAGACCGCTGGAAGACAGTGGGCCCTGCCGCAAGGTGGGGATGTG-----TTTAGCCGGGTGGACGCCGGAGCACGCTATCCGTC--TGTTGGGCCTACTAGCCGGTGCACTTTCTCTGT--

GGTGGACACCACGACCGGTGGGACTGCCAGTCTGCTATGGTCAAGTCGTATTCGGTTGGTCCTTGT-GGCTAACTGGGTGCGAT---CACGGGCAAACTTGGTGAACGGCGTTGACGTGCTCTC----TTGA----GGGTGTGTCTTCGTGTTATCGGTAACCAGTTGTCTTAACGGGCCTGCCTTACGATTGTTCTAGCCGTCGTA---

GGGTGGTCTGGTGGACCATGGTGGTAAGAATAACTGTGCAGGGCACCGGAGTTTTCGGCCTCAAATGCAGCCAGCATGCACGCTAGTAGTGT------

GT---T---

GCCAATATGGGTGCTCTCGTGGTCTGCCTGGTGCCGGGTCTGATTGTCGTGTTGCCTACGCAAAGAAATTTTTGGAGCCGTACTATAATGTTATTAGTAC GGACTGTTATAAATTTTTAATTACTAATCATGGTATTATAATGATTTTTTTCTTTATAATGCCTATTTTGATAGGTGGTTTTGGTAATTATTTGATTCCG TTACTTTGTGGTTTATCTGATTTAAATCTACCCCGTTTAAAAGCACTCAGAGCTTGGTTGTTGTTGCCTTCAGCTCTTTTTTTGGTGGTGAGTATGTGTT TAGGGGCTGGTATAGGTTGGACTTTCTATCCTCCGTTATCTTCTAGATTATTTGAAGGGAGTAAGGGGGTAGATTTTTTAATGTTTTCGTTGCATTTAGC AGGAATTTCTAGTATTTTTAGGTCTATTAAATTTATTTGTACTTTGTATACTGCTTTTAGTGATAGTTTAGCAGCACGTAGATGTATTATACTATGATC r012 scorzai marajo spmar1 GGGAACTGCTATGTAACAACAATACTCGGACCGCTCGTCATAG-TGGTCTGCTACC-

ATTTC GCAAACCAGTACATGTGTCGCAAG---CGTGTGCAAGGTATAAGAA-A-

TTGGCACTACCATATGCCTACGCCCCACTATGCGCCCCTGTCTTTTACACTTACTATACGGGTAGTGTGTGTGTATGTGAGTGTGTGTGTGTGTGTGTGC GTGCGTGCGTGTTGGTATGTAGGTGTGCTGGTGTAT-GCCAGCATTACTACTACTACTACTGCTACCACCACCACCAC---.---

TACTACTACTACTACTACTA---

TCTGTGCAAAACGNNNNNNNNNNNNNNNNNNNNNNNNNNNNNNNNNNNNNNNNNNNNNNNNNNNNNNNNNNNNNNNNNNNNNNNNNNNNNNNNNNNNNNNN NNNNNNGGAAGAGCCCAGCACCGAAGCCTGCGGTAGCTTTACTGTTAGGCAATGTGGTGTTTGGGCCGGCTCGCGGGATTGCCACTCCACTCGAAGTCCA GCATTGAGTATGGTTT-

CTGGATTTGGCCCAGAGAGGGTGAAAGGCCCGTACGGGTGGAGGTGTCAGACAAGTGAGGCAATTCACTAGGCCGGCCTTAGAGTCGGGTTGCTTGGGAA TGCAGCCCAAAGTGGGTGGTAAACTCCATCCAAGGCTAAATACTAGCACGAGTCCGATAGCAAACAAGTACCGTGAGGGAAAGTTGAAAAGTACTTTGAA GAGAGAGTAAACAGTACGTGAAACCGCATGCAGGTAAACGGGTGGCGTCAAGCTGCACGCCCAGAGGATTCAGCCGGTTAGAGTGTAGT-

TATGCGCTTG-CGTATCGAAGGGCCAGAGTAAAGCGCGCGTGGTAGTCCGCTGGAAGACAGCGGGCCCTGCCGCAAGGTGGGGATGTG------TAAGCCGGGTGGAAGCCGGAGCACGCTATCCGTC--TGCGGGGCCGTCTAGCCGGTGCACTTTCTCTGT--

GGTGGACACCACGACCGGTGGAACTGCCAGTCTGCTATGGTCAAGTCGTGTTCGGTTGGTCCTTGT-GGCGAACTGGGCGCGAT---CACGGGCAAATTTGGTGAACGGCGTTGATGTGCCCTC----_-_---_GGGTGCGTCTTCGTGCTATCGGTAGCCAGTTGTCTTAACGGGCCTGCCTTACGATTGTTCTAGCCGTCGTA---

GGGTGGTCTGGTGGGCCGTAGTGGTAAGAATAACTGTGCAGGGCACTGGAGTTATCGGCCTCAAACGCAGCCAGCATGCACGCTAGTAGTGTGTCCCTG--G---T---

ATGTGGGTGCTCTCGTGGTCTGCCTGGTGCCGGGTCTGATTGTCGTGTTGCCTACGCAAAGAAATTTTTAGAACCTTACTATAATGTTATTAGTACTGAT TGTTATAAATTTTTGATTACTAATCATGGTATTATAATGATTTTTTTTTTTATAATGCCTATTTTAATTGGTGGGTTTGGTAATTATTTAATTCCTTTAT TATGTGGTTTATCTGATTTAAACTTACCACGTTTAAACGCGCTTAGTGCTTGGTTACTTTTACCTTCTGTGTTATTTTTAGTTATAAGAATGTGTTTAGG GGCTGGGGTAGGTTGAACTTTTTATCCTCCCCTAGCTTCCAGTGCATTTGAGGGGAGTAAGGGTGTAGACTTTTTAATGTTTTCTTTACACTTAGCGGGG GTTTCTAGAATTTTTAGTTCTATTAATTTTATTTGTACTTTACACACTGCCTTTAGGGGTAATTTAGCTTCTCGAAGTTCTATTGTATTATGGGC 41Rhinebothrium_sp_4_worm_2

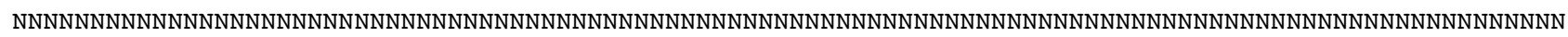

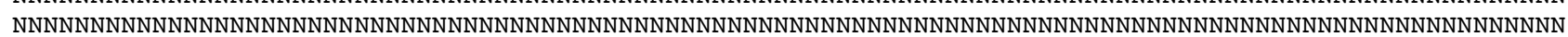

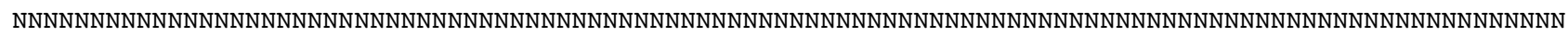

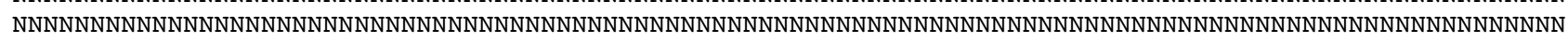

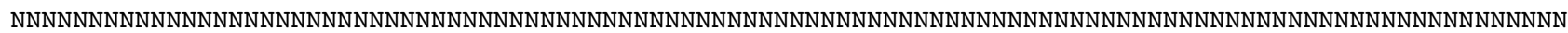
NNNNNNNNNNNNNNNNNNNNNNGGAAGAGCCCAGCACCGAAGCCTGCGGTAGCTTTACTGTTAGGCAATGTGGTGTTTGGGTCGGCTCGCGGGATTGCCA CTCCACTCGAAGTCCAGCATTGAGTATGGTTT-

CTGGATTTGGCCCAGAGAGGGTGAAAGGCCCGTACGGGTGGAGGTGTCAGACAAGTGAGGCAATTCACTAGGCCGGCCTTAGAGTCGGGTTGTTTGGGAA TGCAGCCCAAAGTGGGTGGTAAACTCCATCCAAGGCTAAATACTAGCACGAGTCCGATAGCAAACAAGTACCGTGAGGGAAAGTTGAAAAGTACTTTGAA GAGAGAGTAAACAGTACGTGAAACCGCATGCAGGTAAACGGGTGGCGTCAAGCTGCACGCCGAGAGTATTCAGCCGGTTAGAGTGTAGT- 
TATGCGCTTG-CGTGTCGACAGGCCAGAGTAAGGCG----

TGGTAGTCCGCTGGAAGACAGTGGGCCCTGCCGCGAGGTGGGGATGTGCTTTTTTGTGCCGGGTGGAAGCCGGAGCACGCTATCCGTC-TGTTGGGCCTACTAGCCGGTGCACTTACTCTCT--

GGTGGACACCACGACCGGTGGGACTGCCAGTCTGCTATGGTCAAGTCGTGTTCGGTTGGTCCTTGT-GGCTTACTGGGTGCGAT---

CACGGGCGAACAGTGGCGAACGGCGTTGACGTGCTCTC----TTGA----

GGGTGTGTCTTCGTGTTATCGGTAGCCAGTCGTCTTAACGGACCTGCCTTGCGGTTGTTCTA-GCCGTCGTA---

GGGTGGTCTGGTGGACCTTAGTGGTAGGAATAACTGTGCAGGGCACCGGAGTTGTCGGCCTCAAATGCGGCCAGCATGCACGCTAGTAGTGT-----

GT---T---

GCCCATGTGGGTGCTCGCGTGGCCTGCCTGGTGCCGGGTCTGATTGTCGTGTTGCCTACGCAAAGAAATTTTTAGAACCTTACTATAATGTTATAAGAAC TGATTGTTATAAATTTCTAATTACAAAACATGGTATTATAATGATTTTTTTCTTTATAATGCCTATTTTAATAGGAGGTTTTGGTAATTATTTAATACCT СTTTTATGTGGTTTATCTGATTTAAATTTACCTCGATTAAATGCATTGAGAGCTTGGTTGCTGTTACCATCTGCTGTTTTTTTAATTATTAGCATGTGTT TAGGAGCAGGCATAGGTTGAACTTTTTATCCTCСTTTGTCTTCTAGATTGTTTGAGGGTAGTCGTGGTGTTGATTTTTTAATGTTTTCTTTACATTTAGC TGGAGTTTCAAGTATTTTTAGTTCTATAAAATTTATCTGCACGTTATATACTGCCTTTACGGATAGTTTAGCTTCACGTAGAAGAATAGTTTTATGATC AF286931_Litobothrium_amplifica

NNNNNNNNNNNNNNNNNNNNNNNNNNNNNNNNNNNNNNNNNNNNNNNNNNNNNNNNNNNNNNNNNNNNNNNNNNNNNNNNNNNNNNNNNNNNNNNNNNNN

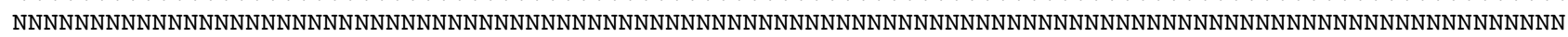

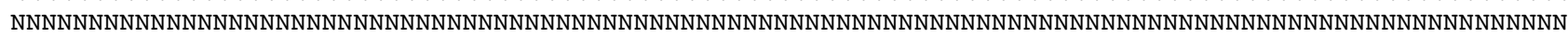

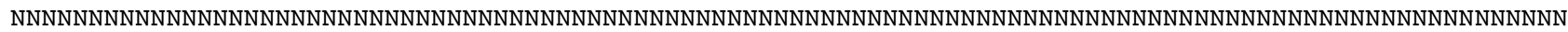

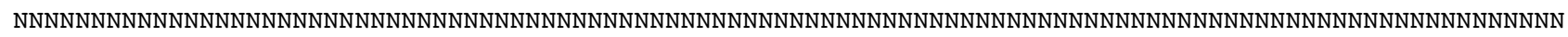
NNNNNNNNNNNNNNNNNNNNNNGGAATAGCCCAGCACCGAAGCCTGCGGCAGTTTTGCTGTTAGGCAATGTGGTGTTTGGGTCGGCTTATGGGATTGCCA СTCCACTCGAAGTCCAGCATTGAGTATGGTCCCCTGGATTTGGCCCAGAGAGGGTGAAAGGCCCGTACGAGTGGATGTATCAGACATGTAAGGCAATTCA CCAGGCCGGCCTTAGAGTCGGGTTGTTTGGGAATGCAGCCCAAAGTGGGTGGTAAACTCCATCCAAGGCTAAATACAAGCACGAATCCGATAGCGAACAA GTACCGTGAGGGAAAGTTGAAAAGTACTTTGAAGAGAGAGTAAACAGTACGTGAAACCGCATGCAGGTAAACGGGTGGCGTCAAGCTGCAAGCCCAGAGG ATTCAGTCGGCTAGGATGTAGTGTATGCGCCTGGCGCATCGAGAGGCCAGAGTAAGATT----

GGGTGATCTGCTGGGAAACAGCAGGCTCAGCCTTACGGTTGAGATATG-----T-GTACCGGGTGGTTGCCGGAGCATGTCACTCGTC--

TGTTGGGCCGTCTAGCCGGTGCACTTCCTCTGTT-

GGTGAACACCACGGCCGGTGGTATTGCCAGTCTGCCATAGTCAAGTCGTGTTCAGTTGGTGCTTGTCGCCAGTTGGATTGCGATGATCACAGGCAAATTCGGTGAACGGTGTAGGGGTGTT--T-----------CGGCATTTCTGCATGTTATCGGACACTGGTTGTC--AACGGGTCTGTTTAGCGATTGTTGTAGTCGTCGCT---

AGATGGCCTGGTGGATTATGGTGGTAAGAATAACTGTGCAAGGCACCGGAGTTCTCGGTCTCTAATGCAACCTACATGCACGCTACAAGTGA-----C-----------ATG-

GGGTGTCGTTGCAGCCTGCCTGTTATTGGGTCTGATTGTCGTGTCGCCTGCGCAAAGNNNNNNNNNNNNNNNNNNNNNNNNNNNNNNNNNNNNNNNNNNN

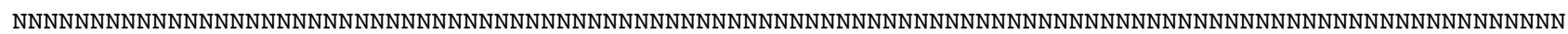

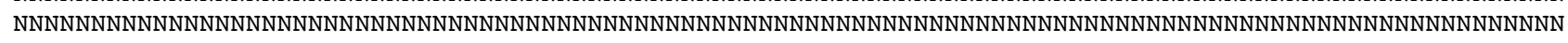

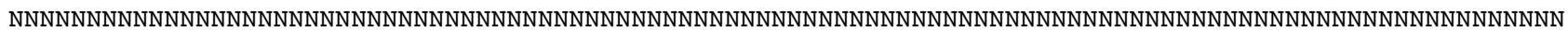
NNNNNNNNNNNNNNNNNNNNNNNNNNNNNNNNNNNNNNNNNNNNNNNNNNNNNNNNNNNNNNNNNNNNNNNNNNNNNNNNNNNNNNNNNNN r01 scorzai marajo spmar1 GGGAACTGCTATGTAACAACAATACTCGGACCGCTCGTCATAG-TGGTCTGCTACC-

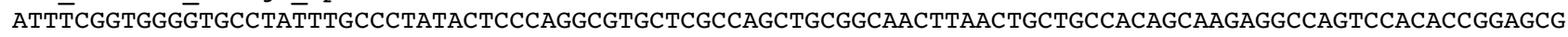
GCAAACCAGTACATGTGTCGCAAG---CGTGTGCAAGGTATAAGAA-A-

TTGGCACTACCATATGCCTACGCCCCACTATGCGCCCCTGTCTTTTACACTTACTATACGGGTAGTGTGTGTGTATGTGAGTGTGTGTGTGTGTGTGCG-TGCGTGCGTGTTGGTATGTAGGTGTGCTGGTGTAT-GCCAGCATTACTACTACTACTACTGCTACCACCACCACCAC---------

TACTACTACTACTACTACTA---

TCTGTGCAAAACGNNNNNNNNNNNNNNNNNNNNNNNNNNNNNNNNNNNNNNNNNNNNNNNNNNNNNNNNNNNNNNNNNNNNNNNNNNNNNNNNNNNNNNN NNNNNNGGAAGAGCCCAGCACCGAAGCCTGCGGTAGCTTTACTGTTAGGCAATGTGGTGTTTGGGCCGGCTCGCGGGATTGCCACTCCACTCGAAGTCCA GCATTGAGTATGGTTT-

CTGGATTTGGCCCAGAGAGGGTGAAAGGCCCGTACGGGTGGAGGTGTCAGACAAGTGAGGCAATTCACTAGGCCGGCCTTAGAGTCGGGTTGCTTGGGAA TGCAGCCCAAAGTGGGTGGTAAACTCCATCCAAGGCTAAATACTAGCACGAGTCCGATAGCAAACAAGTACCGTGAGGGAAAGTTGAAAAGTACTTTGAA GAGAGAGTAAACAGTACGTGAAACCGCATGCAGGTAAACGGGTGGCGTCAAGCTGCACGCCCAGAGGATTCAGCCGGTTAGAGTGTAGT-

TATGCGCTTG-CGTATCGAAGGGCCAGAGTAAAGCGCGCGTGGTAGTCCGCTGGAAGACAGCGGGCCCTGCCGCAAGGTGGGGATGTG-----TAAGCCGGGTGGAAGCCGGAGCACGCTATCCGTC--TGCGGGGCCGTCTAGCCGGTGCACTTTCTCTGT--

GGTGGACACCACGACCGGTGGAACTGCCAGTCTGCTATGGTCAAGTCGTGTTCGGTTGGTCCTTGT-GGCGAACTGGGCGCGAT---CACGGGCAAATTTGGTGAACGGCGTTGATGTGCCCTC----_----GGGTGCGTCTTCGTGCTATCGGTAGCCAGTTGTCTTAACGGGCCTGCCTTACGATTGTTCTAGCCGTCGTA---

GGGTGGTCTGGTGGGCCGTAGTGGTAAGAATAACTGTGCAGGGCACTGGAGTTATCGGCCTCAAACGCAGCCAGCATGCACGCTAGTAGTGTGTCCCTG$--\mathrm{G}---\mathrm{T}---$

ATGTGGGTGCTCTCGTGGTCTGCCTGGTGCCGGGTCTGATTGTCGTGTTGCCTACGCAAAGAAATTTTTAGAACCTTACTATAATGTTATTAGTACTGAT TGTTATAAATTTTTGATTACTAATCATGGTATTATAATGATTTTTTTTTTTATAATGCCTATTTTAATTGGTGGGTTTGGTAATTATTTAATTCCTTTAT TATGTGGTTTATCTGATTTAAACTTACCACGTTTAAACGCGCTTAGTGCTTGGTTACTTTTACCTTCTGTGTTATTTTTAGTTATAAGAATGTGTTTAGG GGCTGGGGTAGGTTGAACTTTTTATCCTCCCCTAGCTTCCAGTGCATTTGAGGGGAGTAAGGGTGTAGACTTTTTAATGTTTTCTTTACACTTAGCGGGG GTTTCTAGAATTTTAGCTCTATTAATTTTATTTGTACTTTACACACTGCCTTTAGGGGTAATTTAGCTTCTCGTAGTTCTATTGTATTATGGGC r07_scorzai_marajo_motGGGAACTGCTATGTAACAACAATACTCGGACCGCTCGTCATAG-TGGTCTGCTACC-

ATTT'CGGTGGGGTGCCTATTTGCCCTATACTCCCAGGCGTGCTCGCCAGCTGCGGCAACTTAACTGCTGCCACAGCAAGAGGCCAGTCCACACCGGAGCG GCAAACCAGTACATGTGTCGCAAG---CGTGTGCAAGGTATAAGAA-A-

TTGGCACTACCATATGCCTACGCCCCACTATGCGCCCCTGTCTTTTACACTTACTATACGGGTAGTGTGTGTGTATGTGAGTGTGTGTGTGTGTGTGTG-----_CGTTTGGTATGTAGGTGTGCTGGTGTAT-GCCAGTATTACTACTACTACTACTGCTACCACCACCACCAC---------

TАСТАСТАСТАСТАСТАСТАСТАТСТGTGCAАAАCGNNNNNNNNNNNNNNNNNNNNNNNNNNNNNNNNNNNNNNNNNNNNNNNNNNNNNNNNNNNNNNNN NNNNNNNNNNNNNNNNNNNNNNNNNNNNNGGAAGAGCCCAGCACCGAAGCCTGCGGTAGCTTTACTGTTAGGCAATGTGGTGTTTGGGCCGGCTCGCGGG ATTGCCACTCCACTCGAAGTCCAGCATTGAGTATGGTTT-

CTGGATTTGGCCCAGAGAGGGTGAAAGGCCCGTACGGGTGGAGGTGTCAGACAAGTGAGGCAATTCACTAGGCCGGCCTTAGAGTCGGGTTGCTTGGGAA TGCAGCCCAAAGTGGGTGGTAAACTCCATCCAAGGCTAAATACTAGCACGAGTCCGATAGCAAACAAGTACCGTGAGGGAAAGTTGAAAAGTACTTTGAA GAGAGAGTAAACAGTACGTGAAACCGCATGCAGGTAAACGGGTGGCGTCAAGCTGCACGCCCAGAGGATTCAGCCGGTTAGAGTGTAGTTATGCGCTTG-CGTATCGAAGGGCCAGAGTAAAGCGCGCGTGGTAGTCCGCTGGAAGACAGCGGGCCCTGCCGCAAGGTGGGGATGTG-----TAAGCCGGGTGGAAGCCGGAGCACGCTATCCGTC--TGCGGGGCCGTCTAGCCGGTGCACTTTCTCTGT--

GGTGGACACCACGACCGGTGGAACTGCCAGTCTGCTATGGTCAAGTCGTGTTCGGTTGGTCCTTGT-GGCGAACTGGGCGCGAT---CACGGGCAAATTTGGTGAACGGCGTTGATGTGCCCTC-----------GGGTGCGTCTTCGTGCTATCGGTAGCCAGTTGTCTTAACGGGCCTGCCTTACGATTGTTCTAGCCGTCGTA---

GGGTGGTCTGGTGGGCCGTAGTGGTAAGAATAACTGTGCAGGGCACTGGAGTTATCGGCCTCAAACGCAGCCAGCATGCACGCTAGTAGTGTGTCCCTG- 
$--\mathrm{G}---\mathrm{T}---$

ATGTGGGTGCTCTCGTGGTCTGCCTGGTGCCGGGTCTGATTGTCGTGTTGCCTACGCAAAGAAATTTTTAGAACCTTACTATAATGTTATTAGTACTGAT TGTTATAAATTTTTGATTACTAATCATGGTATTATAATGATTTTTTTTTTTATAATGCCTATTTTAATTGGTGGGTTTGGTAATTATTTAATTCCTTTAT TATGTGGTTTATCTGATTTAAACTTACCACGTTTAAACGCGCTTAGTGCTTGGTTACTTTTACCTTCTGTGTTATTTTTAGTTATAAGAATGTGTTTAGG GGCTGGGGTAGGTTGAACTTTTTATCCTCCCTTAGCTTCCAGTGCATTTGAGGGGAGTAAGGGTGTAGACTTTTTAATGTTTTCTTTACACTTAGCGGGG GTTTCTAGAATTTTTAGCTCTATTAATTTTATTTGTACTTTACACACTGCCTTTAGGGGTAATTTAGCTTCTCGTAGTTCTATTGTATTATGGGC r03 scorzai marajo spmar1 GGGAACTGCTATGTAACAACAATACTCGGACCGCTCGTCATAG-TGGTCTGCTACC-

ATTT̄CGGTGGGGTGCCTATTTGCCCTATACTCCCAGGCGTGCTCGCCAGCTGCGGCAACTTAACTGCTGCCACAGCAAGAGGCCAGTCCACACCGGAGCG GCAAACCAGTACATGTGTCGCAAG---CGTGTGCAAGGTATAAGAA-A-

TTGGCACTACCATATGCCTACGCCCCACTATGCGCCCCTGTCTTTTACACTTACTATACGGGTAGTGTGTGTGTATGTGAGTGTGTGTGTGTGTGTGTGC GTGCGTGCGTGTTGGTATGTAGGTGTGCTGGTGTAT-

GCCAGCATTACTACTACTACTACTGCTACCACCACCACCACCACСАСТАСTACTACTACTACTACTACTA---

TCTGTGCAAAACGNNNNNNNNNNNNNNNNNNNNNNNNNNNNNNNNNNNNNNNNNNNNNNNNNNNNNNNNNNNNNNNNNNNNNNNNNNNNNNNNNNNNNNN NNNNNNGGAAGAGCCCAGCACCGAAGCCTGCGGTAGCTTTACTGTTAGGCAATGTGGTGTTTGGGCCGGCTCGCGGGATTGCCACTCCACTCGAAGTCCA GCATTGAGTATGGTTT-

CTGGATTTGGCCCAGAGAGGGTGAAAGGCCCGTACGGGTGGAGGTGTCAGACAAGTGAGGCAATTCACTAGGCCGGCCTTAGAGTCGGGTTGCTTGGGAA TGCAGCCCAAAGTGGGTGGTAAACTCCATCCAAGGCTAAATACTAGCACGAGTCCGATAGCAAACAAGTACCGTGAGGGAAAGTTGAAAAGTACTTTGAA GAGAGAGTAAACAGTACGTGAAACCGCATGCAGGTAAACGGGTGGCGTCAAGCTGCACGCCCAGAGGATTCAGCCGGTTAGAGTGTAGT-

TATGCGCTTG-CGTATCGAAGGGCCAGAGTAAAGCGCGCGTGGTAGTCCGCTGGAAGACAGCGGGCCCTGCCGCAAGGTGGGGATGTG-----TAAGCCGGGTGGAAGCCGGAGCACGCTATCCGTC--TGCGGGGCCGTCTAGCCGGTGCACTTTCTCTGT--

GGTGGACACCACGACCGGTGGAACTGCCAGTCTGCTATGGTCAAGTCGTGTTCGGTTGGTCCTTGT-GGCGAACTGGGCGCGAT---CACGGGCAAATTTGGTGAACGGCGTTGATGTGCCCTC-----------GGGTGCGTCTTCGTGCTATCGGTAGCCAGTTGTCTTAACGGGCCTGCCTTACGATTGTTCTAGCCGTCGTA---

GGGTGGTCTGGTGGGCCGTAGTGGTAAGAATAACTGTGCAGGGCACTGGAGTTATCGGCCTCAAACGCAGCCAGCATGCACGCTAGTAGTGTGTCCCTG-

$--\mathrm{G}---\mathrm{T}---$

ATGTGGGTGCTCTCGTGGTCTGCCTGGTGCCGGGTCTGATTGTCGTGTTGCCTACGCAAAGAAATTTTTAGAACCTTACTATAATGTTATTAGTACTGAT TGTTATAAATTTTGATTACTAATCATGGTATTATAATGATTTTTTTTTTATAATGCCTATTTTAATTGGTGGGTTTGGTAATTATTTAATTCCTTTAT TATGTGGTTTATCTGATTTAAACTTACCACGTTTAAACGCGCTTAGTGCTTGGTTACTTTTACCTTCTGTGTTATTTTTAGTTATAAGAATGTGTTTAGG GGCTGGGGTAGGTTGAACTTTTTATCCTCCCCTAGCTTCCAGTGCATTTGAGGGGAGTAAGGGTGTAGACTTTTTAATGTTTTCTTTACACTTAGCGGGG GTTTCTAGAATTTTAGCTCTATTAATTTTATTTGTACTTTACACACTGCCTTTAGGGGTAATTTAGCTTCTCGTAGTTCTATTGTATTATGGGC r121 frt cuiaba brac GGGAACTGCTATGTAACCTCT---C--GGACTGCCGGTCATGG-TGGTCCACAACC-

АTTT $\bar{C} G$ TTG GGGTGC $\bar{C}$ TACTTGCCCTATACTCCCAGGCGTGCTCGCCAGTCGTGGCAACTTAACTGCTGTCACGGCAATCGGCCAGTCCACACCGGAGCG GCAATCCAGTACATGTGCCGCAAGGTACGTGTGCGAGGTATAAGAA-

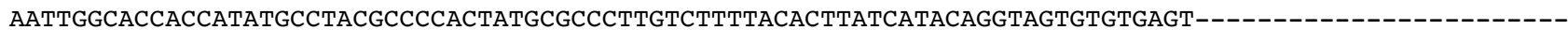
----------------GTACGCGTGTTGGTGTAT-

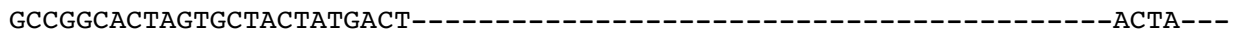

TCTGTGCAAAACGCATGGTCGGCATTAACTTGTTCGACTGTGTGCGGTTCTCATGAGCGTGGTTGGCTATCTT--

GCCTGGTAGTCGATGCGTCTTGTGCAGAGCTGGAAGAGCCCAGCACCGAAGCCTGCGGCAGGTTTGCTGTTAGGCAATGTGGTGTTTGGGTCGGCTCGCG GGATTGCCACTCCACTCGAAGTCCAGCATTGAGTATGGTTT-

CTGGATTTGGCCCAGAGAGGGTGAAAGGCCCGTACGGGTGGAGGTATCAGACAAGTGAGGCAATTCACTAGGCCGGCCTTAGAGTCGGGTTGTTTGGGAA TGCAGCCCAAAGCGGGTGGTAAACTCCATCCAAGGCTAAATACTAGCACGAGTCCGATAGCAAACAAGTACCGTGAGGGAAAGTTGAAAAGTACTTTGAA GAGAGAGTAAACAGTACGTGAAACCGCATGCAGGTAAACGGGTGGCGTCAAGCTGCACGCCCAGAGGATTCAGCCGGTTAGAGTGTATCTATGCGCTTG-CGTATAAATGGGCCAGAGTAAGGCG----TGGTAGTCCGCTGGTAGACAGCGGGCCCTGCCGCAAGGTGGGGATGTG-----CAAGCCGGGTGGATGCCGGAGCACGCTATCCGTC--TGTGGGGCCGTCTAGCCGGTGCACTTTCTCTGT--

GGTGGACACCACGACCGGTGGAACTGCCAGTCTGCTGTGGTCAAGTCGTGTTCGGTTGGTCCTTGT-GGCGAACTGGGCGCGAT---CACGGGCAACCTTGGTGAACGGCGTTGATGTGCCCTC-----------GGGTATGTCTTCGTGTTATCGGTAGCCAGTTGTCTTAACGGGCCTGCCTTGCGATTGTTCTAGCCGTCGTA---

GGGTGGTCTGGTGGGCCATGGTGGTAAGAATAACTGTGCAGGGCACCGGAGTGTTCGGCCTCAAATGCAGCCAGCATGCACGCTAGTAGTGT-----

TG---C---G---

ATGTGGGTGCTCTCGTGGTCTGCCTGGTGCCGGGTCTGATTGTCGTGTTGCCTGCGCAAAGNNNNNNNNNNNGCCTTATTATAATGTTATTAGTACAGAT TGTTATAAATTTTTAATTACTAACCATGGTATAATAATGATTTTTTTCTTTATAATGCСTATCTTAATAGGGGGATTTGGTAATTATTTGATTCCTTTAT TGTGTGGCCTGTCAGATTTAAATTTACCACGTTTAAAAGCATTAAGTGCTTGATTGTTACTGCCTTCTGCAGTTTTTTTGATAATAAGTATGTGTTTAGG GGCAGGAATAGGTTGAACTTTTTATCCACCTTTATCTTCAAGTTTATTTGAAGGGAGTAAGGGTGTAGATTTTTTGATGTTTTCATTACATTTGGCTGGT GTTTCTAGAATTTTTAGTTCTATAAATTTTATTTGTACTTTATATACTGCTTTTAGAGGTAGTTTGGCGTCTCGAAGTTCTATAGTCTTGTGAGC r097_rhoides_negro_spnGGGAACTGCTATGTAACCTCT---C--GGACCGCTGGTCATGG-TGGTCCACAACCАTTT $\bar{C}$ GGTGGGGTGCCTA TTTGCCCTATACTCCCAGGCGTGCTCGCCAGTCGTGGCAGCTTAACTGCTGTCACGGCATCGGCCAGTCCACACCGGAGCGGCAATGCAGTACATGTGCCGGAAGGTATGTGTGCAAGGTATAAGAT-ATTGGCACCACCATATGCCTACGCCCCACTATGCGCCСTTGTCTTTTACACTTACCATACAGGTAGTGTGTGAGT-

---------------GTACGCGTGTTGGTGTATTCCGGCACAAGTGCTACTATTACT-_-_-_-_-_-

TCTGTGCAAAACGCGTGGTCGGCATTAACTTGTCG-ACTGTGCGCGGTTCTCATGAGCGTGGTTGGCTATCTT--

GCCTGGTAGTCAATGCGTCTTGTGCAGAGCTNNNNNNNNNNNNNNNNNNNNNNNNNNNNNNNNNNNNNNNNNNNNNNNNNNNNNNNNNNNNNNNNNNNNN NNNNNNNNNNNNNNNNNNNNNNNNNNNNNNNNNNNNNNNNNNNNNNNNNNNNNNNNNNNNNNNNNNNNNNNNNNNNNNNNNNNNNNNNNNNNNNNNNNNN

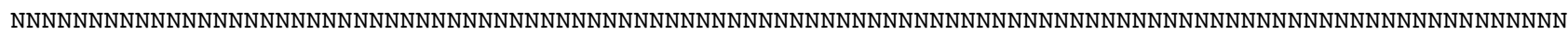

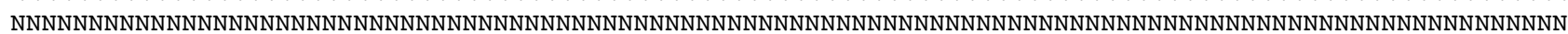

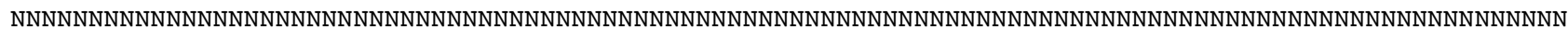

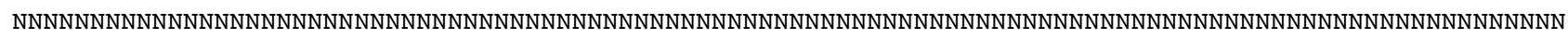

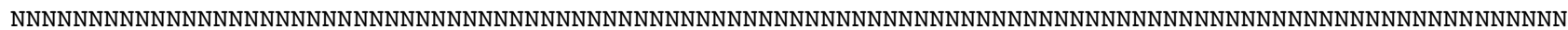

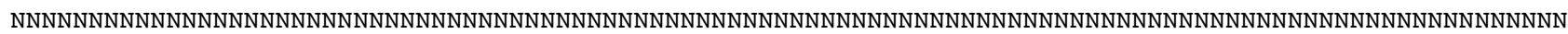

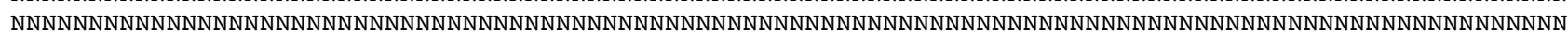
NNNNNNNNNNNNNNNNNNNNNNNNNNNNNNNNNNNNNNNNNNNNNNNNNNNNNNNNNNNNNNNNNNNNNNNNNNNNNNNNAAATTTTTAGAACCTTATTA TAATGTTATAAGTACTGATTGTTATAAATTTTTAATTACAAATCATGGTATCATAATGATTTTTTTCTTTATAATGCCTATATTAATAGGAGGGTTTGGT АATTATTTAATTCCСTTATTATGCGGTTTGTCTGATTTAAATTTACCTCGTTTAAAAGCATTAAGTGCTTGATTGTTGTTACCTTCTATCGTTTTTTTAG TAATAAGCATGTGTTTAGGGGCAGGGATAGGCTGAACTTTTTATCСTCСTTTATCTTCCAGTCTATTTGAAGGAAGTAAGGGTGTGGATTTTTTGATGTT TTCTCTACATTTGGCTGGTGTGTCTAGTATTTTTAGCTCTATTAATTTTATCTGTACTTTGTATACTGCCTTTAGTGGTAGTTTGGCGTCTCGAAGGTCA ATAATTTTATGGGC

r101_frt_negro_schr GGGAACTGCTATGTAACCTCT---C--GGACTGCCCGTCATGG-TGGTCCACAACCАTTTCGGTGGGGTGC $\bar{C}$ TACTTGCCCTATACTCCCAGGCGTGCTCGCCAGTCGTGGCAACTTAACTGCTGTCACGGCAATCGGCCAGTCCACACCGGAGCG 
GCAATCCAGTACATGTGCCGCAAGGTACGTGTGCGAGGTATAAGAA-A-

TTGGCACCACCATATGCCTACGCCCCACTATGCGCССTTGTCTTTTACACTTATCATACAGGTAGTGTGTGAGT--------------------------GTACGCGTGTTGGTGTAA-

GCCGGCACTAGTGCTACTATTACT-_-_-_-

TGTGTGCAAAACGNNNNNNNNNNNNNNNNNNNNNNNNNNNNNNNNNNNNNNNNNNNNNNNNNNNNNNNNNNNNNNNNNNNNNNNNNNNNNNNNNNNNNNN

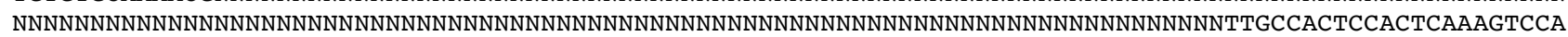
GCATTGAGTATGGTTT-

CTGGATTTGGCCCAGAGAGGGTGAAAGGCCCGTACGGGTGGAGGTATCAGACAAGTGAGGCAATTCACTAGGCCGGCCTTAGAGTCGGGTTGTTTGGGAA TGCAGCCCAAAGCGGGTGGTAAACTCCATCCAAGGCTAAATACTAGCACGAGTCCGATAGCAAACAAGTACCGTGAGGGAAAGTTGAAAAGTACTTTGAA GAGAGAGTAAACAGTACGTGAAACCGCATGCAGGTAAACGGGTGGCGTCAAGCTGCACGCCCAGAGGATTCAGCCGGTTAGAGTGTATCTATGCGCTTG-CGTATAAATGGGCCAGAGTAAGGCG----TGGTAGTCCGCTGGTAGACAGCGGGCCCTGCCGCAAGGTGGGGATGTG-----CAAGCCGGGTGGATGCCGGAGCACGCTATCCGTC--TGTGGGGCCGTCTAGCCGGTGCACTTTCTCTGT--

GGTGGACACCACGACCGGTGGAACTGCCAGTCTGCTGTGGCCAAGTCGTGTTCGGTTCGTCCTTGT-GGCGAACTGGGCGCGAT---CACGGGCAACCTTGGTGAACGGCGTTGATGTGCCCTC-----------GGGTATGTCTTCGTGTTATCGGTAGCCAGTTGTCTTAACGGGCCTGCCTTGCGATTGTTCTAGCCGTCGTA---

GGGTGGTCTGGTGGGCCATGGTGGTAAGAATAACTGTGCAGGGCACCGGAGTGTTCGGCCTCAAATGCAGCCAGCATGCACGCTAGTAGTGT-----

TG---C---G---

ATGTGGGTGCTCTCGTGGTCTGCCTGGTGCCGGGTCTGATTGTCGTGTTGCCTGCGCAAAGAAATTTTTGGAGCCTTATTATAATGTTATTAGCTTAGAT TGTTATAAATTTTTAATTACTAATCATGGCATTATAATGATTTTTTTTTTTATAATGCСTATTTTGATAGGTGGTTTTGGTAATTATTTAATTCCTTTAT TATGTGGCTTATCCGATTTAAACTTACCTCGTTTAAAAGCATTAAGCGCTTGATTATTATTGCCTTCTGCTGTTTTTTTAGTAGTAAGTATGTGTTTGGG AGCAGGAATAGGTTGGACTTTTTATCCTCCTTTATCTTCTAGTTTATTTGAAGGTAGAAAGGGTGTAGATTTTTTAATGTTTTCTCTACATTTGGCAGGA GTTTCTAGTATTTTTAGTTCTATAAATTTTATTTGTACTTTATATACTGCTTTTAGTGGTAGTTTAGCATCTCGAAGTTCGATAGTGTTATGATC r05 rhoides marajo spmar1 GGGAATTTGTATGTAACAACAATACTCGGCCCGCTCGTCATAG-TGGTCTGCTACC-

АTTT'CGGTGGGḠTGCCTATTTGCCCTATACTCCCAGGCGTGCTCGCCAGCTGCGGCAACTTAACTGCTGCCACAGCAAGAGGCCAGTCCACACCGGAGCG GCAAACCAGTACATGTGTCGCAAG---CGTGTGCAAGGTATAAGAA-A-

TTGGCACTACCATATGCCTACGCCCCACTATGCGCCCCTGTCTTTTACACTTACTATACGGGTAGTGTGTGTGTATGTGTATGTGTGTGTGTGTGTGTG-TG--TGCGTGTTGGTATGTAGGTGTGCTGGTGTAT-GCCAGCATTACTACTACTACTACTGCTACCACCACCACCAC---------

TACTACTACTACTACTACTA---

TCTGTGCAAAACGNNNNNNNNNNNNNNNNNNNNNNNNNNNNNNNNNNNNNNNNNNNNNNNNNNNNNNNNNNNNNNNNNNNNNNNNNNNNNNNNNNNNNNN NNNNNNGGAAGAGCCCAGCACCGAAGCCTGCGGTAGCTTTACTGTTAGGCAATGTGGTGTTTGGGCCGGCTCGCGGGATTGCCACTCCACTCGAAGTCCA GCATTGAGTATGGTTT-

CTGGATTTGGCCCAGAGAGGGTGAAAGGCCCGTACGGGTGGAGGTGTCAGACAAGTGAGGCAATTCACTAGGCCGGCCTTAGAGTCGGGTTGCTTGGGAA TGCAGCCCAAAGTGGGTGGTAAACTCCATCCAAGGCTAAATACTAGCACGAGTCCGATAGCAAACAAGTACCGTGAGGGAAAGTTGAAAAGTACTTTGAA GAGAGAGTAAACAGTACGTGAAACCGCATGCAGGTAAACGGGTGGCGTCAAGCTGCACGCCCAGAGGATTCAGCCGGTTAGAGTGTAGT-

TATGCGCTTG-CGTATCSAAGGGCCAGAGTAAAGCGCGCGTGGTATTCCGCTGGAAGACAGCGGGCCCTGCCGCAAGGTGGGGATGTG-----TAAGCCGGGTGGAAGCCGGAGCACGCTATCCGTC--TGCGGGGCCGTCTAGCCGGTGCACTTTCTCTGT--

GGTGGACACCACGACCGGTGGAACTGCCAGTCTGCTATGGTCAAGTCGTGTTCGGTTGGTCCTTGT-GGCGAACTGGGCGCGAT---CACGGGCAAATTTGGTGAACGGCGTTGATGTGCCCTC---------GGGTGCGTCTTCGTGCTATCGGTAGCCAGTTGTCTTAACGGGCCTGCCTTACGATTGTTCTAGCCGTCGTA---

GGGTGGTCTGGTGGGCCGTAGTGGTAAGAATAACTGTGCAGGGCACTGGAGTTATCGGCCTCAAACGCAGCCAGCATGCACGCTAGTAGTGTGTCCCTG$--\mathrm{G}---\mathrm{T}---$

ATGTGGGTGCTCTCGTGGTCTGCCTGGTGCCGGGTCTGATTGTCGTGTTGCCTACGCAAAGAAATTTTTAGAACCTTACTATAATGTTATTAGTACTGAT TGTTATAAATTTTTGATTACTAATCATGGTATTATAATGATTTTTTTTTTTATAATGCCTATTTTAATTGGTGGGTTTGGTAATTATTTAATTCCTTTAT TATGTGGTTTATCTGATTTAAACTTACCACGTTTAAACGCGCTTAGTGCTTGGTTACTTTTACCTTCTGTGTTATTTTTAGTTATAAGAATGTGTTTAGG GGCTGGGGTAGGTTGAACTTTTTATCCTCCCTTAGCTTCCAGTGCATTTGAGGGGAGTAAGGGTGTAGACTTTTTAATGTTTTCTTTACACTTAGCGGGG GTTTCTAGAATTTTTAGCTCTATTAATTTTATTTGTACTTTACACACTGCCTTTAGGGGTAATTTAGCTTCTCGTAGTTCTATTGTATTATGGGC

r091_rhoides_negro_spnGGGAACTGCTATGTAACCTCT---C--GGACCGCTGGTCATGG-TGGTCCACAACC-

ATTTCGGTGGGGTGCCTATTTGCCCTATACTCCCAGGCGTGCTCGCCAGTCGTGGCAGCTTAACTGCTGTCACGGCA-

TCGGCCAGTCCACACCGGAGCGGCAATGCAGTACATGTGCCGGAAGGTATGTGTGCAAGGTATAAGAT-A-

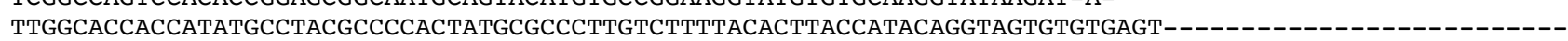
---------------GTACGCGTGTTGGTGTAT-

TCCGGCACAAGTGCTACTATTACT---------

TCTGTGCAAAACGCGTGGTCGGCATTAACTTGTCG-ACTGTGCGCGGTTCTCATGAGCGTGGTTGGCTATCTT--

GCCTGGTAGTCAATGCGTCTTGTGCAGAGCTNNNNNNNNNNNNNNNNNNNNNNNNNNNNNNNNNNNNNNNNNNNNNNNNNNNNNNNNNNNNNNNNNNNNN

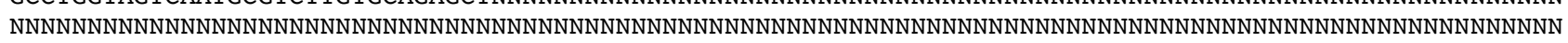

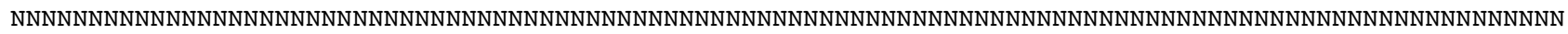

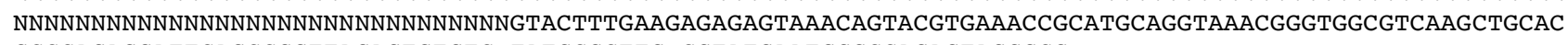
GCCCAGAGGATTCAGCCGGTTAGAGTGTGTC-TATGCGCTTG-CGTATGAATGGGCCAGAGTAGGGCG----

TGGTAGTCCGCTGGAAGACAGCGGGCCCTGCCGCAAGGTGGGGATGTG-----T-GAGCCGGGTGGAAGCCGGAGCACGCTATCCGTC--

TGTGGGGCCGTCTAGCCGGTGCACTTTCTCTGT--

GGTGGACACCACGACCGGTGGAACTGCCAGTCTGCTGTGGTCGAGTCGTGTTCGGTTGGTCCTTGT-GGCTAGCTGGGCGCGAT---CACGGGCAACCTTGGTGAACGGCGTTGGCGTGGTCTCTCGG-------GGGCATGCCTTCGTGTTATCGGTAGCCAGTTGTCTGAACGGGCCTGCCTCGCGATTGTTCTAGCCGTCGTG---

GGGTGGTCTGGTGGGCCATGGTGGTAGGAATAACTGTGCAGGGCACTGGAGTGTTCGGCCTCGAATGCAGCCAGCACGCACGCTAGTAGTGT-----

TGTTGC---G---

ATGTGGGTGCTCTCGTGGTCTGCCTGGTGCCGGGTCTGATTGTCGTGTTGCCTGCGCAAAGAAATTTTAGAGCCTTATTATAATGTTATAAGTACTGAT TGTTATAAATTTTAATTACAAATCATGGTATCATAATGATTTTTTCTTTATAATGCCTATATTAATAGGAGGGTTTGGTAATTATTTAATTCCCTTAT TATGCGGTTTGTCTGATTTAAATTTACCTCGTTTAAAAGCATTAAGTGCTTGATTGTTGTTACCTTCTATCGTTTTTTTAGTAATAAGCATGTGTTTAGG GGCAGGGATAGGCTGAACTTTTTATCCTCCTTTATCTTCCAGTCTATTTGAAGGAAGTAAGGGTGTGGATTTTTTGATGTTTTCTCTACATTTGGCTGGT GTGTCTAGTATTTTTAGCTCTATTAATTTATCTGTACTTTGTATACTGCCTTTAGTGGTAGTTTGGCGTCTCGAAGGTCAATAATTTTATGGGC r047_gld_jamanxim_tpj1GGGAACCGCTATGTAATCTAT---CTGGGACTGCCCGTCATGG-

TGGTCCAAAACCCGTTTCGGTGGGGTGCTACTTGCCTTATACTCCCAGGCGTGCTCGCCTGTTGTGGCAACTTAACTGCTGTCACAACAACCGGCCAGT CCACACCGGAGCGGCATATTAGTACACGTGTCA-AAG---CGTGTGCAAGGTATAAGAACA-

TTGGCACTACCATATGCCTACGCCCCGCTATGCGCCCTTGTCTTTTACACTTACCATACGGATAGTGTGTATGT----------------------------------------GT--GTGTGTTAGTGTAT-

GCTAGCATTACTACTACTACTG-

TCTGTGCAAAACGCATGGAGAGCATTAACTTGCTGTACCGTGTGTGGTTCTCATGAGCGTACTTGGTTACCTT--

GCCTGGGTGCCATTGCGTCTTGTGCAGAGCTGGAAGAGCCCAGCACCGAAGCCTGCGGTAGCTTTACTGTTAGGCAATGTGGTGTTTGGGCCGGCTCGCG 
GGGTTGCCACTCCACTCGAAGTCCAGCATTGAGTATGGTTT-

CTGGATTTGGCCCAGAGAGGGTGAAAGGCCCGTACGGGTGGAGGTTTCAGACAAGTGAGGCAATTCACTAGGCCGGCCTTAGAGTCGGGTTGTTTGGGAA TGCAGCCCAAAGTGGGTGGTAAACTCCATCCAAGGCTAAATACTAGCACGAGTCCGATAGCAAACAAGTACCGTGAGGGAAAGTTGAAAAGTACTTTGAA GAGAGAGTAAACAGTACGTGAAACCGCATGCAGGTAAACGGGTGGCGTCAAGCTGCACGCCCAGAGGATTCAGCCGGTTAGAGTGTAGT-

TATGCGCTTG-CGTATCAAAGGGCCAGAGTAAGGCG----TGGTAGTCCGCTGGAAGACAGCGGGCCCTGCCGCAAGGTGGGGATGTG-----T-

AAGCCGGGTGGATGCCGGAGCACGCTATCCGTC--TGGAGGGCCGTCTAGCCGGTGCACTTTCTCTGT--

GGTGGACACCACGACCGGTGGAACTGCCAGTCTGCTATGGTCAAGTCGTGTTCGGTTGGTCCTTGT-GGCTAGCTGGGCGCGAT---CACGGGCAAATTTGGTGAACGGCGTTGATGTGCCCTC----------GGGTATGTCTTCGTGTTATCGGTAACCAGTTGTCTTAACGGGCCTGCCTTACGATTGTTCTAGCCGTCGTA---

GGGTGGTCTGGTGGGCCATAGTGGTAAGAATAACTGTGCAGGGCACCGGAGTTTTCGGCCTCAAACGCAGCCAGCATGCACGCTAGTAGTGT-----

TG---C--TG---

ATGTGGGTGCTCTCGTGGTCTGCCTGGTGCCGGGTCTGATTGTCGTGTTGCCTACGCAAAGAATTTTTTGGAGCCTTATTATAATGTGATTAGTACAGAT TGTTATAATTTCTGATTACCAAACATGGTATTATAATGATTTTCTTTTTTATAATGCCTATCTTAATAGGGGGGTTTGGTAATTATTTAATTCCCTTAT TAAGGGGTTTGTCCGATTTAAACTTGCCTCGTTTAAAAGCCTTGAGTGCTTGATTGCTTTTACCTTCTGCTGTATTTTTAGTGATTAGTATGTGTTTAGG TGCTGGTATAGGTTGAACTTTCTATCCTCCTTTGTCTTCTAGTGTTTTTGAGGGGAGTAAGGGTGTAGACTTTTTAATGTTTTCATTGCATTTGGCTGGT GTTTCTAGTATATTTAGTTCTATTAATTTTATATGTACTTTGTATACTGCCTTTAGTGGTAGGTTGGCTTCTCGTAGTTCAATTGTATTATGAGC r129_rhoides_cuiaba_mot GGGAACTGCTATGTAACCTCT---C--GGACCGCTGGTCATGG-TGGTCCACAACC-

АTTTC $\bar{C}$ GTGGGTTGCTACTTGCCCTATACTCCCAGGCGTGCTCGCCAGTCGTGGCAACTTAACTGCTGTCACGGCAATCGGCCAGTCCACACCGGAGCG GCAATGCAGTACATGTGTCGGAAGGCACGTGTGCGAGGTATAAGAA-A-

TTGGCACCGCCATATGCCTACGCCCCACTATGCGCCCTTGTCTTTTACACTTACCATACAGGTAGTGTGTGAGT-

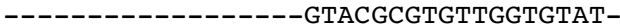

GCCGGCACAAGTGCTACTATTACT-АСТA---

TCTGTGCAAAACGCATGGTCGGCATTAACGTGTTGTACTGTGCGCGGTTCTCATGAGCGTGGTTGGCTATCTTTTGCCTGGTAGCCGATGCGTCTTGTGC AGAGCTGGAAGAGCCCAGCACCGAAGCCTGCGGCAGGTTTGCTGTTAGGCAATGTGGTGTTTGGGTCGGCTCGCGGGATTGCCACTCCACTCGAAGTCCA GCATTGAGTATGGTTT-

CTGGATTTGGCCCASAGAGGGTGAAAGGCCCGTACGGGTGGAGGTGTCAGACAAGTGAGGCAATTCACTAGGCCGGCCTTAGAGTCGGGTTGTTTGGGAA TGCAGCCCAAAGCGGGTGGTAAACTCCATCCAAGGCTAAATACTAGCACGAGTCCGATAGCAAACAAGTACCGTGAGGGAAAGTTGAAAAGTACTTTTGA GAGAGAGTAAACAGTACGTGAAACCGCATGCAGGTAAACGGGTGGCGTCAAGCTGCACGCCCAGAGGATTCAGCCGGTTAGAGTGTATC-

TATGCGCTTG-CGTATAAAAGGGCCAGAGTAAGGCG----TGGTAGTCCGCTGGCAGACAGCGGGCCCTGCCGCAAGGTGGGGATGTG-----TAAGCCGGGTGGATGCCGGAGCACGCTATCCGTC--TGTGGGGCCGTCTAGCCGGTGCACTTTCTCTGT--

GGTGGACACCACGACCGGTGGAACTGCCAGTCTGCTGTGGTCAAGTCGTGTTCGGTTGGTCCTTGT-GGCGAACTGGGCGCGAT---CACGGGCAACCTTGGTGAACGGCGTTGATGTGCCCTC---------_GGGTATTCTTCGTGTTATCGGTAGCCAGTTGTCTTAACGGGCCTGCCTTGCGATTGTTCTAGCCGTCGTA---

GGGTGGTCTGGTGGGCCATGGTGGTAAGAATAACTGTGCAGGGCACCGGAGTGTTCGGCCTCAAATGCAGCCAGCATGCACGCTAGTAGTGT-----

TG---C---G---

ATGTGGGTGCTCTCGTGGTCTGCCTGGTGCCGGGTCTGATTGTCGTGTTGCCTGCGCAAAGNNNNNNNNNNNNNNNNNNNNNNNNNNNNNNNNNNNNNNN NNNNNNNNNNNNNNNNNNNNNNNNNNNNNNNNNNNNNNNNNNNNNNNNNNNNNNNNGCCTATTTTAATAGGTGGCTTTGGTAATTATTTAATTCCTTTGT TATGTGGTTTATCAGATTTAAATTTGCCTCGTTTAAAAGCATTAAGTGCTTGGTTGTTATTACCTTCCGCAGTTTTTTTAATAATAAGTATGTGCTTGGG AGCAGGAATAGGTTGGACTTTTTATCCTCCTTTATCTTCTAGTTTATTTGAAGGTAGAAAGGGTGTAGATTTTTTGATGTTTTCGTTACATTTAGCAGGG GTTTCTAGTATTTTTAGTTCTATAAATTTTATTTGTACTTTGTACACTGCTTTTAGGGGTAGTTTAGCATCTCGGAGTTCTATAGTATTATGGGC ; end;

begin assumptions; usertype $\mathrm{m} 421$ _lsu $=5$ [transversions ${ }^{-} 2$ transitions 1]

$\begin{array}{llllll} & \text { a } & \text { c } & g & t & \\ \text { [a] } & . & 1 & 2 & 1 & 8 \\ \text { [c] } & 1 & . & 1 & 2 & 8 \\ \text { [ } \mathrm{g}] & 2 & 1 & . & 1 & 8 \\ \text { [t] } & 1 & 2 & 1 & . & 8 \\ \text { [-] } & 8 & 8 & 8 & 8 & . \\ \text {; } & & & & & \end{array}$

usertype $\mathrm{m} 4 \times 421$ lsu $=5$

[transversions 2 transitions 1]

\begin{tabular}{|c|c|c|c|}
\hline$a$ & C & $\mathrm{g}$ & $t$ \\
\hline [a]. & 1 & 2 & 1 \\
\hline [C] 1 & . & 1 & 2 \\
\hline g] 2 & 1 & . & 1 \\
\hline ] 1 & 2 & 1 & . \\
\hline -] 32 & 32 & 32 & 32 \\
\hline
\end{tabular}

usertype $\mathrm{m} 4 \times 111$ its $=5$

[transversions 2 transitions 1]

$\begin{array}{llllll} & a & c & g & t & \\ \text { [a] } & . & 1 & 1 & 1 & 4 \\ \text { [c] } & 1 & . & 1 & 1 & 4 \\ \text { [g] } & 1 & 1 & . & 1 & 4 \\ \text { [t] } & 1 & 1 & 1 & . & 4 \\ \text { [-] } & 4 & 4 & 4 & 4 & \text {. } \\ \text {; } & & & & & \end{array}$

end;

ctype m4x111_its:22 $264457178 \quad 182 \quad 204206343490$;

ctype m421 lisu:523-1471;

ctype m4x421_lsu:633 923960 10071012105210871155117311881288 1298; 
Begin trees;

[the tree]

tree tree_from_poy = [\&R] (AF286930_Litobothrium_janovyi,(AF286931_Litobothrium_amplifica, ( (r016_Rfulbrighti_marajo_orbignyi, (r019_Rfulb̄righti_marajo_orbignyi,

(r015_Rfulbrighti_marajo_ōrbignyi,

(r018_Rfulbrighti_marajo_orbignyi,r014_Rfulbrighti_marajo_orbignyi)))),

( ( CH4_Scalithrium_sp_LRP 3895, CH10_Rhinebothrium_megacanthōephalus_LRP3901),

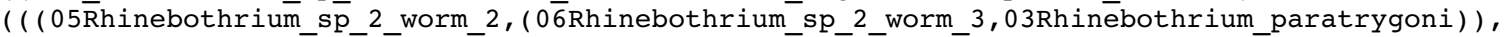

( (42Rhinebothrium_sp_ $\overline{4}$ _worm_ $\overline{3}, 41$ Rhinebothrium_sp__

( (16Rhinebothrium copiānullüm worm 2,15Rhinebōthr̄ium_cōpianullum worm_1),

(32Rhinebothrium_sp_1_worm_18, (31R $\bar{h}$ inebothrium_sp_1_Worm_17, (28Rhinebothrium_sp_1_worm_14,

( (19Rhinebothrium_sp_1_worm_3, (18Rhinebothrium_sp_1_worm_2,17Rhinebothrium_sp_1_worm_1) ),

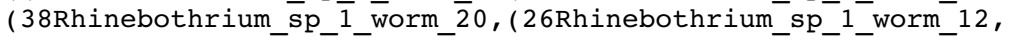

(35Rhinebothrium_sp_3_worm_2,25Rhinebothrium_sp_1_worm_1 1$)))))))))$ ), (( (r07_scorzai_marajo_mot,

(r05 rhoides marajo_spmar1, ( (r04_scorzai_marajo_spmar1, r01_scorzai_marajo_spmar1),

(r03_scorzai_marajo_spmar1,(r012_scorzai_marajo_spmar1, (r09 _scorzai_marajo_mot,

(r08_scorzai_marajo_mot,r06_scorzai_marajo_spmaril))))))),

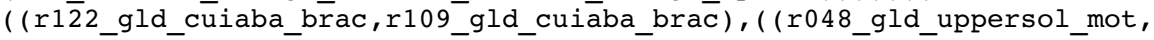

(r050_gld_üppersō̄mot, r049_gld_uppersol_mot)), ( (r030_gld_lagonovo_mot, (r199_gld_lagonovo_mot,

(r201 gld lagonovo mot, r031 gld lagonovo mot $))),(($ r $23 \overline{7} \mathrm{gl} \overline{\mathrm{d}}$ toc toc $\overline{2}$,

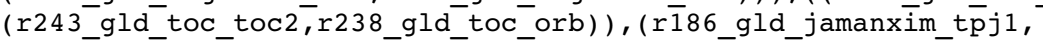

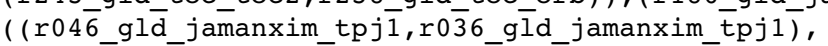

$($ r047_gld_jamanxim_tpj1,r035_ōld_jamanxim_t̄pj1)))))))),(((("r097 Rhinebothroides Rio Negro Potamotrygon sp.","r096 Rhinebothroides Rio Negro Potamotrygon sp."),("r091 Rhinebothroides Rio Negro Potamotrygon sp.",("r095 Rhinebothroides Rio Negro Potamotrygon sp.",("r094 Rhinebothroides Rio Negro Potamotrygon sp.","r092 Rhinebothroides Rio Negro Potamotrygon sp."))) , ( (r129_rhoides_cuiaba_mot, (r117_vnz_salob_mot,r116_vnz_salob_mot)), (r052_vnz_uppersol_mot,

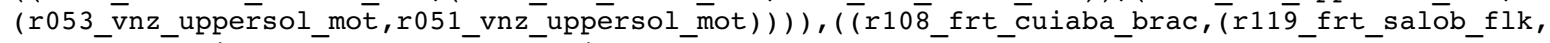

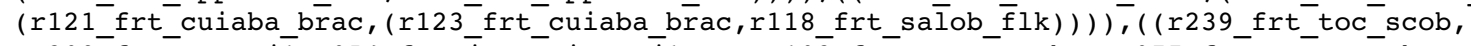

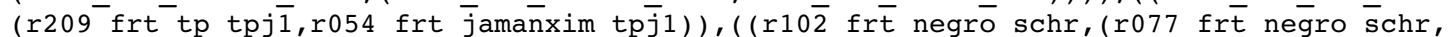

$($ r103_frt_negro_schr, r $\overline{1} 01$ frt_negro_schr $))),(($ r250_rhöides_negro_spn,

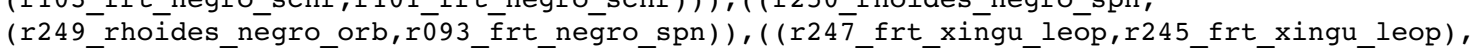

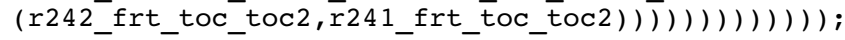

End; 